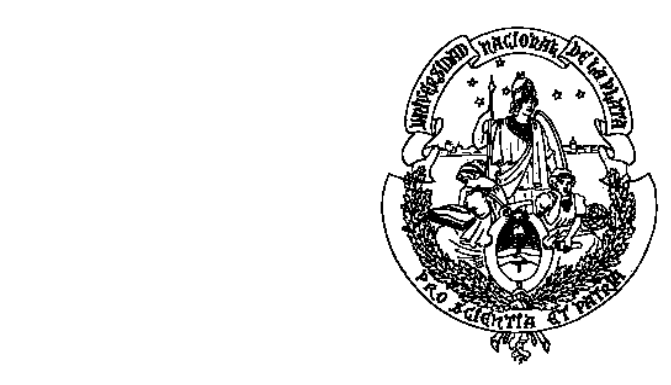

UNIVERSIDAD NACIONAL DE LA PLATA

FACULTAD DE CIENCIAS EXACTAS

DEPARTAMENTO DE CIENCIAS BIOLÓGICAS

Trabajo de Tesis Doctoral

\title{
ESTUDIO DE LA ENTEROPATÍA INDUCIDA POR PÉPTIDOS DE GLIADINAS Y LIGANDOS DE LA INMUNIDAD INNATA EN MODELOS EXPERIMENTALES
}

Lic. Romina Elizabeth Araya

(Director: Fernando G. Chirdo) 

El presente trabajo de tesis para optar por el grado de Doctor de la Facultad de Ciencias Exactas de la Universidad Nacional de La Plata, ha sido realizado bajo la dirección del Dr. Fernando Chirdo en el Laboratorio de Investigaciones del Sistema Inmune (LISIN) actual Instituto de Estudios Inmunológicos y Fisiopatológicos (IIFP-CONICET) sito en la Facultad de Ciencias Exactas, UNLP.

La Plata, Abril de 2015 



\section{ÍNDICE DE CONTENIDOS}

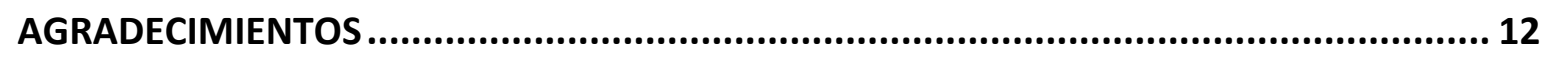

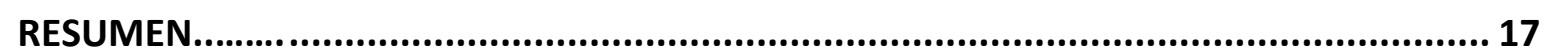

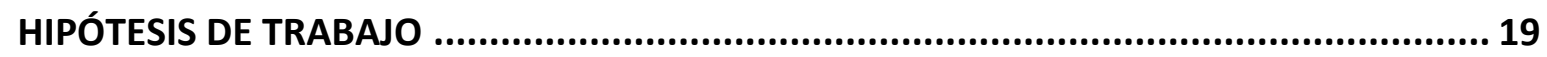

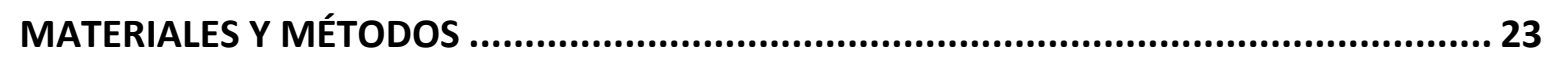

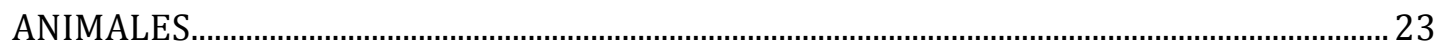

TRATAMIENTO CON INDUCTORES E INOCULACIÓN INTRAGÁSTRICA................................ 24

EVALUACIÓN HISTOLÓGICA .............................................................................................................. 25

DETERMINACIÓN DEL ESTADO PROLIFERATIVO DE LOS TEJIDOS....................................... 26

MÉTODO USSING CHAMBER …………………………................................................................... 27

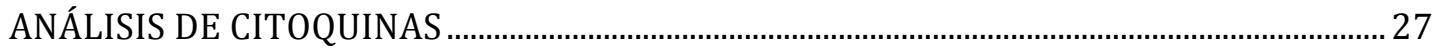

MICROSCOPÍA DE FLUORESCENCIA ………………........................................................... 28

PCR EN TIEMPO REAL......................................................................................................... 28

EXPRESIÓN DE CASPASA 3 POR WESTERN BLOT..................................................................... 29

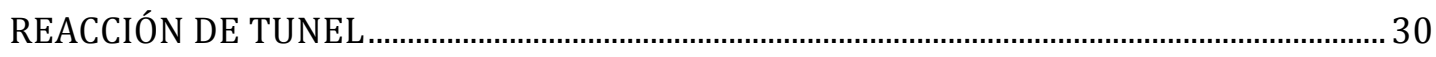

ELECTROFORESIS EN GEL DE AGAROSA................................................................................. 30

ESTUDIO DE MEDIADORES CELULARES DE DAÑO (TRATAMIENTOS CON CÉLULAS

B16-FLT3L, ANTICUERPO ANTI-GR1 Y BINDARIT)............................................................... 30

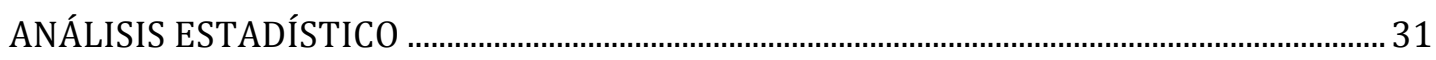

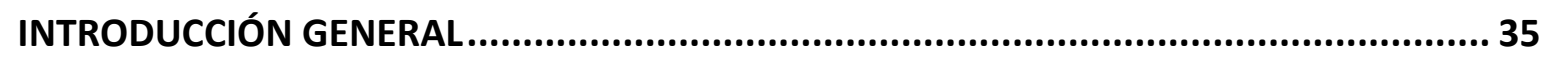

INDUCCIÓN DE MECANISMOS DE LA RESPUESTA PROTECTIVA Y REGULATORIA EN LA

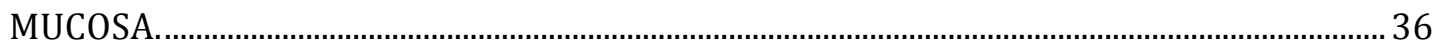

ENFERMEDAD CELÍACA. DEFINICIÓN ................................................................................ 39

MODELOS MURINOS Y ENFERMEDAD CELÍACA..................................................................... 42

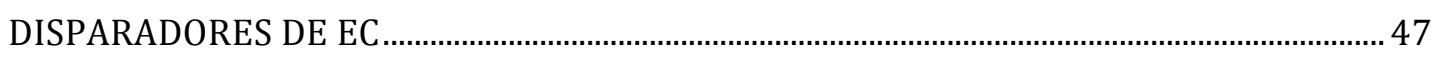

POLY (I:C) Y MODELOS MURINOS DE ENTEROPATÍA........................................................ 50

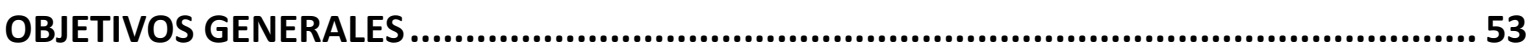

CAPÍtUlo 1. DESARROLLO DE UN MODELO DE ENTEROPATÍA BASAdO EN LA ADMINISTRACIÓN INTRALUMINAL DE POLY (I:C). .............................................. 57

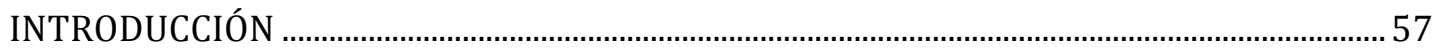

Generalidades sobre las vías de reconocimiento y señalización inducidas por ARNdh. 58 Señalización por TLR3 de los ARNdh. 
Índice de contenidos

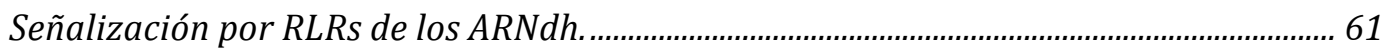

ARNdh y sus efectos sobre la mucosa del intestino delgado............................................... 65

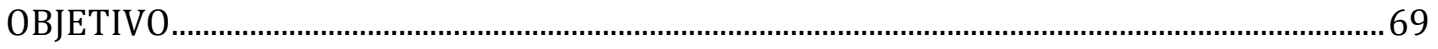

RESULTADOS.....................................................................................................................

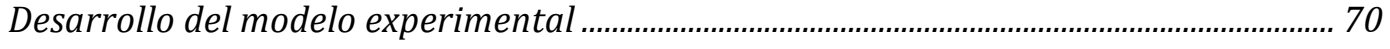

Evaluación de la enteropatía inducida por la administración intraluminal de poly (I:C).

Señalización por diferentes receptores de poly (I:C)........................................................ 78

Los receptores MDA5, RIG-Iy TLR3 son inducidos por poly (I:C) intraluminal............... 79

El tratamiento con poly (I:C) intraluminal induce mediadores proinflamatorios en intestino delgado............................................................................................................................. 81

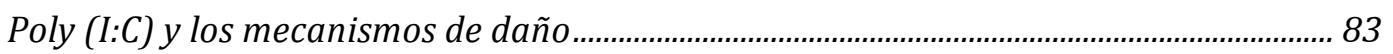

Mediadores celulares de daño implicados en la enteropatía inducida por poly (I:C).... 85

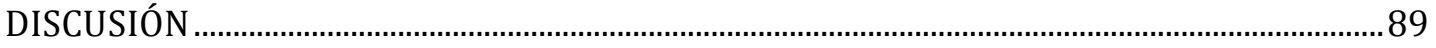

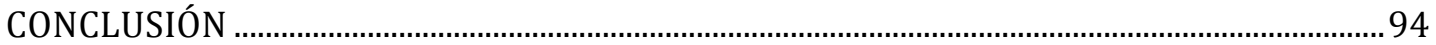

CAPÍTULO 2. EL PÉPTIDO DE GLIADINAS P31-43 INDUCE ENTEROPATÍA MEDIANTE

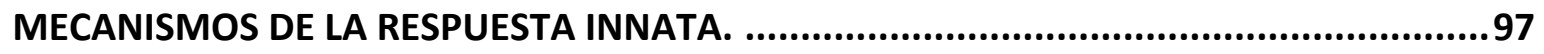

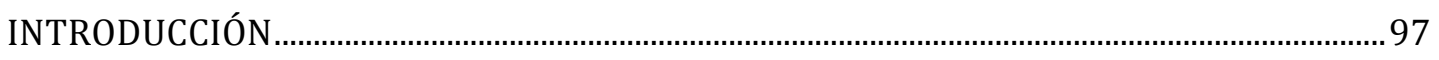

Características del péptido p31-43 en relación a la patogenia de EC................................ 98

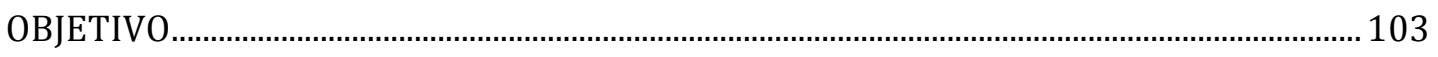

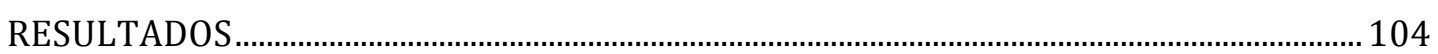

La administración intraluminal de p31-43 induce enteropatía..........................................104

La composición aminoacídica de las prolaminas es suficiente para inducir daño en la

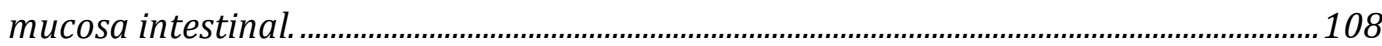

p31-43 incrementa la expresión del ARNm de citoquinas y quimoquinas

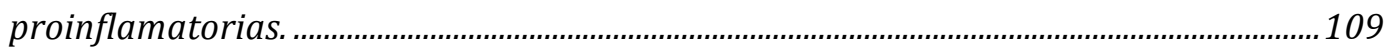

El p31-43 induce muerte celular en lamina propria y enterocitos. ……………................113

La enteropatía inducida por p31-43 es dependiente de MyD88. ......................................116

Poly (I:C), p31-43 y la combinación de ambos generan diferente tipo de enteropatía.

Inducción de muerte celular por el estímulo con poly (I:C)+p31-43................................123

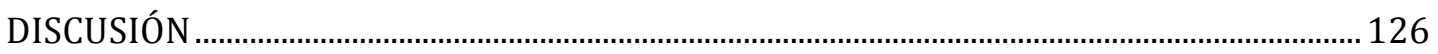

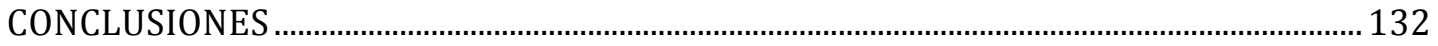




\section{CAPÍTULO 3. POLY I:C Y P31-43 PRODUCEN ENTEROPATÍA QUE PREDISPONE A UNA} RESPUESTA EXACERBADA A LA INGESTA DE GLIADINAS. DESARROLLO DE UN MODELO CRÓNICO DE ENTEROPATÍA DE INTESTINO DELGADO................................................ 135

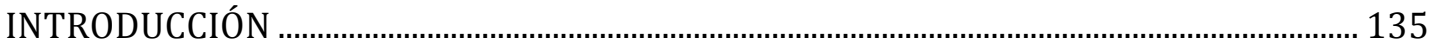

Permeabilidad intestinal: tipos de uniones intercelulares .................................................. 135

Proteínas de la Unión Estrecha. ............................................................................................ 139

Regulación de la integridad de las uniones estrechas............................................................. 140

Permeabilidad intestinal y enfermedad celíaca ................................................................ 141

Modelos animales con ratones NOD-DQ8 …….................................................................. 143

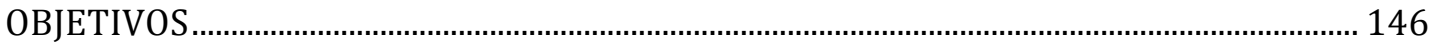

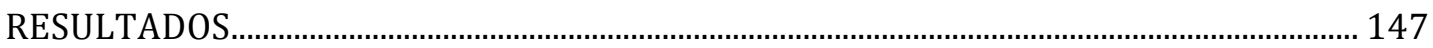

Enteropatía inducida por poly (I:C) en el intestino delgado de ratones NOD-DQ8..... 147 Respuesta inflamatoria inducida por poly (I:C) en el intestino delgado de ratones NODDQ8.

La administración intraluminal de poly (I:C) y un antígeno dietario por vía oral inducen enteropatía en ratones NOD-DQ8.. 150

Enteropatía inducida por p31-43 en el intestino delgado de ratones NOD-DQ8.

La administración intraluminal de p31-43 exacerba la respuesta a gliadinas por vía oral y causa enteropatía severa en ratones NOD-DQ8.

La enteropatía inducida por p31-43 predispone a una respuesta exacerbada a gliadinas.

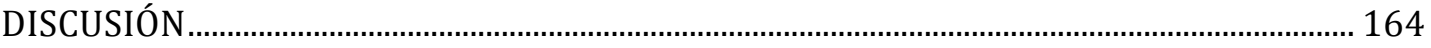

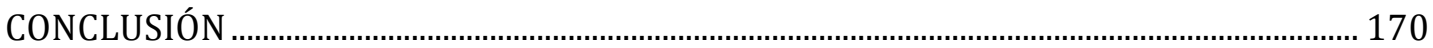

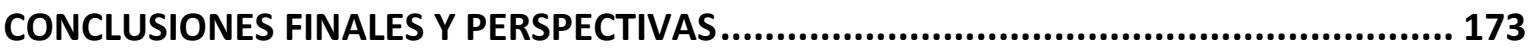

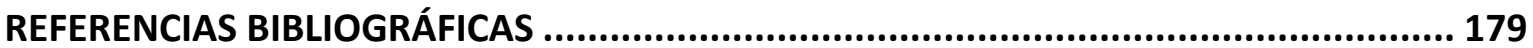




\section{ÍNDICE DE FIGURAS}

Figura 1. Esquema de los elementos que participan en la respuesta inmune en intestino delgado. 35

Figura 2. Los receptores de patrones de reconocimiento (PRRs) sensan las señales microbianas de diversos modos. 37

Figura 3. Patogenia de Enfermedad Celíaca. 40

Figura 4. Efecto del gluten sobre células del epitelio intestinal y células presentadoras de antígenos. 41

Figura 5. Etapas de la patogenia en enfermedad celíaca sobre los que se han orientado modelos animales. 42

Figura 1.1. Reconocimiento de ARNdh viral por TLR3 y RLRs y sus vías de señalización. 58

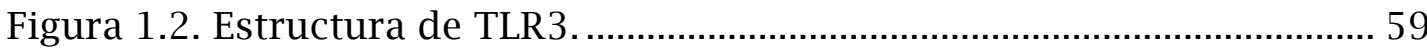

Figura 1.3. Vías de señalización de TLR3..................................................... 60

Figura 1.4. Estructura de los RLRs................................................................... 62

Figura 1.5. Modelo de reconocimiento de ARN por RIG-I y MDA5, e interacción con MAVS para generar la señal de activación. 63

Figura 1.6. Vías de señalización de los RLRs.................................................. 64

Figura 1.7. Imágenes del procedimiento quirúrgico de asa ligada. ................. 70

Figura 1.8. Imagen representativa de una sección de intestino delgado proximal teñida con H\&E. 71

Figura 1.9. Daño intestinal producido por la administración de poly (I:C) en asa ligada (AL) e intraperitoneal (IP) en ratones C57BL/6. 72

Figura 1.10. Contraste entre la administración de poly (I:C) en asa ligada (AL) e intraluminal (IL) en ratones C57BL/6. 73

Figura 1.12. Poly (I:C) intraluminal induce enteropatía.................................. 75

Figura 1.13. Análisis de la respuesta proliferativa en criptas.......................... 76

Figura 1.14. El daño por poly (I:C) afecta la altura de las vellosidades sin modificación de la profundidad de las criptas. 77

Figura 1.15. Inducción de enteropatía por poly (I:C) de diferentes tamaños.

Figura 1.16. Poly (I:C) induce la expresión de sus receptores en intestino delgado de ratones $\mathrm{C} 57 \mathrm{BL} / 6$. 80

Figura 1.17. Poly (I:C) de alto y bajo peso molecular inducen la expresión de RIGI y MDA5 en la mucosa intestinal. 81 
Figura 1.18. Poly (I:C) genera una respuesta proinflamatoria en ratones C57BL/6. 82

Figura 1.19. Análisis de muerte celular y apoptosis en intestino delgado de ratones $\mathrm{C} 57 \mathrm{BL} / 6$ tratados con poly (I:C). 84

Figura 1.20. El pretratamiento con anticuerpo anti-GR1 no evita el daño producido por poly (I:C). 86

Figura 1.21. El pretratamiento con el inhibidor de la síntesis de MCP1 (Bindarit) evita el daño producido por poly (I:C).

Figura 1.22. El incremento en las poblaciones de células dendríticas agrava el daño producido por poly (I:C). 88

Figura 2.1. La administración intraluminal de p31-43 induce enteropatía luego de $12 \mathrm{hs}$. 104

Figura 2.2. La administración intraluminal de p31-43 induce enteropatía luego de $72 \mathrm{hs}$.

Figura 2.3. La administración de p31-43 no modifica los valores de CCPR luego de $72 \mathrm{hs}$ de estímulo. 106

Figura 2.4. p31-43 induce una fuerte respuesta proliferativa en las criptas de intestino delgado de ratones C57BL/6.

Figura 2.5. Un péptido de igual composición pero diferente secuencia al p3143 genera daño en la mucosa intestinal.

Figura 2.6. p31-43 induce la expresión de CXCL9 y CXCL10 pero disminuye CXCL11 y CXCR3.

Figura 2.7. p31-43 induce la expresión de IFN $\beta$ e IFN $\gamma$. 111

Figura 2.8. p31-43 disminuye CXCL2 en intestino delgado de ratones C57BL/6.

Figura 2.9. p31-43 no induce TG2 o IL-15 en intestino delgado de ratones C57BL/6.

Figura 2.10. p31-43 induce muerte celular y un perfil pro-apoptótico en intestino delgado.

Figura 2.11. Niveles de caspasa 3 activada en intestino delgado de animales tratados con p31-43 115

Figura 2.12. La señalización de TLR4 no es necesaria para la inducción de daño por p31-43. 116

Figura 2.13. La enteropatía inducida por p31-43 es dependiente de la señalización por MyD88. 
Índice de figuras

Figura 2.14. La muerte celular inducida por p31-43 es dependiente de MyD88. 118

Figura 2.15. La combinación de poly (I:C) con p31-43 genera enteropatía de un modo distinto a los estímulos individuales.

Figura 2.16. Comportamiento diferencial de los estímulos poly (I:C), p31-43 y poly (I:C)+p31-43......

Figura 2.17. El estímulo doble induce la expresión de ARNm de IL-6 e IL-18. 121

Figura 2.18. El estímulo doble induce la expresión de ARNm de CXCL2, MCP1, CXCL10 y CXCR3.

Figura 2.19. El estímulo doble no induce la expresión de ARNm de TG2 o IL15 123

Figura 2.20. El estímulo doble induce muerte celular en lamina propria de ratones $\mathrm{C} 57 \mathrm{BL} / 6$.

Figura 2.21. Estudio cinético del cociente Bax/Bcl2 luego del tratamiento con poly (I:C)+p31-43. 124

Figura 2.22. El estímulo doble induce la expresión de Caspasa 3 clivada en lamina propria.. 125

Figura 3.1. Rutas de pasaje de solutos y estructura del epitelio. 136

Figura 3.2. Esquema de los complejos macromoleculares de unión entre células del epitelio intestinal.

Figura 3.3. Composición de las uniones intercelulares en el epitelio. 140

Figura 3.4. La administración de poly (I:C) induce daño en el intestino delgado de ratones NOD-DQ8 luego de 12hs. 147

Figura 3.5. Poly (I:C) genera una respuesta proinflamatoria e induce la expresión de ARNm de MDA5 y RIG-I en el intestino delgado de ratones NODDQ8. 148

Figura 3.6. Niveles incrementados de TNF $\alpha$, MCP-1 e IL-6 en suero después de la administración intraluminal de poly (I:C). 149

Figura 3.7. Esquema que representa el desarrollo experimental realizado con los ratones NOD-DQ8 en el modelo crónico. 151

Figura 3.9. Método Ussing chamber. 153

Figura 3.11. La administración oral de gliadinas induce disfunción de la barrera epitelial en ratones NOD-DQ8 tratados con poly (I:C). 155

Figura 3.13. p31-43 incrementa el infiltrado intraepitelial en el intestino delgado de ratones NOD-DQ8 luego de 12hs. 157 
Figura 3.14. El incremento en el cociente V/C por el p31-43 sucede a expensas del aumento de la longitud de las vellosidades 158

Figura 3.15. Inducción de la expresión de ARNm de IFN $\beta$ y CXCL10 en el intestino delgado de ratones NOD-DQ8 tratados con p31-43. 159

Figura 3.16. p31-43 induce un perfil proliferativo en las criptas de intestino delgado de ratones NOD-DQ8. 160

Figura 3.17. Esquema que representa el desarrollo experimental realizado con los ratones NOD-DQ8 en el modelo crónico 161 


\section{AGRADECIMIENTOS}

Este trabajo de tesis ha sido desarrollado gracias al esfuerzo, compañía y dedicación de mucha gente a la cual quiero agradecer en esta sección. Sin ellos, nada de esto hubiese sido posible y por ellos, hoy me encuentro en el lugar en donde estoy.

Primero que nada, quiero agradecer a mi familia, quienes siempre estuvieron para lo que necesité y siempre me apoyaron en mi carrera. Allá por el año 2003 cuando comencé la carrera de Bioquímica (bajo el comentario de "vos estás loca, meterte ahí...”) y posteriormente, una vez recibida, cuando se me ocurrió la loca idea de "investigar". Gracias por el soporte que me dieron en todos los posibles sentidos de la palabra. Los amo y significan mucho para mi.

Gracias a mi director, Fernando, por darme la posibilidad de iniciar y concluir mi doctorado bajo su dirección y por sus horas y esfuerzos dedicados a mi formación.

Gracias a la Dra Graciela De Antoni por darme la posibilidad de iniciarme en el mundo de la investigación y a la maravillosa tarea de la Extensión Universitaria (Proyecto Kefir) en el laboratorio de Microbiología de la Facultad de Ciencias Exactas, UNLP.

Gracias a las instituciones que soportaron económicamente este trabajo. A la Comisión de Investigaciones Científicas (CIC) y al Consejo Nacional de Investigaciones Científicas y Técnicas (CONICET) por las becas otorgadas. A la Canadian Association of Gastroenterology por hacerme entrega del CAG Latin America Student Research Award en el año 2012 que me permitió hacer una enriquecedora pasantía en Canadá.

Gracias a la Dra. Elena Verdú, por darme la posibilidad de visitar su laboratorio en dos oportunidades en los años 2010 y 2012, teniendo paciencia con mi "Spanglish" y abriéndome las puertas de su laboratorio y de su casa. Gracias por mostrarme otro mundo en la investigación y por la inigualable formación laboral y personal que adquirí en ese período.

Gracias a los compañeros del Farcombe Institute (Hamilton, Canadá), que hicieron lo posible y más por ayudarme y principalmente por entenderme durante las pasantías en Canadá. Jen, Heather, Jane, Christina and Justin, thank you very much!! 
Gracias a los integrantes de la hermosa cátedra de Fisiología. Dr Rinaldi, Dr Rebolledo, Vero, Belu, Nico y Pao, gracias por alegrarme los miércoles y viernes por la tarde. Vamos por más Frank-Starlings exitosos y tertulias de las mejores!!

Gracias a todos y cada uno de los compañeros de mi glorioso LISIN (actual IIFP). Los "Lisinos" son una raza muy difícil de encontrar. Ellos son parte de mi formación tanto laboral como personal. Siempre estuvieron presentes, en las buenas y malas del laboratorio y en las buenas y malas de la vida. Desde las pequeñas cosas hasta las grandísimas, disfruté muchísimo de su compañía sin igual. A Facu, Maru, Yessica, Vani, Herni, Trejo, Ceci, Dom, Agus Z, Gri, Reni, Yani, Male, Marina, Pablo, JC, Guille, Alberto, Paula, Martin, gracias por ser parte de este excelente grupo. A Dave por sus ñoñadas de cada día. A Andre por su buena onda y sonrisa todos los días en perfecto funcionamiento. A Rodri por ser tan Rodri y el chivo expiatorio merecidísimo del laboratorio. A Romi por su compañía y buena onda durante el Late night show en el laboratorio. A Juanete por sufrirme, ayudarme y responder eficientemente al "hacé mate, Juan!” mío. A Agus por sus comentarios justos y acertados y su excelente compañía. A Paolín, por ser perfecta compañera y el enorme corazón de un gran laboratorio. A la Coca, por recordarnos que no está bueno estar tan tranquilos y hablar, hablar, hablar y hablar de cosas muuuy interesantes. A la dotora Loli, por ser una excelente persona que predica con el ejemplo y que con sus proyectos de vida nos enseña como ser mejores personas cada día; Lolita, te admiro y quiero muchísimo (Aguante Felicitas!!). A la Lu por solucionar con tranquilidad y serenidad los conflictos en el laboratorio, por su voz suave y delicada, diciendo "lo vas a traer o no lo lo vas a traer!!!” (leáse con voz ultra aguda y en tono de enojo); sos lo más Lu! A Nicolín, por su ayuda constante y desinteresada y por mantener el laboratorio en pie siempre. No me cansaré de decir, iiivolvé Nicolín!!!. A Beluga, que junto con Paolín y Nico me permiten compartir de una excelente compañía en la cátedra de Fisiología. Beluga, sólo voy a decirte que "Vos, Beluga, Yo, Romina”.

Un agradecimiento muy especial a Costy, la Consty para los que la conocemos. Gracias por tu soporte anímico, psicológico, moral, mental y cuanta otra clasificación le valga, para lograr terminar esta etapa y mirar positivamente hacia adelante. Gracias por estar siempre, incondicionalmente. Gracias por tu amistad.

Gracias a los excelentísimos amigos del inigualable Grupo La Loma Cicloturismo, quienes hicieron de mis domingos por la mañana el mejor día de la semana. Gracias a ellos por mostrarme un mundo nuevo, un mundo en bicicleta, 
un mundo al natural lleno de gente hermosa de la que vale la pena estar acompañada. Ferchu, Mechi, Normis, Silvia buena, Edu, Silvia mala, Elportihot, Anita, Sofi, Ruben, Fran, Gonza, Gus, Pela y muchos más y al excelentísimo Luis, Pluma Blanca, cacique de este grupo de locos, que nos enseña día a día lo hermoso de vivir, gracias.

A mis amigos de siempre, Maru (y su hermosa Cami), Susana, Gelita, Marian, Raulo, a quienes tengo bastante abandonados, pero ellos saben que los quiero muchísimo!!

Imposible agradecer en pocas palabras por tanto y mi flojera de palabra escrita no me permite menos. Simplemente gracias por creer en mi, aún cuando ni yo creía. Gracias por levantar mi pedacitos y armarme de nuevo, hacerme fuerte y sensible a la vez. Gracias por el aguante, infinitamente gracias a todos los que se cruzaron por mi camino y lo caminaron a la par mía. Los quiero mucho.

Romina 


\section{ABREVIATURAS}

${ }^{51}$ Cr-EDTA: ${ }^{51}$ Cromo-etilendiaminotetraacetato.

ADNc: Ácido Desoxirribonucleico Complementario.

AFC: Adyuvante de Freund Completo.

AL: Asa Ligada.

ARNdh: Ácido Ribonucleico Doble Hebra.

ARNm: Ácido Ribonucleico Mensajero.

CBA: Cytometric Beads Assay.

CCPR: Cociente de Producción de Células de la Cripta (Cript Cell Production Ratio).

CD: Célula dendrítica.

CEI: Células del Epitelio Intestinal.

CLR: C-Type Lectin Receptors.

CMH: Complejo Mayor de Histocompatibilidad.

CPA: Célula Presentadora de Antígeno.

DLG: Dieta Libre de Gluten.

DMI: Diabetes Mellitus tipo I.

EC: Enfermedad Celíaca.

FRET: Fluorescence Resonance Energy Transfer.

GALT: Tejido Linfoide Asociado a Intestino (Gut-associated lymphoid tissue).

Gt: Conductancia transepitelial.

GWAS: Estudio de Asociación de Genoma Completo (Genome-wide association study).

H\&E: Hematoxilina y Eosina.

HLA: Antígeno Leucocitario Humano (Human Leukocyte Antigen).

Ig: Inmunoglobulina.

IL: Intraluminal.

IP: Intraperitoneal

Isc: Corriente de cortocircuito.

JAMs: (Junctional adhesion molecules) Moléculas de Adhesión de la Unión.

KO: Knock-out.

LIEs: Linfocitos Intraepiteliales.

LP: Lamina Propria.

LPS: Lipopolisacárido.

MAMPs: Patrones moleculares asociados a microorganismos (Microbe-Associated Molecular Pattern). 
NK: Natural Killer.

NKT: Natural Killer T.

NLM: Nódulo Linfático Mesentérico.

NLR: NOD-like receptor.

PBS: buffer fosfato salino.

PCR: (polymerase chain reaction) Reacción en Cadena de la Polimerasa.

PDS: Péptido de Diferente Secuencia.

PIC: poly (I:C).

PICL: Poly (I:C) de bajo peso molecular.

PICS: Poly (I:C) marca Sigma.

PICH: Poly (I:C) de alto peso molecular.

PNR: Péptido No Relacionado.

Poly (I:C): Ácido Poli-inosínico:poli-citidílico.

PRR: Receptor de reconocimiento de patrones (Pattern recognition receptor).

qPCR: PCR cuantitativa o PCR en tiempo real.

RLR: RIG-I-like receptor.

ROS: Especies reactivas del oxígeno (Reactive oxygen species).

RPMI: Roswell Park Memorial Institute Medium.

SG: Gránulos de estrés (Stress Granules).

SNP: Polimorfismo de nucleótido simple (Single Nucleotide Polymorphism).

TER: Resistencia Transepitelial.

TG2: Transglutaminasa 2.

Th1: T helper 1.

TLR: Toll Like Receptor.

TUNEL: Terminal Deoxynucleotidyl Transferase (TdT)-mediated dUTP Nick End Labeling.

UA: Unión adherente

UE: Unión estrecha

V/C: Vellosidad/Cripta

Vt o Vc: Voltaje transepitelial. 


\section{RESUMEN}

La Enfermedad Celíaca (EC) es una enteropatía crónica de base inmune desencadenada por la ingestión de gluten en pacientes con predisposición genética. Se caracteriza por cambios histológicos severos en la mucosa duodenal definidos por atrofia vellositaria, infiltrado linfocitario e hiperplasia de criptas. Es una patología de alta prevalencia (estimada en un 1\% de la población) con una sintomatología variada que puede estar asociada a complicaciones severas.

Esta enfermedad ha sido extensamente estudiada utilizando muestras biológicas de pacientes. A pesar de los esfuerzos para desarrollar un modelo animal que reproduzca esta enteropatía, aún no se ha logrado. Usando distintos y complejos esquemas experimentales se han evaluado algunas etapas de la patogenia. Sin embargo, todos los modelos animales desarrollados han logrado replicar sólo algunas etapas del proceso inflamatorio o describir alguno de los mediadores involucrados en la patología, pero ninguno ha logrado modelar la enteropatía en forma plena. En especial, no se han logrado replicar los cambios histológicos característicos observados en el intestino delgado de pacientes con enfermedad celíaca activa.

Si bien se conoce con detalle gran parte del mecanismo de patogenia de EC, se ignoran cuáles son las etapas iniciales y en especial, qué factores determinan el inicio de la enteropatía. Por este motivo, el objetivo de este trabajo fue obtener un modelo de inflamación intestinal generada por inductores de la respuesta inmune innata en ratones normales, como posible paso inicial para el desarrollo de una enteropatía más severa y a largo plazo en ratones genéticamente predispuestos. Para ello se optimizó un procedimiento de microcirugía que nos permitió inyectar los mediadores de interés directamente en la luz del intestino delgado.

Encontramos que es posible generar enteropatía a las 12 horas en ratones C57BL/6 tanto con la administración de poly (I:C) como con un péptido derivado de gliadina, p31-43. Encontramos que ambos mediadores generan enteropatía por mecanismos diferentes.

Por su parte, ambos inductores fueron capaces de generar una enteropatía a largo plazo cuando se emplearon ratones NOD-DQ8, conocidos por presentar sensibilidad al gluten ante ciertas circunstancias. De este modo, con el tratamiento previo de estos ratones con los inductores poly (I:C) o p31-43 y la 


\section{Resumen}

posterior administración por vía oral de gliadina, obtuvimos dos modelos de enteropatía a largo plazo con características distintivas.

En este trabajo mostramos que estos modelos constituyen herramientas muy útiles para el estudio de los mecanismos innatos, tanto moleculares como celulares, que pueden llevar a la generación de procesos crónicos en la mucosa del intestino delgado y conducir al desencadenamiento de EC. 


\section{HIPÓTESIS DE TRABAJO}

Gran parte de los estudios relacionados a los mecanismos de patogenia de Enfermedad Celíaca (EC) fueron realizados principalmente por estudios ex vivo (sobre material de biopsia intestinal) o ensayos in vitro. Hasta el momento no se ha podido generar un modelo animal que pueda reproducir la enteropatía severa similar a la observada con EC activa. Un modelo animal permitiría evaluar los eventos tempranos que se desarrollan en el intestino delgado en los primeros pasos de la patogenia.

Es sabido que existen péptidos de gliadinas (como el p31-43) que inducen daño tisular en modelos experimentales in vitro o ex vivo, donde la respuesta innata es el principal protagonista. Por lo tanto, suponemos que la presencia de este péptido sumado a un inductor típico de la respuesta innata podría conducir a una rápida y más intensa respuesta inflamatoria que podría modelar los eventos iniciales de la EC.

Poly (I:C) ha sido utilizado como ligando de la inmunidad innata para modelar el curso de una infección viral, dado que mimetiza el material genético producido durante el ciclo de replicación viral. El reconocimiento de los distintos elementos de la replicación viral por receptores de la inmunidad innata causan daño tisular. Previamente se han desarrollado modelos de enteropatía inducida por la administración intraperitoneal (IP) de poly (I:C). Sin embargo, este modo de administración implica efectos sistémicos que impiden individualizar los mecanismos intrínsecos de la mucosa intestinal de aquellos generados en otros sitios. Por este motivo, en este trabajo se utilizó la administración intraluminal de los inductores. Esta técnica permite la administración de inductores o mediadores directamente en la luz del intestino evitando la administración vía oral que podría generar el inconveniente de la degradación de los estímulos en su pasaje por el estómago y duodeno, siendo difícil de estimar esta pérdida y por lo tanto, la concentración efectiva que alcanza el lumen.

Nuestra hipótesis de trabajo fue que poly (I:C) y/o p31-43, administrados localmente desencadenarían diferencialmente una cascada de eventos locales que determinarían la activación y potenciación de los mecanismos de daño tisular. Estos mecanismos podrían además generar cierta predisposición a sensibilidad al gluten en modelos animales genéticamente condicionados y permitirían evaluar 
Hipótesis de trabajo

los efectos a largo plazo de la alteración en la mucosa de intestino delgado y modelar los eventos que conducen a la cronicidad en la patogenia en EC. 


\section{MATERIALES Y MÉTODOS}





\section{MATERIALES Y MÉTODOS}

\section{ANIMALES}

Ratones macho de 8 semanas de edad de la cepa C57BL/6 fueron provistos por el bioterio de la Facultad de Ciencias Veterinarias (UNLP) o por el bioterio de la Facultad de Ciencias Exactas y Naturales (UBA). Los ratones fueron ubicados en cajas plásticas y recibieron alimento balanceado y agua ad libitum. Fueron mantenidos en un ciclo de $12 \mathrm{~h}$ luz/oscuridad y aclimatados por una semana antes del procedimiento experimental.

Ratones macho de 8-10 semanas de edad de la cepa C3H-HeJ fueron provistos por el Dr. Martín Rumbo, investigador del Instituto de Estudios Inmunológicos y Fisiopatológicos (IIFP-CONICET).

Ratones de la cepa MyD88 KO (denominación de la cepa B6.129P2(SJL)Myd88 $8^{\text {tml.1Defr }} / \mathrm{J}$ ) fueron provistos por el Centro de Investigaciones en Bioquímica Clínica e Inmunología (CIBICI-CONICET, Córdoba, Argentina). Estos ratones tienen como cepa control a ratones C57BL/6. Una vez en el bioterio de la Facultad de Ciencias Exactas (UNLP), los ratones fueron ubicados en cajas plásticas ventiladas y recibieron alimento balanceado y agua ad libitum. Para los experimentos se utilizaron ratones de 8-10 semanas de edad.

Ratones transgénicos que expresan HLA-DQ8 en un entorno de deficiencia del MHC clase II endógeno fueron cruzados con ratones NOD por 10 generaciones e intercruzados para producir ratones congeneicos NOD-DQ8 (denominación de la cepa NOD $\mathrm{AB}^{\circ} \mathrm{DQ8}$ ) (Marietta et al. 2004). Ratones machos de 10 semanas de edad fueron usados para estos experimentos. Los ratones fueron criados y mantenidos en una dieta baja en grasas (4.4\%) libre de gluten. El par original de ratones NOD-DQ8 fue provisto por el Dr. Chella David y el Dr. Joseph Murray de Mayo Clinic, Rochester, USA y luego fueron mantenidos en condiciones libres de patógenos específicos en el Bioterio de McMaster University, Hamilton, Canadá, bajo la supervisión de la Dra. Elena Verdú.

Todos los estudios fueron realizados de acuerdo con protocolos internacionales para el cuidado de los animales de laboratorio (Canadian Council on Animal Care). Los experimentos con ratones NOD-DQ8 fueron conducidos con la aprobación del comité de ética de McMaster University (McMaster University Animal Care Committee). 


\section{TRATAMIENTO CON INDUCTORES INTRALUMINALES E INOCULACIÓN} INTRAGÁSTRICA.

Los ratones fueron inyectados con los diferentes tratamientos utilizando una técnica de microcirugía intestinal que permite inyectar el estímulo directamente en la luz del intestino delgado. Para ello, los ratones fueron anestesiados con Ketamina ( $80 \mathrm{mg} / \mathrm{kg}$ de peso) y Xilacina ( $10 \mathrm{mg} / \mathrm{kg}$ de peso). Una

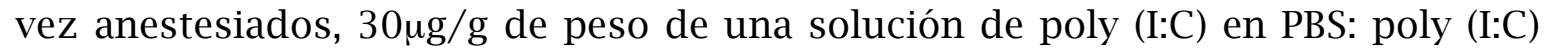
comercial (Sigma), poly (I:C) de bajo peso molecular (PICL) (Invivogen) o poly (I:C) de alto peso molecular (PICH)(Invivogen); 100 $\mathrm{g} / \mathrm{ml}$ de p31-43 (LGQQQPFPPQQPY,

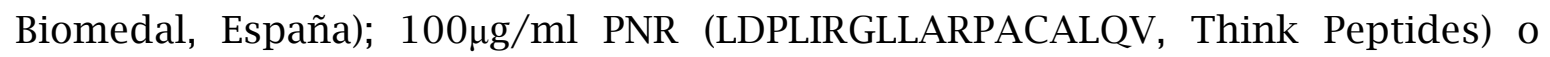
$100 \mu \mathrm{g} / \mathrm{ml}$ de PDS (YQPLFQPQGPQPQ, Think Peptides) fueron inyectados en 100ul de solución en el lumen del intestino delgado, $2 \mathrm{~cm}$ después del estómago, para evitar la degradación enzimática (principalmente debido a la actividad nucleasa y

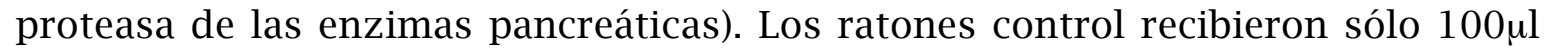
de PBS en el lumen.

En los ratones con tratamiento por medio de asa ligada, por el contrario, se realizaron dos ataduras, una proximal a $2 \mathrm{~cm}$ del estómago y una distal, a $3 \mathrm{~cm}$ de la primera, para luego inyectar $100 \mu \mathrm{l}$ de una solución de poly (I:C) $(30 \mu \mathrm{g} / \mathrm{g})$ o PBS en la luz del asa ligada.

Luego de la cirugía se realizó una reperfusión de fluidos y los ratones fueron estrictamente monitoreados hasta que recuperaron su movilidad por completo.

Los ratones fueron sacrificados entre las 2 y las $72 \mathrm{~h}$ post-tratamiento, dependiendo del esquema experimental, con los distintos poly (I:C)s, péptidos o PBS y las muestras de intestino delgado proximal o de asa ligada fueron colectadas para su análisis.

Los ratones NOD-DQ8 fueron mantenidos bajo dieta libre de gluten hasta el momento de la cirugía. Un grupo de los ratones NOD-DQ8 estimulados intraluminalmente con PBS, poly (I:C) o p31-43 fueron sacrificados a las 3 y a las $12 \mathrm{hs}$ y se colectaron muestras de intestino delgado y sangre para su posterior análisis.

Otro grupo de los ratones NOD-DQ8 fue inoculado luego de las 24hs de la cirugía, por vía oral, con $5 \mathrm{mg}$ de $\alpha$-gliadina cada vez, tres veces por semana durante 2 semanas. La $\alpha$-gliadin (Sigma-Aldrich) fue disuelta en una solución de ácido acético 0,02M en condiciones libres de endotoxinas. Los ratones controles 
fueron inoculados con la solución de ácido acético solamente (ratones en dieta libre de gluten, DLG). Tanto los ratones inoculados con gliadina como aquellos en dieta libre de gluten recibieron alimento libre de gluten ad libitum durante las 2 semanas.

Todas las soluciones fueron controladas por la posible presencia de endotoxinas y se determinaron en las preparaciones usando E-TOXATE endotoxin kit (Sigma). Los ratones fueron pesados en el transcurso del protocolo 3 veces por semana durante las dos semanas luego de realizar la inoculación intragástrica.

\section{EVALUACIÓN HISTOLÓGICA}

Secciones de intestino delgado proximal fueron fijadas en formol al $4 \%$ (formalina), deshidratadas siguiendo un tren de deshidratación (Etanol 50\%, Etanol 70\%, Etanol 96\%, Etanol 100\% x 2, Xilol x 2), incluidas en parafina y teñidas con Hematoxilina y Eosina (H\&E) para su evaluación histológica usando el microscopio de fluorescencia Nikon Eclipse Ti. Las imágenes fueron tomadas con cámara Nikon Digital Sight DS Ril usando el software Nis-Elements y las medidas fueron hechas usando el programa ImageJ apropiadamente calibrado.

Las secciones de intestino delgado proximal de $4 \mu \mathrm{m}$ fueron evaluadas para evidenciar inflamación. Al menos 30 cocientes vellosidad-cripta fueron medidos para cada ratón en un ensayo a ciegas. Se eligieron azarosamente las puntas de 10 vellosidades para contar linfocitos intraepiteliales (LIEs) cada 30 enterocitos por punta observando los cortes en un microscopio de campo ampliado Nikon Eclipse E400. Los resultados se expresaron en LIEs/100 Enterocitos (Biagi et al. 2004).

Los scores histológicos se obtuvieron a partir de secciones de intestino delgado teñidas con H\&E, siguiendo el criterio de Park-Chiu (Quaedackers et al. 2000): 0, mucosa normal; 1, espacio subepitelial en las puntas de las vellosidades 2, extensión del espacio subepitelial con moderada separación del epitelio; 3, masiva separación del epitelio a ambos lados de las vellosidades, algunas vellosidades desnudas; 4, vellosidades desnudas, capilares dilatados; 5, desintegración de la lamina propria; 6, injuria de criptas; 7, infarto transmucosal; 8, infarto transmural. Las observaciones se llevaron a cabo en un microscopio Nikon Eclipse E400. 


\section{DETERMINACIÓN DEL ESTADO PROLIFERATIVO DE LOS TEJIDOS.}

En ratones estimulados durante 24 o 72 hs ser realizó la determinación del Cociente de Producción de las Células de la Cripta (CCPR, Crypt Cell Production Ratio). Para ello, 90 minutos antes del sacrificio de los animales se realizó un arresto mitótico mediante la inyección intraperitoneal de 7,5mg/kg de peso de colchicina (Sigma). Los animales se sacrificaron a los 30, 60 y 90 minutos luego de la inyección de colchicina. Las muestra de intestino tomadas fueron fijadas en etano-ácido acético (70:30\%), deshidratadas (Etanol 50\%, Etanol 70\%, Etanol 96\%, Etanol $100 \%$ x 2, Xilol x 2) e incluidas en parafina como ya fue descripto antes. Secciones de $4 \mu \mathrm{m}$ de espesor fueron teñidas con Hematoxilina (Biopur Diagnostics) durante 3 minutos y Eosina (Biopur Diagnostics) durante 3 minutos.

Otro grupo de secciones de $4 \mu \mathrm{m}$ de espesor se tiñeron mediante la técnica de Feulgen. La técnica de Feulgen consiste en la hidrólisis ácida durante 50 minutos con $\mathrm{HCl} 5 \mathrm{M}$ a temperatura ambiente, la coloración con el reactivo de Schiff durante 60 minutos a temperatura ambiente y en oscuridad, se diferencia con una solución ácida de disulfito de sodio $(94 \mathrm{ml}$ de agua destilada, $5 \mathrm{ml}$ bisulfito de sodio al $100 \mathrm{~g} / \mathrm{l} \mathrm{y} 1 \mathrm{ml} \mathrm{HCl} 5 \mathrm{M}$ ). El reactivo de Schiff se prepara mezclando 2,5 g de Fucsina Básica (Anedra), 50ml de $\mathrm{HCl} 1 \mathrm{~N}$ y $10 \mathrm{~g}$ de bisulfito de sodio (Cicarelli Laboratorios), agitando durante 3 minutos y dejando 24 horas en oscuridad. Luego se agrega carbón activado para eliminar la coloración y se filtra. El reactivo preparado se guarda en heladera y protegido de la luz hasta su uso.

Una vez realizada la reacción de Feulgen, los cortes se observaron al microscopio de campo ampliado Nikon Eclipse E400 y se contaron los núcleos en metafase por cripta, en aproximadamente 40 criptas y en cada uno de los ratones inyectados a distintos tiempos con colchicina. Con el promedio de Metafases/Cripta y el tiempo de exposición a colchicina expresado en horas $(0,5$, 1,0 y 1,5 horas) se obtuvo una recta cuya pendiente es el CCPR, expresado en metafase/cripta/hora. Por lo tanto, cada valor de CCPR proviene de 3 ratones sometidos al mismo estímulo inicial e inyectados a distintos tiempos con colchicina.

El otro método utilizado para la evaluación de la proliferación celular fue la marcación inmunofluorescente de la molécula Ki67. Para ello, cortes de tejido incluido en parafina de $4-5 \mu \mathrm{m}$ de espesor fueron rehidratados (Xilol x 2, Etanol 100\% x2, Etanol 96\%, Etanol 70\%, agua destilada) y sometidos a una recuperación antigénica con Antigen Retrieval Citra Plus Solution (BioGenex) durante 15 minutos en microondas. Todas las secciones fueron bloqueadas con suero de 
cabra al 2\%. Luego, se incubaron los cortes con el anticuerpo monoclonal antiKi67 (NovusBiologicals) diluído 1/50 e incubado durante toda la noche a $4^{\circ} \mathrm{C}$. Para revelar, se utilizó como anticuerpo secundario una dilución 1/200 de un anticuerpo obtenido en cabra anti-IgG de conejo conjugado con Alexa-488 (Invitrogen), incubado durante 30 minutos. Los núcleos fueron teñidos con $1 \mu \mathrm{g} / \mathrm{ml}$ de una solución de DAPI (Sigma) durante 3 minutos a temperatura ambiente. Los cortes fueron montados con un medio de montaje apto para fluorescencia (DakoCytomation) y observados al microscopio de fluorescencia Nikon Eclipse Ti. Las imágenes fueron tomadas con cámara Nikon Digital Sight DS Ri1 usando el software Nis-Elements y los recuentos fueron hechos usando el programa ImageJ apropiadamente calibrado.

\section{MÉTODO USSING CHAMBER}

Dos secciones de intestino delgado proximal de cada uno de los ratones NOD-DQ8 fueron usadas para experimentos de Ussing chamber como se describió previamente (Galipeau et al. 2011; E F Verdu et al. 2008; de Kauwe et al. 2009). Una porción de $3-4 \mathrm{~cm}$ de intestino delgado fue colectada $(3 \mathrm{~cm}$ por debajo del estómago), cortada en dos secciones y ubicada en buffer Krebs aireado con 95\% de $\mathrm{O}_{2}$ y $5 \%$ de $\mathrm{CO}_{2}(\mathrm{pH} 7,3-7,4)$. Cada segmento de intestino fue cortado longitudinalmente por su borde mesentérico para formar una hoja plana y montarlo en una Ussing chamber. La cámara expuso $0,7 \mathrm{~cm}^{2}$ de superficie de tejido a $8 \mathrm{ml}$ de buffer Krebs oxigenado circulante conteniendo $10 \mathrm{mM}$ de glucosa (lado serosal) y $10 \mathrm{nM}$ de Manitol (lado mucosal) y mantenido a $37^{\circ} \mathrm{C}$. El transporte activo de iones neto a través del epitelio fue medido vía una corriente de cortocircuito (Isc, mA) generada a través del tejido bajo condiciones de voltaje prefijado constante (Vc). La conductancia del tejido, Gt (la permeabilidad pasiva a los iones) fue calculada usando la ley de Ohm (Vc = TER x Isc, Gt=1/TER; TER, Resistencia Transepitelial). La Isc $\left(\mathrm{mA} / \mathrm{cm}^{2}\right)$ y Gt $\left(\mathrm{mS} / \mathrm{cm}^{2}\right)$ basales fueron determinadas en equilibrio, 20 minutos después de montadas las secciones. Mediante el uso del isótopo ${ }^{51} \mathrm{Cr}$-EDTA se midió el flujo de solutos (Flujo isotópico) a través del tejido en el tiempo del ensayo.

\section{ANÁLISIS DE CITOQUINAS}

La presencia de citoquinas proinflamatorias en suero de ratones NOD-DQ8 fue determinada usando el kit Cytometric Bead Array (CBA) Inflammation (BD Biosciences) y analizada usando BD FACSarray Bioanalyzer System (BD 
Biosciences). Los resultados fueron graficados mediante el software GraphPad y procesados en este mismo programa.

\section{MICROSCOPÍA DE FLUORESCENCIA}

Secciones de intestino delgado de ratones tratados con PBS, poly (I:C), p3143 o poly (I:C)+p31-43 fueron desparafinadas y se realizó un protocolo de inmunofluorescencia. La recuperación de antígenos fue realizada usando una solución de Antigen Retrieval AR-10 (BioGenex). Se permeabilizó con una solución de PBS-Tween 20 0,01\% y se bloqueó con suero de cabra al 2\%. Para la marcación de MDA5 y RIG-I se utilizó un anticuerpo policlonal anti-MDA5 (Santa Cruz Biotechnology) y un anticuerpo policlonal anti-RIG-I (Santa Cruz Biotechnology), respectivamente, a una concentración 1/10 durante $1 \mathrm{~h}$ a temperatura ambiente. Se utilizó a continuación un anticuerpo secundario anti-conejo conjugado con Alexa488 en una dilución 1/200 durante 30 minutos a temperatura ambiente. Para la marcación de Caspasa 3 clivada, se utilizó un anticuerpo policlonal antiCaspasa 3 clivada conjugado con FITC (Cell Signaling) diluído 1/10, incubando durante $1 \mathrm{~h}$ a temperatura ambiente.

Los núcleos fueron teñidos con ioduro de propidio (Sigma) a una concentración de $1 \mu \mathrm{g} / \mathrm{ml}$ por 15 minutos. Las imágenes fueron obtenidas y analizadas en un Microscopio Confocal TCS SP5 combinado con el programa Leica LAS AF.

\section{PCR EN TIEMPO REAL}

Muestras de intestino delgado de ratones C57BL/6 y NOD-DQ8 fueron almacenadas en RNA later (Ambion, Life Technologies) en un freezer de $-80^{\circ} \mathrm{C}$ hasta su uso. Los tejidos fueron digeridos y se realizó la extracción de ARN usando el kit RNeasy Mini Kit (Qiagen). La síntesis de ADNc se realizó a partir de las muestras de ARN aisladas (2-5 $\mu \mathrm{g})$, usando iScript Reverse Transcription Supermix (Bio-Rad). La reacción de PCR en tiempo real fue realizada con SsoFast EvaGreen Supermix (Bio-Rad) usando un par de primers adecuados y la termocicladora iQ5 con detección de fluorescencia (Bio-Rad). Las reacciones fueron corridas por triplicados. El protocolo para la PCR en tiempo real fue: Ciclo 1 (1X) $95^{\circ} \mathrm{C}$ por $10 \mathrm{~min}$; Ciclo $2(40 \mathrm{X}) 60^{\circ} \mathrm{C}$ por $1 \mathrm{~min}$ y $95^{\circ} \mathrm{C}$ por $15 \mathrm{seg}$. Los primers fueron sintetizados como se ha descripto previamente (Bustin et al. 2009). Las secuencias de primers son provistas en la Tabla 1. La media geométrica del gen constitutivo HPRT fue usado como un control interno para normalizar la 
variabilidad en los niveles de expresión. Todos los resultados fueron expresados como un aumento relativo del tratamiento de PBS, poly (I:C), p31-43 o poly (I:C)+p31-43 versus la media del tratamiento de PBS en cada punto de tiempo (Método de $2^{-\Delta \Delta c t}$ ).

\begin{tabular}{|lll|}
\hline Gen & Forward & Reverse \\
HPRT & CAATGCAAACTTTGCTTTCC & CAAATCCAACAAAGTCTGGC \\
\hline MDA5 & CGATCCGAATGATTGATGCA & AGTTGGTCATTGCAACTGCT \\
\hline RIG-I & CAGACAGATCCGAGACACTA & TGCAAGACCTTTGGCCAGTT \\
\hline TLR3 & GAAGATGATGCAGTCTTTCCA & CCTGTATCATATTCTACTCCTTGC \\
\hline IFN $\boldsymbol{\beta}$ & AATGGAAAGATCAACCTCAC & AAGGCAGTGTAACTCTTCTG \\
\hline CXCL9 & CAACACAGTGACTCAATAGAACTC & CACTAGGGTTCCTCGAACTC \\
\hline CXCL10 & ATAGGGAAGCTTGAAATCATCC & TTCATCGTGGCAATGATCTC \\
\hline CXCL11 & CTTCTGTAATTTACCCGAGTAACG & TTCTATTGCCTGCATTATGAGG \\
\hline CXCR3 & TGTAGTTGGGCTAGCTCGAACTT & ACCTGGATATATGCTGAGCTGTCA \\
\hline TNF $\boldsymbol{\alpha}$ & CTCCCTCTCATCAGTTCTATGG & TTGAGAAGATGATCTGAGTGTG \\
\hline IL-15 & CATCCATCTCGTGCTACTTGTGTT & CATCTATCCAGTTGGCCTCTGTTT \\
\hline MCP1 & CTACAAGAGGATCACCAGCAG & TTCTGATCTCATTTGGTTCCG \\
\hline CXCL2 & AAGATACTGAACAAAGGCAAGG & TTCTTTCTCTTTGGTTCTTCCG \\
\hline IL-1 $\boldsymbol{\beta}$ & CGTTCCCATTAGACAACTGC & CTCATGGAGAATATCACTTGTTGG \\
\hline IL-18 & GATCAAAGTGCCAGTGAACC & GATCTTGTTCTTACAGGAGAGG \\
\hline IL-6 & CATGTTCTCTGGGAAATCGT & TATATCCAGTTTGGTAGCATCC \\
\hline IFN $\boldsymbol{\gamma}$ & CTGAGACAATGAACGCTACAC & TTTCTTCCACATCTATGCCAC \\
\hline Bax & TGCTACAGGGTTCATCCAG & ATTGCTGTCCAGTTCATCTC \\
\hline Bcl2 & GATCTCTGGTTGGGATCCT & ACAACTTGCAATGAATCGGG \\
\hline $\mathbf{1 0}$ & &
\end{tabular}

Tabla 1. Primers utilizados para PCR en Tiempo Real.

\section{EXPRESIÓN DE CASPASA 3 POR WESTERN BLOT}

Se obtuvieron extractos proteicos totales a partir de las muestras de intestino delgado almacenadas a $-80^{\circ} \mathrm{C}$ en tubos secos hasta su procesamiento. Los tejidos fueron lisados con HEPES 10mM, $\mathrm{KCl} 10 \mathrm{mM}$ y Nonidet P-40 0,1\% en presencia de una mezcla inhibidora de proteasas (Roche). Luego de centrifugar el lisado, la fracción soluble se separó y se determinó la cantidad de proteína mediante el kit Pierce BCA Protein Assay Kit (Thermo Scientific). Para los ensayos se utilizaron $30 \mu \mathrm{g}$ de proteínas. Se resolvieron en un gel de SDS-PAGE del 15\% bajo condiciones reductoras (BioRad Mini-Protean III; BioRad). Se transfirieron a una membrana de nitrocelulosa por $1 \mathrm{~h}$ a $300 \mathrm{~mA}$. La membrana fue bloqueada con $5 \%$ de leche descremada en TBS-Tween $0,1 \%$ durante $1 \mathrm{~h}$ a $37^{\circ} \mathrm{C}$ y evaluada con anticuerpo en conejo anti-caspasa 3 (Cell Signaling) en una dilución de 1/1000 en TBS-Tween 0,1\% y leche descremada 1\%. El anticuerpo secundario 
utilizado fue un anti-IgG de conejo conjugado a HRP (BioRad) diluído 1/2000. Las bandas de proteínas fueron visualizadas por quimioluminiscencia amplificada (ECL Plus; GE Healthcare) de acuerdo a las instrucciones del fabricante. Las membranas fueron lavadas adecuadamente e incubadas con un anticuerpo de conejo anti- $\beta$-actina (AbCam) diluido 1/3000 como un control interno de carga y revelado con un anticuerpo anti-conejo HRP diluído 1/2000 (BioRad). Las bandas fueron escaneadas y cuantificadas usando el programa Image J.

\section{REACCIÓN DE TUNEL}

Para la detección y cuantificación inmunohistoquímica de la muerte celular se utilizaron dos kits: el kit Cell Death Detection (Roche) y el kit DeadEnd Fluorometric TUNEL System (Promega). Se utilizaron secciones de intestino delgado incluidos en parafina, los cuales fueron desparafinados, rehidratados y tratados con proteinasa $\mathrm{K}$ para su permeabilización. Luego, una mezcla de reacción para TUNEL fue adicionada y los núcleos fueron teñidos con DAPI $(1 \mu \mathrm{g} / \mathrm{ml}$ por $3 \mathrm{~min})$ o ioduro de propidio $(1 \mu \mathrm{g} / \mathrm{ml}$ por $15 \mathrm{~min})$ dependiendo del microscopio confocal utilizado. Se obtuvieron imágenes con un Microscopio Confocal Olympus FV1000 y en un Microscopio Confocal TCS SP5 Leica combinado con el programa Leica LAS AF. Las imágenes se analizaron con el programa Image $\mathrm{J}$.

\section{ELECTROFORESIS EN GEL DE AGAROSA}

Se realizó una electroforesis en gel de agarosa con bromuro de etidio para determinar el peso molecular de los poly (I:C)s de distinto tamaño. Para ello se utilizó un gel de agarosa al 2\% al que se le agregó bromuro de etidio para evidenciar los ácidos nucleicos de los poly (I:C)s. Se agregó un marcador de peso molecular de 100pb (PB-L Productos Bio-Lógicos) y se corrió en una cuba pequeña a 100V durante 35 minutos hasta la resolución de las bandas. La fotografía del gel se tomó en un transiluminador con luz UV (MultiImage Light Cabitnet) y la imagen se procesó con el programa Image J.

\section{ESTUDIO DE MEDIADORES CELULARES DE DAÑo (TRATAMIENTOS CON CÉLULAS B16-FLT3L, ANTICUERPO ANTI-GR1 Y BINDARIT).}

Para el estudio de mediadores celulares de daño, en primer lugar utilizamos la línea de melanoma B16-Flt3L. Inyectamos por vía subcutánea en el lomo de ratones C57BL/6 la cantidad de $10^{6}$ células de melanoma en $400 \mu$ de medio RPMI 
por ratón y esperamos hasta la formación del tumor sólido (15-20 días). Una vez formado el tumor sometimos a estos ratones al procedimiento quirúrgico antes descripto para la inyección intraluminal de poly (I:C) o PBS como control.

Por otra parte, inyectamos ratones $\mathrm{C} 57 \mathrm{BL} / 6$ con un anticuerpo monoclonal purificado hecho en rata anti-GR1 específico para Ly6G/Ly6C (RB6-8C5; 2,0mg/ml), o un control de isotipo (HB152) según un protocolo previamente establecido para la depleción de la población de neutrófilos principalmente (Zurita et al. 2013). El esquema consistió en la administración de $400 \mu \mathrm{g}$ de anticuerpo 24hs antes de la cirugía. Luego sometimos a los animales a la cirugía antes descripta para la inyección intraluminal de poly (I:C) o PBS.

Ratones C57BL/6 fueron inyectados intraperitonealmente con dos dosis de una solución de $100 \mathrm{mg} / \mathrm{kg}$ de peso de ratón de Bindarit (nombre comercial AF2838, ácido 2-((1-benzil-1H-indazol-3-il)-metoxi)2-metil propiónico) disuelto en metilcelulosa, 12 y $24 \mathrm{hs}$ antes de someterlos a la cirugía de estimulación con poly (I:C) o PBS.

En todos los casos, luego de $12 \mathrm{hs}$ de tratamiento, los animales fueron sacrificados y se obtuvieron muestras de intestino para su análisis histológico.

\section{ANÁLISIS ESTADÍSTICO}

Los análisis estadísticos fueron realizados con el programa GraphPad Prism. Cuando más de dos tipos de tratamiento fueron comparados, se utilizó un test de ANOVA con un test de Bonferroni post hoc para múltiples comparaciones. Cuando dos grupos fueron comparados se utilizó un test $t$ no pareado. Se consideró significativo un $\mathrm{p}<0.05$. Los datos se grafican como la media \pm SEM. 



\section{INTRODUCCIÓN Y OBJETIVOS GENERALES}

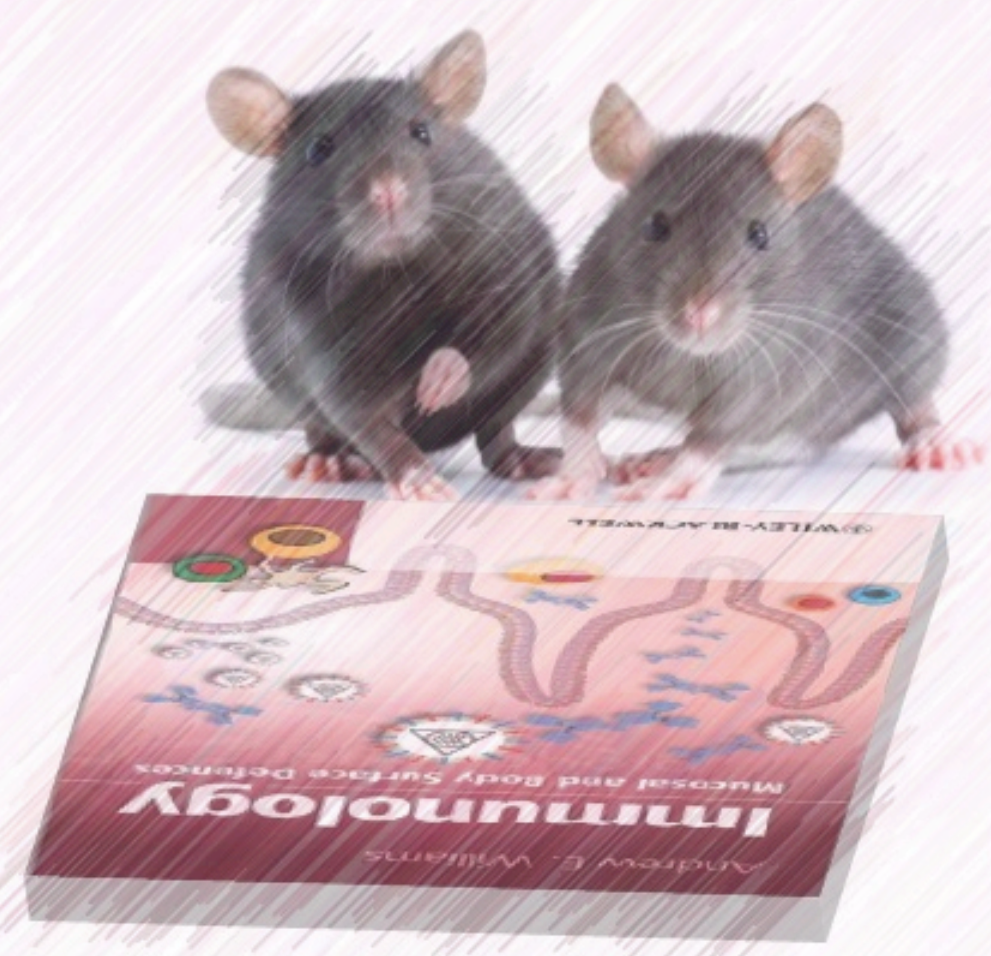





\section{INTRODUCCIÓN GENERAL}

La mucosa intestinal constituye uno de los sitios de más alta actividad inmunológica. El sistema inmune de la mucosa intestinal, desde el punto de vista celular, es el más complejo y numeroso del sistema inmune.

Su función consiste en establecer un estado de respuesta altamente especializado que permita reconocer y montar una respuesta regulada al enfrentarse a antígenos provenientes de la microbiota comensal o de la dieta, como así también responder eficientemente a la presencia de microorganismos patógenos
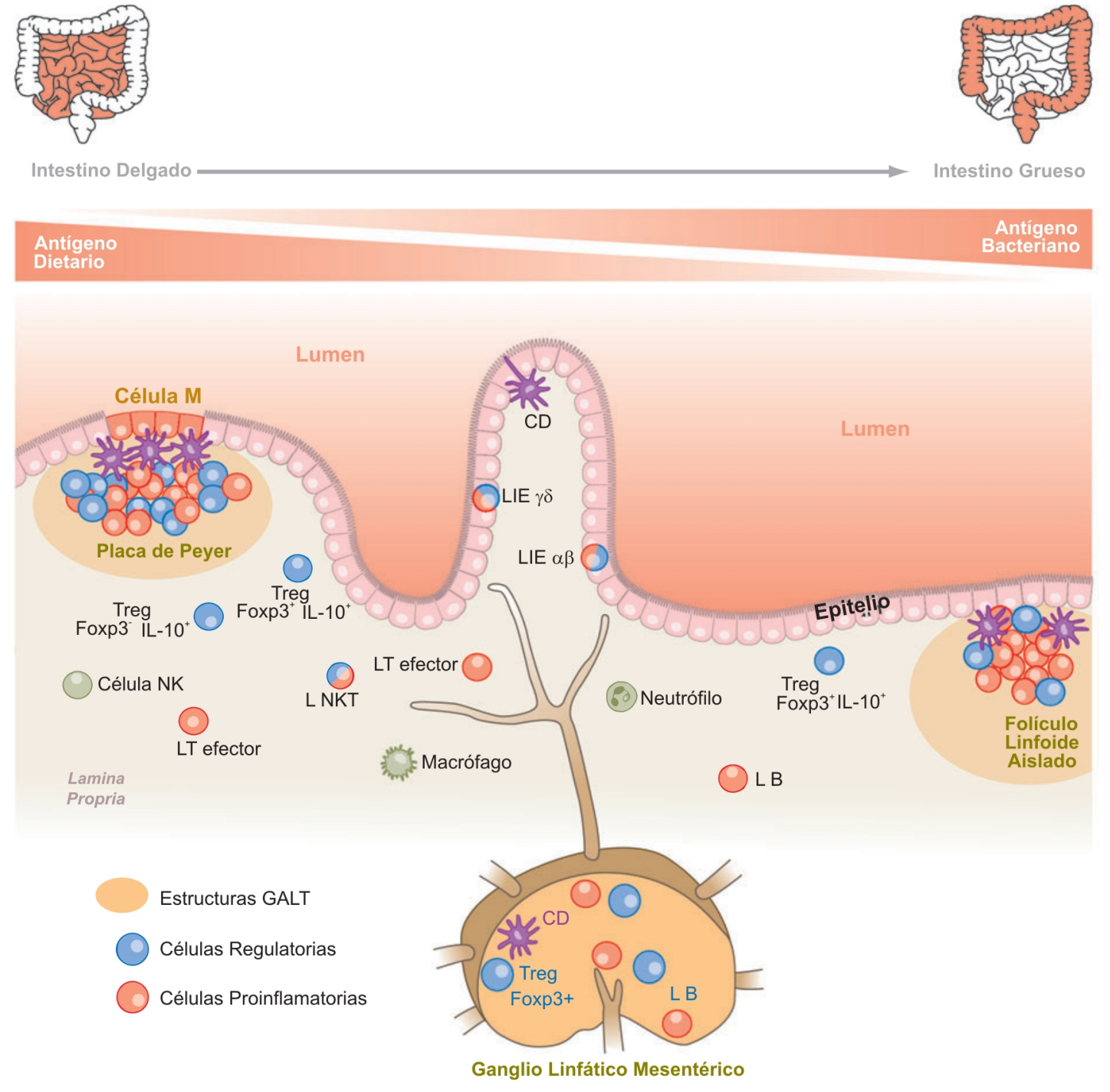

Figura 1. Esquema de los elementos que participan en la respuesta inmune en intestino delgado.

La respuesta inmune tiene lugar en el epitelio, la lamina propria y el tejido linfoide asociado a mucosas (GALT). El intestino recluta poblaciones celulares especializadas en el muestreo y presentación de antígenos, en la inmunidad antimicrobiana y en el mantenimiento de la tolerancia contra antígenos exógenos inocuos. Abreviaturas: LT, Linfocito T; LB, Linfocito B; LIE, linfocito intraepitelial; L NKT, Linfocito NKT o célula NKT; CD, Célula Dendrítica; Treg, Linfocito T regulatorio. (Figura adaptada de Izcue, Coombes, and Powrie 2009) 
montando una adecuada respuesta protectiva (Allan M. Mowat and Agace 2014; A M Mowat 2003). Dicho esto, no es de sorprender que el intestino constituye el órgano linfoide más complejo del organismo. Contiene una amplia red de órganos linfoides secundarios y se ubican en él un enorme número de linfocitos, incluyendo varias subpoblaciones celulares específicas de intestino (Figura 1).

La falla de los mecanismos de regulación conduce a diversas y complejas patologías intestinales, tales como enfermedad inflamatoria intestinal, enfermedad celíaca (EC) y alergias alimentarias (Honda and Takeda 2009; Izcue, Coombes, and Powrie 2009).

Para mantener una condición simbiótica con los componentes de la microbiota existen diversos mecanismos regulatorios que incluyen la secreción de factores solubles, la participación de células dendríticas intestinales y de linfocitos T reguladores.

Entre las primeras estrategias de defensa ante un patógeno se encuentran mecanismos tan diversos como la producción de péptidos anti-microbianos, la generación de mecanismos inflamatorios y el reclutamiento de neutrófilos, células dendríticas y macrófagos (Izcue, Coombes, and Powrie 2009).

\section{INDUCCIÓN DE MECANISMOS DE LA RESPUESTA PROTECTIVA Y} REGULATORIA EN LA MUCOSA.

La inmunidad innata tiene como función principal el reconocimiento de patrones moleculares presentes en distintos microorganismos (MAMPs) de modo específico mediante Receptores de Reconocimiento de Patrones (PRRs) tales como los TLRs (Toll like receptor), NLRs (Nucleotide oligomerization domains like receptors), RIGs (retinoic acid inducible gene I (RIG-1) like receptors), y CLRs (Ctype lectin receptors) (K J Ishii et al. 2008). Estos receptores cooperan para reconocer una variedad de agentes microbianos sensando su pared celular, estructuras de superficie, por ejemplo flagelina, proteínas virales, ácidos nucleicos del huésped o virales o moléculas inducidas por estrés (peligro) sobre la superficie celular, en los endosomas o en el citosol (Figura 2).

Por ejemplo, las paredes celulares bacterianas y fúngicas pueden ser reconocidas sobre la superficie celular por TLR2 dimerizado con TLR1 o TLR6 a través de los adaptadores MyD88 y TIRAP, y por el CLR, Dectin-1, a través de su adaptador CARD9. En cambio, su reconocimiento intracelular ocurre vía NOD1 y NOD2 en una vía de señalización dependiente de RIP2. Estos sistemas de reconocimiento, tomados como ejemplo aquí, a su vez pueden cooperar para 


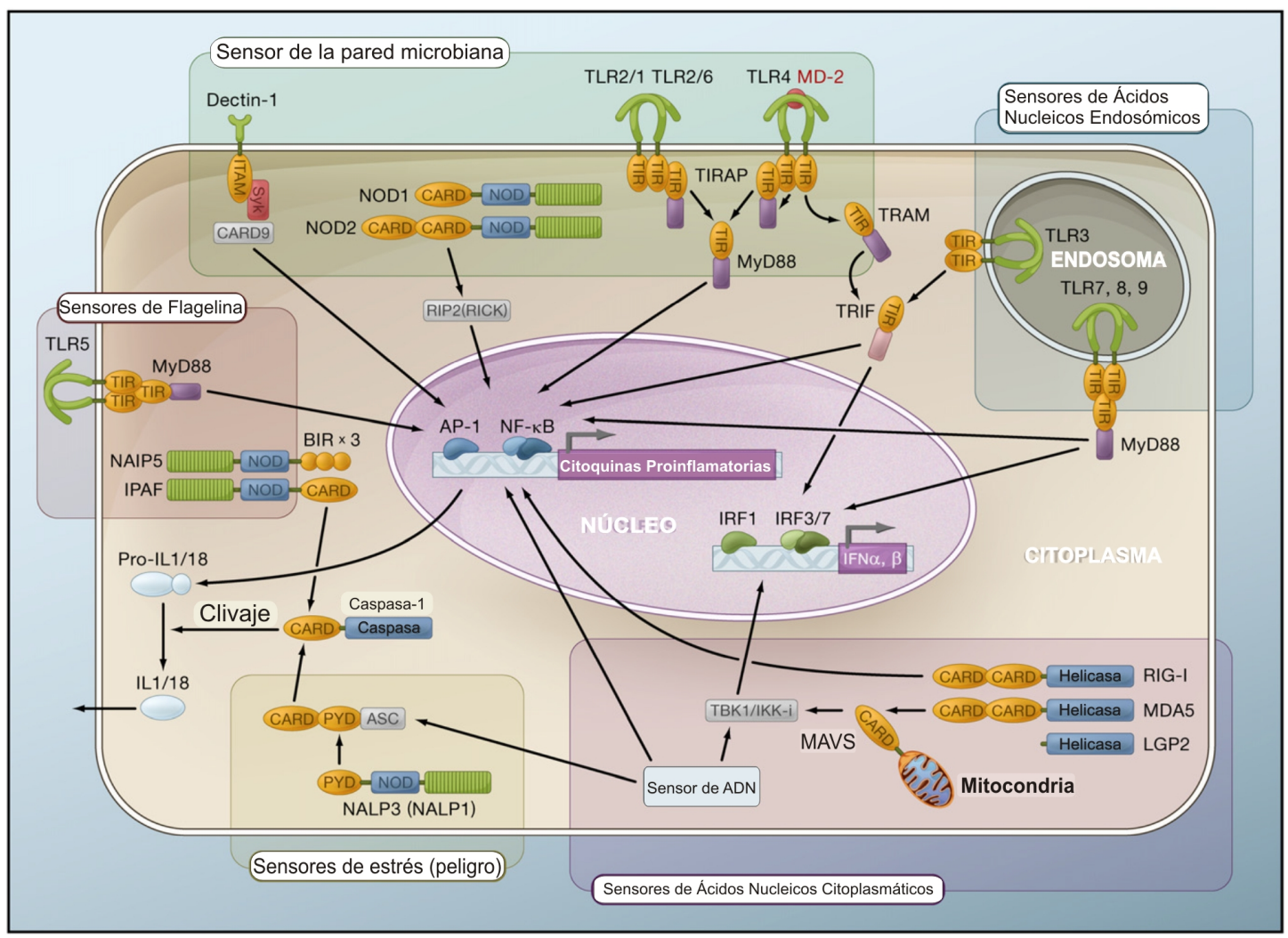

Figura 2. Los receptores de patrones de reconocimiento (PRRs) sensan las señales microbianas de diversos modos.

Los PRRs son capaces de sensar distintos componentes microbianos presentes en el ambiente por medio de un complejo sistema de receptores que se diferencian en su localización, función y vías de señalización implicadas. (Figura adaptada de $\mathbf{K} \mathbf{J}$ Ishii et al. 2008)

activar la célula a través de la activación de diferentes vías como la proteína activadora 1 (AP-1), NFkB y MAPK (Figura 2).

El homodímero de TLR4 con la molécula accesoria de unión a LPS, MD-2, reconoce LPS y proteínas virales, y activa la célula a través de la vía de MyD88 y TIRAP en la superficie celular o TRAM y TRIF en una vía endosómica (Figura 2).

La flagelina bacteriana es reconocida por TLR5 y por dos NLRs (NAIP5 e IPAF). TLR5 está sobre la superficie celular y activa NFkB a través de MyD88, mientras que NAIP5 e IPAF sensan flagelina en el citosol, con la consecuente activación de caspasa-1 y la secreción de IL-1 $\beta$, IL-18 e IL-33 (Figura 2).

Otros NLRs, como NALP3, pueden reconocer una variedad de señales microbianas y también moléculas del huésped derivadas de células dañadas o en proceso de muerte, incluyendo toxinas bacterianas, ácidos nucleicos y ácido úrico. Esta activación conduce a la activación de caspasa-1 junto con ASC, induciendo el procesamiento de pro-IL-1 $\beta$ y pro-IL-1 8 y resultando en la liberación de estas citoquinas (Figura 2).

Otros receptores son los sensores de ácidos nucleicos, entre los que se encuentran TLR3, TLR7, TLR8 y TLR9, que reconocen ácidos nucleicos 
microbianos o modificados del huésped en endosomas, y los RLRs tales como RIG-I, MDA5 y LGP2 como así también sensores de ADN que detectan ácidos nucleicos en el citoplasma. TLR3 o TLR7/9 median su efecto por la señalización a través de TRIF y MyD88, respectivamente, resultando en la inducción de citoquinas proinflamatorias e IFNs de tipo I. La señalización de los RLRs ocurre a través de MAVS en la mitocondria para activar NFאB e IRF3/7 y así producir IFNs de tipo I y quimoquinas (Figura 2).

Sin duda, los trabajos de investigación han estudiado principalmente los receptores de la familia TLR y más recientemente se ha comenzado a conocer en mayor detalle la participación de los otros receptores. En el intestino, la importancia de los TLRs radica en reconocer componentes de la microbiota y elaborar una respuesta acorde, evitando una activación excesiva. La mayoría de las vías de activación tienen como elemento en común al adaptador MyD88, generando la activación por medio del factor de transcripción $\mathrm{NF \kappa B}$, entre otras vías. Sin embargo, el TLR3 tiene como protagonistas en su señalización a TRIF, finalizando en la activación de los factores de transcripción IRF3/7. De este modo, mediante la señalización por TLR3 se produce una fuerte inducción de IFNs tipo I, IFN $\alpha / \beta$ (K J Ishii et al. 2008; Abreu 2010). Por lo tanto, dependiendo de los receptores puestos en juego se inducirán distintas vías de señalización que darán origen al tipo particular de respuesta inmediata inflamatoria que se requiera según cada caso.

La señalización vía los PRRs en la mucosa intestinal es en gran medida la responsable de la homeostasis del tejido. Estas señales conducen al desarrollo de mecanismos proinflamatorios, de defensa, de regulación o de inhibición. Este es un escenario muy complejo donde disecar vías individuales lleva a visiones parciales y en algunos casos contradictorias cuando se analizan modelos o situaciones experimentales diferentes.

El interés de este campo de estudio se encuentra en desarrollar un conocimiento más profundo de los mecanismos de regulación que mantienen la homeostasis del tejido, la generación de respuesta frente a infecciones entéricas de origen bacteriano, viral y parasitario, y los mecanismos de patogenia de las enfermedades crónicas (enfermedad inflamatoria intestinal, EC y alergia alimentaria). 


\section{ENFERMEDAD CELÍACA. DEFINICIÓN}

La EC es una enteropatía crónica mediada por el sistema inmune, en la que intervienen mecanismos tanto de la vía innata como adaptativa, y es desencadenada en individuos susceptibles por la ingesta de un grupo de proteínas de trigo, cebada, centeno y también probablemente avena (Abadie et al. 2011; Ludvig M Sollid and Jabri 2013; Meresse, Malamut, and Cerf-Bensussan 2012).

La visión clásica de la patogenia considera el rol de la presentación de péptidos de gliadinas y gluteninas en el contexto de los alelos de susceptibilidad HLA-DQ2/DQ8, por la que se activan linfocitos T CD4 ${ }^{+}$específicos presentes en la lamina propria y encargados de la producción exacerbada de IFN $\gamma$. En este contexto inflamatorio se activa la expresión de TG2, enzima encargada de la deamidación de los péptidos de gliadina y del incremento de su afinidad por los HLA-DQ2/DQ8, exacerbando la respuesta de linfocitos T CD4 específica.

En condiciones normales, los linfocitos $\mathrm{T}$ regulatorios contribuyen al mantenimiento de la homeostasis en el intestino inhibiendo la inducción de respuesta de linfocitos $\mathrm{T}$ específicos de gluten y promoviendo la producción de IgA. Se ha especulado que durante el curso de una inflamación o una infección, se produciría una activación y expansión descontrolada de los linfocitos Th1 CD4+ específicos de péptidos derivados de gluten, los que secretan mediadores proinflamatorios como IFN $\gamma$. IFN $\gamma$, a su vez, actúa sobre las células del epitelio intestinal, promueve la activación de linfocitos $\mathrm{T}$ citotóxicos intraepiteliales y bloquea los efectos inhibitorios de los linfocitos regulatorios Foxp3+. Además, se promueve la producción de anticuerpos IgA e IgG específicos de péptidos derivados de gluten y de transglutaminasa 2. Ha sido muy discutido el rol de estos anticuerpos en la patogenia, pero es posible que contribuyan en generar algunas de las manifestaciones extraintestinales a través de la deposición de complejos inmunes en tejidos tales como la piel y el cerebro (Jabri and Sollid 2009) (Figura 3).

La inflamación está también asociada con una inducción de la expresión de CD71 (receptor de transferrina) sobre la superficie luminal de las células del epitelio intestinal. Se ha encontrado que CD71 une complejos inmunes formados por IgA y media la transcitosis de complejos IgA-péptidos derivados de gluten por una vía no degradativa. De esta forma, este sería un mecanismo muy eficiente para translocar péptidos derivados de gluten desde el lumen a la mucosa intestinal (Matysiak-Budnik et al. 2008) (Figura 3). 

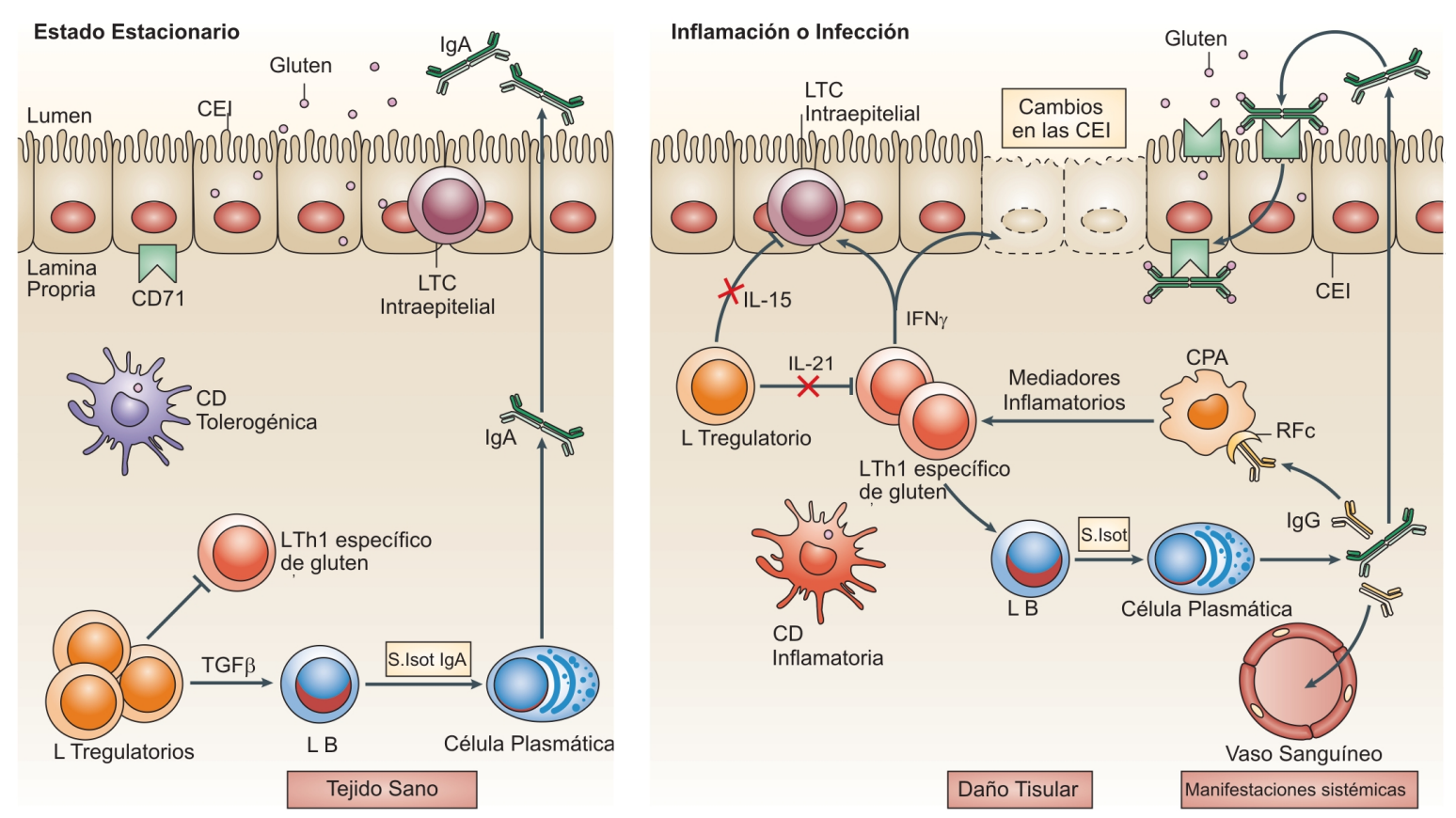

Figura 3. Patogenia de Enfermedad Celíaca.

Los linfocitos T CD4+ específicos de gluten contribuyen a su vez a la generación del ambiente inflamatorio requerido para la activación de linfocitos T citotóxicos intraepiteliales (Figura adaptada de Jabri and Sollid 2009).

Por otro lado, en varios estudios in vitro se ha descripto que péptidos derivados de gliadinas, o péptidos de síntesis como el p31-43 o el 33mer, inducen diversos efectos sobre células del epitelio intestinal (CEI) y células presentadoras de antígeno (CPA). El péptido de $\alpha$-gliadina, p31-43, tiene efectos directos sobre las CEI. No se conoce un receptor específico para este péptido, pero sí se sabe que puede mediar sus efectos alterando el tráfico celular de vesículas y/o activando rutas de estrés aún no muy bien definidas (Maria Vittoria Barone et al. 2010; Luciani et al. 2010). Este péptido ha sido descripto como activador de MAPK y como inductor de la expresión de IL-15, moléculas de CMH clase I no clásicas (MICs) y el EGFR (M. V Barone et al. 2007) (Figura 4).

En diferentes sistemas experimentales se analizaron algunas secuencias derivadas de péptidos de gliadinas o gluteninas observando efectos diversos. Podemos mencionar la activación de células dendríticas o macrófagos, o estabilización de la expresión de moléculas del CMH clase I no clásicas, HLA-E, un ligando para la familia de receptores de las células NK (NKG2), CD94 (Luigi Maiuri et al. 2003; Hue et al. 2004) (Figura 4).

Además en algunos casos se ha observado que estos péptidos son capaces de inducir mecanismos proinflamatorios dependientes de MyD88 que determinan un incremento en la expresión de IL-12p35, IL-6, IFN $\beta$, CXCL10, IL-15. Muchos de 


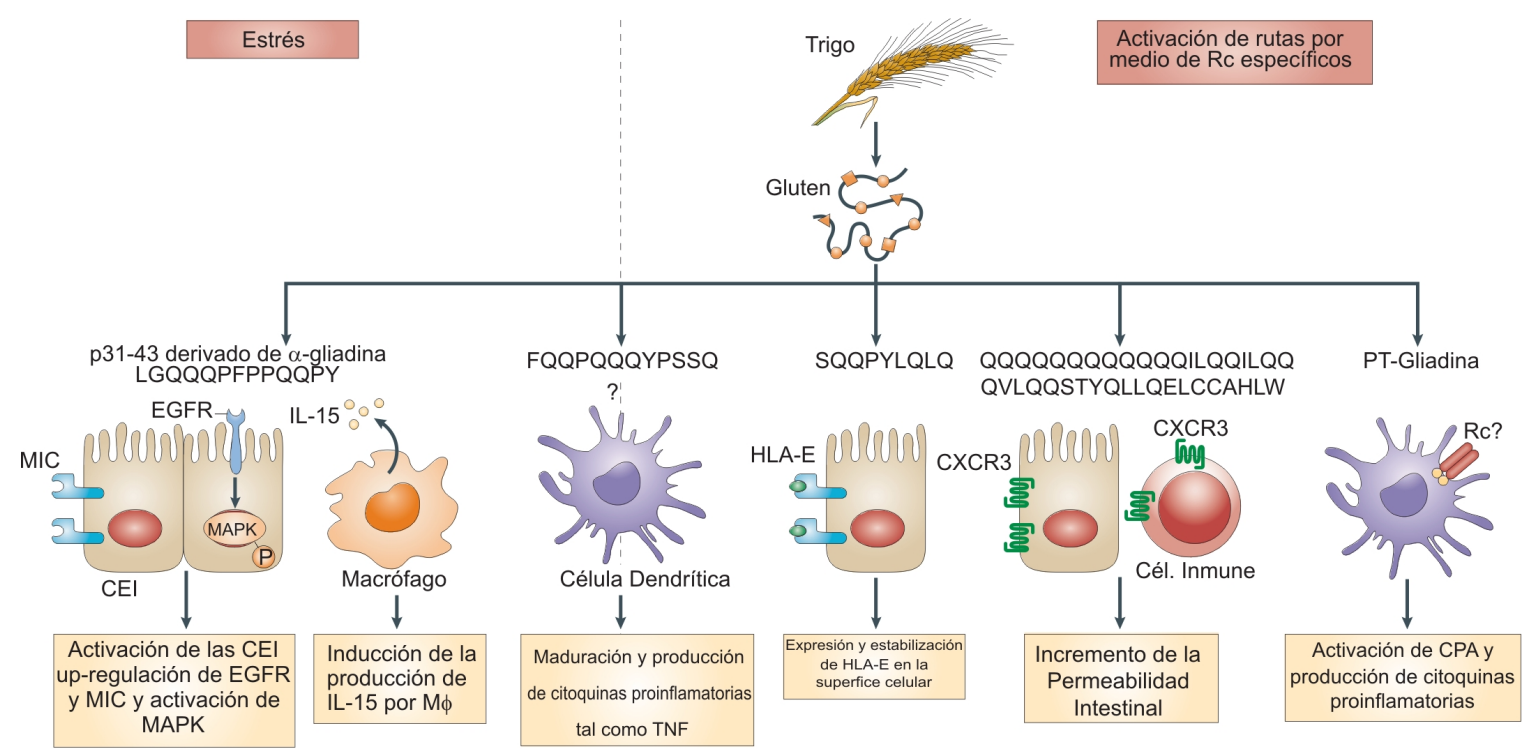

Figura 4. Efecto del gluten sobre células del epitelio intestinal y células presentadoras de antígenos.

(Figura adaptada de Jabri and Sollid 2009)

estos cambios se acompañan de la alteración en la permeabilidad intestinal, que sería fundamentalmente mediada por zonulina (Thomas et al. 2006). Este es un factor liberado por PT-gliadinas o algunos péptidos sintéticos, que induce el aumento de permeabilidad intestinal por disrupción de la unión estrecha. Más recientemente, se describió que los péptidos de gliadinas podrían ser reconocidos por el receptor de quimoquinas CXCR3, que a su vez sería responsable de mediar parte de los efectos inflamatorios, entre ellos la liberación de zonulina (Lammers et al., 2008). CXCR3 es el receptor de CXCL10 (antes IP-10), CXCL9 y CXCL11, se expresa en linfocitos Th1, y es determinante para el reclutamiento de linfocitos Th1 en particular a la mucosa intestinal (Di Sabatino A. et al. 2006, 2007) (Figura 4).

Aunque la observación descripta por Lammers et al. es muy importante, ésta se basa en el hallazgo de dos secuencias de gliadinas que tienen muy escasa representatividad en el conjunto de las prolaminas, lo que reduce sustancialmente el impacto biológico de esta observación. Por otro lado, estudios posteriores de otros grupos de investigación no han podido reproducir tales hallazgos.

Como mencionamos, la mayor parte de la información sobre la actividad tóxica de los péptidos derivados de gluten se ha obtenido en ensayos in vitro o ex vivo. No existe hasta el momento un modelo experimental que reproduzca la lesión histológica típica observada en el intestino en EC activa. Por lo tanto, no ha sido posible el estudio de los efectos in vivo de estos péptidos. Sin embargo, en 
los últimos años se ha realizado un gran esfuerzo con el fin de generar un modelo murino que reproduzca parcialmente algunas de las etapas de la enteropatía.

\section{MODELOS MURINOS Y ENFERMEDAD CELÍACA}

Existen modelos de sensibilidad al gluten desarrollados en diversas especies de animales, entre ellas perros, monos, conejos, ratas y ratones. Cada una de las especies tiene más fuerza en la representación de una o varias de las etapas en la patogénesis de EC descriptas en la Figura 5. Sin embargo, nuestra atención estará puesta en los modelos murinos, debido a la facilidad de manejo de estos animales en el laboratorio, el conocimiento de su biología, en especial en relación a la respuesta inmune y la disponibilidad de reactivos específicos. Especialmente, nos enfocaremos en los modelos agudos de sensibilidad al gluten y cómo estos pueden predisponer a enteropatía crónica.

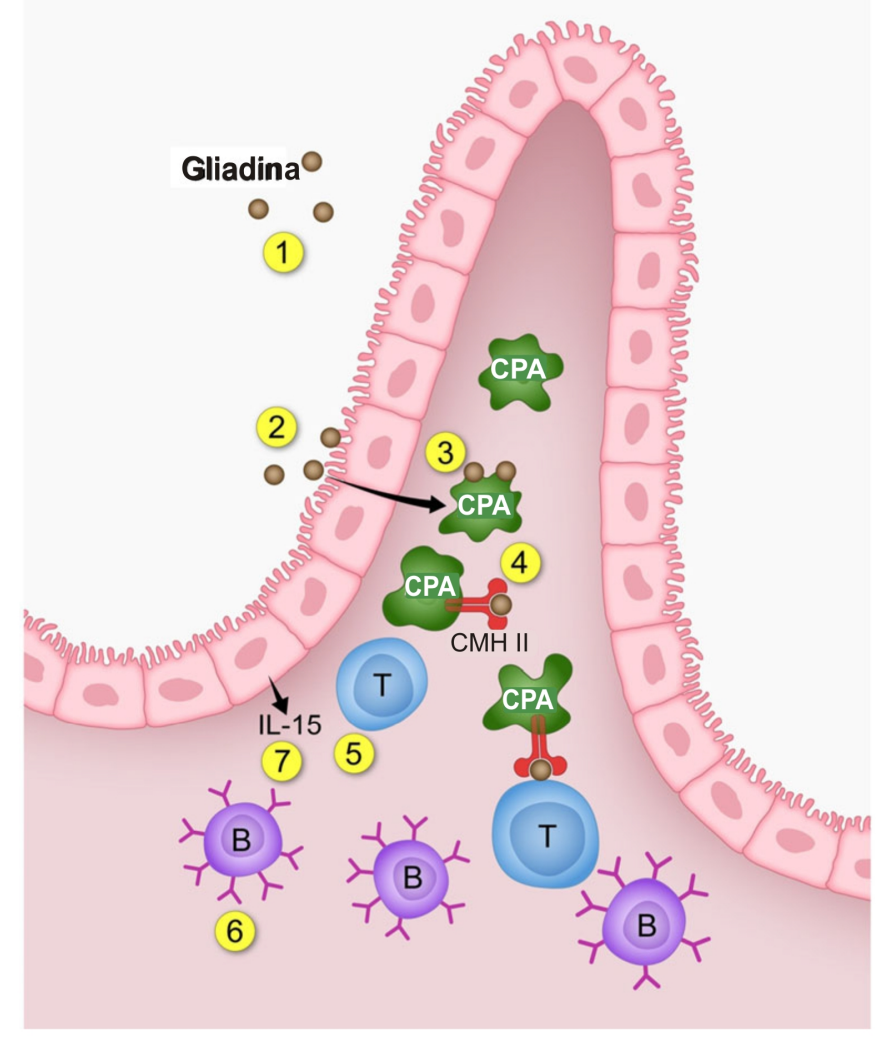

Figura 5. Etapas de la patogenia en enfermedad celíaca sobre los que se han orientado modelos animales.

Los diferentes modelos animales desarrollados hasta la actualidad se han basado en el estudio de distintas etapas de la patogenia de EC. Estos son: 1. Generación de péptidos de gliadinas en el lumen intestinal (simio, ratón); 2. Respuesta innata a gliadinas por enterocitos, monocitos y células dendríticas (perro, simio y ratón); 3 . Translocación de péptidos derivados de gliadinas a través del epitelio (simio y ratón); 4. Rol de las moléculas de CMH II (perro y ratón); 5. Activación de linfocitos T específicos de gliadinas (perro, simio y ratón); 6. Rol de los linfocitos B y los anticuerpos anti-TG2; 7. Rol de IL-15 (ratón). (Figura adaptada de Marietta and Murray 2012) 
Los modelos de sensibilidad al gluten desarrollados hasta la actualidad requieren la sensibilización de los animales con gliadinas, tratamiento con drogas y/o químicos y modificaciones genéticas de modo de alcanzar a desarrollar alguna de las características de EC. Aún cuando cada modelo reproduce alguna de las características de EC, todavía ninguno ha logrado reproducir completamente la patología.

Todos los modelos murinos que emplearon animales que expresan las moléculas de susceptibilidad de HLA clase II (DQ2 y DQ8), en contraste con lo esperado, no desarrollaron enteropatía dependiente de gluten. Estos resultados refuerzan la hipótesis de que las moléculas de HLA y la consiguiente presentación y activación de linfocitos T específicos, no es suficiente para la generación de la patología sino que deben existir otros genes, así como factores ambientales o del entorno involucrados, para desencadenar la enteropatía.

Los diferentes modelos animales contribuyeron a evaluar el rol de distintos mediadores de la patogenia de EC. Así, se demostró el rol de los linfocitos T CD4+, las moléculas de CMH de clase II, la enzima transglutaminasa 2, IL-15 y los linfocitos T regulatorios en el desarrollo de susceptibilidad, como así también evaluar elementos del entorno, como la microbiota intestinal y agentes químicos o mediadores capaces de provocar alteración de la funcionalidad de la mucosa intestinal.

El rol de los linfocitos T CD4+ ha sido estudiado mediante la transferencia adoptiva de estas células como una adaptación de conocidos modelos de colitis (Freitag et al. 2009). En estos estudios se emplearon ratones donantes C57BL/6 alimentados con una dieta libre de gluten (DLG) e inyectados en la base de la cola con gliadinas y adyuvante de Freund completo (AFC), con el fin de inducir linfocitos $\mathrm{T}$ efectores específicos de gliadinas. A partir del bazo de estos animales se aislaron linfocitos $\mathrm{T} \quad \mathrm{CD}^{+} \mathrm{CD} 45 \mathrm{RB}^{\text {bajo }} \mathrm{CD} 25$. Estas células fueron luego transferidas adoptivamente inyectándolas IP en ratones Rag $1 \%$. Estos animales presentaron hiperplasia de criptas y atrofia de vellosidades cuando fueron inoculados oralmente con gluten. Los animales recuperaron la histología normal cuando fueron mantenidos en DLG, demostrando la dependencia del gluten en la enteropatía (Freitag et al. 2009). Sin embargo, en este modelo los linfocitos $\mathrm{T}$ fueron generados en un ambiente no relacionado con el que ocurre en la patología, y no contempla la respuesta de linfocitos $\mathrm{T}$ restringida a los alelos de susceptibilidad (HLA-DQ2 y DQ8) en la enteropatía. 
Otras estrategias fueron direccionadas a evaluar el rol de las moléculas de CMH clase II (específicamente DQ8). Para esto se obtuvieron ratones transgénicos para las moléculas de clase II HLA-DQ8, pero que no expresaban moléculas de clase II propias. Estos animales no mostraron ningún tipo de alteración. Sin embargo, luego de la sensibilización con péptidos de gluten por vía intraperitoneal, desarrollaron una fuerte respuesta proliferativa $\mathrm{T}$ así como también una respuesta de anticuerpos anti-gliadinas sin cambios en la histología intestinal (Black, Murray, and David 2002). Otro estudio utilizando los mismos animales mostró un incremento en el número de LIEs en ausencia de atrofia vellositaria, cuando además de la sensibilización con gluten vía intraperitoneal se administró gliadina por vía oral durante tres semanas (E F Verdu et al. 2008). Otros estudios con ratones que coexpresaban DQ2 con DR3 obtuvieron similares resultados, sin observar alteración histológica de la mucosa intestinal (de Kauwe et al. 2009). Por lo tanto, estos estudios mostraron que otros factores, además de las moléculas de HLA son necesarios para el desarrollo de EC.

Para evaluar el rol de la enzima TG2 y de los anticuerpos anti-TG2 en la patogenia, se desarrollaron algunos esquemas experimentales utilizando la transferencia pasiva de anticuerpos anti-TG2. En primer lugar, se observó el efecto de los depósitos de complejos inmunes formados por IgA anti-TG2/TG2, que fueron evidentes en dermis, generando una histología similar a la que presenta Dermatitis Herpetiforme (una enfermedad asociada a EC). En ninguno de los esquemas experimentales se observó enteropatía (Zone et al. 2004; Zone et al. 2011). Por este motivo, otros estudios estuvieron dirigidos a sobreexpresar anticuerpos anti-TG2 in vivo. Para esto, se empleó una secuencia de anticuerpos anti-TG2 humano obtenida mediante una biblioteca de anticuerpos de linfocitos B intestinales de lamina propria de pacientes celíacos al diagnóstico. Estas secuencias de anticuerpos anti-TG2 fueron sobreexpresadas empleando un virus recombinante inyectado en ratones $\mathrm{C} 57 \mathrm{BL} / 6$. Luego de 4 semanas los animales no mostraron depósitos de anticuerpos, alteración histológica ni funcional del intestino delgado (Di Niro et al. 2007; Di Niro et al. 2008). Estos resultados indican que la sola presencia de anticuerpos anti-TG2 no es suficiente para el establecimiento de la patología.

Estudios realizados con ratones que sobreexpresan IL-15 en enterocitos mostraron la inducción de anticuerpos anti-TG2 e incremento de células plasmáticas en la mucosa intestinal. Si bien estos son rasgos asociados a EC, no estuvieron asociados a la presencia de gluten. Por lo tanto, esta estrategia 
experimental no modela la inducción de la enteropatía por gluten aunque destaca un rol importante para IL-15 (Yokoyama et al. 2011). IL-15 es sin duda un eje de gran controversia en la patogenia de EC. Es un mediador crítico en la patogenia, pero debido a la compleja modulación de su expresión y la dificultad para tener medidas eficientes de su actividad biológica, la interpretación de resultados es muchas veces controvertida.

Para estudiar el efecto de la sobreproducción de IL-15 en la inducción de enteropatía se generaron ratones que sobreexpresaron IL-15 sistémicamente bajo el promotor de la molécula de $\mathrm{CMH}$ clase $\mathrm{I}^{\mathrm{d}} \mathrm{y}$ fueron cruzados con ratones transgénicos DQ8 (DQ8 D ${ }^{\mathrm{d}}$ IL-15). En este estudio, los autores encontraron que al alimentar con gliadinas ratones que estaban bajo DLG se produjo un incremento del número de LIEs $\mathrm{CD}^{+}$, aunque con baja actividad citotóxica. Sin embargo, los ratones transgénicos DQ8 $\mathrm{D}^{\mathrm{d}} \mathrm{IL} 15$ estimulados con gliadinas no desarrollaron alteraciones histológicas. Esto fue en parte atribuido a que la expresión de IL-15 en enterocitos era muy baja (DePaolo et al. 2011). En este sentido, un estudio previo mostró que la sobreexpresión de IL-15 humana bajo un promotor específico de enterocitos, conducía a respuesta inflamatoria en intestino delgado con un descenso del cociente V/C (Ohta et al. 2002). En este caso, la respuesta inflamatoria no fue dependiente de gluten ni estuvo asociada a un perfil genético de predisposición a EC. De esta forma, se destaca la relevancia del contexto inductor de respuesta inflamatoria mediado por IL-15, en una situación análoga a la observada en EC. En este sentido, sería interesante evaluar un modelo de sobreexpresión de IL-15 en enterocitos en animales DQ8 estimulados con gliadinas.

Otra serie de modelos estuvieron basados en animales con factores de predisposición genética asociada a enfermedades autoinmunes. En este aspecto, es conocida la estrecha relación entre EC y Diabetes Mellitus tipo I (DMI), probablemente debido a que comparten muchos de los factores genéticos de susceptibilidad, entre ellos la molécula DQ8 (Ludvig M Sollid and Jabri 2013). El modelo experimental más usado es el de ratones NOD (Non-obese diabetic), los que desarrollan espontáneamente diabetes y que permite modelar el curso de DM1. Cabe destacar que los ratones NOD presentan reducción de la altura de las vellosidades y un incremento en el número de LIEs mientras sean mantenidos en dieta que contenga gluten (Maurano et al. 2005).

Para evaluar las implicancias de un entorno genético predisponente a autoinmunidad en la sensibilidad al gluten se cruzaron ratones NOD con ratones 
transgénicos DQ8, resultando en los ratones NOD ABo DQ8 (HLA-DQ8). Estos ratones son capaces de desarrollar lesiones en piel que se asemejan a Dermatitis Herpetiforme cuando son estimulados con gluten. Las lesiones revierten cuando los animales son mantenidos en dieta libre de gluten. Por lo tanto, estos resultados muestran la relevancia del entorno genético de susceptibilidad y la estimulación con gluten en el desarrollo de la patología (Marietta et al. 2004).

Otra de las estrategias utilizadas fue estudiar el rol de las células $\mathrm{T}$ regulatorias en la inducción de enteropatía. Empleando los ratones NOD-DQ8, en un trabajo en colaboración, encontramos que la depleción parcial de células $\mathrm{T}$ regulatorias con la inyección de un anticuerpo anti-CD25 conduce a un incremento en el número de LIEs $\mathrm{CD}^{+}$y a un descenso del cociente $\mathrm{V} / \mathrm{C}$ cuando los animales fueron sensibilizados con gliadinas (Galipeau et al. 2011). Este resultado demuestra que la ruptura de los mecanismos regulatorios, aún cuando sea temporaria, condiciona a la mucosa intestinal al desarrollo de enteropatía. En este trabajo también se observó que la estimulación con gliadinas produce una respuesta inflamatoria con infiltrado linfocitario en el páncreas lo cual destaca la importancia que estos mecanismos tienen en la patología local (intestinal) como así también en sitios extraintestinales (Galipeau et al. 2011).

Otras estrategias experimentales apuntaron a la disrupción de la homeostasis de la mucosa intestinal. Con este objetivo, se empleó indometacina como regulador de la expresión de COX2 y PGE2. Se emplearon ratones transgénicos que expresan HLA-DQ8 los cuales fueron tratados con indometacina en el agua de bebida luego de haber sido sensibilizados por vía oral con gluten y toxina colérica durante 3 semanas. Se observó un descenso en la altura de las vellosidades sin hiperplasia de criptas ni incremento en los LIEs, pero con un incremento en la producción de IFN $\gamma$ (D’Arienzo et al. 2009). Un estudio similar, utilizó animales transgénicos que expresaban las moléculas DQ8 y CD4 humano que recibieron gluten intraperitoneal y luego fueron inoculados por vía oral con gluten durante 7 semanas, con la administración de indometacina luego de cada inoculación. Se observó que la administración de gliadinas más indometacina incrementó sustancialmente la permeabilidad transcelular y la producción de IFN $\gamma$ (Natividad et al. 2009). A pesar de los resultados obtenidos en estos dos estudios, la indometacina no indujo atrofia vellositaria dependiente de gluten, ni incremento en el número de LIEs o hiperplasia de cripta.

Con el mismo objetivo de provocar una alteración severa en la mucosa intestinal, un estudio mas reciente utilizó la administración de poly (I:C) 
intraperitoneal en ratones transgénicos DQ2 que recibieron gliadinas por vía oral. Si bien poly (I:C) provocó un daño severo pero transitorio en intestino delgado, no se observó la generación de linfocitos T específicos restringidos a DQ2 (Siegel et al. 2008). Un esquema experimental análogo, pero utilizando la inoculación de metotrexato obtuvo resultados similares, sin lograr la inducción de células $\mathrm{T}$ específicas para gliadinas (de Koning et al. 2006). Estos resultados demostraron que una disrupción transitoria de la homeostasis intestinal no es suficiente para inducir una enteropatía dependiente de gluten aún en individuos predispuestos genéticamente. Por lo tanto, los próximos esfuerzos deberán estar orientados a investigar si una disrupción permanente de la homeostasis es capaz de inducir una enteropatía mediada por gluten en un entorno genético adecuado.

\section{DISPARADORES DE EC}

No existen evidencias experimentales que indiquen que el gluten podría promover la activación de linfocitos $\mathrm{T}$ autorreactivos a través de un mecanismo de mímica molecular como se ha propuesto en otras patologías autoinmunes (por ejemplo, miocarditis autoinmune disparada por Coxackie virus). Por lo tanto, en este punto se plantea la necesidad de encontrar un agente disparador de EC. HLA es un factor genético necesario pero no suficiente en EC, lo cual, como ya mencionamos indica que se requieren factores adicionales para el desarrollo de la enfermedad.

En particular, la escasa digestión de los péptidos de gluten y su deamidación por TG2 proveen una explicación sobre el origen de péptidos inmunogénicos derivados de gluten de relativamente alta afinidad por HLA-DQ2 y HLA-DQ8. Sin embargo, esto no explica por qué se montan las respuestas contra gluten de linfocitos $\mathrm{T}$ inflamatorios en lugar de la activación de los linfocitos T regulatorios en el intestino, lo cual normalmente promovería una respuesta tolerogénica a proteínas antigénicas.

Los IFNs de tipo I están inducidos en la mucosa intestinal de pacientes con enfermedad celíaca activa. Se supone que los IFNs tipo I podrían potencialmente ser un componente de una ruta alternativa que cause una pérdida de tolerancia al gluten, a través de su capacidad de activar células dendríticas, promover una respuesta del tipo Th1 e inducir pérdida de la tolerancia oral. Por otra parte, la enzima TG2 no está constitutivamente activa in vivo y su activación se asocia con un estado previo inflamatorio. Finalmente, otro aspecto clave de EC es la inducción de la expresión de IL-15 y moléculas de CMH clase II en el epitelio. Si 
bien es probable que los linfocitos $\mathrm{T} \mathrm{CD}^{+}$tengan este rol, no es suficiente este hecho para inducir todas estas alteraciones del epitelio.

Entonces, estas observaciones apuntan a la sentencia clásica de que una fuerte respuesta inmune adaptativa está típicamente asociada a un componente innato que facilita dicha respuesta. Por ello, en la actualidad, muchas investigaciones se han enfocado a encontrar este desconocido componente innato que es capaz de iniciar la respuesta observada en EC.

El modelo más simple que ha sido planteado al respecto, indica que es el gluten en sí mismo quien tiene propiedades como ligando innato y puede servir de disparador de EC. Para explicar esto, se han sugerido dos mecanismos de inducción de una respuesta de linfocitos $\mathrm{T}$ específicos de péptidos derivados de gluten a través de la activación de células dendríticas: uno de ellos involucra la inducción por gluten de la expresión de IL-15 en la lamina propria y el otro involucra a los IFNs tipo I (DePaolo et al. 2011; Di Sabatino et al. 2007). Los mecanismos por los cuales el gluten podría llevar a cabo estas dos respuestas se desconocen pero sería de este modo capaz de alterar el fenotipo tolerogénico de las células dendríticas.

Otro factor que podría ser afectado por gluten desde un mecanismo de la respuesta inmune innata es la regulación de las células del epitelio intestinal (CEI) (Luigi Maiuri et al. 2003; M. V Barone et al. 2007). La proteína del gluten podría tener un rol en la fase efectora destructiva de la enfermedad activando las CEI y promoviendo la sobreexpresión de IL-15 y moléculas de CMH clase I no clásicas sobre estas mismas (Hue et al. 2004; Terrazzano et al. 2007). Más allá del modo de acción propuesto para el gluten, se desconocen los mecanismos que pueden llevar a la activación innata por medio de estas proteínas. No está claro por qué el gluten podría tener efectos innatos solo en ciertos individuos o qué es lo que determina la adquisición de estas propiedades en un individuo dado, en cierto tiempo. Es posible que esta sensibilidad al gluten requiera del encuentro de un contexto genético predisponente y un factor ambiental. Por lo tanto, aún suponiendo que el gluten tiene estas propiedades innatas, es difícil explicar de este modo las fases de iniciación y efectora de la enfermedad sin la existencia de algún otro disparador (Jabri and Sollid 2009). Por este motivo, las siguientes hipótesis apuntaron a factores bacterianos y virales como disparadores de EC.

Hoy en día se reconoce que la microbiota puede afectar la homeostasis inmune intestinal y el estado de las células epiteliales (Hooper and Macpherson 2010). Por otra parte, la microbiota intestinal comprende bacterias que 
promueven respuestas inmunes regulatorias (simbiontes) y bacterias que promueven respuestas inmunes inflamatorias (patobiontes) (Hooper and Macpherson 2010). Como en otras enfermedades autoinmunes, se han descripto diferencias en la composición de la microbiota de pacientes con enfermedad celíaca activa comparados con individuos control. También se observaron alteraciones en pacientes siguiendo una dieta libre de gluten. (Di Cagno et al. 2011; Tjellström et al. 2005; Forsberg et al. 2004). Aún se desconoce si estos cambios son una consecuencia de la presencia de un perfil inflamatorio o si la microbiota tiene un rol activo en la generación de la enfermedad.

Se ha sugerido que las infecciones virales, en particular las infecciones con enterovirus (por ejemplo, rotavirus) incrementan la incidencia de EC y otros desórdenes autoinmunes, tales como DM1 (Troncone and Auricchio 2007; Stene et al. 2006; García et al. 2009).

Las infecciones virales conducen a la producción de IFNs tipo I, los cuales tienen propiedades inmunoestimulatorias (D. Devendra and Eisenbarth 2004; Devasenan Devendra et al. 2005; Rizza, Moretti, and Belardelli 2010). Sin embargo, se asume que las infecciones virales podrían disparar desórdenes autoinmunes como una consecuencia de la inducción de IFNs tipo I. Los IFNs tipo I podrían también ser inducidos por infecciones bacterianas y potencialmente por factores del huésped no definidos que no se relacionan con las infecciones (Carrero, Calderon, and Unanue 2004; Manca et al. 2001). Es necesario estudiar cómo los IFNs tipo I podrían permanecer sobreexpresados en la mucosa intestinal de pacientes celíacos y como su producción podría hacerse dependiente de gluten una vez que los virus ya fueron eliminados. Aún en infecciones virales crónicas, parece que las infecciones virales podrían ser responsables del disparo de la inducción inicial de IFNs tipo I, pero otros factores, aún no definidos, son responsables del mantenimiento de los niveles incrementados de IFNs tipo I en la mucosa intestinal. Aún no se ha podido determinar cómo el gluten podría contribuir a la producción de los IFNs tipo I.

En conjunto, esta información muestra que aunque hay una fuerte evidencia del rol de los microorganismos como disparadores de la activación inmune innata, no hay evidencia de un rol de mímica molecular en EC. No hay pruebas de que la patogénesis de EC sea el resultado de una respuesta de linfocitos T contra un péptido microbiano que pueda tener una reacción cruzada con gluten. Por lo tanto, nuevos mecanismos de patogénesis deberán estudiarse para resolver este "rompecabezas" inmunológico. 


\section{POLY (I:C) Y MODELOS MURINOS DE ENTEROPATÍA.}

La administración intraperitoneal de poly (I:C) (ácido poli-inosítico-policitidílico), un análogo sintético de ARN doble hebra (ARNdh) viral, produce enteropatía y ha sido también un modelo experimental que ha permitido estudiar el daño en la mucosa intestinal y algunos aspectos funcionales de los linfocitos intraepiteliales (Garside et al. 1991; R. Zhou, Wei, Sun, Zhang, et al. 2007; R. Zhou, Wei, Sun, and Tian 2007). Aunque poly (I:C) es empleado como ligando modelo de TLR3, puede señalizar también por helicasas de ARN como MDA5 y RIG-I, generando una respuesta proinflamatoria por medio de la actividad de IRF3/7 y NF-кB (Ken J Ishii et al. 2008). Como mencionamos, la administración intraperitoneal de poly (I:C) produce una alteración de la mucosa intestinal con pérdida del epitelio y alteración estructural de las vellosidades 12 horas postinyección (R. Zhou, Wei, Sun, Zhang, et al. 2007; R. Zhou, Wei, Sun, and Tian 2007). Estos cambios fueron precedidos por una rápida modificación en la expresión de ciertas citoquinas (entre ellas: IFN $\beta$, IFN $\alpha$, IL-15, TNF $\alpha$ e IL-1). Se encontró que el bloqueo funcional de IL-15 reduce la severidad de los cambios histológicos, evidencia de que IL-15 es un mediador crítico en este modelo. En la generación del daño participarían linfocitos intraepiteliales $\left(\mathrm{CD}^{+} \mathrm{CD} 8 \alpha \alpha^{+} \mathrm{NKG} \mathrm{D}^{+}\right.$ que expresan marcadores de células NK (NK1.1)). Se observó que estas células tienen actividad citotóxica potenciada cuando son pre-incubadas con poly (I:C). El efecto citotóxico requirió además la presencia de células epiteliales, las que, probablemente, actúen proveyendo IL-15. La alteración histológica postinoculación intraperitoneal de poly (I:C) sólo se observó en intestino delgado, pudiendo esto relacionarse con la alta expresión de TLR3 en el epitelio intestinal.

McAllister C. et al (McAllister et al. 2013) demostró que las vías de señalización activadas a través de los sensores de ARNdh y particularmente, TLR3/TRIF/Caspasa 8, conducen a patología intestinal pero también a protección del huésped durante la infección viral. Este modelo experimental mostró una patología de la mucosa muy severa, con destrucción completa del tejido, que no guarda relación con lo observado en EC y sugiere que los mecanismos que participan en cada caso son diferentes.

En estos estudios no se evalúan las vías inducidas localmente y el rol de la contribución de mediadores sistémicos no puede descartarse. Es por eso que el mayor interés en este campo se encuentra en generar modelos que estudien la inducción de enteropatía mediante un estímulo local relevante a la patología y 
Introducción y Objetivos Generales

que permitan evaluar el daño y la disfunción de la mucosa intestinal. En particular, los ligandos de origen viral, como los ARNdh y su acción sobre el intestino y en interacción con factores dietarios, como gliadinas, son un punto interesante de estudio en la búsqueda de disparadores iniciales de la patogenia de EC. 



\section{OBJETIVOS GENERALES}

$\infty$ Desarrollar un modelo de enteropatía por medio de la administración intraluminal de distintos ligandos de la inmunidad innata.

- Estudiar los mecanismos de daño implicados en la generación de enteropatía a nivel molecular y disecar las posibles vías de señalización implicadas

$\infty \quad$ Estudiar los posibles mediadores celulares de daño en el modelo de enteropatía planteados.

- Determinar si mecanismos asociados a la inmunidad innata son capaces de predisponer a una enteropatía a largo plazo en un modelo animal con un contexto genético adecuado. 

CAPÍTULO 1. Desarrollo de un modelo de enteropatía basado en la administración intraluminal de poly $(\mathrm{I}: \mathrm{C})$ 



\section{CAPÍTULO 1. Desarrollo de un modelo de enteropatía basado en la administración intraluminal de poly (I:C).}

Parte de los resultados de este capítulo fueron publicados en el artículo "Intraluminal Administration of Poly I:C Causes an Enteropathy That Is Exacerbated by Administration of Oral Dietary Antigen”. Araya, Romina E., Jury, Jennifer, Bondar, Constanza, Verdu, Elena F., Chirdo, Fernando G. PLoS ONE, 2014

\section{INTRODUCCIÓN}

La detección de componentes microbianos se realiza mediante un sistema complejo de receptores de patrones moleculares conservados en microorganismos, llamados PRR. Los PRR inician los mecanismos de la respuesta innata que contribuyen sustancialmente a la defensa del huésped. En el tracto gastrointestinal habitan alrededor de $10^{12}$ bacterias, pero también hongos y virus, por lo que los mecanismos inmunes encargados del control de la respuesta en este contexto tienen un rol crítico en la homeostasis tisular (Honda and Takeda 2009). Es así que la activación descontrolada de estas vías puede conducir a diferentes situaciones patológicas, como se observa en las enfermedades inflamatorias intestinales. Aunque los mecanismos no son completamente conocidos, la respuesta inmune inadecuada frente a componentes de la microbiota parece ser el principal desencadenante en estas patologías. En estos casos, se han empleado extensamente modelos experimentales que evalúan la generación de daño en la mucosa del colon.

El reconocimiento de componentes de la microbiota desencadena procesos inflamatorios que involucran vías de señalización diversas. Desde el punto de vista experimental se han empleado ligandos que mimetizan la respuesta generada en un contexto que, si bien es limitado, permite una interpretación más simple de los fenómenos desencadenados. En este sentido, nos interesó particularmente el estudio de un ligando sintético, poly (I:C), que ha sido ampliamente utilizado como modelo de infección viral en distintos sistemas experimentales. A su vez, varios estudios han demostrado que la administración sistémica de este ligando induce enteropatía en intestino delgado (Garside et al. 1991; R. Zhou, Wei, Sun, and Tian 2007; R. Zhou, Wei, Sun, Zhang, et al. 2007; McAllister et al. 2013). Nuestra atención se enfocará en la caracterización del 
efecto de la inducción local de fenómenos inflamatorios y de daño en la mucosa de intestino delgado desencadenados por poly (I:C).

\section{Generalidades sobre las vías de reconocimiento y señalización inducidas por} ARNdh.

El ARNdh es un potente modulador de múltiples funciones biológicas claves en la célula huésped, las cuales incluyen la defensa antiviral, las respuestas inmunes innata y adaptativa, la inflamación y efectos anti-tumorales. Los ARNdh son ligandos de los PRRs, incluyendo al Receptor de tipo Toll 3 (TLR3) y a los receptores del tipo de Gen Inducible por Ácido Retinoico-I (RIG-I) (RLRs), entre los que encontramos a RIG-I y MDA5 (Figura 1.1) (Kawai and Akira 2008).

Estos receptores de ARNdh viral median la activación de los Factores Regulados por Interferón 3 y 7 (IRF3 e IRF7) con la expresión resultante de Interferones de tipo I (IFN- $\alpha / \beta)$, así también como la activación de NF-кB y la expresión de citoquinas proinflamatorias. El ARNdh viral puede también activar el inflamosoma NLRP3, el cual media el clivaje y liberación de las formas maduras de IL-1 $\beta$ e IL-18. En contraste con TLR3 el cual puede sensar el ARNdh viral tanto

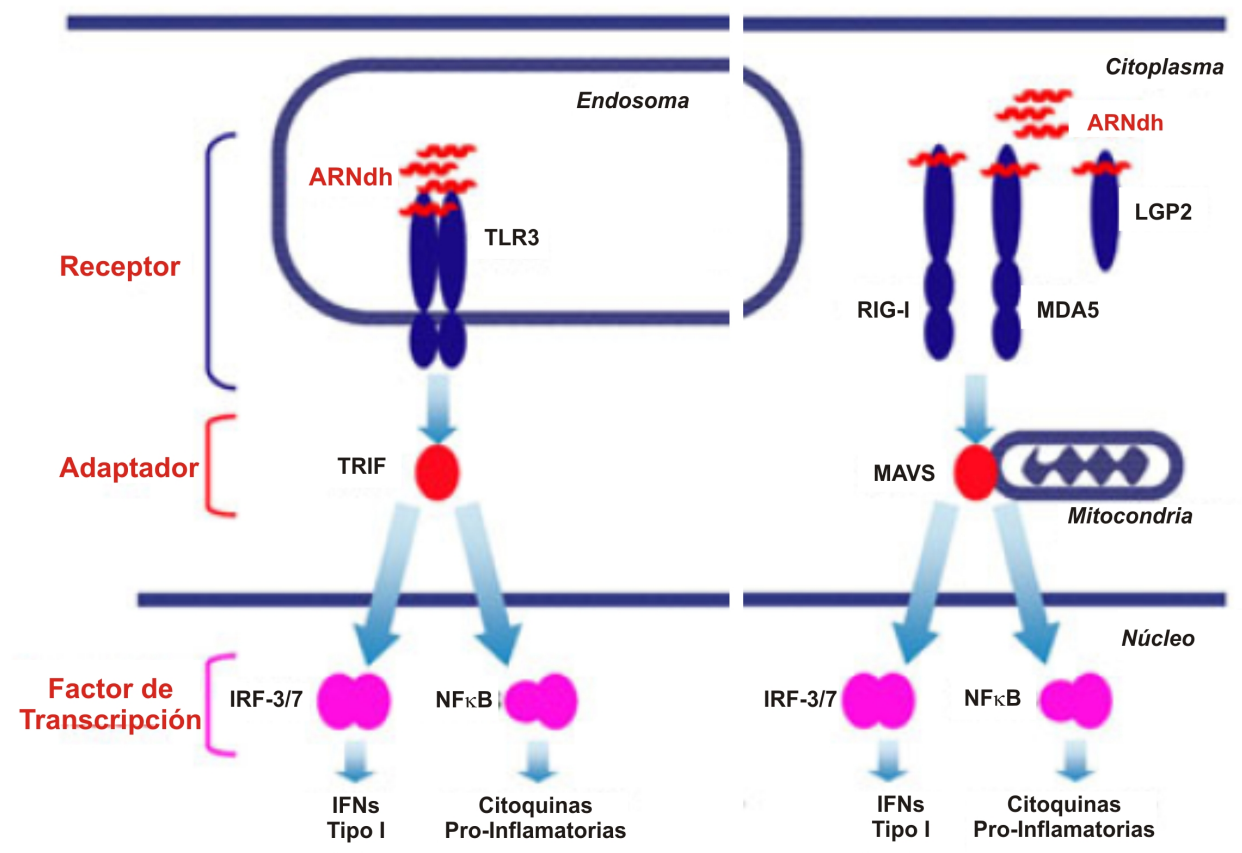

Figura 1.1. Reconocimiento de ARNdh viral por TLR3 y RLRs y sus vías de señalización.

Se muestra la detección de ARNdh mediante distintas vías. TLR3 es uno de los receptores de ARNdh, capaz de reconocerlos por vía endosómica, mientras que RIG-I y MDA5 lo hacen en el citoplasma. Ambas vías requieren la interacción de diversos componentes. TLR3 requiere de la molécula adaptadora TRIF para su señalización, mientras que los RLRs requieren de la molécula adaptadora MAVS, que se encuentra unida a la membrana mitocondrial. Las consecuencias principales serán la activación de las vías de IRF3/7 y NFkB, que conducen a la síntesis de IFNs tipo I y citoquinas proinflamatorias, respectivamente. (Figura adaptada de Kawai \& Akira 2008) 
en el compartimiento extracelular como en endosomas, los RLRs y el inflamosoma NLRP3 son sensores intracelulares. Poly (I:C), como análogo sintético de ARNdh, señaliza vía TLR3 endosómico y RLRs (Yu and Levine 2011).

\section{Señalización por TLR3 de los ARNdh.}

TLR3 se encuentra expresado en múltiples tipos celulares, incluyendo células dendríticas, células epiteliales, fibroblastos, queratinocitos y células tumorales. Está localizado tanto en la superficie celular como en el compartimiento endosómico y se compone de distintos dominios estructurales, un dominio extracelular o ectodominio (ECD), un dominio transmembrana y un dominio de tipo Toll/IL-1 intracelular que une la proteína adaptadora TRIF (Figura 1.2).

Para la unión al ligando es necesaria la dimerización del receptor (Figura 1.2). Las moléculas de ARNdh deben ser de al menos 40-50pb de longitud para inducir la señalización por TLR3 (Yu and Levine 2011).

Cuando el ARNdh se une a TLR3, se produce el reclutamiento de la proteína adaptadora TRIF por medio de la interacción de los dominios TIR de ambas proteínas. TRIF actúa como plataforma que recluta las moléculas de señalización que

\section{Membrana Plasmática}

\section{Citoplasma}

\section{Endosoma}

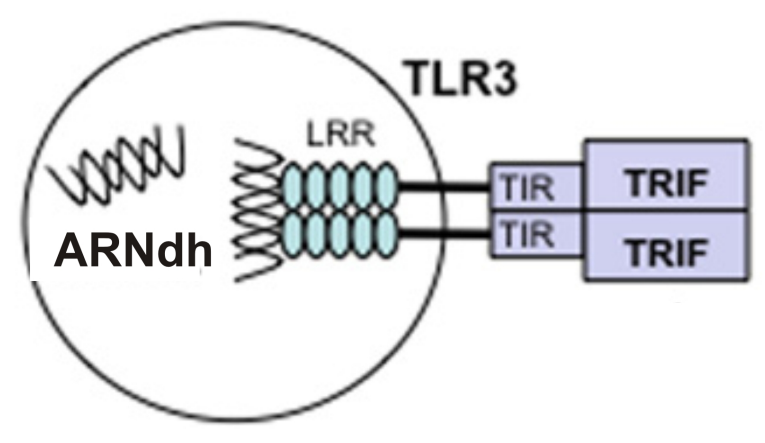

Figura 1.2. Estructura de TLR3.

Se muestra la estructura de TLR3, el cual puede estar expresado tanto en la membrana plasmática como en el compartimiento endosómico. Comprende un ectodominio que tiene un capuchón con un motivo de repetición rico en leucina (LRR) que une ARNdh viral, un dominio transmembrana y un dominio intracelular TIR (Toll/IL-1 receptor) que une a la proteína adaptadora TRIF vía su dominio de interacción TIR. La dimerización de TLR3 es necesaria para que el ligando pueda unirse (Figura adaptada de Yu \& Levine 2011). 
forman parte de la respuesta final, con la activación de los factores de transcripción IRF-3/7, NF-кB у AP-1, conduciendo a la inducción de IFNs de tipo I y la producción de citoquinas y quimoquinas (Figura 1.3).

Los dominios TIR de TRIF reclutan fosfatidilinositol 3-quinasa (PI3-K), la cual es requerida para la fosforilación de IRF-3/7. También se asocian con la tirosín-quinasa c-Src, sobre el endosoma. Por otra parte, cuando TRIF se oligomeriza, la serin-treonin quinasa, TBK-1 (también llamado NAK o T2K) e IKK- $\varepsilon$ (también llamada IKK-i) son activadas y fosforilan IRF-3/7. Dicha activación es dependiente de NAP1 y TRAF3. IRF3/7 fosforilado transloca al núcleo e induce la transcripción de IFNs tipo I (Matsumoto and Seya 2008).

RIP-1 (Proteína de Interacción con el Receptor 1), una quinasa que contiene dominios de muerte, se asocia a TRIF y actúa como un inductor de NF-кB y un mediador de apoptosis. Una vez activado TLR3, RIP1 es reclutado a TRIF donde es

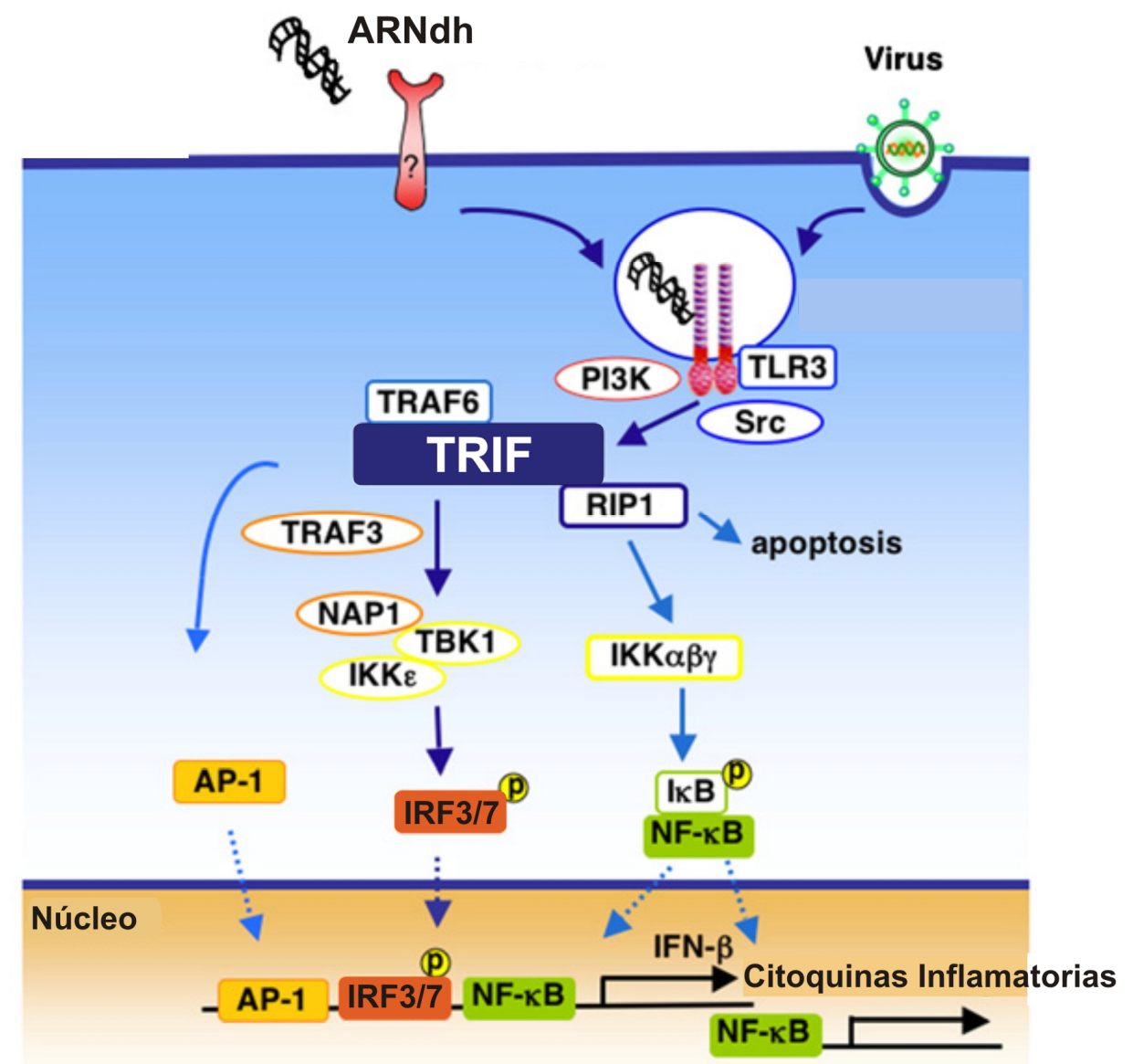

Figura 1.3. Vías de señalización de TLR3.

Una vez que el TLR3 se dimeriza por el ARNdh internalizado, recluta la proteína adaptadora TRIF. Después de la asociación transitoria, TRIF se disocia de TLR3 para formar un complejo que contiene a RIP1, TRAF3, NAP1 donde la señalización mediada por TRIF da inicio. RIP1 se asocia con TRIF y con TRAF6 y actúa como inductor de NF-kB y también de apoptosis. TRAF3 y NAP1 participan en el reclutamiento y activación de las quinasas TBK1 e IKKe, que fosforilan IRF-3/7. IRF3/7 fosforilado transloca al núcleo y junto con NF-kB y AP-1 inducen la transcripción de IFNs tipo I. La activación de AP-1 por TRIF es aún desconocida. (Figura adaptada de Matsumoto \& Seya 2008) 
fosforilado y poliubiquitinilado, evento que conduce a la formación de un complejo de proteínas que trasloca al citoplasma donde se genera la activación de los complejos IKK (IKK $\alpha$, IKK $\beta$ y IKK $\gamma$ ) y la posterior activación y translocación al

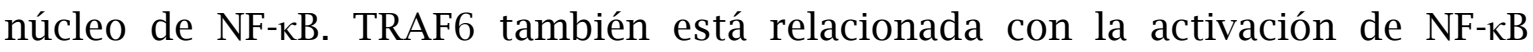
asociándose a TRIF.

RIP1 también juega un rol crítico en las vías de supervivencia celular por medio de la regulación de la apoptosis, necrosis y autofagia. Por ejemplo, TRIF puede reclutar RIP1 y RIP3 con la activación subsecuente de FADD y la inducción de apoptosis vía caspasa-8. El complejo RIP1-RIP3 ha sido identificado como un regulador clave de la necrosis programada y la inflamación inducida por virus.

RIP3 gobierna el switch entre la apoptosis y la necrosis activando enzimas involucradas en el metabolismo energético celular. Estas enzimas participan en la formación de Especies Reactivas del Oxígeno (ROS), las cuales en parte contribuyen a la necrosis mediada por RIP3. RIP1 también puede inducir de modo similar la producción de ROS, la cual media tanto una muerte celular apoptótica como no apoptótica (Matsumoto and Seya 2008; Kawai and Akira 2008; Yu and Levine 2011).

\section{Señalización por RLRs de los ARNdh.}

Como mencionamos, los RLRs son helicasas de ARN citosólicas que activan IRF3/7 y NFкB. La familia de los RLRs está compuesta por el Receptor Inducible por Ácido Retinoico (RIG-I), el Gen Asociado a la Diferenciación de Melanoma (MDA5) y Laboratory of Genetics and Phisiology 2 (LGP2). Mientras RIG-I y MDA5 contienen un dominio de helicasa de ARN (caja DExD/H), dos dominios de reclutamiento de caspasas (CARD) N-terminales que activan la vía de señalización por medio de la unión de proteínas adaptadoras que contienen CARD y un dominio C-terminal, LGP2 carece de CARDs (Kawai and Akira 2008; Yu and Levine 2011; Yoneyama et al. 2015) (Figura 1.4).

MAVS/IPS-1 está compuesta de un CARD en el extremo N-terminal, una región central rica en prolina (PRR), la cual contiene dos motivos de unión al Factor Asociado al Receptor del Factor Necrosis Tumoral (TBMs: TBM1 y TBM2), un tercer TBM (TBM3) y un dominio transmembrana (TM), el cual restringe la localización de MAVS específicamente a la mitocondria (Figura 1.4).

RIG-I y MDA5 sensan grupos complementarios de ligandos de ARN viral. RIG-I reconoce preferencialmente ARNdh cortos $(<300 \mathrm{pb})$ con extremos truncados y un 5'-trifosfato (5'-ppp) típico de ARNdh genómico de virus, mientras 


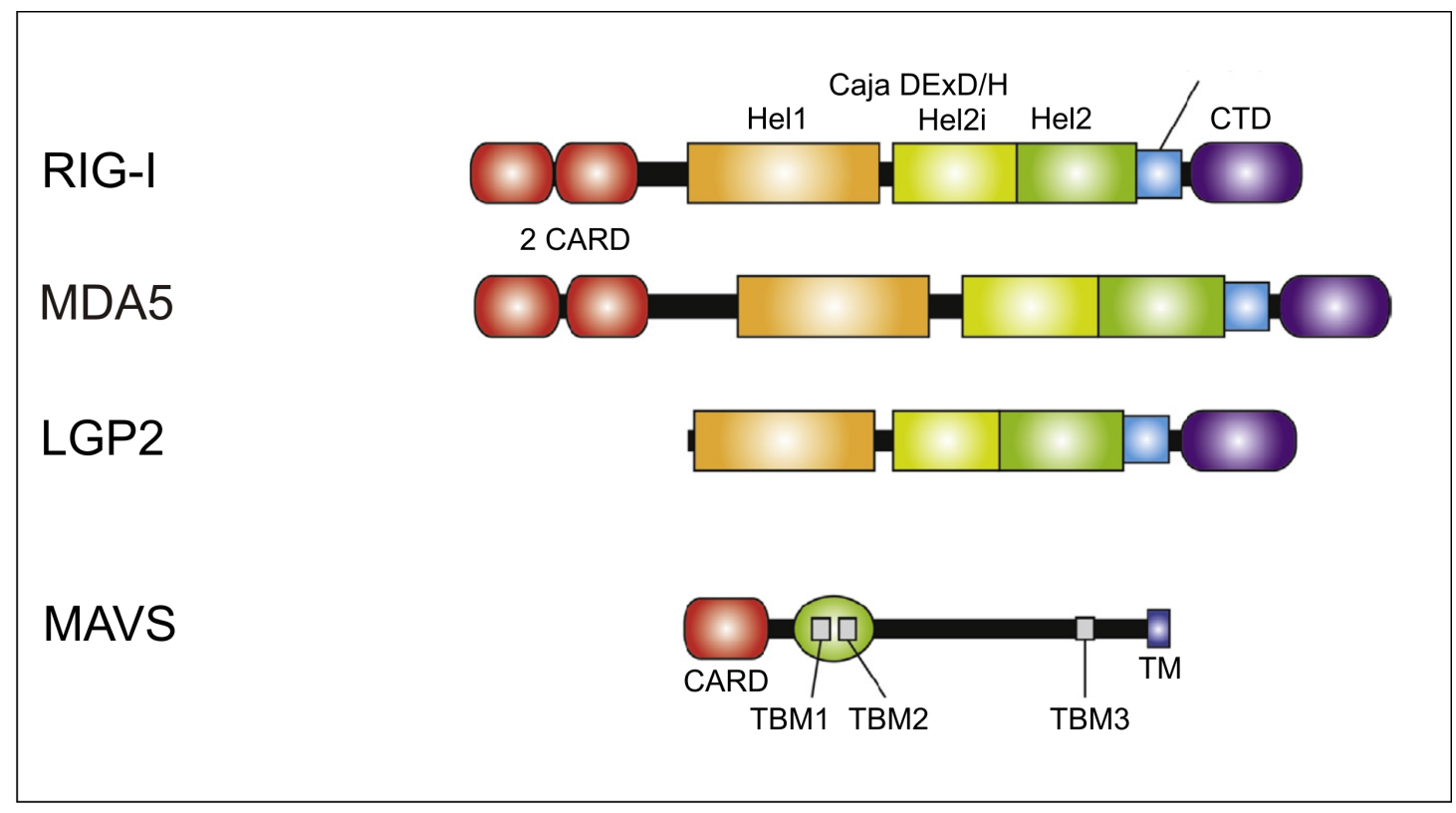

Figura 1.4. Estructura de los RLRs.

Representación esquemática de las estructuras de los dominios de los RLRs y de MAVS. Los tres RLRs son Helicasas de ARN cuyo dominio está ubicado en una caja DExD/H y comprende el dominio helicasa 1 (Hel1) y 2 (Hel2), el dominio de inserción de Helicasa (Hel2i), un dominio puente y el dominio C-terminal (CTD). RIG-1 y MDA5, pero no LGP2, tienen un tándem N-terminal de CARDs. MAVS está compuesto de un CARD, una región central rica en prolina (PRR) que contiene 2 sitios de unión a TRAF (TBM1 y TBM2), un tercer TBM (TBM3) y un dominio transmembrana (TM). (Figura adaptada de Yoneyama et al. 2015).

que MDA5 se une a ARNdh largos (>1000pb) sin extremos específicos (Reikine, Nguyen, and Modis 2014).

En ausencia de ARNdh, RIG-I tiene una conformación inactiva cerrada. Al unirse al ARN a través de la helicasa y el dominio C-terminal, se liberan los CARDs, los cuales entonces reclutan y activan el adaptador de señal MAVS. Se produce un ensamblaje de RIG-I en forma de "perlas de un collar" a partir del extremo 5'ppp, proceso que es dependiente de ATP. En contraste, MDA5 tiene sus CARDs en conformación activa y puede ensamblarse cooperativamente desde cualquier ubicación del ARNdh, dando origen a filamentos sensibles a ATP. Los filamentos formados por la interacción de CARDs de MDA5 son los responsables de nuclear el ensamble de MAVS para dar lugar a la formación de esta forma polimérica activa (Yoneyama et al. 2015) (Figura 1.5).

En ambos casos se requiere una conformación de agregados proteicos para que la señalización pueda ser llevada a cabo. La formación del agregado de estos receptores con MAVS es lo que permitirá la interacción de este último con los miembros de la familia TRAF (Yoneyama et al. 2015) (Figura 1.5).

Más recientemente, se ha demostrado que en ciertas infecciones virales se observa la aparición de los denominados agregados proteicos similares a gránulos de estrés (SG) en el citoplasma celular. Se ha demostrado que PKR es 


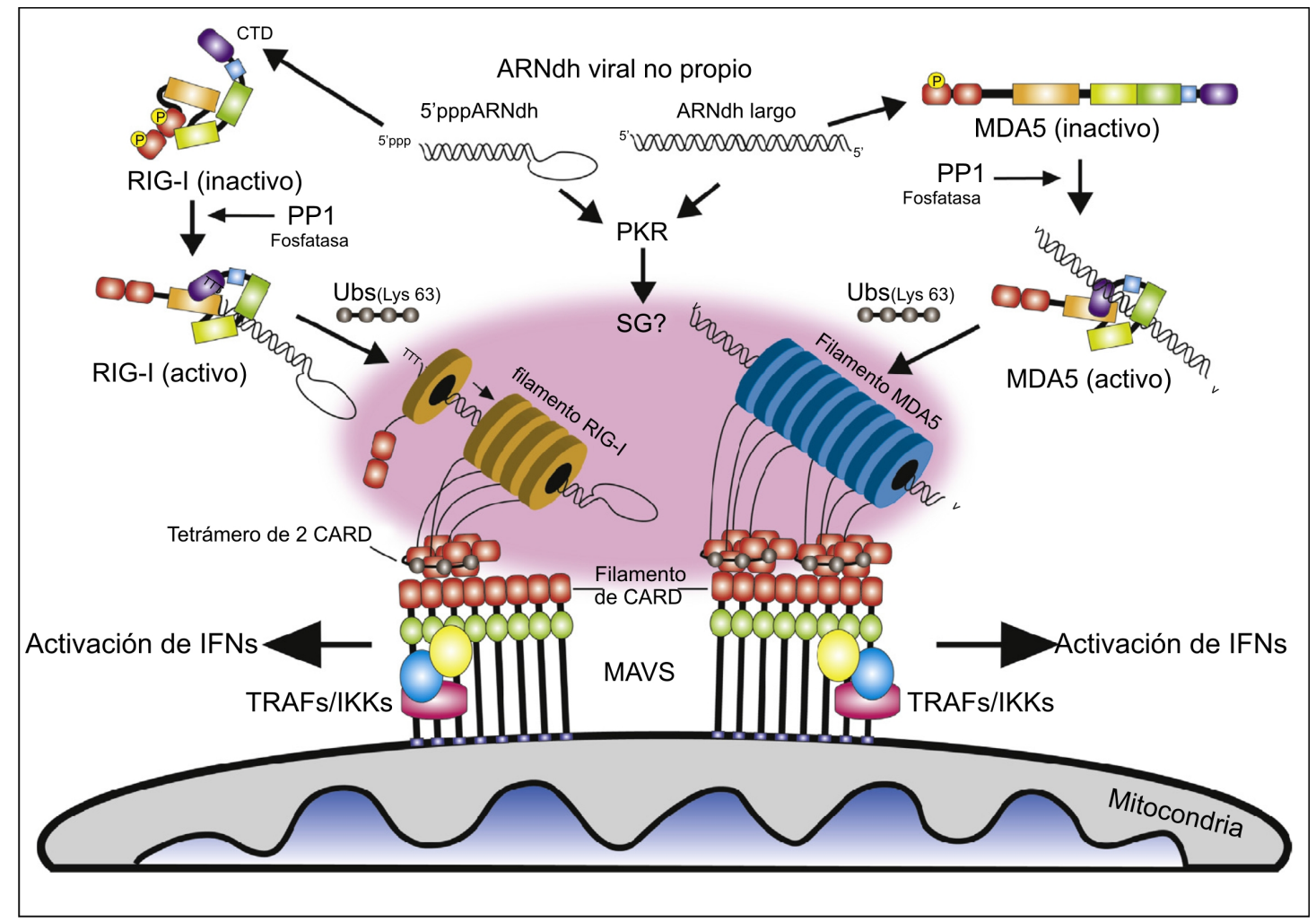

Figura 1.5. Modelo de reconocimiento de ARN por RIG-I y MDA5, e interacción con MAVS para generar la señal de activación.

Una vez presentado el extremo 5'ppp de un ARNdh corto, RIG-I sufre un cambio conformacional de un estado inactivo a uno activo y oligomeriza sobre el ARNdh desde su extremo. En cambio MDA5 no posee una forma inactiva en ausencia de ligando. MDA5 se une preferencialmente a un sector interno de un ARNdh largo, sin especificidad por los extremos. Se ensambla cooperativamente en un filamento sobre el ARNdh. En ambos casos, la forma oligomérica de los CARDs de los RLRs favorece la interacción con el CARD de MAVS y la formación de oligómeros RLR-MAVS. (Figura adaptada de Yoneyama et al. 2015)

capaz de sensar la entrada de un virus y dar origen a estos gránulos. Pero también se ha descripto que estos gránulos pueden contener también RLRs y varias moléculas con acción antiviral. Se supone que estos gránulos tienen la función de favorecer el reconocimiento del ARNdh viral por los receptores MDA5 y RIG-I (Yoneyama et al. 2015) (Figura 1.5).

La señal entonces es propagada secuencialmente a partir del ligando unido al RLR hacia MAVS y hacia las protein-quinasa citosólicas IKK y TBK1, las cuales activan los factores de transcripción NF- $\mathrm{B}$ e IRF3/7, respectivamente. La interacción entre MAVS e IKK y TBK1 está dada por TRAF3.

A su vez, MAVS también es capaz de interactuar con RIP-1 y FADD, dos proteínas asociadas a la señalización de receptores de muerte. Una vez activados NF-кB e IRF3/7, son translocados al núcleo, donde inducen la expresión de interferones tipo I y otras moléculas proinflamatorias (Figura 1.6). 


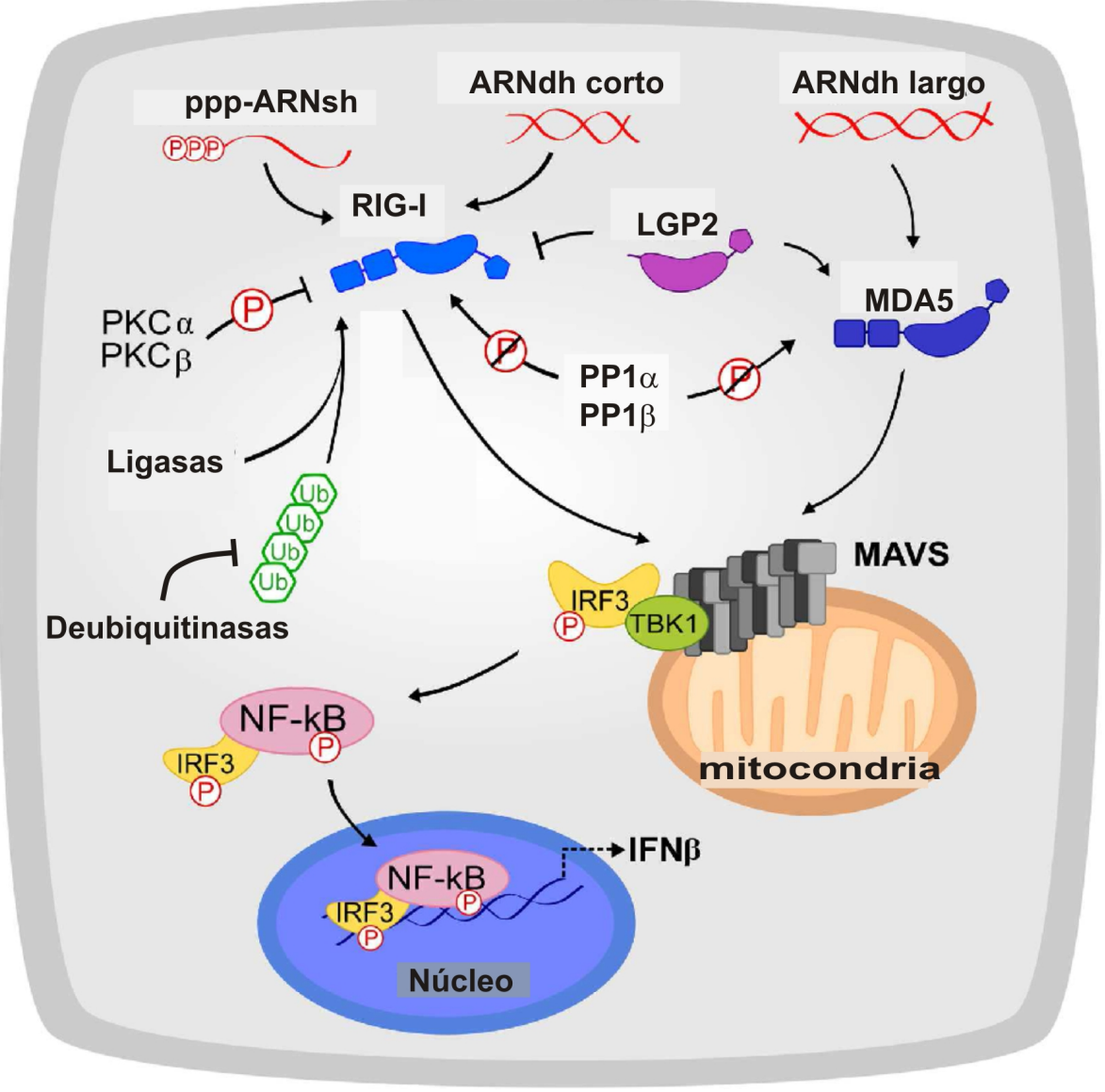

Figura 1.6. Vías de señalización de los RLRs.

RIG-I y MDA5 reconocen un grupo complementario de ligandos de ARNdh viral citosólico. Su activación está finamente regulada por fosforilación, ubiquitinación y proteínas como LGP2. RIG-I y MDA5 señalizan por MAVS, el cual inicia la producción de la señalización para la producción de interferones tipo I (Figura adaptada de Reikine et al. 2014).

Un dominio transmembrana liga a MAVS a la membrana mitocondrial o del peroxisoma. La señalización por MAVS es diferente dependiendo de si la unión ocurre en la mitocondria o en el peroxisoma. Unido a peroxisoma induce una rápida expresión independiente de interferón de factores de defensa antiviral, activando ISGs (IFN-stimulated genes), los cuales preceden a la activación de la vía principal dependiente de IFNs por MAVS unido a mitocondria, que amplifica y estabiliza la respuesta antiviral. Además, MAVS unido a la mitocondria sería responsable de la inducción de apoptosis por disrupción del potencial de membrana mitocondrial y la activación de caspasas (Reikine, Nguyen, and Modis 2014; Dixit et al. 2010).

La señal de los RLRs es regulada por numerosos factores del huésped y virales a través de varios mecanismos, incluyendo la degradación de la cadena de poliubiquitina unida a los CARDs y el clivaje de las MAVS por proteasas codificadas por virus. La poliubiquitinación ha sido una de las modificaciones más extensivamente estudiadas de RIG-I y MDA5. La oligomerización de los 
sensores de ARNdh RIG-I y MDA5 que activa la respuesta inmune innata antiviral depende en parte de una cadena de poliubiquitina no anclada, ligada por interacciones no covalentes a una lisina en la posición 63 del dominio CARD. Existen ciertas ligasas y deubiquitinasas que son responsables de la activación e inactivación respectivamente, de la formación de los agregados de proteínas y por tanto, de la señalización posterior (Reikine, Nguyen, and Modis 2014) (Figura 1.6).

Además de la ubiquitinación, la fosforilación es un mecanismo regulador importante de la señalización. Tanto RIG-I como MDA5 tienen sitios de fosforilación en sus dominios CARDs que producen la inhibición de la unión a ARNdh. Las enzimas responsables de esta fosforilación son la protein-quinasa $\mathrm{C} \alpha$ y $\beta(\mathrm{PKC} \alpha / \beta)$. Por otra parte, RIG-I y MDA5 están constitutivamente fosforilados hasta la aparición del ARN viral, en cuyo caso los RLRs deben ser desfosforilados por la Fosfoproteina Fosfatasa $1 \alpha$ y $\gamma(\mathrm{PP} 1 \alpha / \gamma)$ para lograr la unión al ligando y la activación (Reikine, Nguyen, and Modis 2014) (Figura 1.6).

Además de las mencionadas modificaciones postraduccionales de los RLRs, la señalización está también modulada por varias proteínas diferentes. Una de ellas es la tercera RLR, LGP2. Dado que carece de CARDs, no es capaz de activar MAVS, sin embargo sí posee capacidad de reconocer ARNdh, lo que permite modular la capacidad de señalización por RIG-I y MDA5. LGP2 inhibe la señalización por RIG-I, debido a que reconoce completamente el mismo ligando viral. En contraste, LGP2 amplifica la señalización por MDA5, por un mecanismo poco claro, pero que parece facilitar el reconocimiento de ARNdh viral por MDA5 a través de interacciones entre el extremo C-terminal de LGP2 y el ARNdh (Reikine, Nguyen, and Modis 2014) (Figura 1.6).

\section{ARNdh y sus efectos sobre la mucosa del intestino delgado.}

La inducción de una respuesta inflamatoria exacerbada en intestino delgado ha sido evaluada en modelos experimentales, aunque estos estudios han sido mucho más limitados que aquellos que investigan patología en colon. En particular, destacamos el empleo de la administración intraperitoneal de ARNdh que induce la sobreactivación de la señalización por TLR3 (Garside et al. 1991; R. Zhou, Wei, Sun, and Tian 2007; R. Zhou, Wei, Sun, Zhang, et al. 2007; McAllister et al. 2013). McAllister C. et al demostraron que las vías de señalización activadas a través de los sensores de ARNdh y particularmente TLR3/TRIF/Caspasa 8, conducen a patología intestinal pero también a protección del huésped durante la infección viral (McAllister et al. 2013). Sin embargo, en estos modelos el rol de las 
vías inducidas localmente no puede aislarse de fenómenos generados a nivel sistémico debido a que el ARNdh utilizado se inyectó por vía intraperitoneal. Por lo tanto, la interpretación de los eventos generados no es simple.

En un estudio de Hirata, Y. et al. se evaluó la importancia de RIG-I como sensor y como impulsor de la señalización a partir de la inducción con poly (I:C) en células epiteliales intestinales, encontrando que TLR3 y PKR no juegan un rol de importancia en este tipo celular (Hirata et al. 2007). Estudios posteriores in vitro e in vivo demostraron el rol fundamental de RIG-I y MDA5 en la señalización requerida para la producción de IFNs tipo I en células epiteliales ante una infección con el virus a ARNdh, rotavirus. Este estudio resaltó que estos receptores son fundamentales para la correcta eliminación del virus, mientras que TLR3, TRIF o PKR no tuvieron un rol significativo (Broquet et al. 2011).

Por otra parte, un estudio en líneas celulares de epitelio intestinal demostró que TLR3 es importante en la señalización luego de la estimulación con poly (I:C), en particular dado que incrementó la expresión de la molécula de adhesión ICAM1. Este factor es importante para el reclutamiento y tráfico de leucocitos al sitio de inflamación por lo cual se pone de manifiesto un rol adicional relevante de TLR3 en las células epiteliales en la respuesta inmune innata y adaptativa (Omagari et al. 2009). Otro estudio evaluó la importancia de la activación de NFкB por medio del receptor TLR3 para la inducción de $\beta$-defensina humana luego de la estimulación de una línea de células epiteliales intestinales con poly (I:C) (Omagari et al. 2011). Una vez más queda claro que, como modelo de infección viral, la acción de este ligando en las células epiteliales va más allá de la inducción de IFNs tipo I y que la importancia de los diversos receptores implicados radica en la complementariedad de los mismos en la respuesta final observada.

Por otra parte, se demostró que poly (I:C) es capaz de inducir una respuesta de IFNs tipo I mediada por TLR3 con distinta eficiencia dependiendo el peso molecular del poly (I:C) empleado y también el tipo celular estimulado (hepatocitos, macrófagos, células endoteliales, etc.) (Y. Zhou et al. 2012). Otros estudios sobre el rol de TLR3 y los RLRs en la interacción entre Células Dendríticas y Células NK, utilizaron el estímulo con poly (I:C) in vitro para poner en evidencia que tanto TLR3 como los RLRs son necesarios para la activación de células dendríticas por este ligando. Sin embargo, sólo los RLRs son necesarios en las células NK para la correcta interacción con las células dendríticas y liberación de IFN $\gamma$ (Perrot et al. 2010; McCartney et al. 2009). 
Estos trabajos plantean la necesidad de evaluar los efectos de la inducción con poly (I:C) o ARNdh en un contexto celular más amplio y complejo, teniendo en cuenta que los distintos grupos celulares responden diferencialmente a este ligando y señalizan por distintas vías. El resultado final en intestino delgado está aún poco definido debido a que la información disponible en este sentido es muy limitada. La generación de modelos directamente relevantes a la inducción de patología en el intestino delgado y la consecuente disfunción intestinal producida por estos ligandos han sido escasamente estudiados.

El efecto de poly (I:C) en la inducción de daño en intestino delgado correlaciona con la alta expresión de TLR3 en condiciones normales, mientras que la expresión en intestino delgado de otros TLRs es muy baja o indetectable (Abreu 2010). Además, la estimulación del intestino delgado con otros ligandos de TLRs, como CpG (TLR9), LPS (TLR4), o ácido lipoteicoico (TLR2), no generó cambios histológicos relevantes en la mucosa de ratones C57BL/6 (R. Zhou, Wei, Sun, and Tian 2007).

En varios estudios se puso en evidencia la importancia de TLR3 en el curso de una infección viral intestinal evaluando sus niveles de expresión, señales proinflamatorias generadas y la susceptibilidad a la infección por rotavirus en ratones neonatos y de corta edad. Se encontró que la expresión de TLR3 se incrementa sustancialmente en la primera etapa postnatal en ratones, correlacionando en forma inversa con la susceptibilidad a la infección por rotavirus. Efectos similares fueron observados en relación a las mismas infecciones en pacientes pediátricos (Pott et al. 2012).

Estudios epidemiológicos sugieren la asociación de las infecciones entéricas con el desarrollo subsecuente de enfermedad inflamatoria intestinal (Marshall et al. 2007; Verdu 2012). Ha sido sugerido que las infecciones virales incrementan la incidencia de enfermedad celíaca (EC), en particular aquellas debidas a enterovirus tal como rotavirus (Stene et al. 2006; Troncone and Auricchio 2007). Se ha descripto una asociación entre la infección por rotavirus y la patogenia de EC. El estudio se realizó en una población pediátrica que expresaban los alelos HLA de susceptibilidad para EC. Se determinó el título de anticuerpos antirotavirus y se encontró que la infección por rotavirus generaba un riesgo significativamente mayor al desarrollo de EC (Stene et al. 2006).

Usando una biblioteca sintética para el estudio del repertorio de anticuerpos de sangre periférica, se encontró que los pacientes celíacos al diagnóstico presentaban reactividad frente a la proteína VP7 de enterovirus. Este epítope 
tiene homología compartida con proteínas propias como transglutaminasa 2, HSP60 y TLR4. Estos resultados muestran, por un lado la infección por rotavirus como un potencial disparador de la respuesta inmune en intestino de pacientes celíacos y, por otro lado, la generación de anticuerpos autorreactivos (Zanoni et al. 2006). Otros reportes también han observado la asociación de las infecciones entéricas con la aparición de EC (E F Verdu et al. 2007).

No han sido completamente dilucidados los mecanismos que vinculan la infección viral con la inducción de patología. Sin embargo, es bien conocido que la activación de la respuesta inmune innata genera una rápida y fuerte respuesta anti-viral, la cual esencialmente involucra la producción de IFNs de tipo I y otros componentes de la respuesta inflamatoria. Teniendo en cuenta la asociación entre la infección con enterovirus y EC, se puede considerar a los IFNs tipo I como un potencial mediador involucrado en la pérdida de tolerancia al gluten a través de su capacidad de promover inflamación y una fuerte respuesta del tipo Th1 (Ludvig M Sollid and Jabri 2013).

Se observó que las células dendríticas plasmacitoideas de intestino delgado de pacientes con EC activa producen IFNs de tipo I, y que este mediador podría ser relevante para sostener la producción de IFN $\gamma$ durante la fase crónica, ya que el bloqueo ex vivo de IFN $\beta$ en piezas de biopsias duodenales reduce la producción de IFN $\gamma$ (Di Sabatino et al. 2007).

La participación de IFNs tipo I como inductores de patología fue sugerida en un caso de una paciente diagnosticada con esclerosis múltiple, quien recibió IFN $\beta$ como tratamiento. Luego de dos meses de administración de IFN $\beta$, la paciente presentó diarrea severa, sin lesión colónica pero con enteropatía en intestino proximal que revirtió ante una dieta libre de gluten. Si bien no se habían realizado estudios previos de intestino delgado, la paciente no tuvo ningún signo previo asociado. El diagnóstico de EC se estableció luego del tratamiento con IFN $\beta$ (Fernández-Salazar et al. 2011).

Por lo antedicho, los IFNs de tipo I parecen tener un rol relevante en la inducción de una respuesta inflamatoria que desencadena mecanismos de daño tisular en intestino delgado. Si bien las vías de señalización que generan la expresión de IFNs Tipo I son bien conocidas, la contribución de estas vías en los mecanismos de enteropatía ha sido solo parcialmente estudiada. 


\section{OBJETIVO}

En el presente capítulo, el objetivo fue imitar la respuesta inmune local desencadenada durante una infección viral entérica como modelo de factor ambiental precipitante de enteropatía de intestino delgado. Para esto, desarrollamos un modelo experimental en ratón mediante la administración intraluminal de poly (I:C) y evaluamos las fases más tempranas de la respuesta inmune y el daño tisular producido en la mucosa del intestino delgado. 


\section{RESULTADOS}

\section{Desarrollo del modelo experimental}

Como hemos mencionado, varios estudios han demostrado que la administración sistémica (intraperitoneal) de poly (I:C), análogo sintético del ARNdh, induce enteropatía (Garside et al. 1991; R. Zhou, Wei, Sun, Zhang, et al. 2007). Si bien ha sido descripto que el intestino delgado presenta una muy alta expresión de TLR3 y que esto promovería el disparo de las señales inflamatorias, en este modelo no se puede descartar la generación de efectos sistémicos que involucren a células y mediadores de sitios extraintestinales. Por otro lado, la asociación de enteropatía con infecciones entéricas implica la inducción de una respuesta local.

Con el objetivo de evaluar el rol de la respuesta inflamatoria generada por el ligando de receptores de la inmunidad innata (poly (I:C)), desarrollamos una técnica de microcirugía denominada asa ligada mediante la cual se puede administrar en forma controlada una determinada cantidad de este ligando en el lumen del intestino delgado proximal. Para tal fin, se eligieron secciones de intestino a $2 \mathrm{~cm}$ del estómago y se ligaron dos sitios para determinar un área cerrada de 2-3 cm de longitud. En la Figura 1.7 se pueden observar dos ejemplos del procedimiento de asa ligada realizado en ratones C57BL/6. Señaladas con flechas se encuentran las ligaduras que permiten aislar el sitio a tratar del resto del intestino.

Una vez finalizada la inyección intraluminal, se procedió a suturar la pared abdominal del ratón y se esperó la recuperación de la anestesia. Pasado distintos

PBS

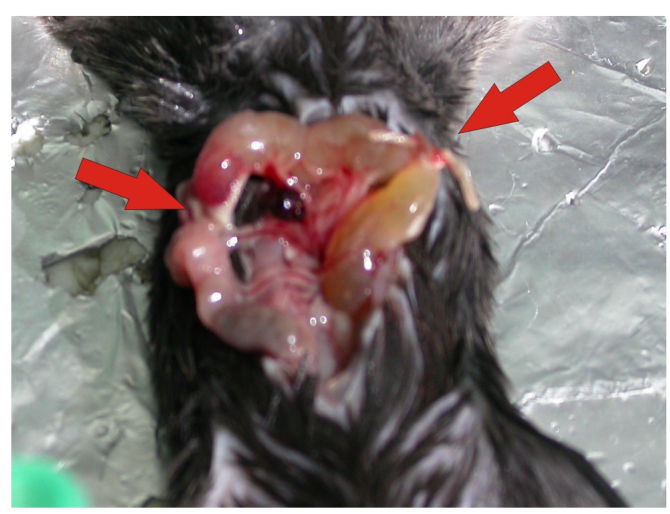

PIC

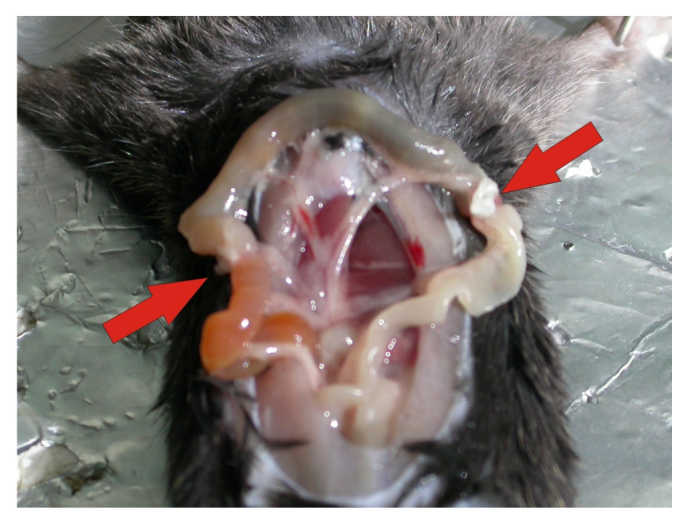

Figura 1.7. Imágenes del procedimiento quirúrgico de asa ligada.

Ratones C57BL/6 fueron estimulados en un asa ligada con PBS o poly (I:C) (30ug/g de ratón) y luego sacrificados a las $12 \mathrm{hs}$ para procesar el segmento de intestino encerrado en el asa para estudios posteriores. Las imágenes fueron adquiridas luego de sacrificar a los animales. 
períodos de tiempo según el ensayo a realizar, los animales se sacrificaron y se tomaron muestras del asa ligada para su análisis posterior.

Como un método para evaluar la producción de daño histológico por los distintos estímulos procedimos a realizar medidas morfométricas que nos permitieron comparar el daño ejercido por distintos mediadores. De este modo, se procedió a determinar la altura de las vellosidades y la profundidad de las criptas, para luego calcular el cociente Vellosidad-Cripta $(\mathrm{V} / \mathrm{C})$ para cada animal bajo cada uno de los tratamientos (Figura 1.8). El cociente V/C es una de las formas de evaluación más empleada ya que es un buen indicador de daño en la mucosa intestinal.

Nuestra primer inquietud fue contrastar los efectos producidos por poly (I:C) inyectado intraperitonealmente, como había sido previamente descripto (Garside et al. 1991; R. Zhou, Wei, Sun, and Tian 2007; R. Zhou, Wei, Sun, Zhang, et al.2007) , respecto al método de inoculación en asa ligada

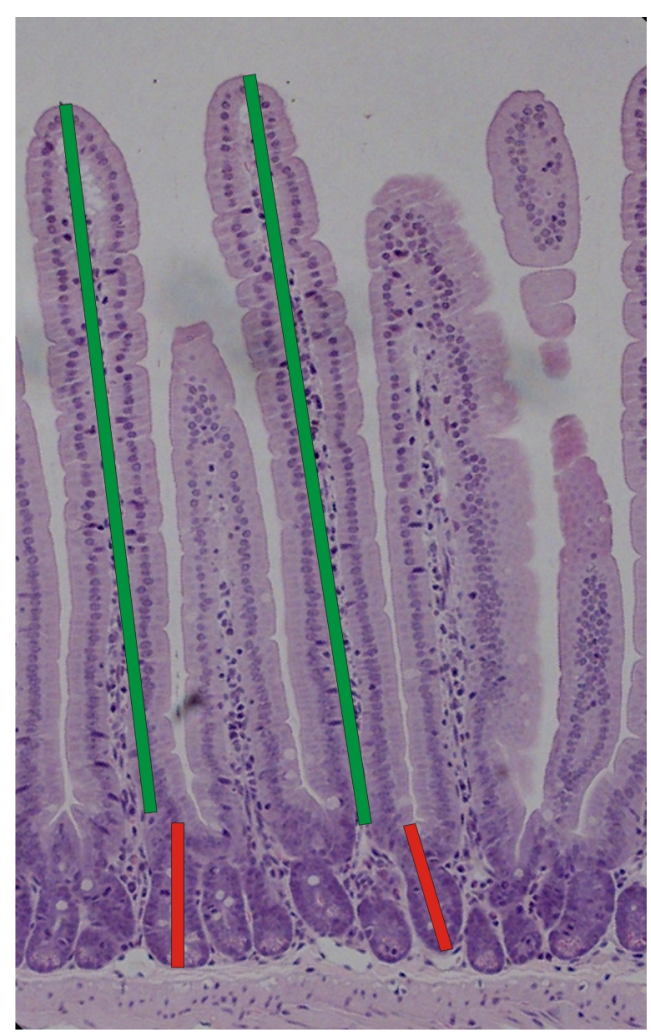

Profundidad de Cripta

Altura de Vellosidad

Figura 1.8. Imagen representativa de una sección de intestino delgado proximal teñida con H\&E.

Ejemplo de las medidas de altura de vellosidad (barras verdes) y profundidad de cripta (barras rojas) sobre la microfotografía obtenida con una de las secciones. 


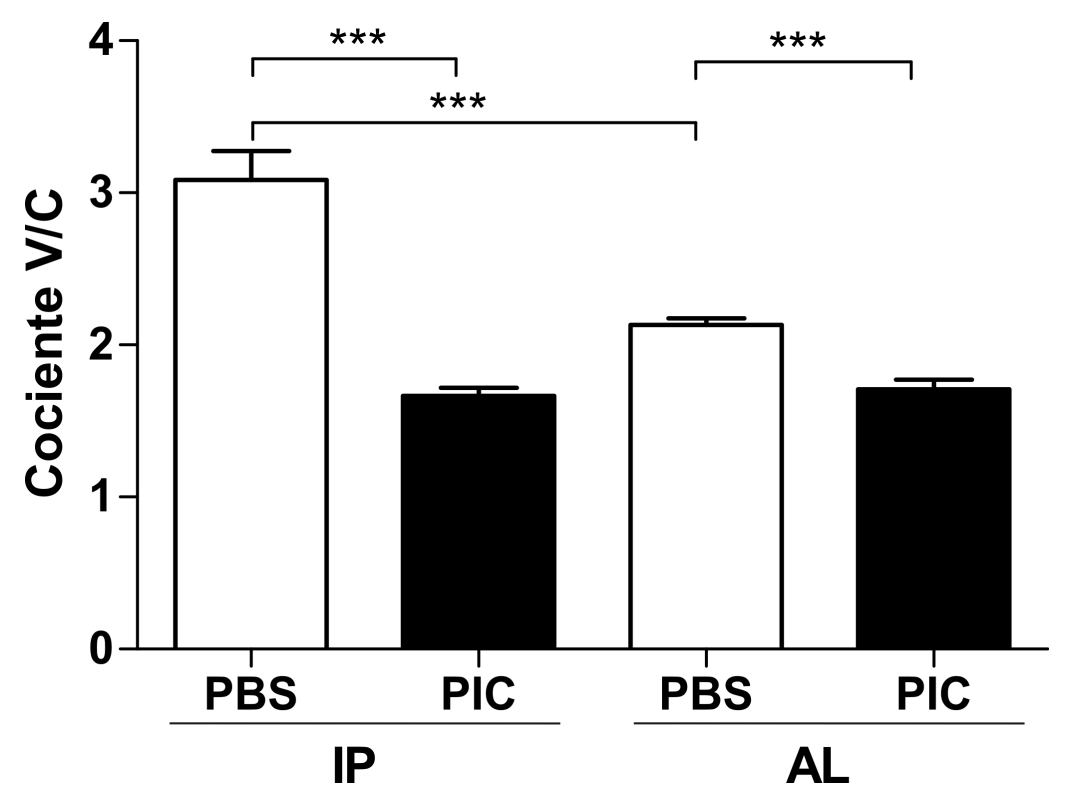

Figura 1.9. Daño intestinal producido por la administración de poly (I:C) en asa ligada (AL) e intraperitoneal (IP) en ratones C57BL/6.

Análisis morfológicos de intestino delgado de ratones C57BL/6 mediante el uso del Cociente Vellosidad/Cripta (V/C) después de $12 \mathrm{hs}$ post-tratamiento. $\mathrm{N}=4$ ratones por grupo, test $\mathrm{t}$ no pareado, ${ }^{* * *} \mathrm{P}<0,001$.

propuesto por nosotros. De este modo estimulamos ratones C57BL/6 con poly (I:C) o PBS mediante administración intraperitoneal o intraluminal en asa ligada por $12 \mathrm{hs}$. Luego de sacrificar los animales se obtuvieron muestras de intestino delgado para realizar el análisis morfométrico.

Como se observa claramente en la Figura 1.9 la inducción con poly (I:C) intraperitoneal genera una reducción significativa del cociente $\mathrm{V} / \mathrm{C}$ cuando se compara con el control de PBS intraperitoneal. Por otro lado cuando se administra poly (I:C) en asa ligada se observa una reducción significativa del cociente $\mathrm{V} / \mathrm{C}$ comparable con el observado en los ratones tratados intraperitonealmente. Sin embargo, es claro el efecto nocivo del procedimiento, dado que puede observarse que el control de PBS en asa ligada presenta un descenso del cociente V/C significativo cuando se compara con los ratones tratados con PBS intraperitonealmente. Además, si se observa la Figura 1.7, podrá verse el enrojecimiento de las asas por la manipulación propia del procedimiento. Por ello, los siguientes procedimientos estuvieron orientados a determinar otro método de administración luminal de los mediadores que permita reducir el daño inducido por el procedimiento quirúrgico.

Así, desarrollamos un estudio morfológico comparativo entre la administración en asa ligada con poly (I:C) o PBS y la administración intraluminal sin previa ligadura de las asas intestinales. El método utilizado en todos los estudios intraluminales se basó en la microcirugía de los animales, inyectando en 


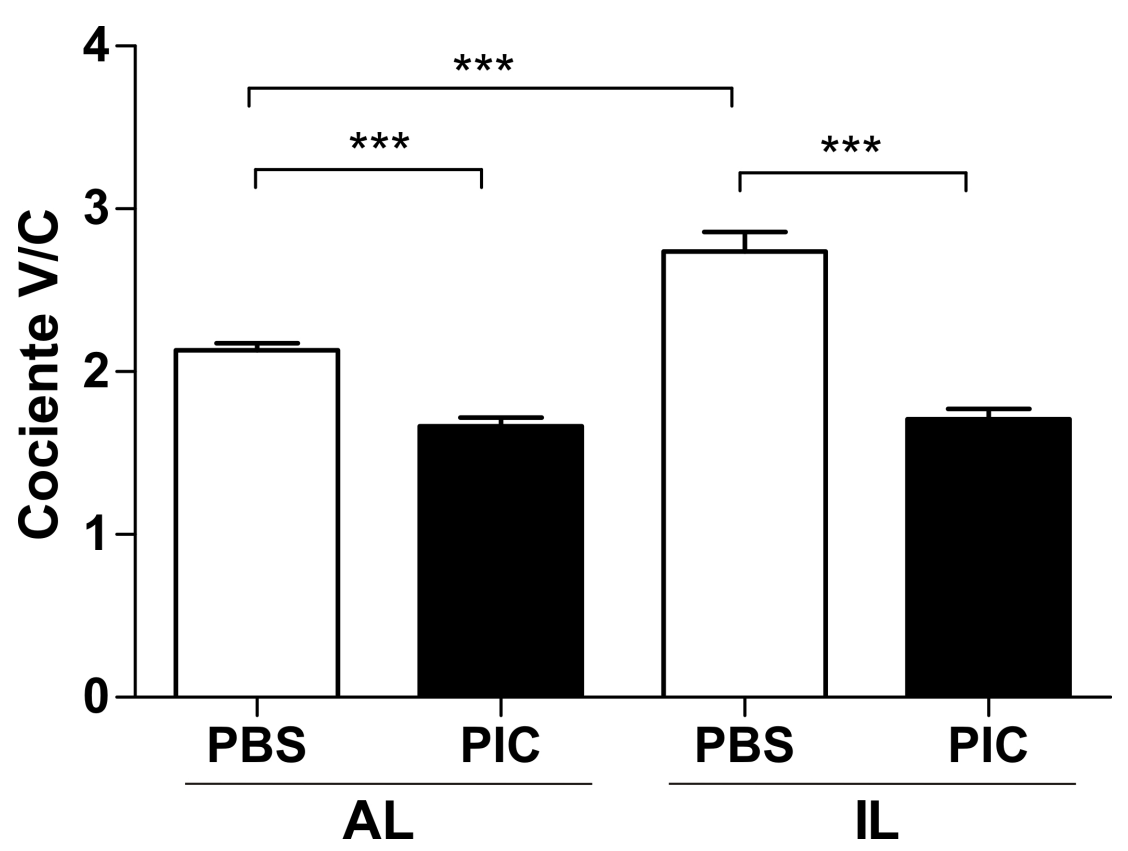

Figura 1.10. Contraste entre la administración de poly (I:C) en asa ligada (AL) e intraluminal (IL) en ratones C57BL/6.

Análisis morfológicos de intestino delgado de ratones C57BL/6 mediante el uso del Cociente Vellosidad/Cripta (V/C) después de $12 \mathrm{hs}$ del tratamiento. $\mathrm{N}=4$ ratones por grupo, test $\mathrm{t}$ no pareado, $* * * \mathrm{P}<0,001$.

un punto distante $2 \mathrm{~cm}$ del estómago, sobre el primer asa intestinal, procurando evitar la primer porción de duodeno que recibe la mayor concentración de enzimas provenientes de páncreas que podrían degradar el estímulo en estudio.

Como se observa en el análisis comparativo entre los dos tipos de administración, poly (I:C) induce daño de modo similar cuando es administrado en asa ligada y cuando se inyecta intraluminalmente sin ligaduras. Por el contrario, se observa un daño menor cuando la administración de PBS es directamente intraluminal (IL) que cuando los ratones fueron sometidos al procedimiento de asa ligada (AL) (Figura 1.10). Con estos resultados como base, los siguientes estudios fueron realizados utilizando la inyección directa intraluminal de poly (I:C) como así también de los estímulos que serán descriptos posteriormente.

Evaluación de la enteropatía inducida por la administración intraluminal de poly (I:C).

Habiendo demostrado que la vía intraluminal es efectiva para inducir enteropatía, comenzamos los estudios para caracterizar el modelo de enteropatía inducida por poly (I:C). Para esto se analizó el efecto de poly (I:C) en animales C57BL/6 luego de 12hs de la administración intraluminal. 
A

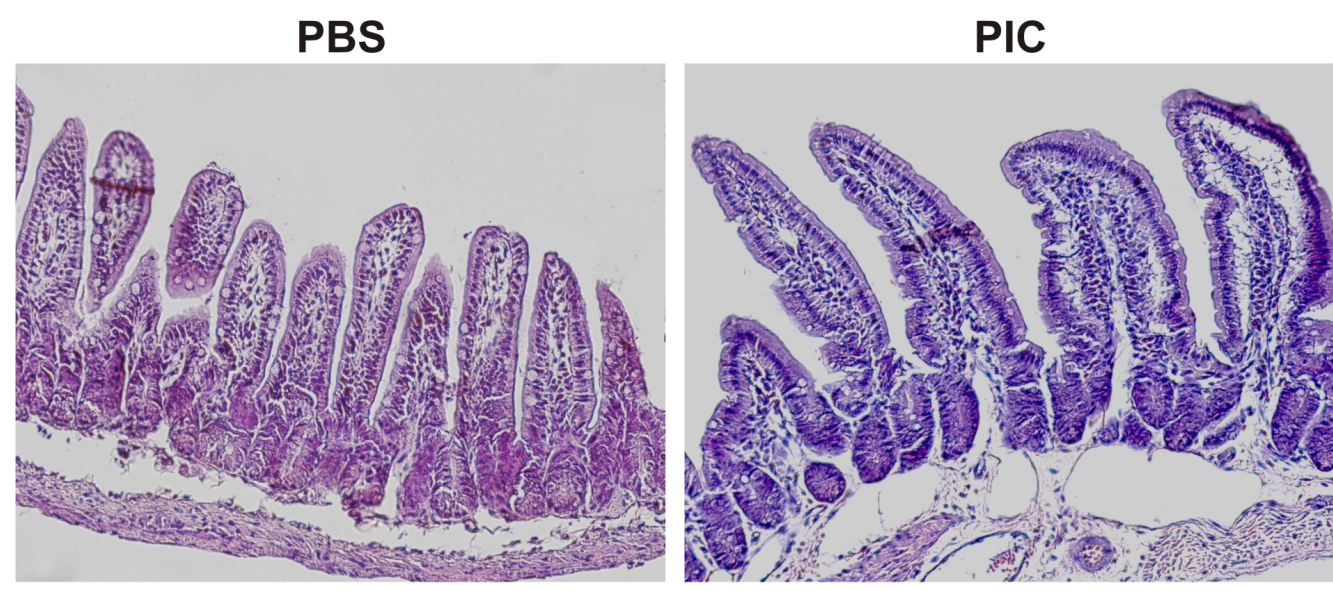

B
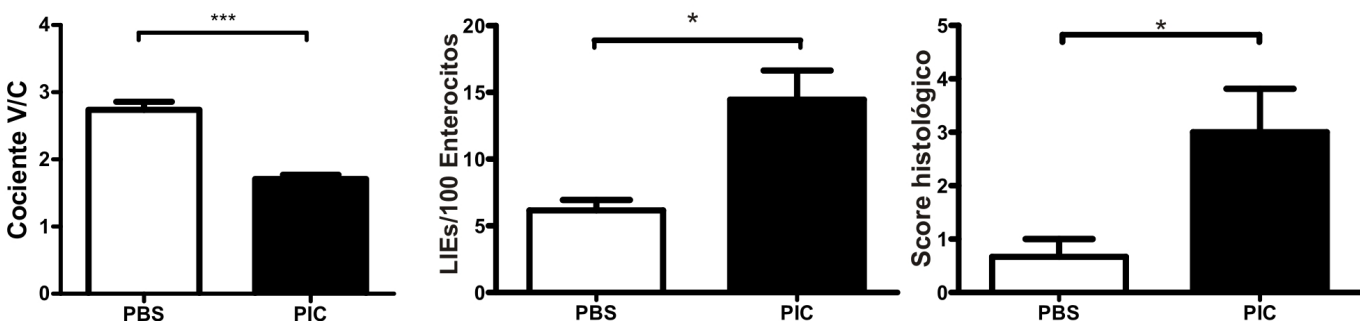

Figura 1.11. Poly (I:C) intraluminal induce enteropatía.

Secciones teñidas con H\&E representativas de intestino delgado proximal de ratones C57BL/6 después de $12 \mathrm{hs}$ de administración de poly (I:C) o PBS (A). Análisis morfológicos de intestino delgado de ratones C57BL/6: Cociente Vellosidad/Cripta (V/C), número de LIEs y score histológico (B) después de $12 \mathrm{~h} s$. $\mathrm{N}=4$ ratones por grupo, test t no pareado, ${ }^{*} \mathrm{P}<0,05$, ${ }^{* *} \mathrm{P}<0,01,{ }^{* * *} \mathrm{P}<0,001$.

Encontramos que poly (I:C) produjo un acortamiento y ensanchamiento de las vellosidades intestinales, edema e incremento del infiltrado celular en la lamina propria (LP) (Figura 1.11A).

Analizando con detalle la estructura de la mucosa con una tinción de H\&E, evidenciamos además del edema, la dilatación de los capilares y la generación de espacio intersticial en las vellosidades intestinales (Figura 1.11A).

A pesar del daño producido por el procedimiento quirúrgico es claro que los parámetros histológicos evaluados evidencian un daño inducido por poly (I:C). La evaluación del cociente $\mathrm{V} / \mathrm{C}$ mostró un descenso significativo, indicando un daño severo en la mucosa (Figura 1.11B). En animales tratados con poly (I:C), se evidenció un incremento en el número de linfocitos intraepiteliales (LIEs), fenómeno que ocurre como consecuencia de la respuesta inflamatoria. Este es un indicador que guarda paralelismo con lo observado en intestino delgado en piezas de biopsias de pacientes con EC activa. El análisis del score histológico, el cual contempla la producción de edema y la separación y disrupción del epitelio y la lamina propria, mostró valores más elevados post-tratamiento con poly (I:C) (Figura 1.11B). Este score confirma la generación de un daño severo en la mucosa intestinal por el tratamiento local con poly (I:C). 
A

PBS

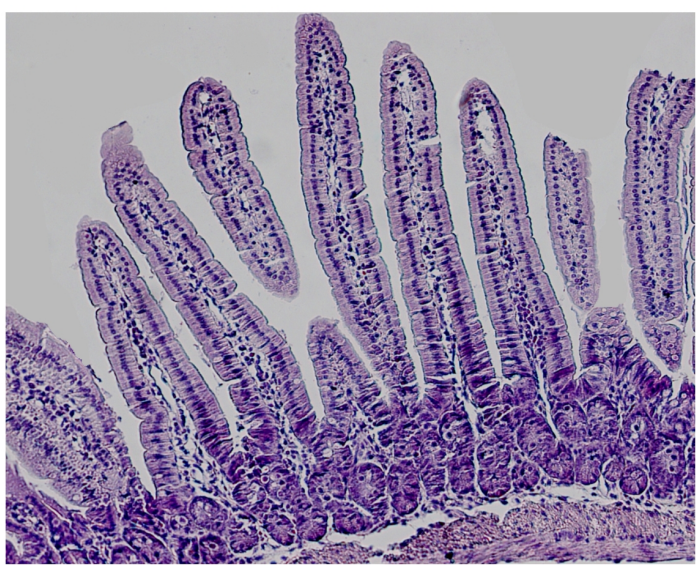

PIC

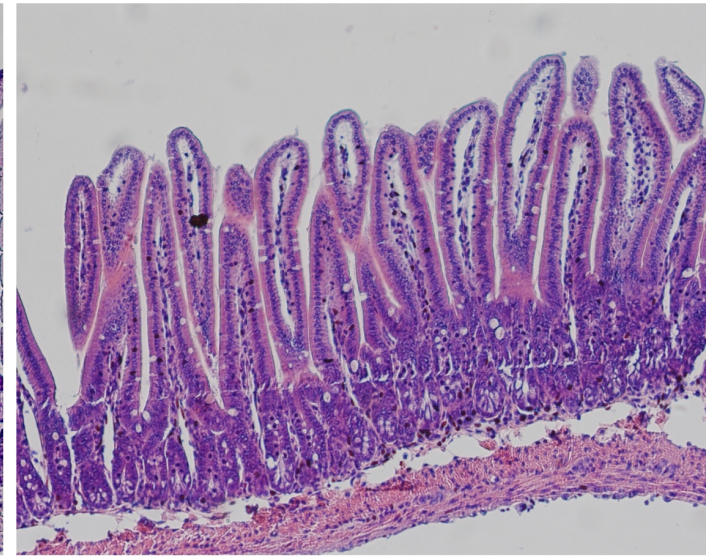

B
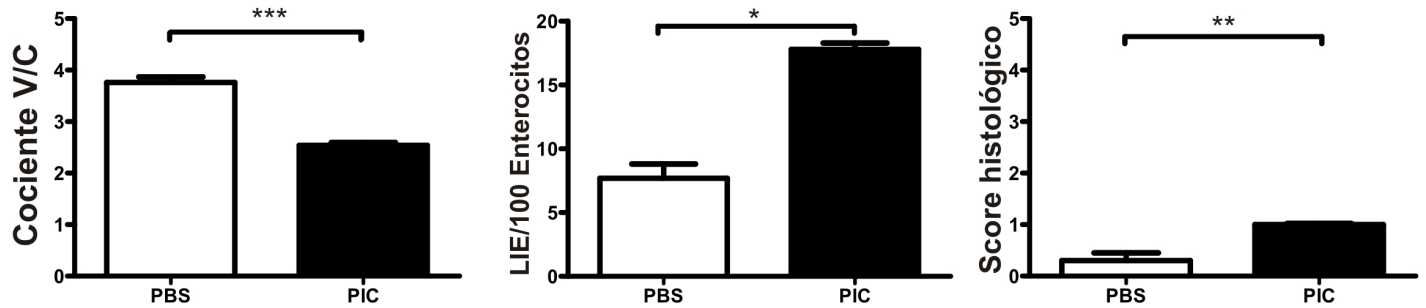

Figura 1.12. Poly (I:C) intraluminal induce enteropatía.

Secciones teñidas con H\&E representativas de intestino delgado proximal de ratones C57BL/6 después de 72hs de administración de poly (I:C) o PBS (A). Análisis morfológicos de intestino delgado de ratones C57BL/6: Cociente Vellosidad/Cripta (V/C), número de LIEs y score histológico (B) después de $72 \mathrm{hs}$. $\mathrm{N}=4$ ratones por grupo, test $\mathrm{t}$ no pareado, ${ }^{*} \mathrm{P}<0,05$, ${ }^{* *} \mathrm{P}<0,01{ }^{* * *} \mathrm{P}<0,001$.

Como fue demostrado en los animales que se sometieron al tratamiento de asa ligada, el procedimiento quirúrgico fue capaz de producir daño per se y por lo tanto, fue de nuestro interés evidenciar si el procedimiento intraluminal, aún siendo menos nocivo que el de asa ligada, era capaz de inducir daño histológico cuyo efecto se vea reflejado al tratar a los animales con poly (I:C). Por ello realizamos el mismo estudio a tiempos más largos, de modo de ver los efectos de poly (I:C) cuando los efectos de la cirugía disminuyen.

Luego de $72 \mathrm{hs}$ de la intervención quirúrgica, los animales control mostraron una recuperación rápida, mientras que en los animales tratados con poly (I:C) se observaron signos claros de daño (Figura 1.12A). Los valores de cociente V/C mostraron una recuperación en ambos grupos aunque los animales tratados con poly (I:C) mostraron siempre valores significativamente más bajos (Figura 1.12B). Los recuentos de LIEs mostraron valores más elevados cuando los animales fueron tratados con poly (I:C) que cuando se los trató con PBS, aún a las $72 \mathrm{hs.}$ Algo similar se observa cuando se analiza el score histológico en cada caso, donde los ratones tratados con poly (I:C) aún presentan valores de score más 
elevados que los ratones tratados con PBS. Sin embargo, estos valores son inferiores a los observados a las $12 \mathrm{hs}$ de tratamiento.

Como era de esperar, el procedimiento quirúrgico alteró la histología intestinal. Sin embargo, estos cambios fueron transitorios y los ratones control presentaron una recuperación más rápida después del tratamiento.

A continuación buscamos caracterizar el estado proliferativo de las criptas de estos animales, ya que este es un indicador de la respuesta del tejido frente al daño inducido. Para ello, utilizamos una técnica de arresto mitótico y recuento de

A
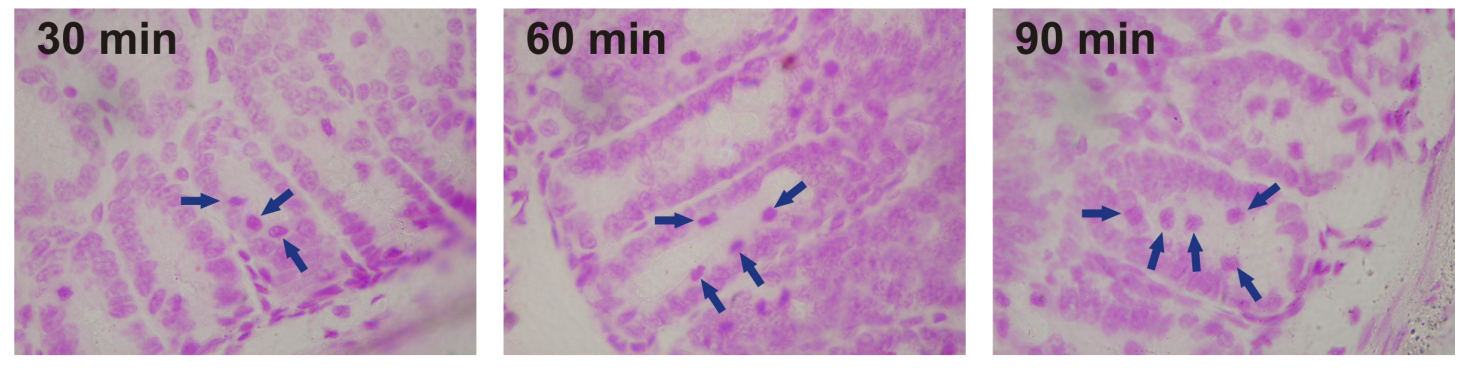

$\mathrm{B}$

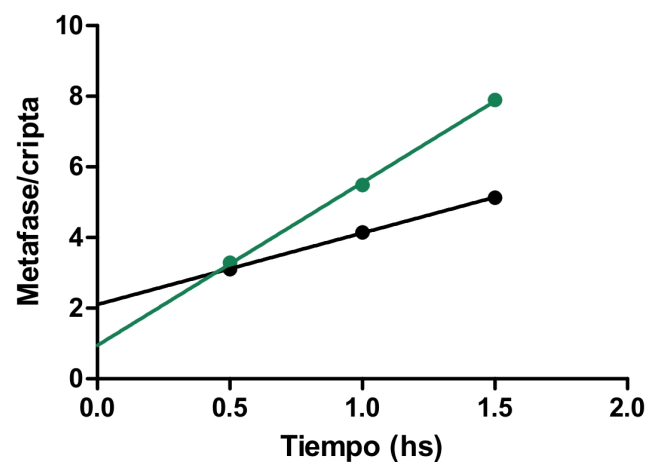

C

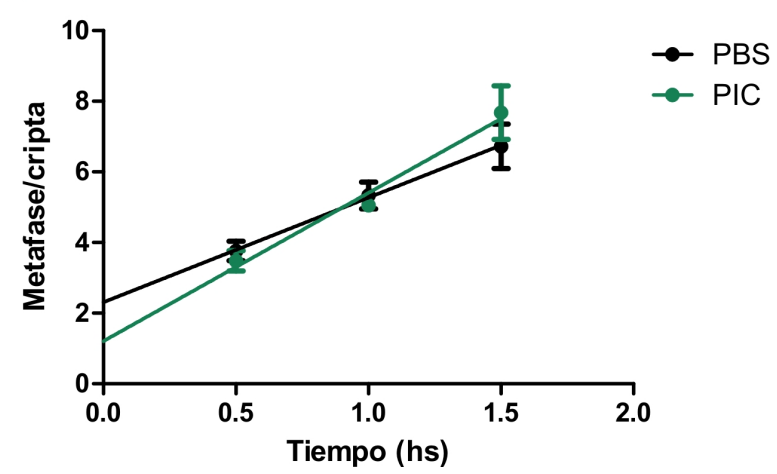

\begin{tabular}{|ccc|}
\hline 24hs & CCPR $^{*}$ & Ordenada al origen \\
\hline PBS & $2,026 \pm 0,03223$ & $2,103 \pm 0,03481$ \\
\hline PIC & $4,612 \pm 0,1232$ & $0,9443 \pm 0,1331$ \\
\hline p & $0,002419 \star$ & nd \\
\hline 72 hs & CCPR* & Ordenada al origen \\
\hline PBS & $2,961 \pm 0,6092$ & $2,311 \pm 0,6580$ \\
\hline PIC & $4,198 \pm 0,6592$ & $1,208 \pm 0,7120$ \\
\hline p & 0,1836 & 0,7252 \\
\hline
\end{tabular}

Figura 1.13. Análisis de la respuesta proliferativa en criptas.

Imágenes representativas de la técnica de determinación del CCPR (Crypt Cell Production Ratio) de secciones de intestino de ratones tratados con colchicina a 3 tiempos distintos y coloreadas con la tinción de Feulgen (A). Los ratones fueron tratados con poly (I:C) (PIC) o PBS intraluminal por 24hs (B) y 72hs (C) y luego se determinó el Cociente de Producción de Células de la Cripta (CCPR) utilizando la inyección de colchicina previo al sacrificio de los animales, a 3 tiempos distintos (30, 60 y 90 minutos). Los tejidos obtenidos de los diferentes grupos de animales fueron fijados, incluidos en parafina, cortados y teñidos con Feulgen. Estadísitica: Test de comparación de pendientes y ordenadas, $\mathrm{N}=2, \star \mathrm{p}<0,05$. *Unidades: metafases/cripta/hora. 
núcleos en metafase en las criptas de intestino delgado como fue previamente descripto (Garside et al. 1991). El fundamento de esta técnica se basa en que el aumento proliferativo del tejido será observado a nivel de sus criptas. Por lo tanto, un arresto de todas las células de la cripta en metafase con el uso de colchicina a tres tiempos distintos permitiría saber si la tasa o velocidad de producción de células de la cripta (Crypt Cell Production Ratio, CCPR) resultó afectada por el tratamiento. En resumen, esta técnica permitiría determinar los efectos fisiológicos del tratamiento con poly (I:C) en la regeneración tisular del intestino delgado de un modo dinámico.

Como se puede observar en la Figura 1.13A, sobre la tinción de Feulgen se realizan los recuentos de núcleos en metafase (flechas azules) a los distintos tiempos de inyección de colchicina (30, 60 y 90min). Estos recuentos son los que se graficarán luego como puntos de la recta para cada estímulo.

Cuando los animales fueron estimulados con poly (I:C) durante 24hs se observó un incremento significativo del CCPR respecto a los ratones control tratados con PBS (Figura 1.13B). Sin embargo, no existen diferencias significativas en el CCPR entre los ratones tratados con poly (I:C) y los tratados con PBS a las 72hs de tratamiento (Figura 1.13C). Además, tampoco se observa una diferencia en las ordenadas al origen de las rectas, sugiriendo que el estado proliferativo al momento de la inyección de colchicina fue similar para ambos tratamientos (tiempo=0hs).

Por otro lado, deseamos determinar si el descenso observado en el cociente V/C se debió a una afectación de la altura de las vellosidades, de la profundidad

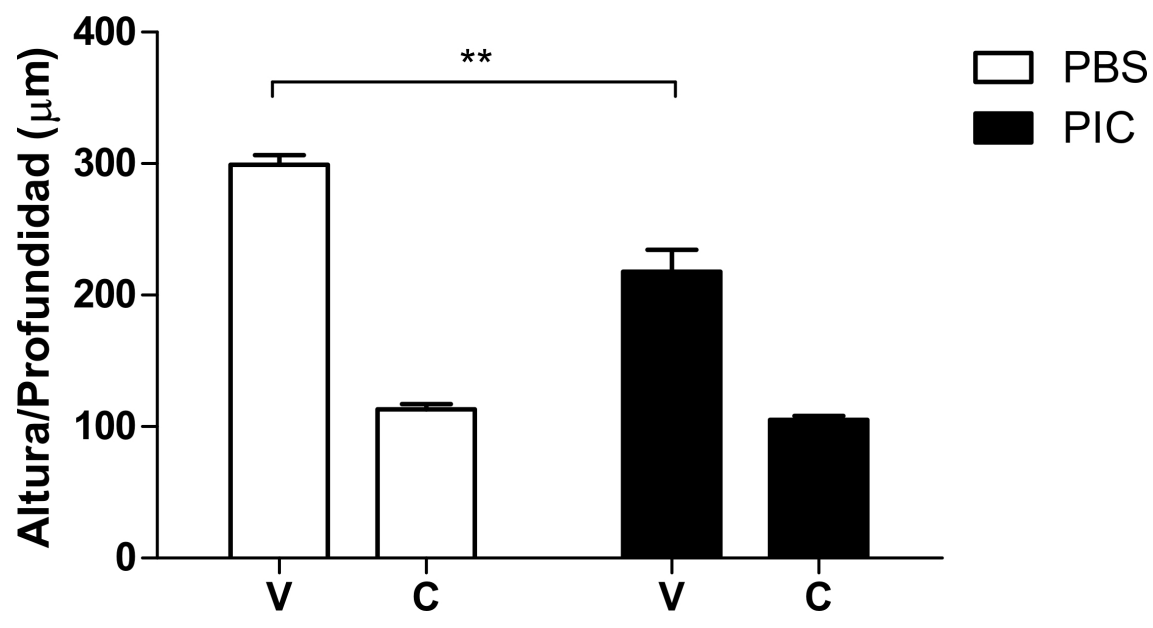

Figura 1.14. El daño por poly (I:C) afecta la altura de las vellosidades sin modificación de la profundidad de las criptas.

Análisis morfológicos de intestino delgado de ratones C57BL/6 luego de 12hs de tratamiento con PIC o PBS. Se grafican las alturas de vellosidades y las profundidades de las criptas por separado en cada grupo de ratones. $\mathrm{N}=4$ ratones por grupo, test $\mathrm{t}$ no pareado, ${ }^{* *} \mathrm{P}<0,01$. 
de las criptas o de ambas. Para ello, en la Figura 1.14 graficamos por separado la altura de las vellosidades y la profundidad de las criptas tanto para el grupo de ratones tratados con PBS como para el tratado con poly (I:C). Allí podemos observar claramente que hay una reducción significativa de la altura de las vellosidades en los ratones tratados con poly (I:C) respecto a lo que se observa en aquellos tratados con PBS. Sin embargo, la profundidad no se ve afectada por el tratamiento. Por lo tanto, el daño ejercido por poly (I:C) se basa en la reducción de la altura de las vellosidades.

El estado hiperproliferativo observado en los ensayos de $24 \mathrm{hs}$, evidenciado por valores mayores de CCPR (Figura 1.13B), no se ve reflejado en un crecimiento desmedido de las criptas. A las 72hs, los valores de CCPR son iguales en los animales tratados con poly (I:C) y en los controles, indicando que existe sólo un incremento transiente de la respuesta proliferativa, la cual es insuficiente para recuperar completamente el cociente $\mathrm{V} / \mathrm{C}$ a valores normales. Por lo tanto, los parámetros morfológicos (cociente $\mathrm{V} / \mathrm{C}$ y score histológico) evidencian una recuperación del tejido a las $72 \mathrm{hs}$, aunque no es completa y el proceso inflamatorio se acompaña de un aumento persistente del número de LIEs aún a ese tiempo.

\section{Señalización por diferentes receptores de poly (I:C)}

El empleo de poly (I:C) de diferentes tamaños moleculares evidenció la compartimentalización del reconocimiento de poly (I:C) por los receptores citoplasmáticos. Los trabajos de McCartney et al. y Kato et al. mostraron que mientras que los poly (I:C) de bajo peso molecular son detectados por RIG-I, los de mayor peso señalizan mediante MDA5 (McCartney et al. 2009; Kato et al. 2008). En base a estas observaciones, nos interesó evaluar si esta señalización diferencial podría tener consecuencias en nuestro modelo de enteropatía inducida por poly (I:C). Para esto, realizamos el mismo protocolo de administración intraluminal empleando poly (I:C) de bajo peso molecular (PICL) y de alto peso molecular (PICH) (ambos de Invivogen) y los comparamos con el poly (I:C) comúnmente empleado (de la empresa Sigma-Aldrich), aquí denominado PICS. Previamente, evaluamos los tamaños moleculares de nuestros reactivos mediante electroforesis en gel de agarosa. La Figura 1.15A muestra que los pesos moleculares de PICS y de poly (I:C) de bajo peso molecular (PICL) fueron menores a $1 \mathrm{~kb}$, mientras que el poly (I:C) de alto peso molecular (PICH) presentó un peso molecular mayor a $1 \mathrm{~kb}$. 
A

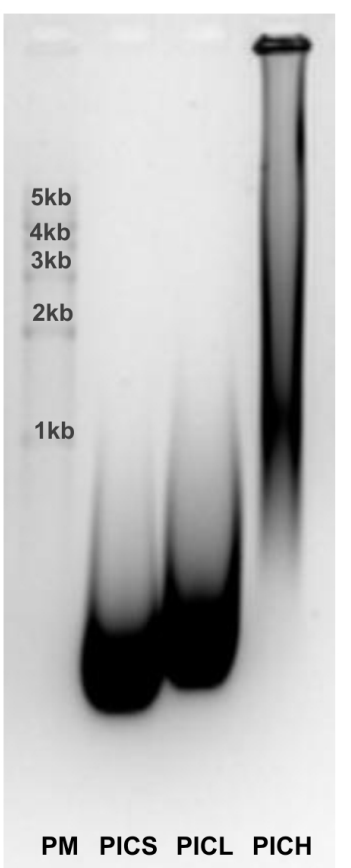

B
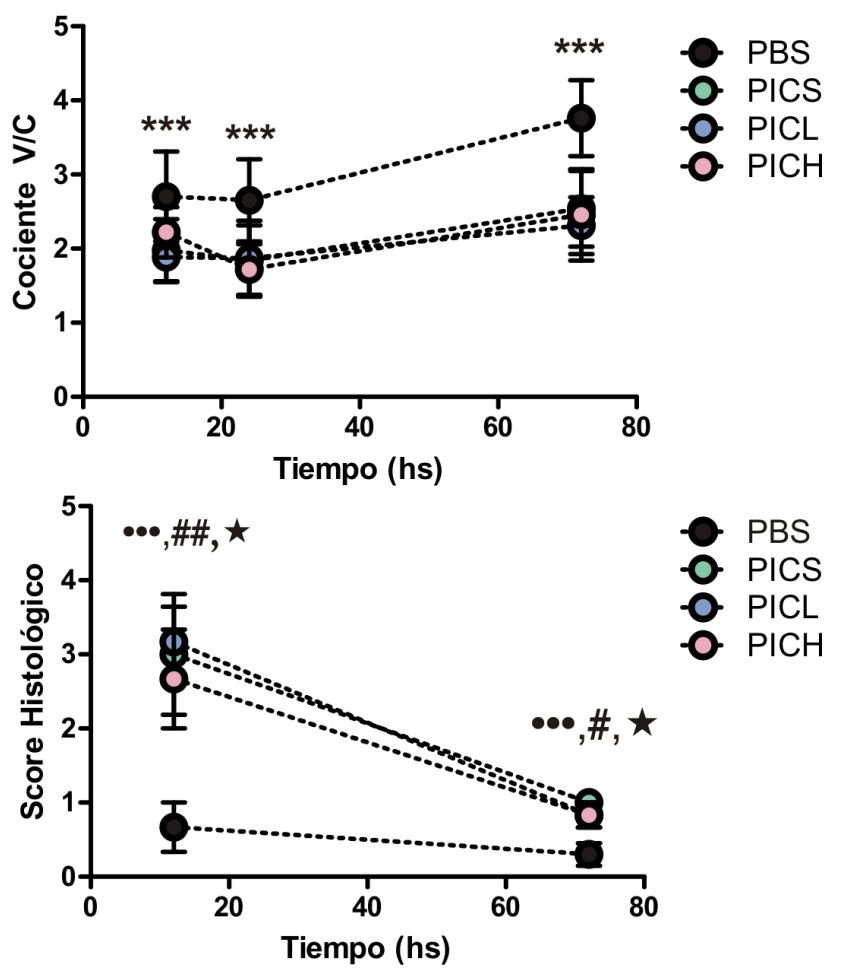

Figura 1.15. Inducción de enteropatía por poly (I:C) de diferentes tamaños.

Electroforesis en gel de agarosa (2\%p/v) de poly (I:C) comercial (PICS, Sigma), poly (I:C) de bajo peso molecular (PICL, Invivogen) y poly (I:C) de alto peso molecular (PICH, Invivogen). Los pesos moleculares fueron controlados con un marcador de peso molecular adecuado (PM) (A). Análisis morfológicos de intestino delgado de ratones C57BL/6: Cociente Vellosidad/Cripta (V/C) y score

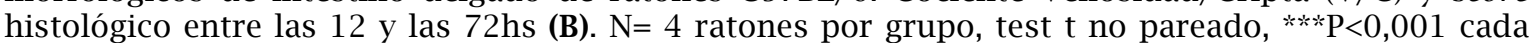
uno de los poly (I:C)s vs PBS. $\cdots \bullet p<0,001$ PICS vs PBS, \#p<0,05 y \#\#p<0,01 PICL vs PBS, $\star \mathrm{p}<0,05$ PICH vs PBS. No hay diferencias significativas entre los distintos Poly (I:C)s.

Para evaluar el efecto de la administración de poly (I:C)s de diferentes tamaños, se determinó el cociente V/C y el score histológico. Como se muestra en la Figura 1.15B, tanto el cociente V/C como los parámetros histológicos encontrados fueron similares para los poly (I:C)s analizados. No encontramos evidencia de que las vías de RIG-I o MDA5 puedan activarse selectivamente y generar mecanismos de alteración histológica diferentes en su cinética o en la gravedad del daño observado. Las diferencias descriptas en la bibliografía fueron obtenidas analizando sistemas in vitro. Pensamos que en nuestro sistema experimental in vivo estas vías pueden involucrar componentes solapados o generar procesos de activación y control más complejos que no permiten observar una respuesta diferencial en el tejido.

Los receptores MDA5, RIG-I y TLR3 son inducidos por poly (I:C) intraluminal.

Con el fin de comprender los mecanismos desencadenados por la activación de la respuesta innata inducidos por poly (I:C), estudiamos los cambios de 

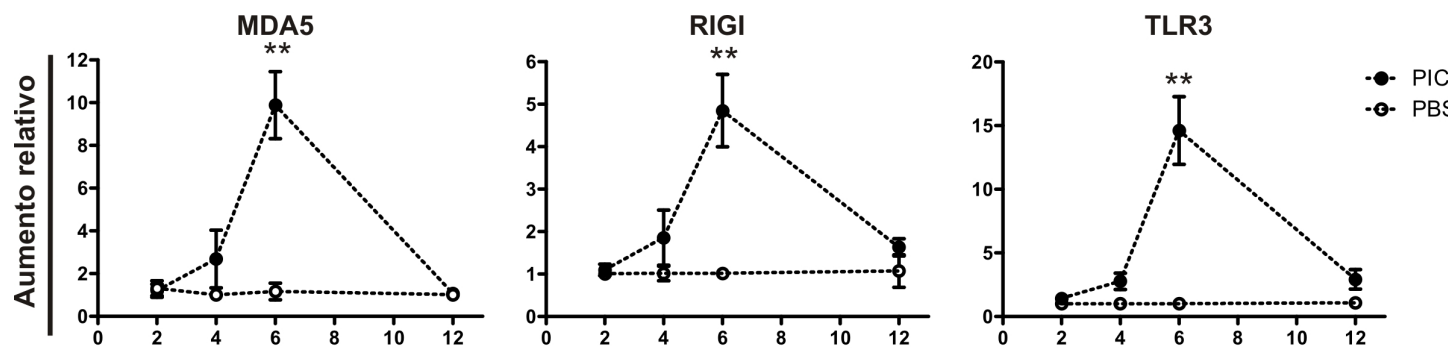

Tiempo (hs)

Figura 1.16. Poly (I:C) induce la expresión de sus receptores en intestino delgado de ratones $\mathrm{C} 57 \mathrm{BL} / 6$.

Análisis por PCR en tiempo real de ARNm de TLR3, MDA5 y RIG-I entre las 2 y las $12 \mathrm{hs}$ posttratamiento con PIC (puntos negros) o PBS (puntos blancos). Todos los valores fueron normalizados con el gen constitutivo HRPT. Todos los resultados fueron expresados como aumento relativo del tratamiento con PBS o PIC versus la media de los valores de los animales tratados con PBS en cada punto de tiempo $\left(2^{-\Delta \Delta c t}\right)$. $\mathrm{N}=4$ ratones por grupo, Test $\mathrm{t}$ No pareado, ${ }^{* *} \mathrm{P}<0.01$, ratón tratado con PIC versus el control de PBS en cada punto de tiempo.

expresión de sus receptores así como de mediadores proinflamatorios. Se ha descripto en otros sistemas experimentales, que la expresión de TLR3, MDA5 y RIGI es modulada por poly (I:C) (Kato et al. 2008). Para esto realizamos la evaluación de los niveles de ARNm de TLR3, RIG-I y MDA5 en intestino delgado mediante PCR cuantitativa a distintos tiempos post administración intraluminal de poly (I:C). El estudio cinético mostró que los niveles de ARNm de MDA5, RIGI y TLR3 fueron incrementados por poly (I:C) en comparación con lo observado en ratones control. La expresión de estos tres receptores tuvo su pico a las 6hs posteriores al tratamiento (Figura 1.16). Esta observación es relevante ya que mostramos que la presencia de poly (I:C) en el lumen induce un aumento significativo del nivel de sus receptores en la pieza de tejido entero.

A partir del incremento observado en los niveles de ARNm de los receptores de poly (I:C), decidimos realizar estudios por microscopía confocal de fluorescencia, con el fin de identificar la localización de estos receptores y si los cambios de expresión podían evidenciarse a nivel de proteína. Como puede observarse en la Figura 1.17, la mucosa intestinal de animales tratados con poly (I:C), tanto de alto como de bajo peso molecular, mostró un incremento marcado en el número de células RIG-I', las cuales se observaron en la lamina propria en el caso de los ratones tratados con PICL y en lamina propria y epitelio en ratones tratados con PICH. En cambio, cuando analizamos la expresión del receptor intracelular MDA5 encontramos un patrón distinto al observado con RIGI. Los ratones tratados con PICL presentan algunas células $\mathrm{MDA}^{+}$en lamina propria mientras que no se observa expresión en los tratados con PICH. De esta manera, 

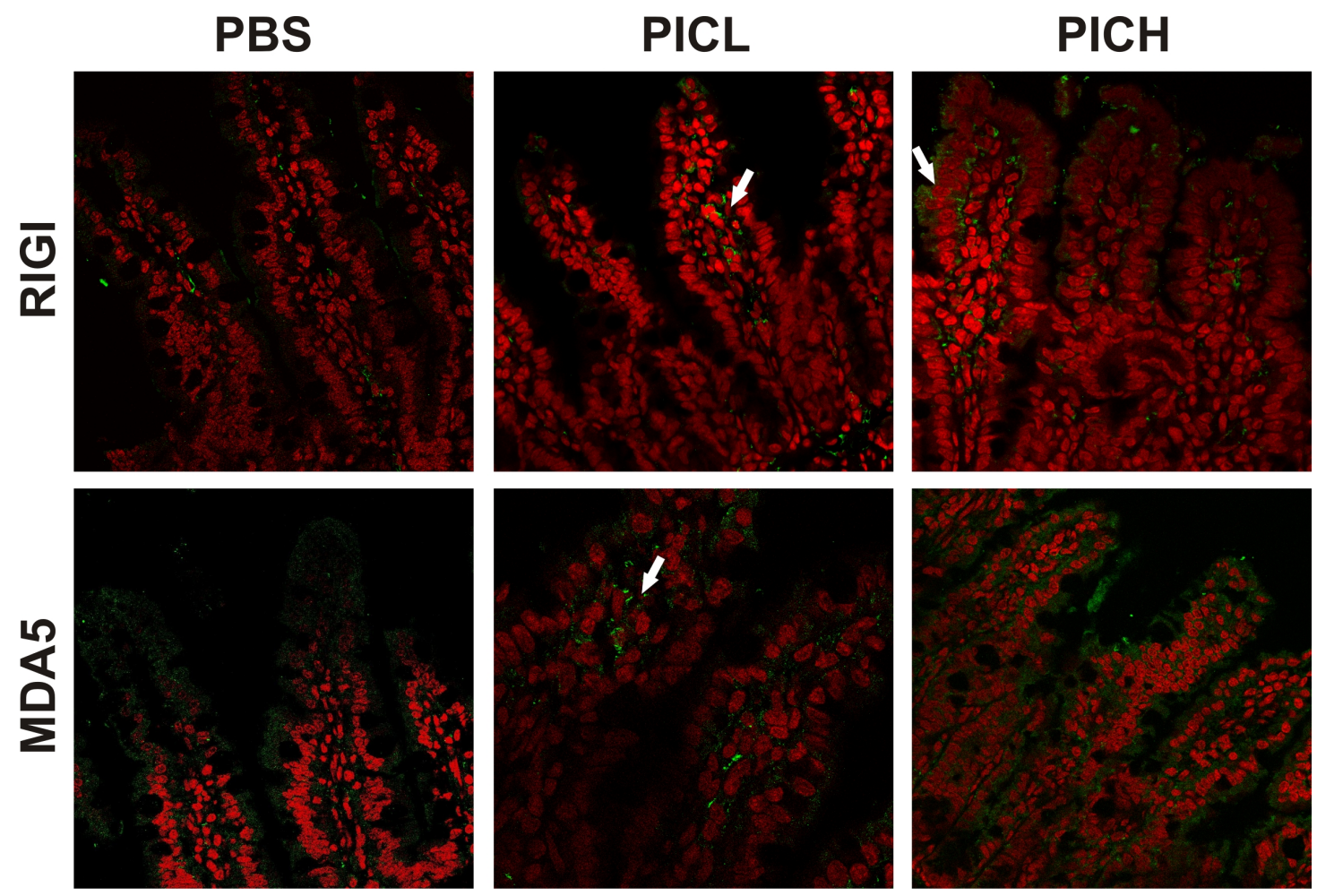

Figura 1.17. Poly (I:C) de alto y bajo peso molecular inducen la expresión de RIGI y MDA5 en la mucosa intestinal.

Imágenes de microscopía obtenidas a partir de cortes de intestino delgado de ratones estimulados intraluminalmente por $12 \mathrm{hs}$ con PBS, poly (I:C) de bajo peso molecular (PICL) y poly (I:C) de alto peso molecular (PICH). Las imágenes fueron obtenidas con un microscopio confocal Leica y procesadas con el programa Image J.

demostramos que la expresión de RIGI y MDA5 es consecuencia de la activación completa de la vía inducida por poly (I:C) aunque los patrones de expresión en un caso y otro difieren dependiendo el peso molecular del poly (I:C) empleado.

Estos resultados sugieren que las vías inducidas en cada caso no son redundantes y que cada una podría tener consecuencias funcionales diferentes. Dado que los estudios de expresión de ARNm de estos receptores intracitoplasmáticos fueron realizados con poly (I:C) Sigma y que éste posee un peso molecular similar al poly (I:C) de bajo peso molecular, podemos sugerir que la utilización de poly (I:C) Sigma inducirá a nivel proteína tanto RIGI como MDA5 de manera similar a lo observado con poly (I:C) de bajo peso molecular.

El tratamiento con poly $(\mathrm{I}: \mathrm{C})$ intraluminal induce mediadores proinflamatorios en intestino delgado.

En busca de investigar las vías de señalización implicadas en la estimulación con poly (I:C) intraluminal evaluamos la producción de diversas citoquinas, quimoquinas y moléculas relacionadas con distintos aspectos de un proceso inflamatorio. 


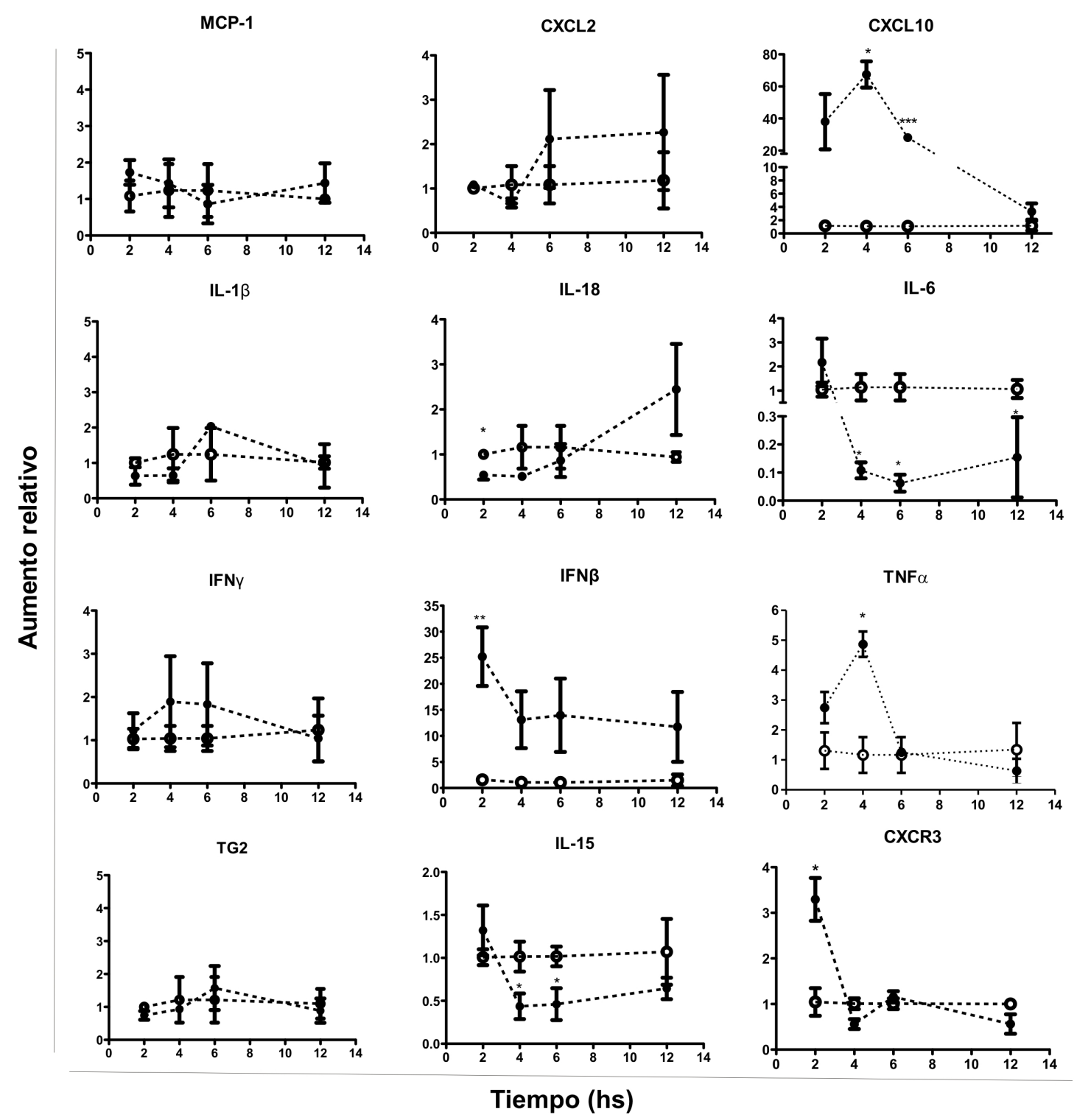

Figura 1.18. Poly (I:C) genera una respuesta proinflamatoria en ratones C57BL/6.

Análisis con PCR en tiempo real de ARNm de MCP1, CXCL2, CXCL10, IL-1 $\beta$, IL-18, IL-6, IFN $\gamma$, IFN $\beta$, TNF $\alpha$, TG2, IL-15, CXCR3 entre las 2 y 12hs post-tratamiento con PIC (Puntos negros) o PBS (Puntos blancos). Todos los valores fueron normalizados con el gen constitutivo HRPT. Todos los resultados fueron expresados como aumento relativo del tratamiento con PBS o PIC versus la media de los valores en los animales tratados con PBS en cada punto de tiempo $\left(2^{-\Delta \Delta \mathrm{Ct}}\right) . \mathrm{N}=4$ ratones por grupo, Test t No pareado, ${ }^{*} \mathrm{P}<0.05,{ }^{* *} \mathrm{P}<0.01,{ }^{*} * * \mathrm{P}<0.001$ ratón tratado con PIC versus el control de $\mathrm{PBS}$ en cada punto de tiempo.

En primer lugar, evaluamos la expresión de las moléculas MCP-1 (quimioatractante de monocitos), CXCL2 (quimioatractante de neutrófilos) y CXCL10 (quimioatractante de células CXCR3+). Tanto los niveles de MCP-1 como los de CXCL2 no se modificaron entre las 2 y las 12 hs post-estimulación. En cambio, CXCL10 presentó un fuerte y significativo incremento a las 4hs que se mantuvo aún a las 6hs post-poly (I:C) (Figura 1.18). El incremento de CXCL10 era esperado dado que en otros sistemas ha sido descripto que poly (I:C) es un fuerte inductor de su expresión. 
Por otro lado, se evaluó la expresión de IL-1 $\beta$ e IL-18, reconocidas citoquinas inflamatorias. No se observó incremento de IL-1 $\beta$ en ningún punto de tiempo. Por el contrario, se presentó una disminución significativa de IL-18 a las $2 \mathrm{hs}$ en ratones tratados con poly (I:C) respecto a los animales del grupo control. Dicha disminución revirtió a las 4hs post-estímulo y luego parece haber una tendencia al aumento a las $12 \mathrm{hs}$, la cual no es estadísticamente significativa. A su vez, IL-6, citoquina relacionada con un efecto sinérgico e inflamatorio cuando se asocia a IL-1 $\beta$, presentó también una disminución significativa a partir de las 4 hs que se mantiene hasta las $12 \mathrm{hs}$ post-poly (I:C) (Figura 1.18). Si bien parece no existir una activación de estos mediadores inflamatorios, otros estudios deberán realizarse para evaluar la expresión proteica de dichos mediadores y así determinar su participación o no en este proceso inflamatorio mediado por poly (I:C). Esto es de relevancia si se considera que tanto IL-1 $\beta$ como IL-18 son generados como procitoquinas que son activadas por modificaciones post-traduccionales, por lo que su activación puede no estar directamente relacionada a un cambio en los niveles de expresión del ARNm.

El estímulo por poly (I:C) produjo además un incremento de la expresión de IFN $\beta$ y TNF $\alpha$, mostrando y confirmando el perfil proinflamatorio inducido con dicha molécula (Figura 1.18). No se observaron incrementos significativos de IFN $\gamma$ en los tiempos estudiados.

Por último, evaluamos la expresión de transglutaminasa 2 (TG2), IL-15 y CXCR3, moléculas relacionadas con la patogenia de enfermedad celíaca. Encontramos un fuerte y temprano incremento de CXCR3 en los ratones tratados con poly (I:C) que correlaciona con el incremento de la expresión de CXCL10 en el mismo tejido (Figura 1.18). Sin embargo, sorpresivamente, ni TG2 ni IL-15 presentaron incrementos en su expresión a causa de este estímulo. Más aún, IL-15 se ve disminuido significativamente a partir de las 4 hs de estimulación (Figura 1.18). De igual modo a lo observado con IL-1 $\beta$ e IL-18, deberíamos evaluar los niveles de proteína de IL-15 para concluir acerca de su participación o no en la enteropatía generada por poly (I:C). Sin embargo, deben considerarse que las determinaciones de IL-15 a nivel de proteína son técnicamente complejas, y la interpretación de los resultados es frecuentemente motivo de controversias.

\section{Poly (I:C) y los mecanismos de daño}

En busca de comprender los mecanismos subyacentes por los cuales se produce daño en la mucosa intestinal por poly (I:C), decidimos evaluar la presencia de 
muerte celular mediante el recuento de células TUNEL positivas. Observando secciones de intestino delgado con esta tinción encontramos pocas diferencias entre los ratones tratados con PBS y los ratones tratados con poly (I:C) (Figura 1.19A).

Sorprendentemente, si bien se observa un claro daño de la mucosa intestinal, no existen diferencias significativas en el número de células TUNEL $^{+}$ respecto del total de células de la mucosa cuando se compara los ratones tratados con poly (I:C) y los animales del grupo control (Figura 1.19B).

A

PBS

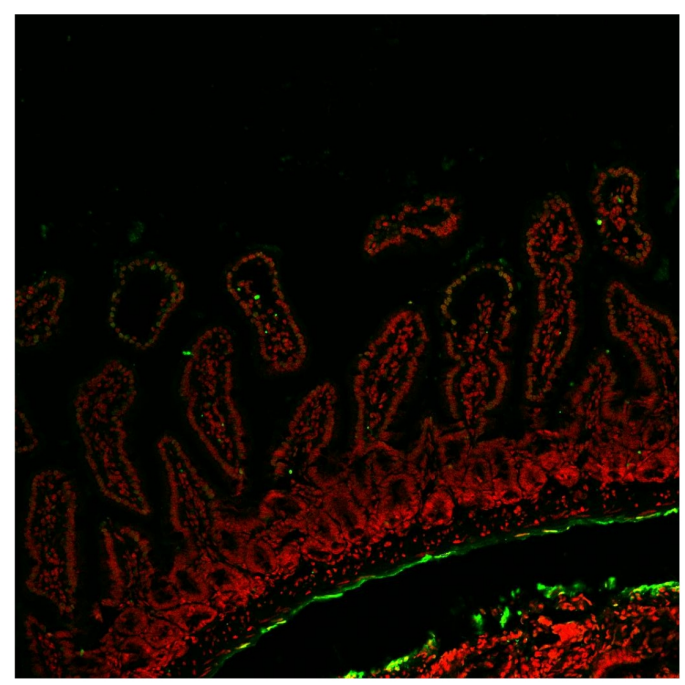

$\mathrm{PIC}$

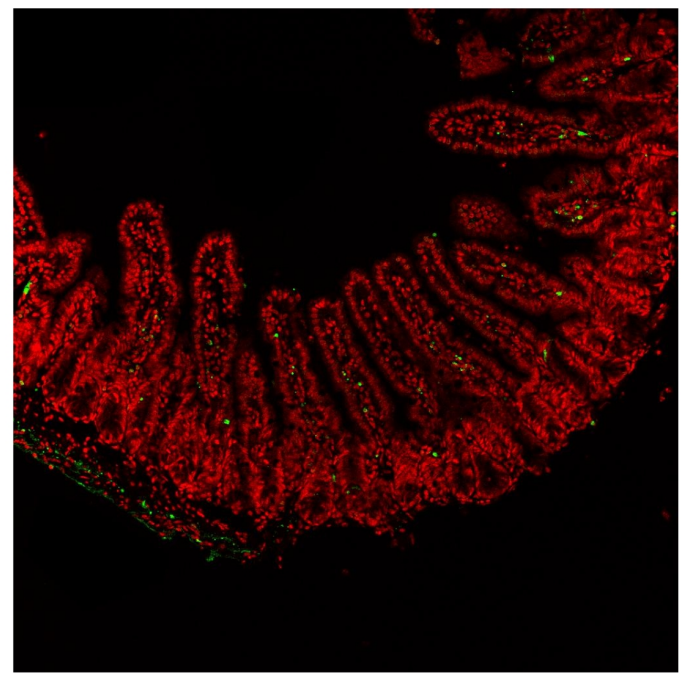

B

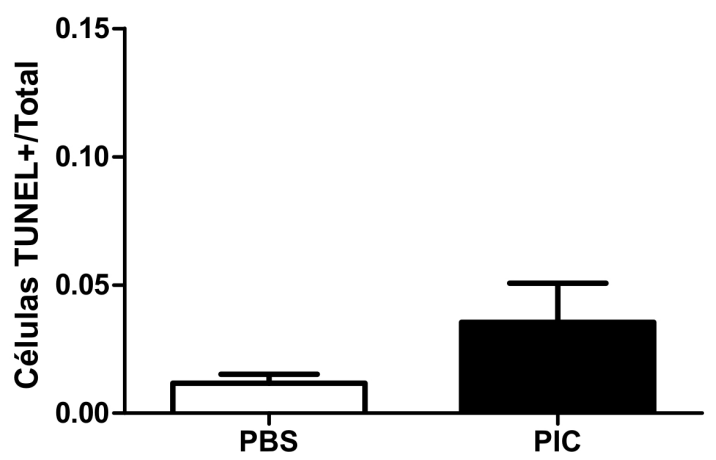

C

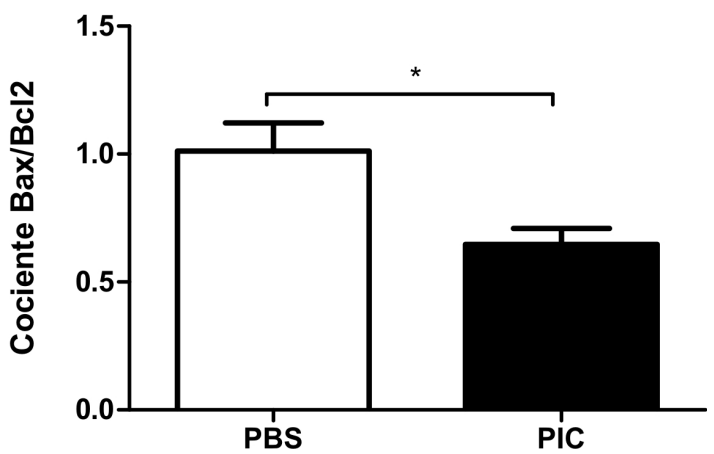

Figura 1.19. Análisis de muerte celular y apoptosis en intestino delgado de ratones C57BL/6 tratados con poly (I:C).

Secciones de intestino delgado incluidas en parafina fueron teñidas con un kit de TUNEL (Promega) luego de haber sido estimuladas durante $12 \mathrm{hs}$. Los núcleos fueron contrateñidos con ioduro de propidio (rojo) y las células $\mathrm{TUNEL}^{+}$se observan teñidas con fluoresceína (verde). Las imágenes fueron tomadas en un microscopio confocal TCS SP5 de Leica (A). De las imágenes tomadas se realizó una cuantificación automatizada mediante el programa Image J (B). La expresión de ARNm de Bcl2 y Bax fue determinada en muestras de intestino delgado luego de 2 hs mediante PCR en Tiempo Real y se calculó el cociente Bax/Bcl2. N=4, test t no pareado, * $\mathrm{p}<0,05$ (C) 
Siendo posible que por el tiempo de ensayo utilizado para la evaluación de TUNEL no hayamos observado evidencias del proceso de muerte, analizamos si la inducción de apoptosis podía estar involucrada en los mecanismos de daño. Con este fin determinamos los niveles de ARNm de Bax y Bcl2 por PCR cuantitativa a distintos tiempos de inducción con poly (I:C). Los valores en la relación Bax/Bcl2 muestran un cociente anti-apoptótico a las $2 \mathrm{hs}$ post-estimulación con poly (I:C) comparado con el que se observa en las muestras estimuladas con PBS (Figura 1.19C). Luego de este tiempo y hasta las $12 \mathrm{hs}$ los cocientes de ambos grupos son similares entre sí (No se muestra).

No hemos encontrado evidencias de que el proceso de apoptosis explique la muerte celular en el curso del daño en la mucosa. En adelante, otros mecanismos de muerte deberán ser estudiados para comprender el fenómeno de daño inducido con poly (I:C) intraluminal en el intestino delgado de ratones C57BL/6.

\section{Mediadores celulares de daño implicados en la enteropatía inducida por poly (I:C)}

En esta sección nuestro objetivo fue evaluar el rol de ciertos tipos celulares en la generación de daño en la mucosa de ratones tratados con poly (I:C) intraluminalmente. Con este fin llevamos a cabo tres diferentes estrategias experimentales de pre-tratamiento de los animales en busca de provocar la inhibición o el incremento de diferentes poblaciones celulares en el intestino. De este modo, centramos nuestra atención en tres poblaciones celulares: neutrófilos, monocitos/macrófagos y células dendríticas.

La primera de las estrategias se basó en la inhibición sistémica previa a la cirugía de la población de neutrófilos, por medio de la inyección intraperitoneal de anticuerpos anti-GR1 24hs antes del procedimiento quirúrgico. De este modo, depletamos principalmente la población de neutrófilos, lo cual nos permite evaluar si estas células son relevantes en la generación de enteropatía con poly (I:C). Como se puede observar en la Figura 1.20, el tratamiento con el anticuerpo anti-GR1 produjo un efecto nocivo sobre los animales ya que se observó una reducción significativa del cociente $\mathrm{V} / \mathrm{C}$ en los ratones sometidos al pretratamiento con anti-GR1 que recibieron PBS intraluminal. A pesar del daño producido por el tratamiento, se puede observar que la administración de poly (I:C) provocó daño en los animales pre-tratados con el anticuerpo anti-GR1 (Figura 1.20). Estos resultados sugieren que los neutrófilos no participarían en el mecanismo de daño inducido por poly (I:C) al menos en esta etapa. 


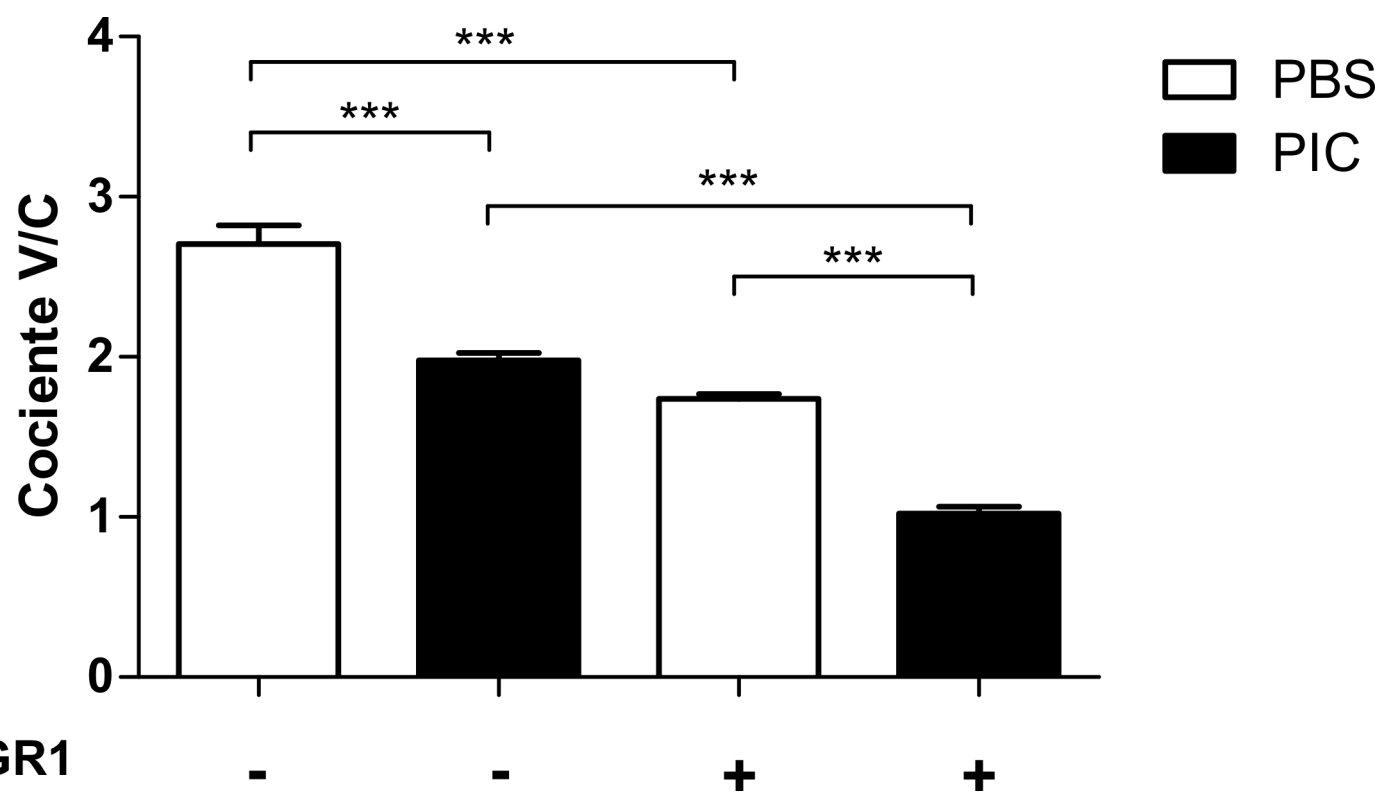

Figura 1.20. El pretratamiento con anticuerpo anti-GR1 no evita el daño producido por poly (I:C).

Ratones C57BL/6 fueron pre-tratados con un anticuerpo anti-GR1 inyectado intraperitonealmente y luego de $24 \mathrm{hs}$ los animales fueron sometidos a la inyección intraluminal con poly (I:C) y con PBS como control. Secciones de intestino obtenidas de cada grupo fueron teñidas con hematoxilina y eosina y se obtuvieron los cocientes vellosidad-cripta. $\mathrm{N}=2$ ratones, test t no pareado, ${ }^{* * *} \mathrm{p}<0,001$.

La segunda estrategia se basó en el bloqueo del reclutamiento de la población de monocitos/macrófagos. Para ello utilizamos un inhibidor de la síntesis de MCP1 denominado Bindarit (Angelini Farmaceutici, ACRAF S.p.A.). El Bindarit (ácido 2-metil-2-[[1-(fenilmetil)-1H-indazol-3-il]metoxi]propanoico) es un fármaco que ha sido cuidadosamente estudiado debido a su posible utilización en la terapia antiviral (Rulli et al. 2009) y descripto como un inhibidor de la síntesis de los MCPs (Sironi et al. 1999; Mirolo et al. 2008). El Bindarit ha sido probado también en el tratamiento de las consecuencias renales en patologías autoinmunes como Diabetes Mellitus tipo II, Lupus Eritematoso Sistémico y Artritis Reumatoidea tanto en modelos animales como en ensayos clínicos (Perico, Benigni, and Remuzzi 2008).

En nuestra estrategia experimental, inyectamos ratones C57BL/6 con Bindarit intraperitoneal (100mg/kg de peso del ratón) 12 y 24 hs antes de realizar la cirugía para la inyección de los estímulos. Luego de 12hs post-estimulación con poly (I:C) y con PBS, los ratones fueron sacrificados y se tomaron muestras de intestino delgado para su evaluación.

Como se puede observar en la Figura 1.21, el tratamiento con Bindarit no tiene ningún efecto adverso sobre los ratones controles y los cocientes $\mathrm{V} / \mathrm{C}$ de los ratones tratados o no con Bindarit son estadísticamente comparables. Por el contrario, el tratamiento con Bindarit de los ratones que luego fueron 


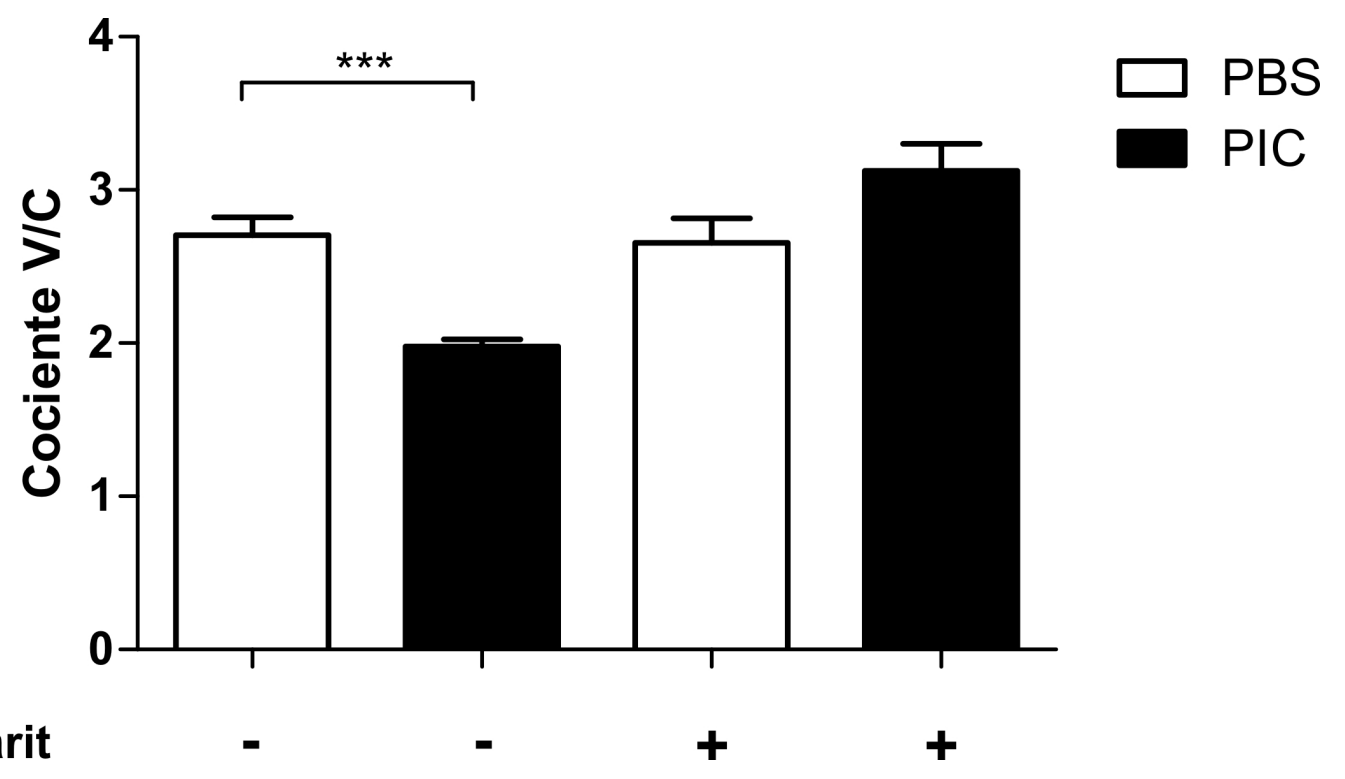

Figura 1.21. El pretratamiento con el inhibidor de la síntesis de MCP1 (Bindarit) evita el daño producido por poly (I:C).

Ratones C57BL/6 fueron pre-tratados con Bindarit y luego sometidos a la inyección intraluminal con poly (I:C) y con PBS como control. Secciones de intestino delgado obtenidas de cada grupo 12hs post-tratamiento fueron teñidas con hematoxilina y eosina y se obtuvieron los cocientes vellosidadcripta. Test t no pareado, ${ }^{* * *} \mathrm{p}<0,001$.

estimulados con poly (I:C) mostró valores comparables en el cociente $\mathrm{V} / \mathrm{C}$ a los observados en los animales del grupo control tratados con PBS. De esta manera, la administración de Bindarit evitó el desarrollo del daño inducido por poly (I:C). Estos resultados sugieren que la población de monocitos que arriban a la mucosa intestinal serían una parte clave en la generación de daño por poly (I:C). En adelante, sería de interés analizar de qué modo esa población celular está implicada en el daño y qué mediadores moleculares son puestos en juego.

Por último, la tercer estrategia abordada consistió en incrementar el número de las poblaciones celulares de células dendríticas convencionales y plasmacitoideas que arriban a la mucosa intestinal con el fin de evaluar su participación en el daño producido con poly (I:C). Para ello se utilizó una línea celular tumoral de melanoma productora de la citoquina Flt3L, denominada B16Flt3L. Estas células se inyectan subcutáneamente en ratones C57BL/6 y producen un tumor que secreta Flt3L. Esta citoquina se caracteriza por expandir las poblaciones de células dendríticas convencionales y plasmacitoideas, y en particular produce un sustancial aumento de la población de células dendríticas intestinales (Chirdo et al. 2005). De este modo, con un protocolo previamente validado, se indujo el tumor de células B16-Flt3L en ratones C57BL/6 y una vez establecido el tumor se sometió al estímulo con poly (I:C) o PBS intraluminal mediante la microcirugía previamente descripta. 


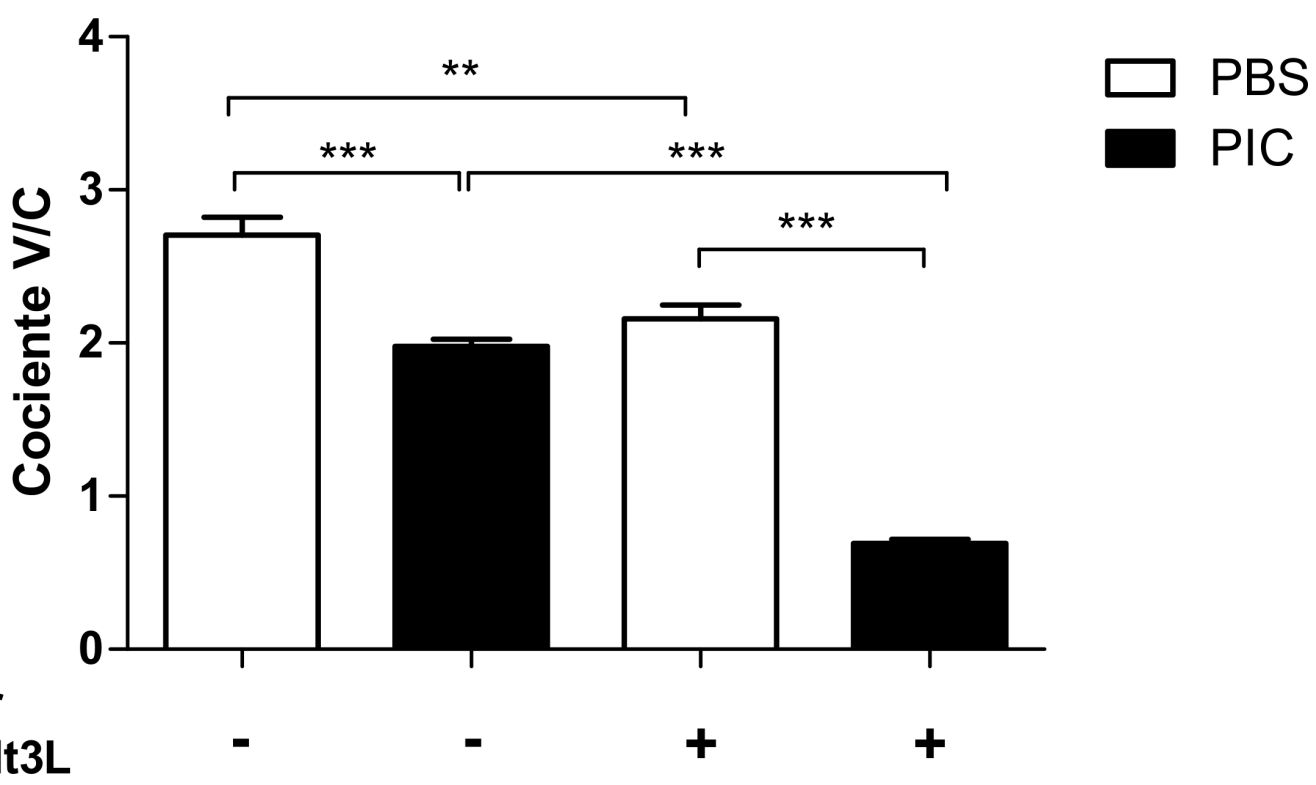

Figura 1.22. El incremento en las poblaciones de células dendríticas agrava el daño producido por poly (I:C).

Ratones C57BL/6 fueron pre-tratados con la línea tumoral B16-Flt3L y luego sometidos a la inyección intraluminal con poly (I:C) o con PBS como control. Secciones de intestino delgado obtenidas de cada grupo fueron teñidas con hematoxilina y eosina y se obtuvieron los cocientes vellosidad-cripta. $\mathrm{N}=2$, test t no pareado, ${ }^{* *} \mathrm{p}<0,01,{ }^{* * *} \mathrm{p}<0,001$.

En primer lugar pudimos observar que la presencia de células tumorales tiene un efecto dañino per se en la mucosa intestinal, presentándose un descenso del cociente $\mathrm{V} / \mathrm{C}$ en aquellos animales que fueron inoculados con las células tumorales y luego tratados con PBS. Sin embargo y pese al daño preestablecido por la estrategia, observamos que los ratones con tumor y tratados con poly (I:C) presentan valores de cociente $\mathrm{V} / \mathrm{C}$ sorprendentemente reducidos a valores nunca antes observados con otros tratamientos (Figura 1.22).

Aunque no fue evaluado en este estudio, como ya hemos mencionado es conocido que la administración de Flt3L induce un aumento masivo en el número de células dendríticas particularmente en la mucosa intestinal. A partir de estos resultados, podemos concluir que el incremento de las poblaciones de células dendríticas afectan y agravan la generación de enteropatía inducida por poly (I:C) intraluminal. Deberán llevarse a cabo más estudios para determinar qué población particular de células dendríticas está implicada y qué mecanismos están puestos en juego. 


\section{DISCUSIÓN}

A diferencia de los estudios previos en los que se inducía enteropatía mediante la administración intraperitoneal de poly (I:C) (Garside et al. 1991; R. Zhou, Wei, Sun, Zhang, et al. 2007; R. Zhou, Wei, Sun, and Tian 2007; McAllister et al. 2013), en este trabajo demostramos que es posible inducir una inflamación intestinal mediante la administración intraluminal de poly (I:C) en ratones C57BL/6. De esta manera, al menos en las etapas más tempranas evaluamos efectos generados localmente. También introdujimos un cambio metodológico que fue significativo. Los protocolos convencionales de administración intraluminal consistían en la técnica denominada asa ligada, la cual fue desarrollada por primera vez como un ensayo in vivo para enterotoxinas (Schiff et al. 1974). Es una técnica muy antigua que se ha practicado en diversas especies animales, como conejos o conejillos de indias y puede ser adaptada a ratón. Se utiliza anestesia gaseosa o inyectable y se realiza una incisión en la línea ventral media abdominal exponiendo las vísceras. Se localiza el segmento de interés y usando sutura se realizan dos ligaduras de una sección pequeña. Se asegura no ocluir los vasos sanguíneos mesentéricos con las ligaduras, para permitir que la mucosa intestinal siga viable. La sustancia a testear se inyecta en el interior del loop formado (Fox et al. 2007). Sin embargo, esta técnica de microcirugía introduce un daño tisular muy severo. En nuestro caso, la administración intraluminal sin ligaduras redujo sustancialmente los procesos inflamatorios y de daño generados a causa del procedimiento.

El compuesto sintético poly (I:C) ha sido muy empleado para modelar la señalización inducida por una infección viral, como ligando de receptores de la inmunidad innata. Durante las infecciones virales entéricas, los intermediarios de la replicación tales como los ARNdh son producidos por las células infectadas (Weber et al. 2006) y disparan una rápida cascada inflamatoria, la cual involucra la activación de TLR3 y las helicasas de ARN RIG-I y MDA5 (Broquet et al. 2011; Yu and Levine 2011; Yoneyama and Fujita 2007; Yoneyama et al. 2015). Poly (I:C) es un análogo sintético comúnmente utilizado para imitar los efectos de los ARNdh, los cuales causan patología intestinal cuando son administrados por una vía parenteral (Garside et al. 1991; R. Zhou, Wei, Sun, Zhang, et al. 2007; R. Zhou, Wei, Sun, and Tian 2007). El marcado acortamiento de las vellosidades y el incremento en la apoptosis de enterocitos observados luego de su inyección 
intraperitoneal ha sido sugerido como una consecuencia de la activación de la vía TLR3/TRIF/Caspasa 8 (McAllister et al. 2013).

Como mencionamos, con el fin de evitar los efectos sistémicos de la administración intraperitoneal, usamos en cambio la administración intraluminal de poly (I:C). Demostramos que poly (I:C) es capaz de producir una enteropatía severa caracterizada por un cociente $\mathrm{V} / \mathrm{C}$ reducido, incremento en el número de LIEs e incremento en el score histológico global. Encontramos una alteración en el estado proliferativo de las criptas en ratones tratados con poly (I:C) después de 24 hs post-estímulo que se normaliza luego de las $72 \mathrm{hs}$. El descenso del cociente V/C se debió principalmente a un acortamiento de la longitud de las vellosidades sin cambios en la profundidad de las criptas. Estos resultados contrastan con los obtenidos por Garside et al., dado que ellos observaron que poly (I:C) intraperitoneal era capaz de producir tanto un acortamiento de las vellosidades como una hiperplasia de criptas, con valores de CCPR significativamente aumentados luego de $72 \mathrm{hs}$ de estímulo (Garside et al. 1991). Esto demuestra que la administración intraluminal de poly (I:C) en el intestino tiene mecanismos de acción distintos, con una cinética de daño diferente a lo observado con una inyección intraperitoneal.

La inducción de los receptores de ARNdh TLR3, MDA5 y RIG-I fue transitoria, teniendo su pico a las 6hs de inducción y retornando a los niveles basales a las 12hs. En modelos desarrollados previamente usando la administración de poly (I:C) sistémico, el daño de la mucosa pareció ser específico de la activación de TLR3 únicamente (R. Zhou, Wei, Sun, and Tian 2007; R. Zhou, Wei, Sun, Zhang, et al. 2007; McAllister et al. 2013). Si bien no pudimos determinar por qué vías de señalización se está generando daño en nuestro modelo, sabemos que además hay un incremento en la inducción de la expresión proteica de RIG-I y MDA5. Por lo tanto, nuestra hipótesis es que estas vías podrían estar implicadas también en el mecanismo de daño. El análisis de expresión por microscopía de fluorescencia mostró una inducción diferente para cada uno de estos receptores en la mucosa intestinal, lo que sugiere que las vías de señalización y el rol funcional de RIG-I y MDA5 en distintos tipos de células en la mucosa puede ser diferente.

Por otra parte, y a diferencia de lo observado en otros sistemas, el daño observado en nuestro modelo no depende de la longitud del poly (I:C) utilizado. En el trabajo de Kato, et al. se demuestra que la señalización de ARNdh de distintos pesos moleculares es diferente en líneas de fibroblastos y células 
dendríticas dependiendo de la longitud del ARNdh sintético utilizado (Kato et al. 2008). En otro trabajo se demuestra que el estímulo de células $\beta$ del páncreas por ARNdh produce una inducción de ARNm de MDA5 y RIG-I que es independiente de la señalización por TLR3 (García et al. 2009). Por lo tanto, nuestro modelo de enteropatía requiere de estudios de señalización específicos para determinar el rol de los RLRs y TLR3 en la inducción de daño.

Usando poly (I:C) intraluminal encontramos un fuerte y temprano incremento de los niveles de ARNm de IFN $\beta$ en el intestino delgado de ratones C57BL/6 luego de 2hs posteriores al tratamiento, indicando una activación específica de la señalización por poly (I:C). TNF $\alpha$, una citoquina comúnmente involucrada en los estadíos tempranos de la respuesta inflamatoria, también estuvo transitoriamente elevada. Llamativamente, un enorme incremento de 60 unidades de inducción de los niveles de ARNm de CXCL10 se observó luego de 4hs después de la inyección de poly (I:C) intraluminal. CXCL10 ha sido demostrado que puede inducirse fuertemente por poly (I:C) en diferentes estrategias experimentales, y puede jugar un rol crucial en el desarrollo de patología en el intestino delgado dado que es uno de los mayores quimioatractantes de las células Th1 $\mathrm{CXCR}^{+}$en los tejidos inflamados (Groom and Luster 2011; Østvik et al. 2013); en especial, es de destacar que este hecho fue observado en intestino proximal en el curso de enfermedad celíaca activa, como ha sido demostrado en estudios de nuestro grupo (Bondar et al. 2014).

Se analizó también la expresión de ARNm de citoquinas proinflamatorias tales como IL-15, IL-18, IL-1 $\beta$ e IFN $\gamma$ y quimioquinas tales como MCP1 y CXCL2 pero no se observaron cambios. Esto fue consistente con el estudio de McAllister C. et al. usando el modelo de poly (I:C) intraperitoneal (McAllister et al. 2013).

Por otra parte, el estudio de moléculas anti- y pro-apoptóticas tales como Bcl-2 y Bax, respectivamente, arrojó un cociente anti-apoptótico a tan sólo $2 \mathrm{hs}$ post-tratamiento con poly (I:C). Sin embargo, tiempos posteriores mostraron una normalización de este cociente a valores comparables a los controles de PBS. Esta observación se corresponde con los valores hallados en el recuento de células TUNEL $^{+}$en estos mismos animales a las $12 \mathrm{hs}$, donde no se observaron diferencias entre los ratones tratados con poly (I:C) y los controles.

Nuestra hipótesis es que a lo largo del proceso de daño se desarrollan distintos mecanismos de muerte que serían responsables del proceso total de daño observado. Dado el cociente anti-apoptótico tan tempranamente observado en los ratones tratados con poly (I:C) suponemos que al menos en los primeros 
momentos post-inducción otros mecanismos participan en la generación del daño. Por ejemplo, en un trabajo realizado en el año 2014, se describe a Caspasa8 con un rol fundamental en la inducción de recambio celular y apoptosis en intestino delgado luego del tratamiento con ligandos de TLR. Este estudio mostró que cuando se deleta transitoriamente caspasa 8 , se observa un cambio en el patrón de muerte desde apoptosis a necroptosis dependiente de RIP3, causando la destrucción masiva de las vellosidades de un modo muy severo (Günther et al. 2014). Esto demuestra que distintas vías de muerte podrían correr en paralelo y también en distintas etapas del proceso de daño. Sin embargo, lo observado en dicho trabajo no se corresponde con lo observado en la enteropatía crónica de EC. La velocidad, tipo y severidad del daño es diferente a la histología observada en los distintos tipos de alteración de la mucosa duodenal encontrada en pacientes con EC. En este sentido, pensamos que un estímulo de la inmunidad innata puede predisponer a la mucosa del intestino delgado a la generación de daño, sin embargo probablemente no sea suficiente para la generación de una enteropatía crónica. Por lo tanto, es preciso describir completamente los posibles mecanismos de daño de nuestro modelo de enteropatía por inyección intraluminal de poly (I:C) para entender cómo sería posible desarrollar un proceso crónico posterior.

Debido a que poly (I:C) dispara una cascada de reacciones inflamatorias involucrando distintas vías de señalización, algunos de los efectos posteriores a la administración de poly (I:C) podrían también tener un origen diverso.

Algunos estudios han sugerido que ciertos péptidos de gliadinas interactúan con un receptor luminal. Experimentos in vitro mostraron una colocalización de gliadinas con el receptor de quimioquinas CXCR3 (Karen M Lammers et al. 2011; K M Lammers et al. 2008). Nuestros resultados sugieren que poly (I:C) intraluminal induce una rápida activación inmune de la mucosa involucrando a IFN $\beta$ y al eje CXCL10/CXCR3 que podría conducir a inflamación potenciando el perfil Th1 y propiciar una mayor interacción entre CXCR3 y ciertos péptidos de gliadinas.

Los mecanismos subyacentes propuestos para el daño intestinal incluyen a las células NK (Garside et al. 1991) y los LIEs CD8 $\alpha \alpha^{+}$con una participación crítica de IL-15 (R. Zhou, Wei, Sun, and Tian 2007; R. Zhou, Wei, Sun, Zhang, et al. 2007). Sin embargo, un estudio reciente en contraposición a ese modelo sostiene que las células NK, LIEs o IL-15 no están involucrados en la inducción de patología intestinal (McAllister et al. 2013). En este sentido, los resultados obtenidos en 
nuestro estudio indican que las células dendríticas y los macrófagos tienen un rol relevante en el desarrollo del daño. Observación que no se había hecho hasta el presente y que genera nuevos objetivos de estudio destinados a determinar de qué modo estas células están implicadas y cuáles serían los mediadores de daño. 


\section{CONCLUSIÓN}

Entender las consecuencias tempranas y tardías de la activación inmune por infecciones entéricas virales, o ARNdh, tiene implicancias importantes en el conocimiento sobre las consecuencias funcionales y la inflamación post-infección (Verdu, EF 2012). En nuestro caso, el desarrollo de este primer modelo de inducción de enteropatía en la mucosa del intestino delgado es un punto de partida interesante para plantear modelos similares con otros inductores, como así también evaluar la capacidad del modelo para representar un estadío inicial inflamatorio como el que podría estar gestándose en enfermedades que afectan al intestino delgado crónicamente como, por ejemplo, en la EC. Este primer modelo es un puntapié inicial para investigar los mecanismos puestos en juego tempranamente en el desarrollo de enteropatía desde el punto de vista inflamatorio, como así también los mecanismos de muerte y estrés disparados por este inductor. 


\section{CAPÍTULO 2: El péptido de gliadinas p31-43}

induce enteropatía mediante mecanismos de la respuesta innata.

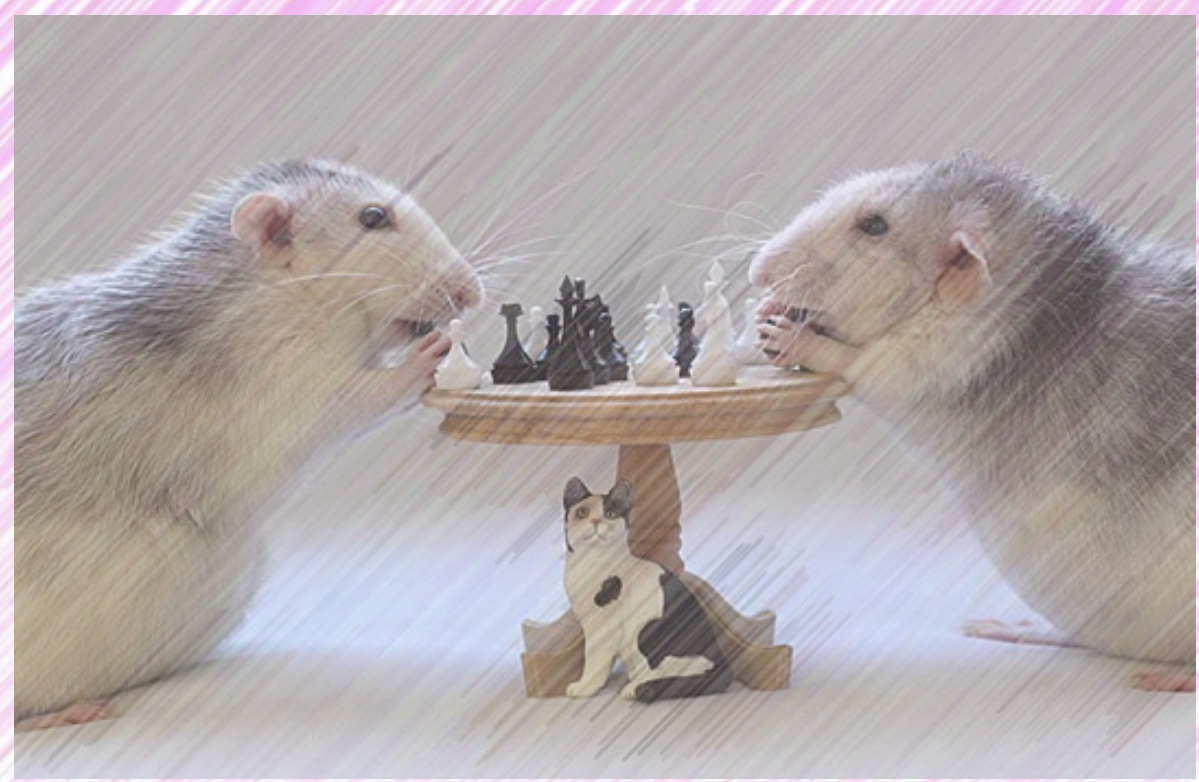





\section{CAPÍTULO 2. El péptido de gliadinas p31-43 induce enteropatía mediante mecanismos de la respuesta innata.}

\section{INTRODUCCIÓN}

La EC es una enteropatía crónica de base inmune que se desencadena por la ingestión de gluten en individuos genéticamente susceptibles. Entre los factores genéticos, la expresión de los alelos de susceptibilidad HLA-DQ2 (DQA1*05:01 y DQB1*02:01) y HLA-DQ8 (DQA1*03:01 y DQB1*03:02) son los que más contribuyen al riesgo de desarrollar la patología (L M Sollid and Thorsby 1994; Ludvig M Sollid, Lie, and Benedicte 2005). Además de los alelos HLA, se han identificado 39 regiones de asociación genética entre las cuales se encuentran muchas con genes involucrados en la respuesta inmune, mientras que otras no tienen genes identificados o corresponden a secuencias no codificantes que probablemente tengan funciones regulatorias de la expresión (Ludvig M Sollid, Lie, and Benedicte 2005; Wapenaar et al. 2008).

EC es de origen multifactorial, donde los elementos mejor caracterizados son las proteínas que la desencadenan, las prolaminas o en términos generales, gluten. Sin embargo, EC se puede presentar en cualquier etapa de la vida aun en personas con ingesta normal de gluten. Por lo tanto, además de la susceptibilidad genética y el gluten, deben existir otros factores que contribuyan al inicio de la patología. Entre estos factores, se consideran ciertas infecciones entéricas, cambios hormonales, situaciones de stress o modificación en la microbiota. El rol de estos factores no es completamente comprendido aún (Ludvig M Sollid, Lie, and Benedicte 2005; Plot and Amital 2009; Abadie et al. 2011).

La enfermedad presenta un daño característico de la mucosa del intestino delgado con un incremento en el número de LIEs, infiltrado linfocitario en la lamina propria, hiperplasia de criptas y atrofia de vellosidades, asociado a un conjunto variable de signos sistémicos y frecuentemente a enfermedades autoinmunes.

En la patogenia de EC participan tanto mecanismos de la inmunidad innata como de la adaptativa (Meresse, Malamut, and Cerf-Bensussan 2012; Abadie and Jabri 2014). La inducción de la respuesta adaptativa basada en la generación de linfocitos $\mathrm{T} \mathrm{CD}^{+} \mathrm{Th} 1$ específicos de péptidos derivados de gluten ha sido caracterizada con gran detalle. De hecho, el conocimiento generado en EC ha 
servido para interpretar fenómenos en otras patologías de base inmune. Es así que la respuesta adaptativa ha sido estudiada ampliamente a lo largo de las últimas dos décadas. Sin embargo, muy poco se sabe acerca de los mecanismos de la respuesta innata. Mientras que la respuesta adaptativa ha explicado parte de los procesos de daño y los mecanismos que operan en la cronicidad de la lesión, los eventos iniciales no se conocen. En este sentido, la activación de vías de la respuesta innata es de gran relevancia ya que es posible que fragmentos derivados de prolaminas puedan inducir mecanismos proinflamatorios. Estos eventos proinflamatorios podrían conducir al daño directo de la mucosa intestinal, iniciar o potenciar la respuesta adaptativa y contribuir al sostenimiento y expansión de los mecanismos efectores de daño a largo plazo (Ludvig M Sollid and Jabri 2013).

\section{Características del péptido p31-43 en relación a la patogenia de EC.}

El término gluten principalmente refiere a proteínas de almacenamiento de trigo. Es una mezcla extremadamente heterogénea, la cual se clasifica en dos grupos de proteínas llamadas gliadinas y gluteninas. Las gliadinas son proteínas monoméricas que están subdivididas en fracciones $\alpha / \beta, \gamma$ y $\omega$ de acuerdo con su perfil electroforético. Las gluteninas están presentes como complejos poliméricos que comprenden dos tipos de subunidades, las de alto peso molecular y las de bajo peso molecular. Los cereales centeno y cebada también contienen proteínas homólogas llamadas secalinas y hordeínas, respectivamente, las cuales son tóxicas e inmunogénicas en pacientes con EC (Wieser 2007).

La característica común de las proteínas de gluten es la presencia de un alto contenido de residuos de prolina y glutamina. La particular secuencia de las proteínas del gluten le confiere una alta resistencia a la degradación proteolítica en el tracto gastrointestinal. Consecuentemente, los péptidos derivados de gluten, algunos de gran tamaño, pueden cruzar la barrera epitelial del intestino y alcanzar la lamina propria de la mucosa, disparando dos rutas inmunológicas: la respuesta inmune innata y adaptativa (Iacomino et al. 2013; Ménard et al. 2012; Lebreton et al. 2012; Meresse, Malamut, and Cerf-Bensussan 2012).

Desde hace más de 100 años, las prolaminas de trigo han sido muy estudiadas dadas sus propiedades fisicoquímicas y tecnológicas en relación a su cualidad de formación de una estructura viscoelástica (masa) ampliamente utilizada en nuestra alimentación. Sin embargo, los estudios más detallados sobre 
secuencias definidas con el objetivo de caracterizar la respuesta en pacientes celíacos comenzaron hacia fines de la década del '80.

Como mencionamos, las prolaminas están formadas por dos grupos, gliadinas y gluteninas que contienen entre 150 y 200 proteínas. Estas no son solubles en solventes acuosos salinos, tienden a agregarse fácilmente, poseen secuencias repetitivas y regiones homólogas, que en conjunto hacen muy difícil su separación y aislamiento. La primer prolamina aislada fue una $\alpha$-gliadina (Kasarda et al. 1984). Más recientemente algunas prolaminas fueron clonadas y expresadas en forma recombinante (Snégaroff et al. 2007).

En el estudio de la patogenia de EC, la respuesta frente a las proteínas de trigo fue estudiada mediante fragmentos obtenidos por la digestión de gliadinas comerciales completas con las enzimas pepsina y tripsina, fracción comúnmente llamada PT-gliadinas. Estos estudios permitieron caracterizar la respuesta

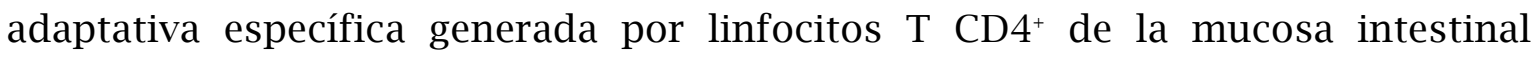
(Troncone et al. 1998).

Con el fin de lograr un conocimiento más detallado de la respuesta inmune en EC, y ante la dificultad de obtener proteínas aisladas o fragmentos de las fuentes naturales, se comenzaron a utilizar péptidos de síntesis. En este caso, se debe tener en cuenta que el altísimo contenido de prolina y glutamina, y la alta proporción de regiones repetitivas en las secuencias de prolaminas dificultan la interpretación de los resultados cuando se analiza el efecto de diferentes secuencias.

De este modo, la respuesta inmune adaptativa ha sido intensamente estudiada a través de la identificación de la secuencia de péptidos inmunogénicos específicos, los cuales son presentados por medio de las moléculas de HLA-DQ2 o HLA-DQ8 a células $\mathrm{T}$ CD4+ específicas de péptidos derivados de gluten (L. M. Sollid 1989; Lundin 1993; Mazzarella 2003). La unión de los péptidos de gluten, particularmente a las moléculas de HLA-DQ2, presenta mayor afinidad cuando ciertos residuos de glutamina son deamidados por la enzima transglutaminasa 2 convirtiéndolos en ácido glutámico. Además de dar origen a un neoepitope $\mathrm{T}$ de mayor afinidad por la molécula de presentación, esta modificación produce una mayor actividad estimulatoria de los linfocitos $\mathrm{T}$ (Molberg et al. 1998). Los linfocitos $\mathrm{T} \mathrm{CD}^{+}$efectores específicos de péptidos derivados de gluten localizados en la lamina propria, producen abundantemente IFN $\gamma$, citoquina dominante en los procesos de remodelación y daño en la mucosa durante la enteropatía (Siegel et al. 2008; Jabri and Sollid 2009). De los más de 50 epítopes 
de gliadinas y gluteninas estimulatorios de células $\mathrm{T}$, el péptido 33mer, liberado a partir de $\alpha_{2}$-gliadina por la digestión de enzimas gastropancreáticas, es considerado corrientemente el péptido inmunogénico predominante debido a que su secuencia tiene 6 epítopes superpuestos. El 33mer es, además, altamente resistente a la digestión de las enzimas del ribete en cepillo de la membrana del enterocito (Shan et al. 2005).

Además de actuar en la inmunidad adaptativa, los péptidos de gliadinas son capaces de generar una respuesta innata en la que pueden participar tanto el epitelio como células presentes en la lamina propria: monocitos/macrófagos y células dendríticas. Esta respuesta inflamatoria conduce a la activación de linfocitos intraepiteliales, entre otros fenómenos.

Contrario a la respuesta adaptativa, poca atención ha recibido la respuesta inmune innata en los estudios relacionados a EC. Recientemente, sin embargo, el interés se ha centrado en evaluar los mecanismos de la inmunidad innata en relación a los péptidos derivados de gliadina.

En forma llamativa, se observó que los fragmentos de gliadinas podían tener funciones no asociadas a la respuesta específica de linfocitos $\mathrm{T}$ y que podían tener efectos directos en la mucosa intestinal. Entre los primeros ensayos que emplearon un panel de péptidos sintéticos de $\alpha$-gliadinas se incluyó la secuencia de p31-43 (L Maiuri et al. 1996). El p31-43 fue considerado un péptido tóxico, dado que inducía daño en la mucosa cuando se estimulaban biopsias duodenales de pacientes celíacos en tratamiento, y los mecanismos involucrados no parecían depender de la respuesta de linfocitos T (Luigi Maiuri et al. 2003).

El p31-43 (LGQQQPFPPQQPY) representa un péptido modelo único para el estudio de la respuesta innata de EC. Actualmente, los mecanismos ejercidos por los péptidos de gliadinas, con respecto a sus propiedades biológicas y las vías metabólicas involucradas en la activación de la inmunidad innata en EC, permanecen poco claros. Además, no ha sido encontrado aún el receptor y tampoco se conoce el mecanismo por el cual este péptido atraviesa el epitelio o entra a la célula.

Un estudio demostró que el p31-43 (o también el p31-49) no es liberado durante la digestión de proteínas en el tracto digestivo pero sí está comprendido dentro de un péptido más largo, el p31-55 (LGQQQPFPPQQPYPQ-PQPFPSQQPY), el cual es resistente a las enzimas gastropancreáticas y a las enzimas del ribete en cepillo aún después de una exposición prolongada (Mamone et al. 2007). 
En la actualidad, varios estudios demostraron el rol tóxico del p31-43 y lo relacionaron con la patogenia de EC. Sin embargo, la mayoría de estos estudios fueron realizados en experimentos in vitro con células de líneas enterocíticas o ex vivo en cultivo de biopsias intestinales o fibroblastos. Aún cuando estudios más recientes han apuntado a inhibir la toxicidad del p31-43 como posible estrategia terapéutica, se desconocen los efectos del mismo en un organismo entero (Sarno et al. 2014; Capozzi et al. 2013).

Por una parte, ha sido demostrado que los péptidos no inmunogénicos inducen una expresión rápida de IL-15 y apoptosis de enterocitos cuando se utilizan sobre biopsias intestinales en cultivo (Luigi Maiuri et al. 2003). Los péptidos derivados de gliadina, p31-43 y 33mer, son potentes inductores de aumento de la permeabilidad intestinal y de un perfil proinflamatorio de citoquinas en macrófagos aislados de ratones C57BL/6 estimulados in vitro. PTgliadina produce efectos proinflamatorios similares, y se demostró que las vías de señalización son dependientes de MyD88 (Thomas et al. 2006). Este estudio mostró por primera vez la inducción de mecanismos de la inmunidad innata asociados a péptidos tóxicos y mostró también que estos pueden contribuir a potenciar la respuesta adaptativa frente a los péptidos inmunogénicos. Sin embargo, los mecanismos innatos específicamente asociados al p31-43 aún no se conocen.

Por otra parte, se diseñaron varios estudios con el objetivo de evaluar los mecanismos implicados en la toxicidad del p31-43. Barone et al. (M. V Barone et al. 2007) encontraron una interacción entre el receptor para el factor de crecimiento epidermal (EGFR) y p31-43, la cual resultó en la inhibición de la endocitosis y el retraso de la inactivación de EGFR, con la consecuente activación de la vía de EGF. Con un estímulo con PT-gliadinas, las células epiteliales de un cultivo primario de biopsias intestinales entraron en fase $S$, lo cual explica el patrón proliferativo en la EC activa. El mismo grupo determinó que p31-43 interactúa con el complejo IL-15/IL-15Ra retrasando la disociación y la endocitosis. En conjunto, estos estudios mostraron el incremento de la proliferación celular y remodelación tisular por la interacción de p31-43 con las vías de IL-15 y EGF (M Vittoria Barone et al. 2011; Nanayakkara, Lania, et al. 2013).

Por otro lado, Luciani A. et al (Luciani et al. 2010) demostraron que hay una acumulación de p31-43 en lisosomas tempranos, los cuales generan un persistente estrés oxidativo en enterocitos. El nivel elevado de especies reactivas del oxígeno (ROS) conduce a un incremento y activación de la enzima 
transglutaminasa 2 (TG2) en células epiteliales humanas T84 y Caco-2 a través de la vía de PPAR $\gamma$. Este estudio describió un mecanismo diferente de toxicidad de p31-43 y su posible relación con la sobreexpresión de TG2 en EC. Otros estudios asociaron a TG2 con la captación de p31-43 y demostraron que los anticuerpos anti-TG2 son capaces de inhibir esta captación (Caputo et al. 2010). Por otro lado, Barone MV et al (Maria Vittoria Barone et al. 2010), trabajando con biopsias duodenales, mostraron que p31-43, pero no p57-68, produjo un retraso madurativo de los endosomas. Este trabajo presentó la activación del Receptor de Tirosin Quinasa (RTK) como un mecanismo por el cual p31-43 podría disparar una excesiva proliferación celular en pacientes con EC. Otro estudio demostró una estrecha relación entre p31-43 y el Patrón Preferido por Lipomas (Lipoma Preferred Partner, LPP). LPP interviene en la morfología y adhesión de células, especialmente en fibroblastos, y ha sido asociado a EC en estudios de asociación a gran escala (GWAS). Se observó que la incubación de fibroblastos de explantos de piel normales con p31-43 genera las mismas anomalías que las observadas en fibroblastos obtenidos de pacientes celíacos en cuanto a la organización de citoesqueleto (Nanayakkara, Kosova, et al. 2013).

La información disponible sobre el p31-43 fue obtenida mediante experimentos in vitro con células de línea enterocíticas o ex vivo en cultivo de biopsias intestinales o fibroblastos. Sin embargo, no hay información sobre los efectos del p31-43 in vivo. 


\section{OBJETIVO}

El objetivo de esta sección fue evaluar si la administración intraluminal del p31-43 induce daño en la mucosa intestinal empleando el modelo de enteropatía experimental ya establecido. También buscamos caracterizar los mecanismos de daño, en especial la respuesta inflamatoria y la muerte celular en la mucosa intestinal producidas por p31-43. A su vez, nos propusimos evaluar si la administración conjunta de p31-43 y poly (I:C) es capaz de generar daño como así también estudiar los mecanismos disparados por el estímulo conjunto. 


\section{RESULTADOS}

La administración intraluminal de p31-43 induce enteropatía.

Empleando diferentes ensayos in vitro o ex vivo (en piezas de biopsias duodenales) se han descripto diferentes efectos proinflamatorios del p31-43. Por esta razón, decidimos evaluar si este péptido era capaz de inducir daño en un modelo de enteropatía in vivo. Por lo tanto, empleando la misma estrategia experimental puesta a punto en el capitulo anterior, se administró intraluminalmente p31-43 en una concentración de $10 \mu \mathrm{g} / \mathrm{ml}$ en ratones C57BL/6 (Materiales y métodos). En paralelo hemos usado un péptido no relacionado (PNR) como control. Este péptido deriva de la proteína peroxidasa de tiroides humana y ya ha sido usado como control para el p31-43 (Luigi Maiuri et al. 2003).

La administración intraluminal de p31-43 a ratones C57BL/6 produjo una enteropatía severa. A las $12 \mathrm{~h}$ post-estimulación con p31-43, observamos acortamiento y ensanchamiento de las vellosidades, incremento en el infiltrado celular en lamina propria y edema, el cual se evidenció como un incremento del espacio intersticial en las puntas de las vellosidades (Figura 2.1A).

A
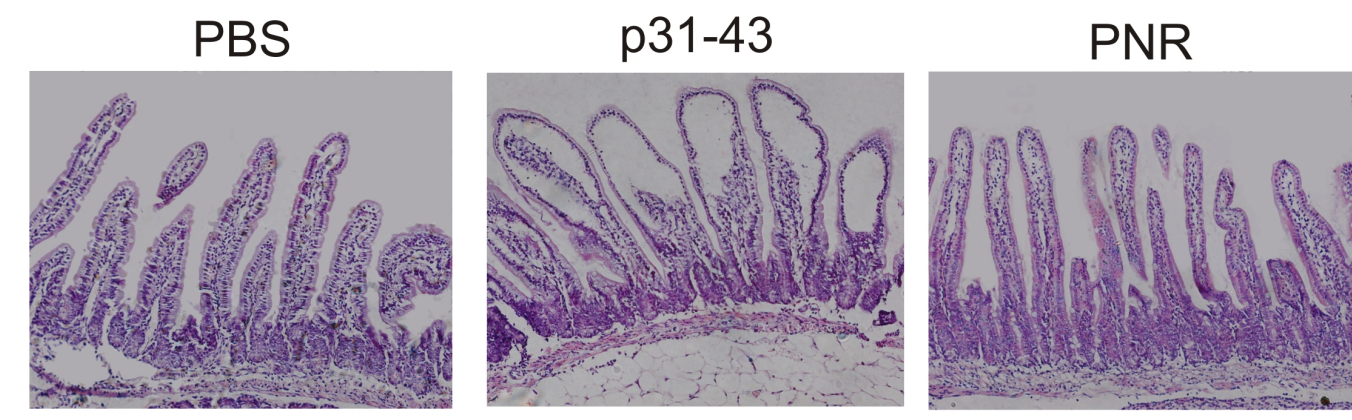

B
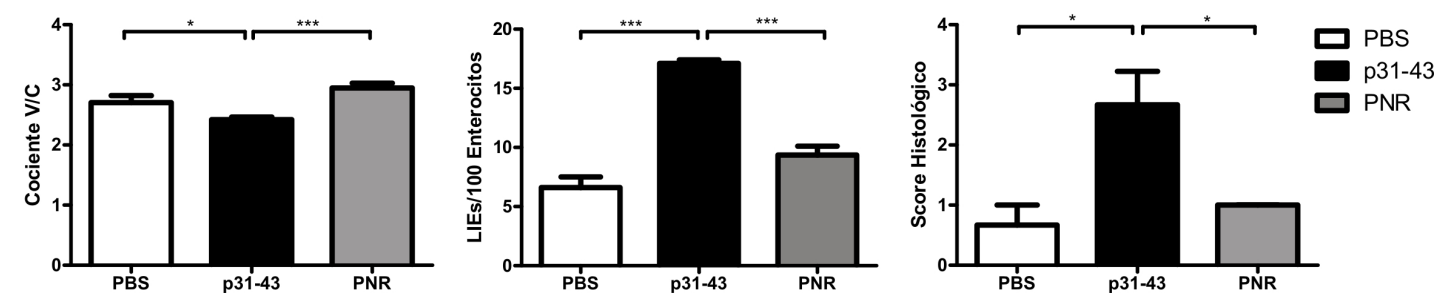

Figura 2.1. La administración intraluminal de p31-43 induce enteropatía luego de 12hs.

Secciones teñidas con H\&E representativas de intestino delgado proximal de ratones C57BL/6, después de 12hs de administración de p31-43, PNR o PBS (A). Análisis morfológicos de secciones de intestino delgado de ratones C57BL/6: Cociente V/C, score histológico y número de LIEs después de $12 \mathrm{hs}$ de tratamiento (B). $\mathrm{N}=4$ ratones por grupo, test $\mathrm{t}$ no pareado, ${ }^{*} \mathrm{P}<0,05,{ }^{* * *} \mathrm{P}<0,001$. 
A
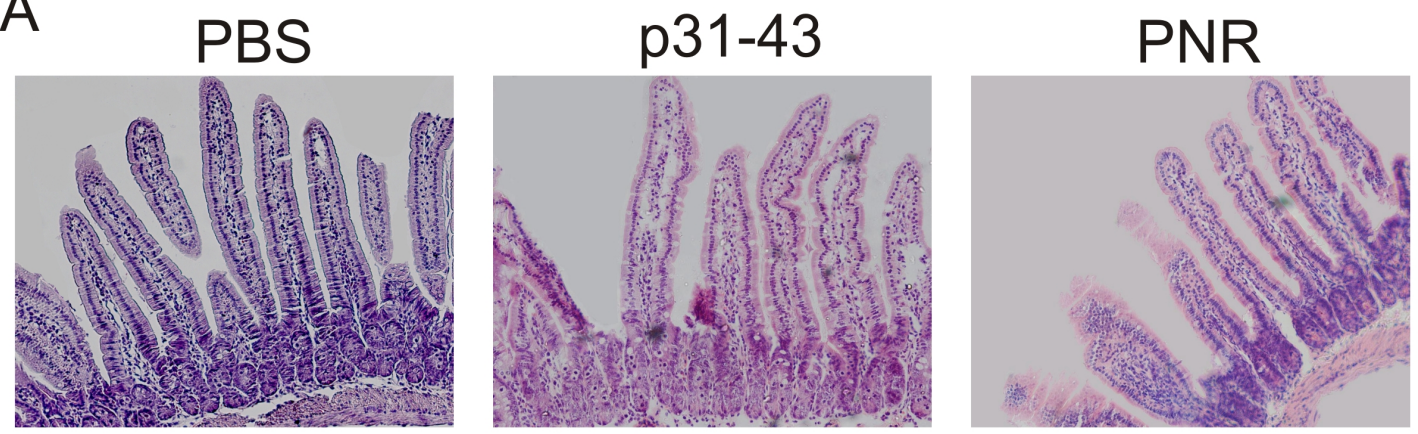

$\mathrm{B}$
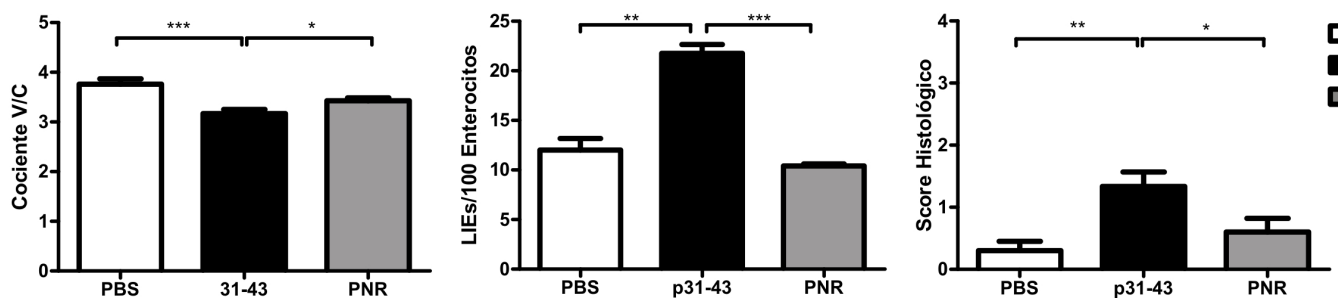

Figura 2.2. La administración intraluminal de p31-43 induce enteropatía luego de 72hs. Secciones teñidas con H\&E representativas de intestino delgado proximal de ratones C57BL/6 después de 72hs de administración de p31-43, PNR o PBS (A). Análisis morfológicos de secciones de intestino delgado de ratones C57BL/6: Cociente Vellosidad/Cripta (V/C), score histológico y número de LIEs después de $72 \mathrm{hs}$ de tratamiento (B). $\mathrm{N}=4$ ratones por grupo, test t no pareado, ${ }^{*} \mathrm{P}<0,05$, $* * \mathrm{P}<0,01, * * * \mathrm{P}<0,001$.

Por otro lado, el tratamiento con PBS o con el péptido control (PNR) no generó ninguna alteración histológica. Además, el cociente V/C fue menor, mientras el número de LIEs y el score histológico global se incrementaron en los ratones tratados con p31-43 comparados con los tratados con PBS y PNR (Figura 2.1B).

Como fue mencionado en el Capítulo 1, el procedimiento quirúrgico introduce alteraciones en la mucosa intestinal. Con el fin de evaluar el impacto de la respuesta inflamatoria debida a la cirugía, se analizaron los cambios histológicos luego de 72hs post-tratamiento. Como hemos observado anteriormente, este tiempo es suficiente para evidenciar una recuperación de la cirugía. Luego de $72 \mathrm{hs}$ de la administración intraluminal de p31-43, se observaron signos de alteración histológica con una recuperación parcial de la relación V/C, el número de LIEs y el score histológico. En contraste, los ratones tratados con PBS mostraron una mayor recuperación de la histología de la mucosa, al igual que los ratones tratados con el péptido control (Figura 2.2B). Los resultados obtenidos con PBS y PNR fueron similares en todas las evaluaciones realizadas. Estos resultados muestran que la administración de un péptido de secuencia no relacionada no genera alteración histológica, con lo cual podemos descartar que los efectos observados luego de la administración de p31-43 sean 
debidos a la presencia de un péptido inoculado en el lumen donde podrían observarse efectos tóxicos y/o osmóticos, que podrían disparar una respuesta inflamatoria.

Por lo tanto, concluimos que el daño inducido en la mucosa intestinal es específico del p31-43, siendo ésta la primera evidencia en un modelo in vivo. De este modo, de aquí en más se mostrarán resultados obtenidos con el p31-43 en referencia al control con PBS únicamente.

Como hemos mencionado en el capítulo 1, la medida de CCPR es un indicador dinámico del proceso de regeneración de la mucosa y se produce como respuesta compensadora del daño producido. De acuerdo a protocolos descriptos en la bibliografía determinamos los valores de CCPR en animales luego de $72 \mathrm{hs}$ de tratamiento (Garside et al. 1991; Goodlad et al. 1987; Hall, Youngs, and Keighley 1992). La evaluación de CCPR en animales tratados muestra valores similares cuando se inyecta p31-43 comparado con PBS. Sin embargo, se observa una tendencia a una mayor pendiente por parte de los ratones estimulados con p31-43, que sugiere que a tiempos cortos (12 o 24hs post-cirugía) la respuesta frente al péptido podría diferenciarse de la obtenida con animales del grupo control (Figura 2.3). Sin embargo, esto no pudo confirmarse ya que por cuestiones de tiempo y material disponible, este estudio no pudo ser realizado para este trabajo de tesis.

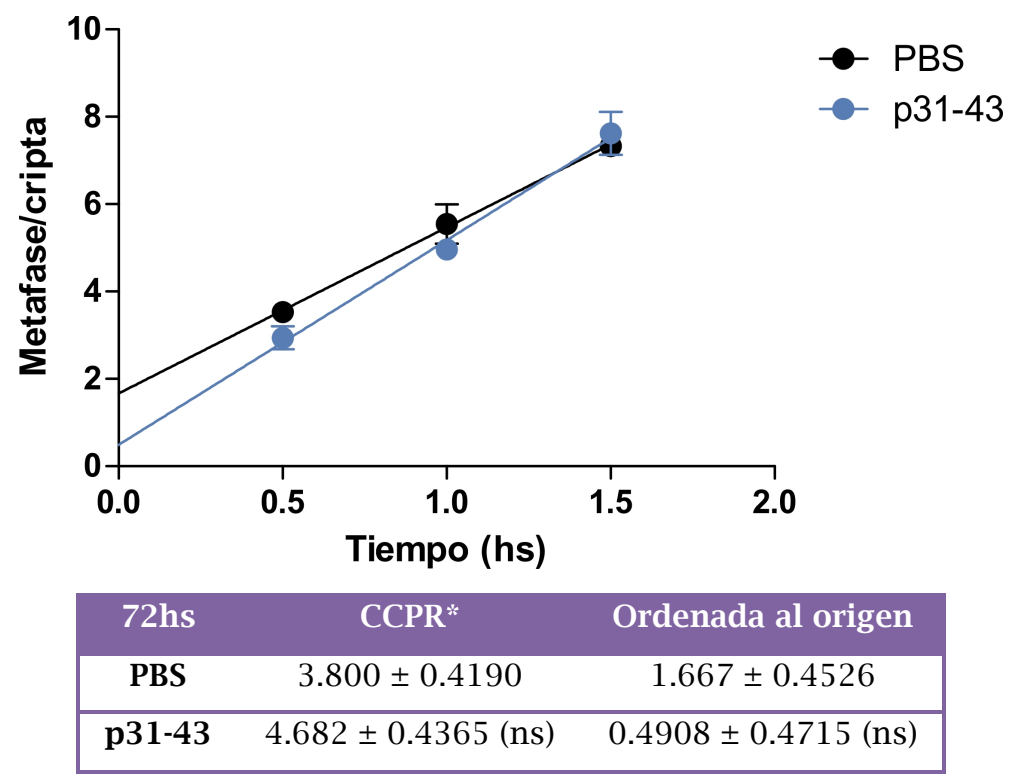

Figura 2.3. La administración de p31-43 no modifica los valores de CCPR luego de 72hs de estímulo.

Determinación del CCPR (Cociente de proliferación de las células de la cripta) en ratones C57BL/6 estimulados con p31-43 o PBS intraluminalmente por $72 \mathrm{hs}$, a los que se sometió a un arresto mitótico con Colchicina 30, 60 y 90 minutos antes del sacrificio. Se grafica la Recta de Regresión obtenida con 9 ratones por cada estímulo. *Unidades: Metafase/Cripta/h. Estadística: Test para comparación de parámetros de la recta. 
Estudios previos han mostrado que PT-gliadina inducía una respuesta proliferativa en las células del epitelio intestinal humano (M. V Barone et al. 2007; M Vittoria Barone et al. 2011; Nanayakkara, Lania, et al. 2013). Por ello decidimos analizar el estado proliferativo del epitelio intestinal en el modelo de enteropatía a las 12 hs post-tratamiento con p31-43, mediante la evaluación de la expresión de Ki67 en las criptas de los ratones tratados. Ki67, es un conocido marcador de células en proliferación que se encuentra presente en todas las fases del ciclo celular y representa una medida estática del estado proliferativo de un tejido (Hall, Youngs, and Keighley 1992).

Para esto realizamos la marcación con un anticuerpo anti-Ki67 de secciones de intestino delgado en animales luego de $12 \mathrm{hs}$ de tratamiento. Observamos que p31-43 produjo un incremento en el número de células $\mathrm{Ki} 67^{+}$en las criptas luego de 12 hs post-estimulación en comparación con los animales del grupo control

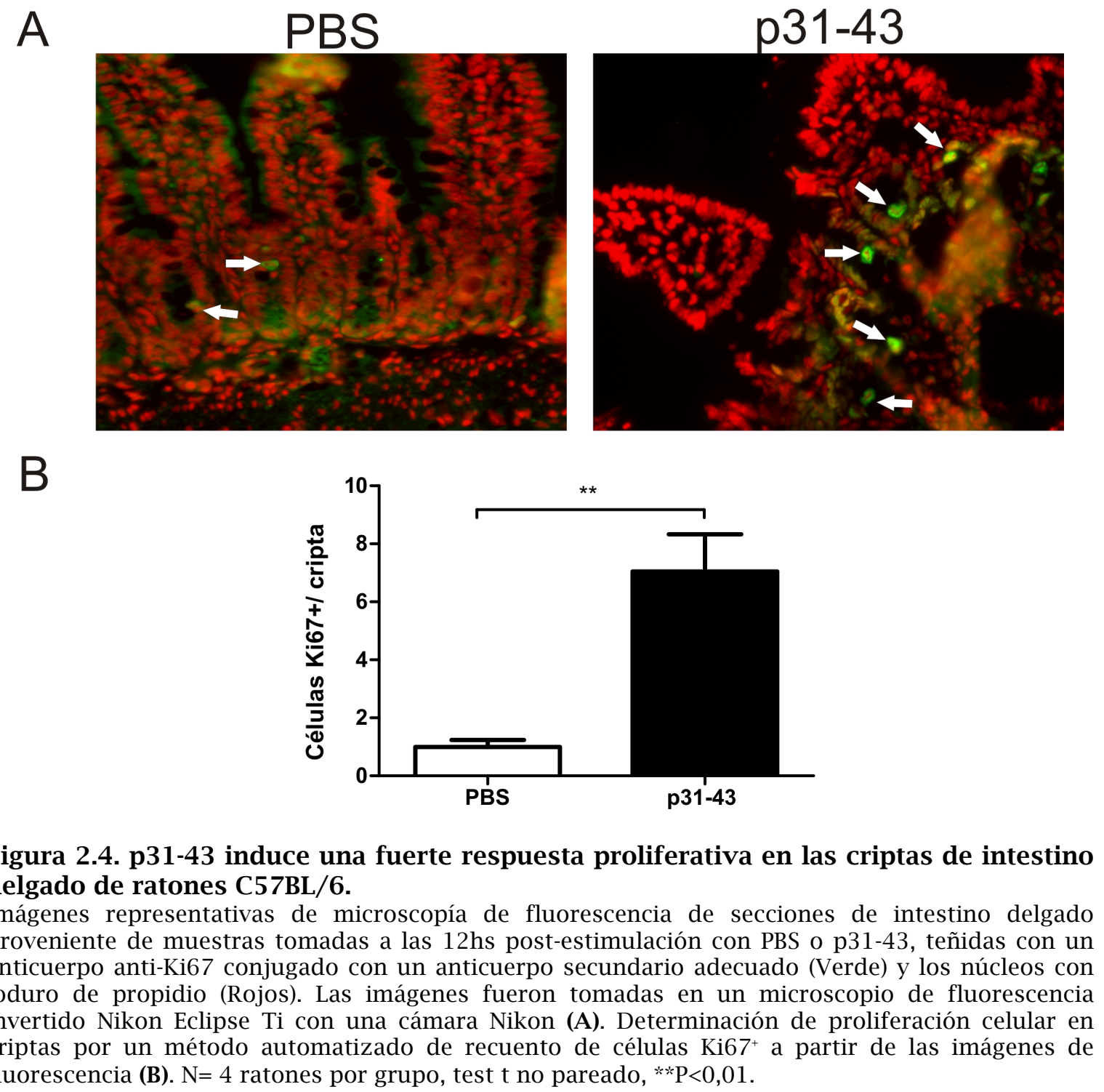


(Figura 2.4). Este resultado indica que en el curso de la enteropatía inducida por p31-43 se produce una fuerte y rápida respuesta proliferativa en las criptas. A su vez, este resultado correlaciona con la interpretación sobre la necesidad de conocer los valores de CCPR a tiempos menores.

La composición aminoacídica de las prolaminas es suficiente para inducir daño en la mucosa intestinal.

Las prolaminas tienen una composición muy particular con una elevada proporción de prolinas y glutaminas. En este sentido, son proteínas únicas en la naturaleza. En varios estudios se demostró que algunas prolaminas podían tener un efecto tóxico per se y esto ha sido atribuido a dicha particularidad en su composición aminoacídica (Visser et al. 2009). Por otro lado, aún no se ha identificado el receptor de gliadinas o en nuestro caso particular, del p31-43, que media las señales proinflamatorias. Por tales razones, decidimos evaluar la respuesta en la mucosa intestinal frente a otro péptido de síntesis que contiene los mismos aminoácidos que el p31-43 pero distribuidos en secuencia aleatoria (al que llamamos péptido de diferente secuencia, PDS) (Tabla 2.1).

Observamos que la administración intraluminal del PDS genera un daño en la mucosa intestinal medido por el cociente V/C, similar al p31-43 y significativamente diferente al PBS (Figura 2.5). Por lo tanto, concluimos que el daño inducido por p31-43 se debe a su composición de aminoácidos y no parece ser dependiente de su secuencia.

Estas observaciones sugieren que los fragmentos de prolaminas podrían causar daño directo en la mucosa intestinal, y que las señales generadas no dependen de la secuencia sino de la composición particular de estos péptidos. Esta observación es de alta relevancia en la comprensión de los fenómenos iniciales en los que podrían participar algunos péptidos derivados de gliadinas, aunque se requieren estudios adicionales para dilucidar estos aspectos.

\begin{tabular}{|ll|}
\hline Péptido & Secuencia \\
\hline p31-43 & LGQQQPFPPQQPY \\
\hline PDS & YQPLFQPQGPQPQ \\
\hline
\end{tabular}

Tabla 2.1. Secuencias aminoacídicas de los péptidos de síntesis p31-43 y PDS.

Ambas secuencias sólo se diferencian en el orden de los aminoácidos, pero su composición es la misma. 


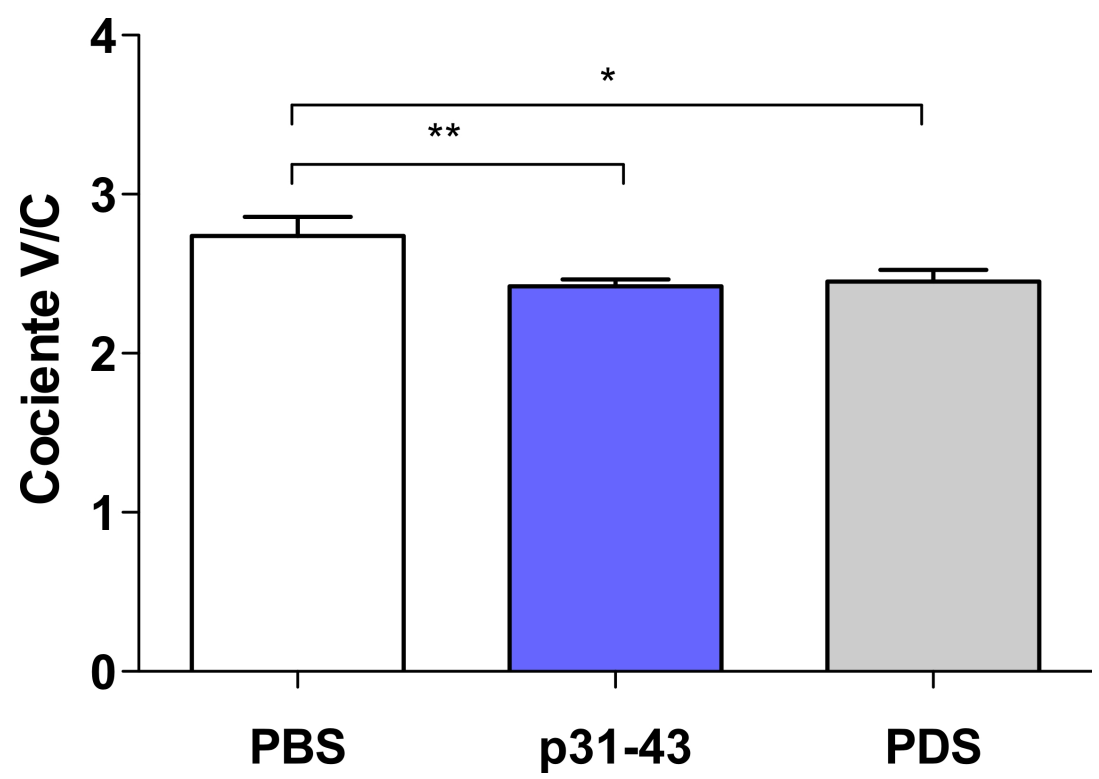

Figura 2.5. Un péptido de igual composición pero diferente secuencia al p31-43 genera daño en la mucosa intestinal.

Análisis morfométrico de secciones de intestino delgado obtenidas de ratones C57BL/6 luego de 12hs de estímulo intraluminal con PBS, p31-43 o PDS. Se representa el cociente V/C en cada caso determinado a partir de la tinción con $\mathrm{H} \& \mathrm{E}$. $\mathrm{N}=4$ ratones por grupo, Test t no pareado. ${ }^{*} \mathrm{P}<0,05$, $* * \mathrm{P}<0,01$.

Los mecanismos inflamatorios y de muerte celular inducidos son críticos en las etapas iniciales de EC y pueden determinar el desencadenamiento de la Sensibilidad al gluten. Sin embargo, ambos fenómenos no pueden ser completamente dilucidados por no haber sido identificado un receptor de péptidos derivados de gliadinas que desencadene un proceso inflamatorio mediante mecanismos de la respuesta innata.

p31-43 incrementa la expresión del ARNm de citoquinas y quimoquinas proinflamatorias.

Una vez establecido que la administración intraluminal de p31-43 produce daño en la mucosa intestinal, decidimos estudiar los mediadores inducidos por este péptido.

En primer lugar analizamos la expresión del receptor CXCR3 y sus ligandos CXCL9, CXCL10 y CXCL11 en nuestro modelo de enteropatía inducida por p31-43, ya que estudios de nuestro grupo mostraron el rol de este eje quimiotáctico en el reclutamiento celular en la mucosa duodenal en pacientes con enfermedad celíaca activa (Bondar et al. 2014). El aumento de la expresión de CXCL9, CXCL10 y CXCL11 determina el reclutamiento de células CXCR3 ${ }^{+}$al tejido. Dicho receptor se encuentra en linfocitos $\mathrm{T}$, linfocitos $\mathrm{B}$ y células $\mathrm{NK}$, células que pueden participar de manera relevante en el proceso de daño. 
Con el fin de evaluar la expresión de las quimoquinas y su receptor, determinamos el nivel de expresión de ARNm mediante una cinética establecida por PCR en tiempo real entre las 2 y las $12 \mathrm{hs}$ post-tratamiento, en muestras de intestino de ratones C57BL/6 previamente estimulados con PBS o p31-43.

Como puede observarse en la Figura 2.6, hay un aumento significativo de CXCL9 a las 2hs y de CXCL10 a las 4hs post-tratamiento con p31-43. En cambio, CXCL11 está disminuido a lo largo de todo el período evaluado. En el caso de CXCL9, su aumento es seguido por una disminuido a las 4hs para luego normalizar sus niveles a valores comparables al PBS. Por su parte, los niveles de CXCR3 presentan una leve tendencia al aumento a las $2 \mathrm{hs}$ que no es significativa, para luego disminuir su expresión a partir de las 4 hs post-tratamiento con p3143.

El aumento de la expresión de cualquiera de estos ligandos significará el arribo de células $\mathrm{CXCR}^{+}$al tejido. Un patrón de quimoquinas determinado podrá limitar o activar la respuesta de dichas células dependiendo del estímulo CXCL10

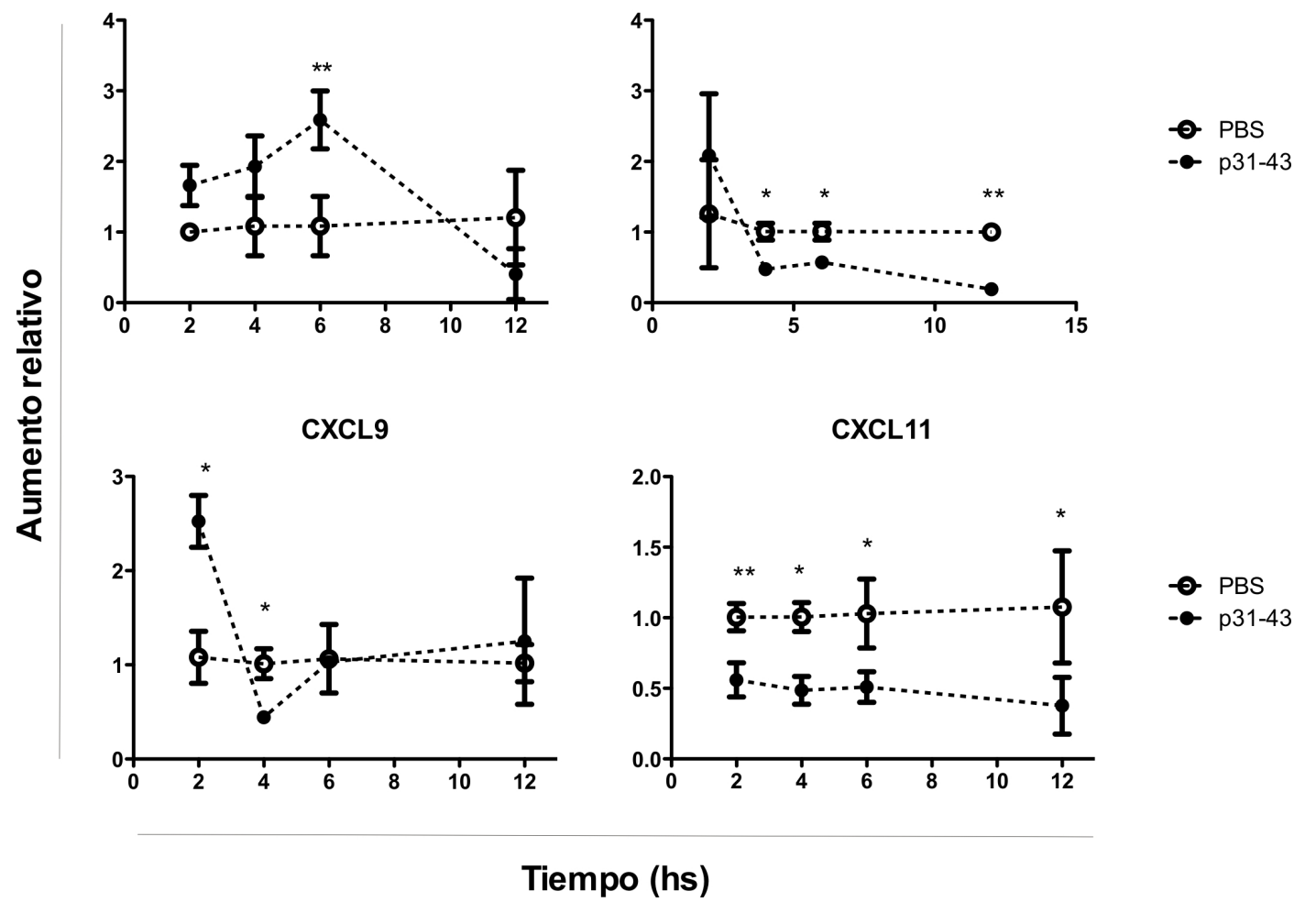

Figura 2.6. p31-43 induce la expresión de CXCL9 y CXCL10 pero disminuye CXCL11 y CXCR3.

Análisis por PCR en tiempo real de los niveles de ARNm de CXCL9, CXCL10, CXCL11 y su receptor CXCR3 entre las 2 y 12hs post-tratamiento con p31-43 (puntos negros) o PBS (puntos blancos). Para cada tiempo, todos los valores fueron normalizados con el gen constitutivo HPRT. Todos los resultados fueron expresados como aumento relativo en el tratamiento con PBS y p31-43 versus la media de los valores del tratamiento con PBS en cada punto de tiempo $\left(2^{-\Delta \Delta c t}\right)$. $\mathrm{N}=4$ ratones por grupo, Test t No pareado, ${ }^{*} \mathrm{P}<0.05,{ }^{* *} \mathrm{P}<0.01$, ratón tratado con $\mathrm{p} 31-43$ versus el control de $\mathrm{PBS}$ en cada punto de tiempo. 
IL-1 $\beta$

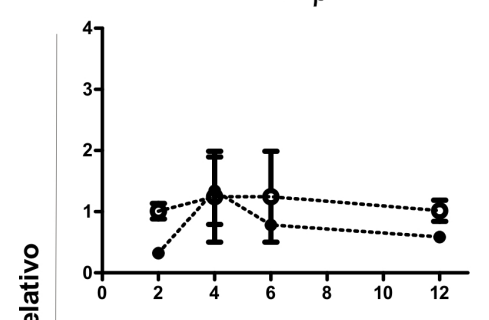

IFN $\beta$

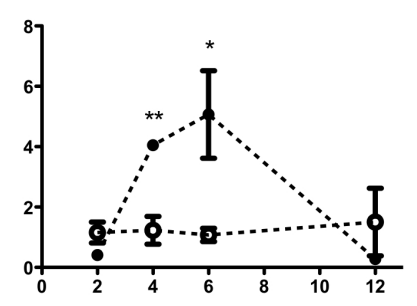

IL-6

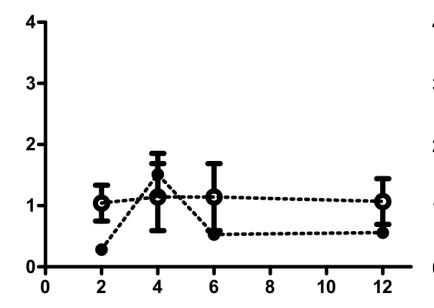

IFN $\gamma$

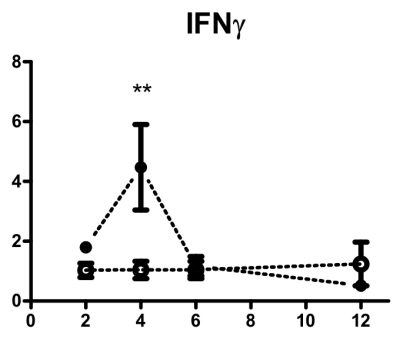

IL-18

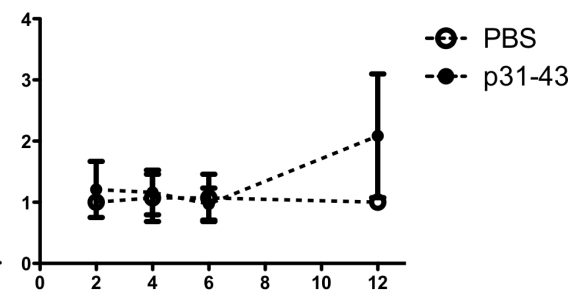

TNF-a

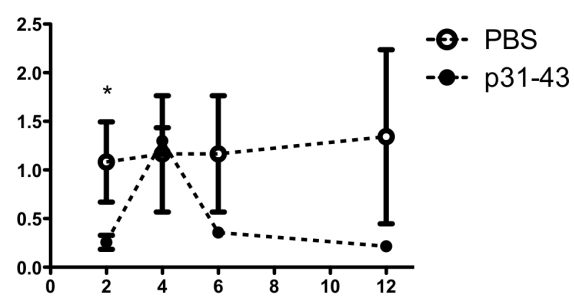

Tiempo (hs)

Figura 2.7. p31-43 induce la expresión de IFN $\beta$ e IFN $\gamma$.

Análisis con PCR en tiempo real de los niveles de ARNm de IFN $\beta$, IFN $\gamma$ y TNF $\alpha$ entre las 2 y $12 \mathrm{hs}$ post-tratamiento con p31-43 (puntos negros) o PBS (puntos blancos). Para cada tiempo, todos los valores fueron normalizados con el gen constitutivo HPRT. Todos los resultados fueron expresados como aumento relativo en el tratamiento con PBS y p31-43 versus la media de los valores del tratamiento con PBS en cada punto de tiempo $\left(2^{-\Delta \Delta \mathrm{ct}}\right)$. $\mathrm{N}=4$ ratones por grupo, Test t No pareado, $* \mathrm{P}<0.05,{ }^{*} * \mathrm{P}<0.01$, ratón tratado con $\mathrm{p} 31-43$ versus el control de PBS en cada punto de tiempo.

efectuado.

Por otra parte, evaluamos la inducción a nivel de ARNm de diferentes grupos de citoquinas que podrían condicionar la respuesta establecida antes de la inyección intraluminal de p31-43. El análisis por PCR en Tiempo Real de IL-1 $\beta$, IL6 e IL-18 no presentó diferencias significativas entre los animales tratados con p31-43 y los controles de PBS. Sin embargo, las expresiones de IFN $\beta$ y de IFN $\gamma$ mostraron un incremento significativo entre las 2 y $4 \mathrm{hs}$ en el primer caso y a las $4 \mathrm{hs}$ en el segundo. Por el contrario, la expresión de TNF $\alpha$ sufrió una disminución significativa por el tratamiento a las $2 \mathrm{hs}$ permaneciendo esta tendencia a las $6 \mathrm{y}$ a las 12hs (Figura 2.7).

En paralelo, hemos estudiado otras quimoquinas con el fin de evaluar qué grupos celulares podrían ser reclutados al tejido y participar en la generación de daño por el p31-43. Así fue como evaluamos la expresión de CXCL2, quimioatractante para polimorfonucleares y monocitos y MCP-1, quimioatractante para la línea monocitos/macrófagos. Ninguna de estas quimoquinas fue aumentada por el p31-43. Por el contrario, CXCL2 fue claramente disminuido a las $2 \mathrm{hs}$ post-p31-43 continuando esta tendencia en todos los tiempos evaluados (Figura 2.8). 
CXCL2

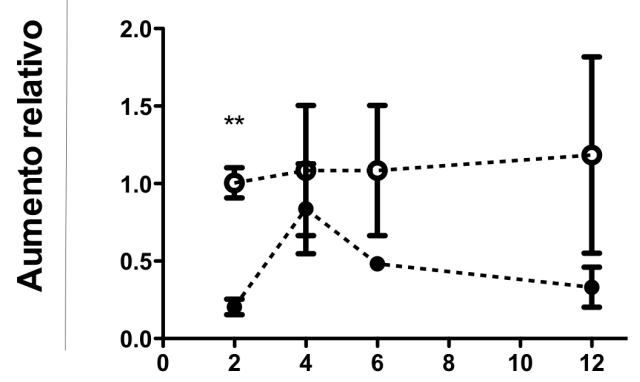

MCP1

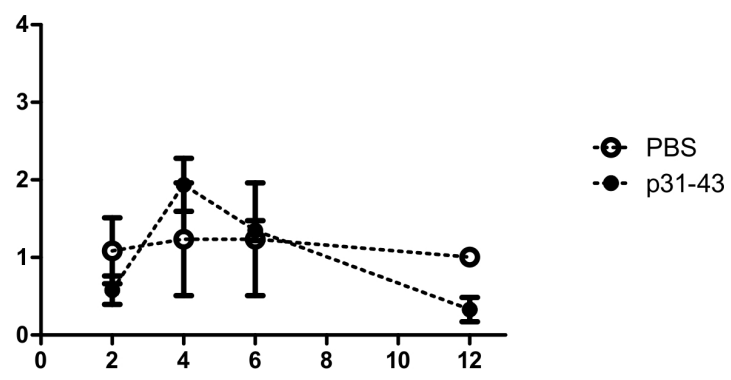

Tiempo (hs)

Figura 2.8. p31-43 disminuye CXCL2 en intestino delgado de ratones C57BL/6.

Análisis con PCR en tiempo real de los niveles de ARNm de CXCL2 y MCP1 entre las 2 y 12hs posttratamiento con p31-43 (puntos negros) o PBS (puntos blancos). Para cada tiempo, todos los valores fueron normalizados con el gen constitutivo HPRT. Todos los resultados fueron expresados como aumento relativo en el tratamiento con PBS y p31-43 versus la media de los valores del tratamiento con PBS en cada punto de tiempo $\left(2^{-\Delta \Delta c t)}\right.$. $\mathrm{N}=4$ ratones por grupo, Test t No pareado, ${ }^{* *} \mathrm{P}<0.01$, ratón tratado con p31-43 versus el control de PBS en cada punto de tiempo.

Por otro lado, dado que este es un péptido derivado de $\alpha$-gliadina, deseamos evaluar si p31-43 modula la expresión de IL-15 y la enzima transglutaminasa 2 (TG2), dos moléculas relevantes en la patogenia de EC. No se vio inducida por el tratamiento con p31-43 la expresión a nivel de ARNm de ninguna de estas moléculas. En cambio, la expresión de IL-15 se vio significativamente disminuida en el intestino delgado de estos ratones a las 4 hs post-tratamiento (Figura 2.9). Sin embargo, debemos considerar que la determinación de los niveles de ARNm no brinda información a nivel de la funcionalidad de estas moléculas. En particular, en el caso de la actividad de TG2, la cual entre otros roles es necesaria para la deamidación de péptidos de gliadina, está sujeta a cambios conformacionales de la enzima. Por otro lado, IL-15 tiene un complejo sistema post-traduccional de regulación, puede ser almacenada en vesículas y, además, unida a su receptor en superficie (transpresentación), cambios que no son reflejados por modificaciones en los niveles de ARNm (Gaggero et al. 1999).

En conclusión, en ratones C57BL/6, el p31-43 produce un perfil inflamatorio caracterizado por un incremento fuerte de la expresión de IFN $\gamma$ seguido de IFN $\beta$ y CXCL10. El incremento de CXCL10 y su relación con el eje CXCL10/CXCR3+ sería responsable del reclutamiento de células $\mathrm{CXCR}^{+}$al tejido, entre ellas linfocitos $\mathrm{T}$ CD4+ Th1, células que son críticas en EC activa. A su vez, la inducción de IFN $\gamma$ e IFN $\beta$ claramente puede ejercer un rol relevante en la expansión de la respuesta inflamatoria y en los mecanismos de daño. Entre otros efectos, pueden potenciar la respuesta de los linfocitos $\mathrm{T} \mathrm{CD}^{+} \mathrm{Th} 1$ y los linfocitos citotóxicos en la 
TG2

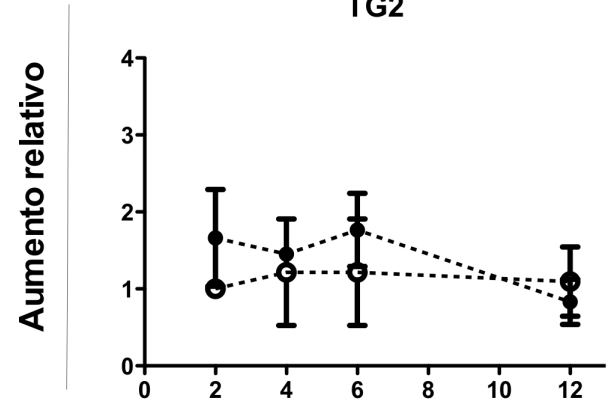

IL-15

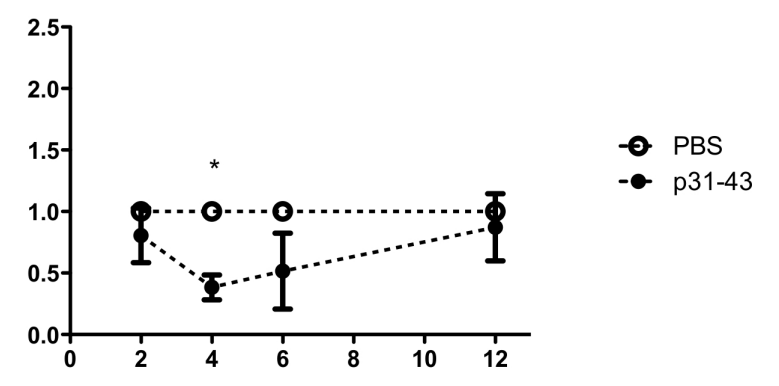

\section{Tiempo (hs)}

Figura 2.9. p31-43 no induce TG2 o IL-15 en intestino delgado de ratones C57BL/6.

Análisis con PCR en tiempo real de los niveles de ARNm de TG2 e IL-15 entre las 2 y $12 \mathrm{hs}$ posttratamiento con p31-43 (puntos negros) o PBS (puntos blancos). Para cada tiempo, todos los valores fueron normalizados con el gen constitutivo HPRT. Todos los resultados fueron expresados como aumento relativo en el tratamiento con PBS y p31-43 versus la media de los valores del tratamiento con PBS en cada punto de tiempo $\left(2^{-\Delta \Delta c t}\right)$. $\mathrm{N}=4$ ratones por grupo, Test t No pareado, ${ }^{*} \mathrm{P}<0.05$, ratón tratado con p31-43 versus el control de PBS en cada punto de tiempo.

cronicidad. Estas observaciones son altamente relevantes ya que le asignan un rol importante al p31-43 en la inducción de daño.

\section{El p31-43 induce muerte celular en lamina propria y enterocitos.}

La alteración histológica en la mucosa intestinal observada en la enteropatía muestra daño con pérdida estructural del tejido conjuntamente con procesos de remodelamiento, e involucra tanto procesos de muerte celular como de respuesta proliferativa incrementadas. Habiendo estudiado la respuesta proliferativa nos interesó caracterizar la muerte celular y sus diferentes vías de inducción.

Para esto evaluamos secciones de intestino delgado por la técnica de TUNEL. Encontramos un fuerte incremento en el número de células TUNEL $^{+}$ principalmente en lamina propria, en ratones tratados con p31-43 en comparación con los ratones controles (núcleos verdes, Figura 2.10A). Además, en animales tratados con p31-43, se observaron células TUNEL $^{+}$en el compartimiento epitelial, evidenciadas como núcleos verdes puntuales, los cuales no pueden observarse en los controles de PBS (flechas blancas, Figura 2.10A).

Cuando se determinó, mediante un método automatizado, el cociente de células $\mathrm{TUNEL}^{+}$(tanto de lamina propria como de enterocitos) respecto a las células totales del tejido, encontramos que existían diferencias significativas en la mucosa intestinal de animales tratados con p31-43 comparada con los animales del grupo control con PBS luego de $12 \mathrm{hs}$ post-estímulo (Figura 2.10B). Por lo tanto, demostramos que p31-43 produce un incremento significativo de la muerte celular en lamina propria y en el epitelio. Este fenómeno es un efecto directo de la acción del p31-43. 
Con el fin de caracterizar las vías de muerte, se analizó por PCR cuantitativa la expresión de genes anti- y pro-apoptóticos, Bcl2 y Bax, respectivamente.

Encontramos un incremento en la relación $\mathrm{Bax} / \mathrm{Bcl} 2$ en intestino delgado de ratones tratados con p31-43, 12hs post-estimulación, lo cual está relacionado con un perfil pro-apoptótico inducido por este tratamiento (Figura 2.10C). Otros tiempos evaluados no mostraron diferencias entre el control y el p31-43 (No se muestra). La relación $\mathrm{Bax} / \mathrm{Bcl} 2$ aumentada sugiere que el p31-43 induce in vivo un proceso pro-apoptótico activo y que esto podría ser parte de los mecanismos de daño en la mucosa intestinal llevados a cabo por este péptido.
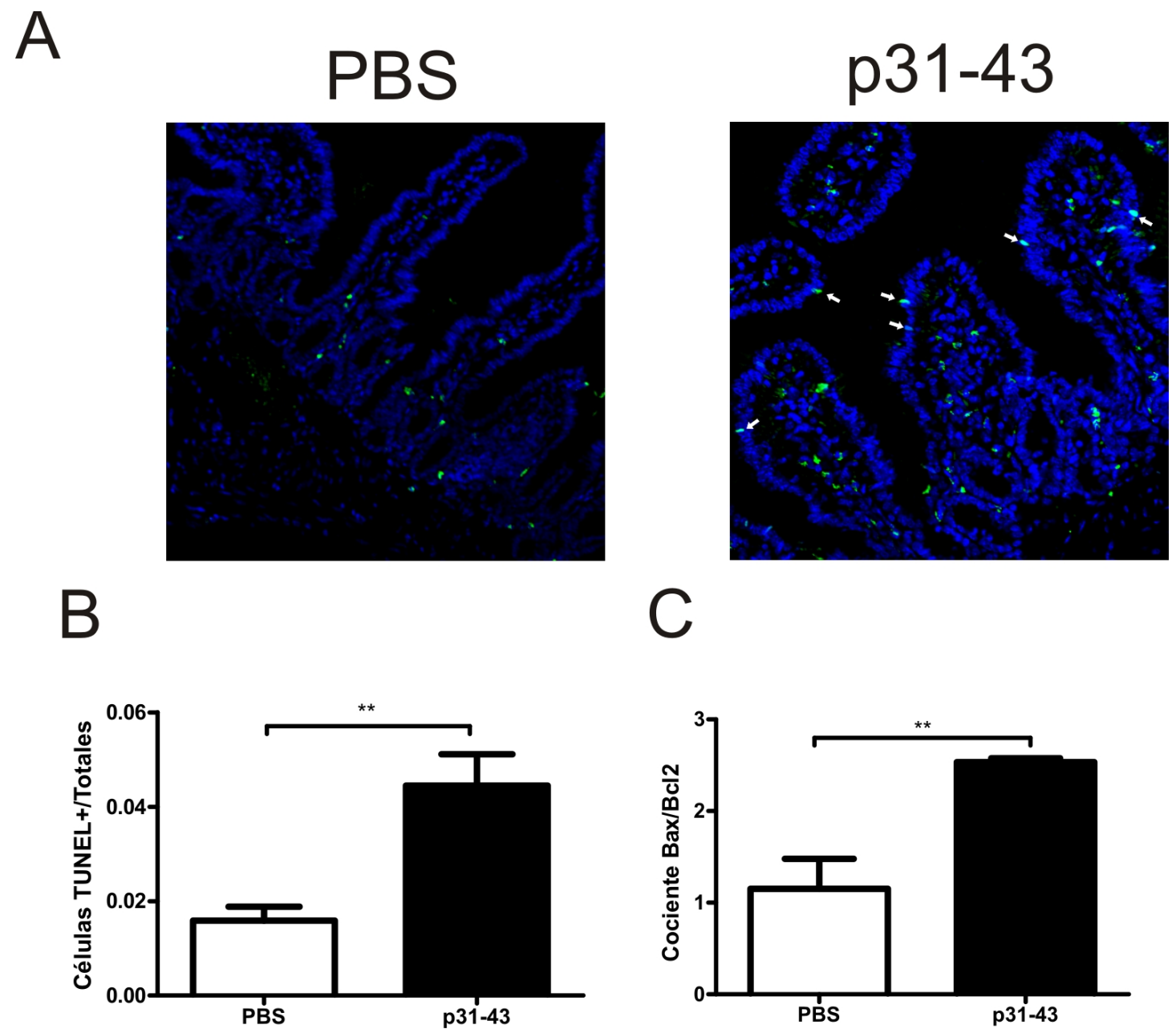

Figura 2.10. p31-43 induce muerte celular y un perfil pro-apoptótico en intestino delgado.

Secciones de intestino delgado luego de $12 \mathrm{hs}$ de tratamiento fueron incluidas en parafina y marcadas mediante la técnica de TUNEL. Los núcleos fueron contrateñidos con DAPI (azul) y las células TUNEL ${ }^{+}$se observan teñidas con fluoresceína (verde). Se muestran imágenes representativas tomadas en un microscopio confocal Olympus (A). De las imágenes tomadas se realizó una cuantificación automatizada del número de células TUNEL $^{+}$y de células totales mediante el programa Image J (B). La expresión de ARNm de Bcl2 y Bax fue determinada en muestras de intestino delgado luego de $12 \mathrm{hs}$ post-estimulación mediante PCR en Tiempo Real. Se muestra el cociente Bax/Bcl2 (C). $\mathrm{N}=4$,Test t no pareado, $* * \mathrm{p}<0,01$ del tratamiento con $\mathrm{p} 31-43$ versus el control de PBS. 
Estos resultados son claramente diferentes a los mostrados en el capítulo anterior (Figura 1.19), donde el daño por poly (I:C) no se acompañaba de un aumento del cociente pro-apoptótico y que destacan las diferentes vías que se desencadenan frente a ambos estímulos.

Por otro lado, medimos la expresión a nivel de proteína de Caspasa-3 clivada. Para esto se evaluaron los niveles de pro-caspasa 3 y caspasa 3 clivada por western blot en muestras de intestino delgado $12 \mathrm{hs}$ post-tratamiento con p31-43 o PBS. La cuantificación por densitometría de las bandas del western blot mostró que la relación de los niveles de caspasa 3 activada con respecto al total, se encontraban significativamente disminuidos en animales tratados con p31-43 referidos a PBS. (Figura 2.11A). Por otra parte, la tinción específica de Caspasa 3 clivada por inmunofluorescencia arrojó resultados similares a los observados con la técnica de western blot, no presentándose diferencias entre los ratones tratados con el péptido y los controles (Figura 2.11B)

A
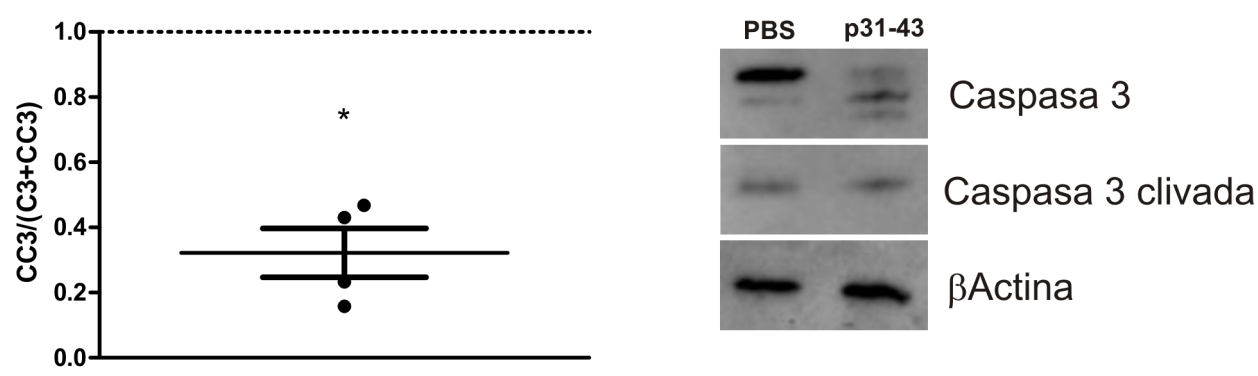

$\mathrm{B}$
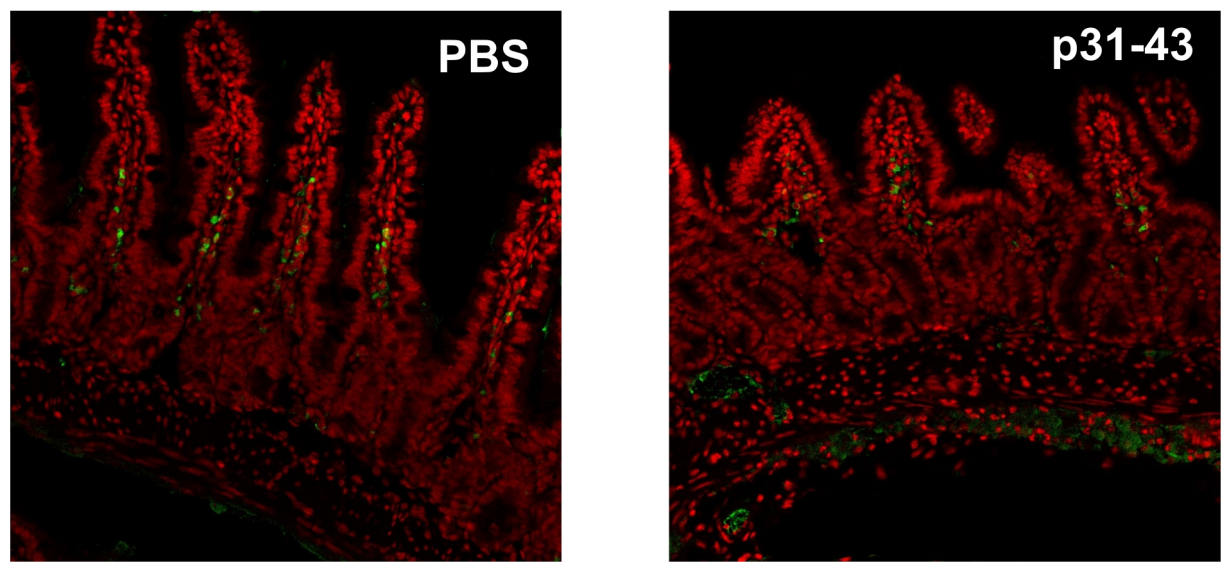

Figura 2.11. Niveles de caspasa 3 activada en intestino delgado de animales tratados con p31-43.

La expresión de caspasa 3 y caspasa 3 clivada fue evaluada mediante la técnica de Western blot en muestras de proteína extraídas de intestino delgado $12 \mathrm{hs}$ post-estimulación. La cantidad de proteína fue determinada por densitometría y expresada como la relación Caspasa3 clivada/(Caspasa3 clivada+ Caspasa3). El resultado expresa la comparación entre los estímulos con p31-43 referidos al control de PBS (al cual le corresponde el valor 1). $\mathrm{N}=4$ ratones por grupo, Test $\mathrm{t}$ No pareado, ${ }^{*} \mathrm{P}<0.05$ (A). Imágenes representativas de microscopía confocal de cortes marcados con un anticuerpo anti-Caspasa 3 clivada conjugado con Alexa488 (Verde) observados en un microscopio confocal Leica. Los núcleos fueron teñidos con ioduro de propidio (Rojos). Aumento: 20X (B). 
Estos resultados no indican la participación de la vía canónica de apoptosis en la muerte celular observada en la enteropatía inducida por p31-43. Sin embargo, no podemos descartar el rol de esta vía de muerte ya que es necesario reevaluar muestras de intestino delgado a tiempos más cortos post-estimulación para evidenciar si la Caspasa 3 fue activada tempranamente.

\section{La enteropatía inducida por p31-43 es dependiente de MyD88.}

Como hemos mencionado, si bien se han descripto diferentes efectos de p31-43 en distintos sistemas experimentales no se conoce aún su receptor y, por lo tanto, tampoco las vías de señalización que participan en la inducción de los mediadores proinflamatorios. Con el objetivo de comprender estas vías analizamos, en primer lugar, si la señalización por TLR4 estaba implicada en la transducción de la señal de daño propiciada por p31-43. Para esto se evaluó la respuesta obtenida ante la estimulación intraluminal de este péptido en el intestino delgado de animales $\mathrm{C} 3 \mathrm{H} / \mathrm{HeJ}$. Los ratones $\mathrm{C} 3 \mathrm{H} / \mathrm{HeJ}$ tienen un déficit en la señalización de TLR4, por lo cual su uso nos permitiría evaluar la importancia de esta vía en la inducción de daño.

El análisis del cociente $\mathrm{V} / \mathrm{C}$ indica que el p31-43 induce enteropatía en animales $\mathrm{C} 3 \mathrm{H} / \mathrm{HeJ}$ de modo similar a lo previamente observado con ratones C57BL/6 (Figura 2.12). De esta forma, podemos concluir que la señalización por TLR4 no es requerida en la enteropatía inducida por p31-43. Sin embargo, no

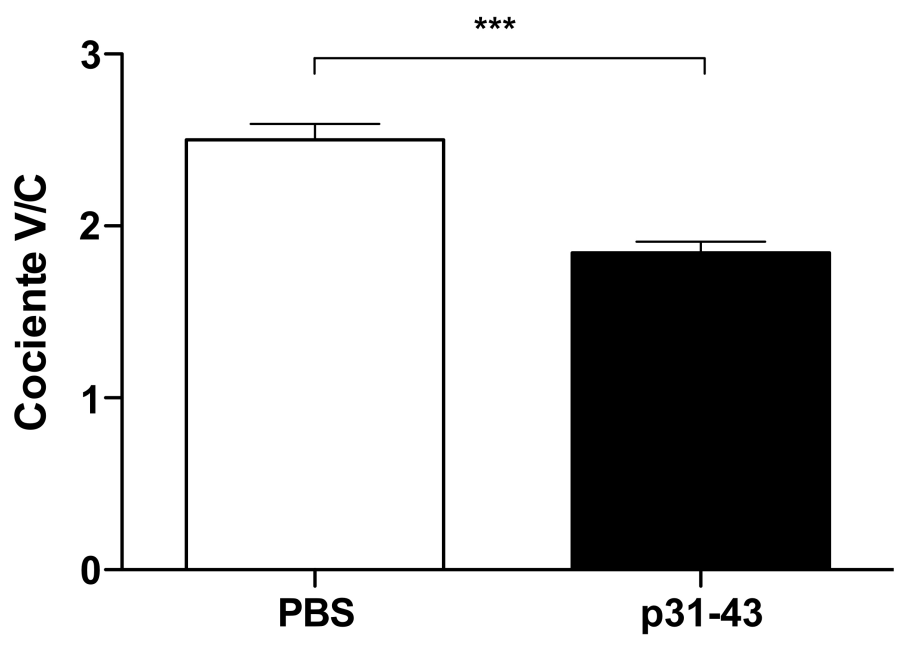

Figura 2.12. La señalización de TLR4 no es necesaria para la inducción de daño por p31-43.

Análisis morfométrico de secciones de intestino delgado obtenidas de ratones $\mathrm{C} 3 \mathrm{H}-\mathrm{HeJ}$ luego de $12 \mathrm{hs}$ de estímulo intraluminal con PBS o p31-43. Se representa el cociente V/C en cada caso determinado a partir de la tinción con H\&E. $\mathrm{N}=4$ ratones por grupo, Test t no pareado. ${ }^{* * *} \mathrm{P}<0,001$. 
podemos descartar que los intermediarios de la vía downstream de este receptor no participen en uno o varios pasos de la inducción con p31-43. Este resultado también descarta el efecto de LPS, que comúnmente se encuentra como contaminante en el curso de los experimentos y puede introducir errores en la interpretación de los resultados obtenidos. En nuestro caso, la enteropatía inducida por p31-43 no es debida a la presencia de LPS en la preparación del péptido de síntesis u otro reactivo empleado en el protocolo.

Estudios in vitro revelaron que el aumento de permeabilidad intestinal y el perfil proinflamatorio inducido por gliadinas está asociado a la señalización por MyD88 (Thomas et al. 2006; K M Lammers et al. 2008), vía central en la respuesta innata. En nuestro trabajo hemos observado una rápida respuesta (2-4hs postestimulación) de varios genes proinflamatorios, hecho que sugiere que la vía de MyD88 podría estar involucrada en la enteropatía inducida por p31-43. Con este fin decidimos evaluar si el p31-43 genera daño cuando se inyecta intraluminalmente en animales MyD88 KO.

A
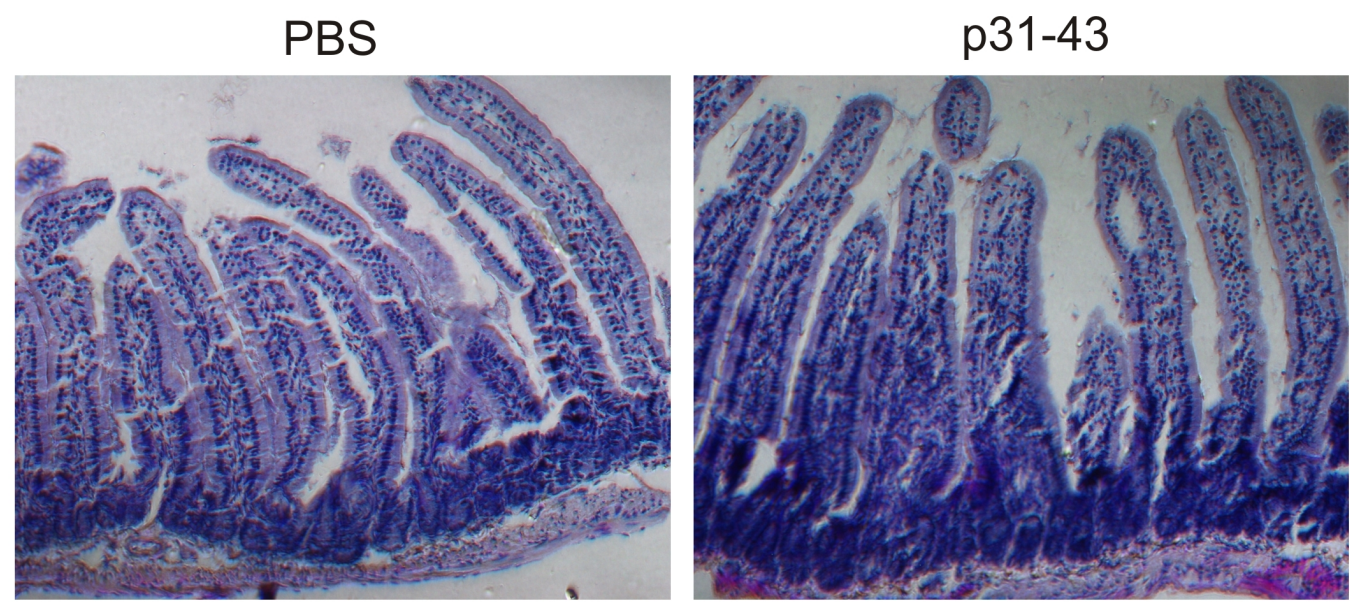

B
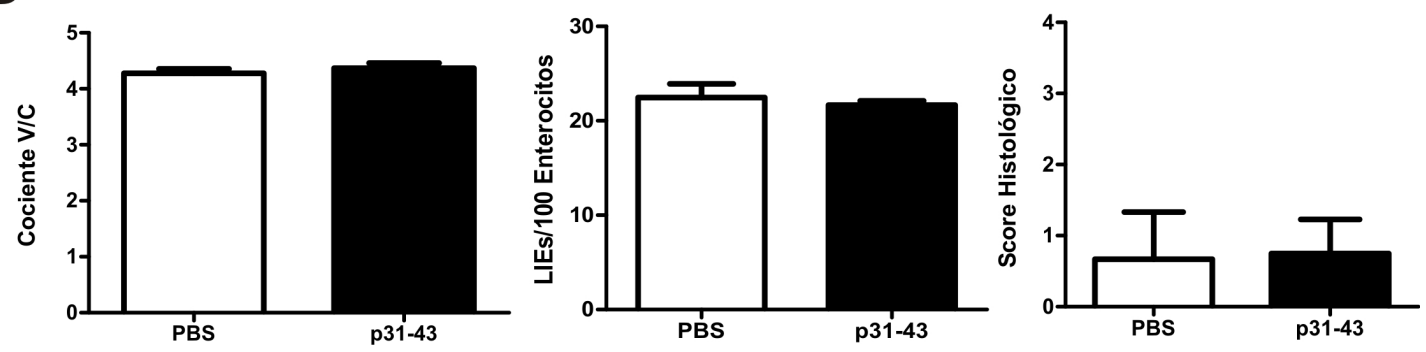

Figura 2.13. La enteropatía inducida por p31-43 es dependiente de la señalización por MyD88.

Secciones teñidas con H\&E representativas de intestino delgado proximal de ratones MyD88 KO después de 12hs de la administración de p31-43 o PBS (A). Análisis morfológico de intestino delgado de ratones C57BL/6: Cociente V/C, número de LIEs y score histológico después de 12hs (B). $\mathrm{N}=5$ ratones por grupo, test $\mathrm{t}$ no pareado. 
El análisis morfológico del intestino delgado de animales MyD88 KO a las $12 \mathrm{hs}$ post-estimulación, mostró estructuras histológicamente normales y ausencia de inflamación o infiltrado tanto en ratones tratados con p31-43 como con PBS (Figura 2.13A). El cociente V/C no presentó diferencias significativas entre ambos grupos (Figura 2.13B). De la misma forma, el recuento de LIEs y el score histológico fueron similares en animales tratados con p31-43 o con PBS, presentando el score una leve afectación propia de la cirugía, como ya ha sido observado en la puesta a punto del modelo (Figura 2.13B).

Hasta este punto es claro que para generar el daño histológico en la enteropatía inducida por p31-43 se requiere la participación del adaptador MyD88.

En esta misma línea de análisis, nos propusimos evaluar si la señalización por MyD88 participaba en los mecanismos de muerte ya caracterizados para p3143 in vivo. Para esto se evaluó el número de células TUNEL $^{+}$en secciones de intestino delgado de ratones MyD88 KO tratados intraluminalmente con p31-43 o PBS.

Las imágenes obtenidas para p31-43 y PBS presentaron sólo algunos núcleos TUNEL $^{+}$de modo similar en ambos estímulos (Figure 2.14A). El recuento de células TUNEL $^{+}$fue similar en animales MyD88 KO tratados con p31-43 o PBS (Figura 2.14B) y también similares a los obtenidos en ratones C57BL/6 tratados con PBS (Figura 2.10B).
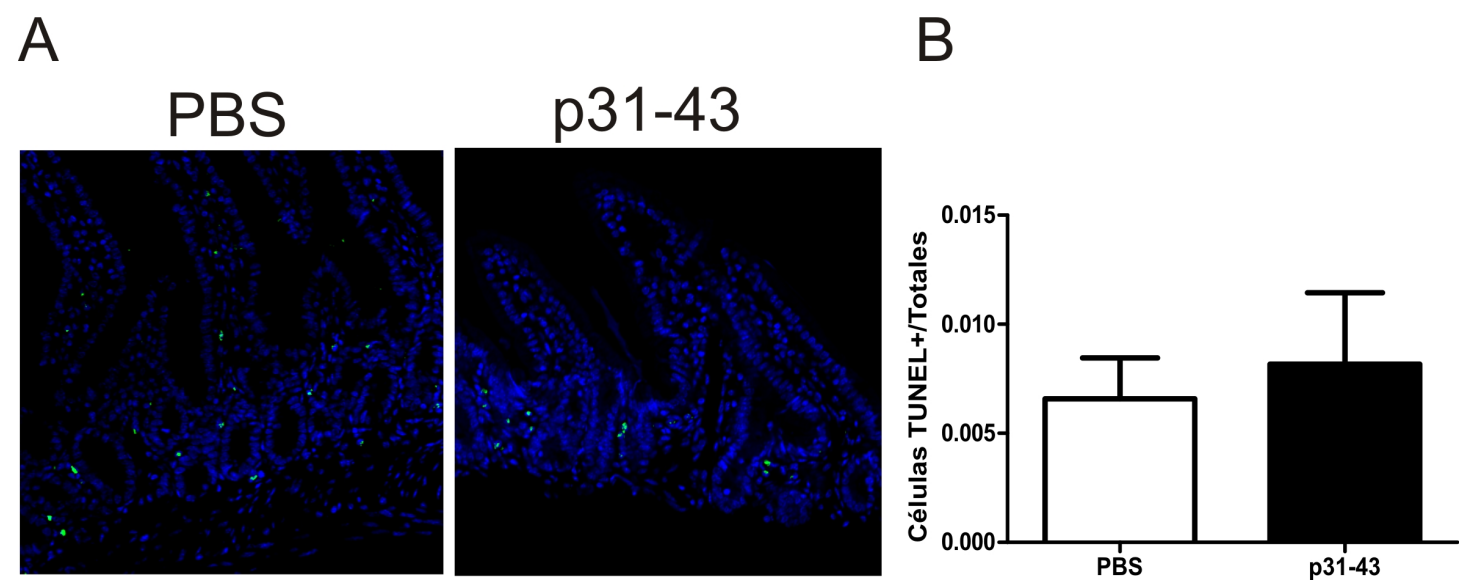

Figura 2.14. La muerte celular inducida por p31-43 es dependiente de MyD88.

Análisis de muerte celular mediante la técnica de TUNEL en secciones de intestino delgado de ratones MyD88 KO 12hs post-estimulación con p31-43 o PBS. Los núcleos fueron teñidos con DAPI (azul) y las células TUNEL ${ }^{+}$se observan teñidas con fluoresceína (verde). Las imágenes fueron tomadas en un microscopio confocal Olympus (A). De las imágenes tomadas se realizó una cuantificación automatizada del número de células TUNEL $^{+}$y de células totales mediante el programa Image J. Se grafica la relación del número de células TUNEL ${ }^{+}$referido al número de células totales (B). Test t no pareado. No se presentaron diferencias significativas. 
En conclusión, la señalización por MyD88 es necesaria para la inducción de daño y muerte celular en la enteropatía causada por administración intraluminal de p31-43.

Poly (I:C), p31-43 y la combinación de ambos generan diferente tipo de enteropatía.

Como pudimos observar a lo largo de los capítulos 1 y 2, tanto poly (I:C) como p31-43 generan enteropatía cuando son inyectados intraluminalmente. Sin embargo, es claro que ambos estímulos tienen mecanismos de daño diferentes: implican diferentes mediadores moleculares y la característica histológica de la enteropatía generada presenta particularidades que apuntarían a mecanismos distintos.

Por este motivo, nos propusimos evaluar si la combinación de estos dos mediadores era capaz de inducir un daño distinto al observado con cada uno individualmente. De este modo, si nuestro modelo busca imitar los mecanismos tempranos en la inducción de enteropatía por infecciones virales que podrían predisponer a una respuesta exacerbada a un antígeno dietario, con la combinación de poly (I:C) y el p31-43 buscamos poner en juego el factor viral y el factor dietario en el mismo modelo.

En un primer estudio comparativo, pudimos ver el efecto sobre la histología de los ratones C57BL/6 tratados con poly (I:C), p31-43 o ambos luego de 12 y 72hs post-estímulo. Se puede observar en la Figura 2.15A que si bien tanto poly (I:C) como p31-43 generaron daño a las 12hs post-tratamiento, la combinación de ambos también lo generó, pero no parece presentar un efecto cooperativo de

A

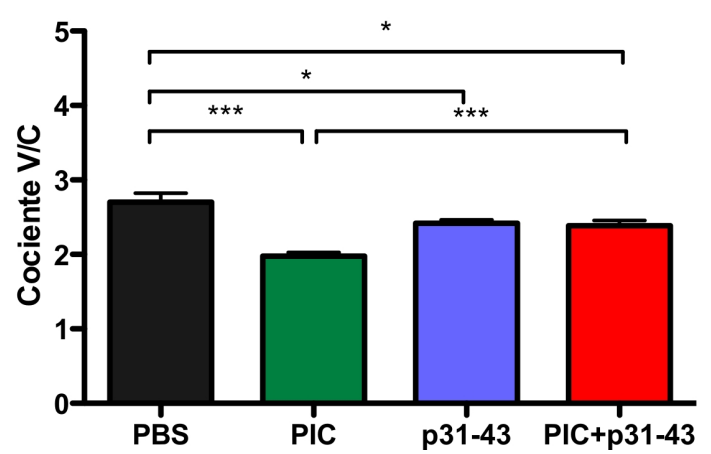

B

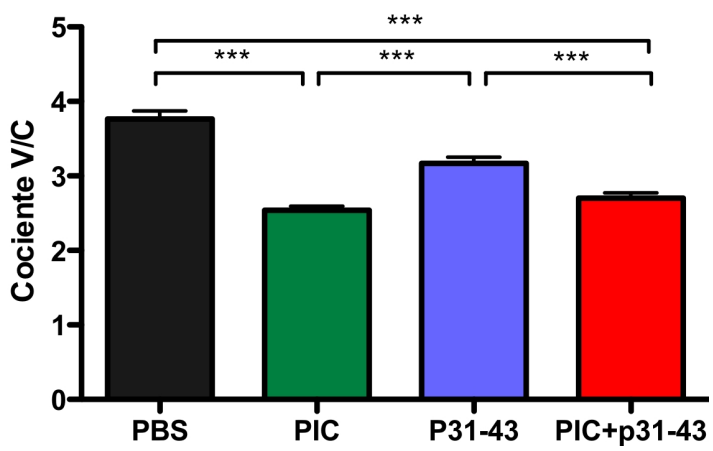

Figura 2.15. La combinación de poly (I:C) con p31-43 genera enteropatía de un modo distinto a los estímulos individuales.

Análisis morfométrico de secciones de intestino delgado obtenidas de ratones C57BL/6 luego de 12 (A) y $72 \mathrm{hs} \mathrm{(B)} \mathrm{de} \mathrm{estímulo} \mathrm{intraluminal} \mathrm{con} \mathrm{PBS,} \mathrm{poly} \mathrm{(I:C),} \mathrm{p31-43} \mathrm{o} \mathrm{poly} \mathrm{(I:C)+p31-43.} \mathrm{Se} \mathrm{representa}$ el cociente $\mathrm{V} / \mathrm{C}$ en cada caso determinado a partir de la tinción con H\&E. $\mathrm{N}=4$ ratones por grupo, Test t no pareado. ${ }^{*} \mathrm{p}<0,05,{ }^{* * *} \mathrm{P}<0,001$. 
ambos estímulos. Así, el cociente V/C de los ratones tratados con poly (I:C)+p3143 es significativamente mayor al observado con poly (I:C) solo (Figura 2.15A). No hay diferencias estadísticamente significativas con lo observado en los ratones tratados con p31-43 (Figura 2.15A). Cuando evaluamos la recuperación de estos animales luego de $72 \mathrm{hs}$ de estímulo, observamos que todos los grupos presentaron cocientes $\mathrm{V} / \mathrm{C}$ significativamente menores al control de PBS, pero esta vez la combinación de poly (I:C)+p31-43 presentó valores de cociente V/C significativamente menores a los observados en ratones tratados sólo con p31-43 y no hubieron diferencias con los tratados con poly (I:C) solo (Figura 2.15B). Por lo tanto, si bien en todos los casos hubo una leve recuperación del cociente $\mathrm{V} / \mathrm{C}$ respecto de las $12 \mathrm{hs}$, dicha recuperación fue distinta para los animales tratados con poly (I:C) y p31-43, como ya lo hemos mencionado con anterioridad. La combinación de ambos por su parte parece estar siendo dominada por mecanismos diferentes, cambiando su comportamiento entre las 12 y las $72 \mathrm{hs}$ respecto a los tratamientos individuales.

Debido a lo observado hasta el momento, decidimos determinar si las diferencias a nivel histológico entre el estímulo doble y los estímulos individuales se reflejaban en la expresión de mediadores proinflamatorios evaluados previamente. Así determinamos la expresión a nivel de ARNm de los diferentes mediadores entre las 2 y las $12 \mathrm{hs}$ a partir de muestras de intestino delgado de ratones C57BL/6 tratados con poly (I:C)+p31-43.

Encontramos varias diferencias en el estudio de la expresión de citoquinas proinflamatorias. Se observó un incremento de la expresión de IFN $\beta$ a las 4 hs, la cual es tardía, respecto al estímulo de poly (I:C) pero más intensa respecto a lo

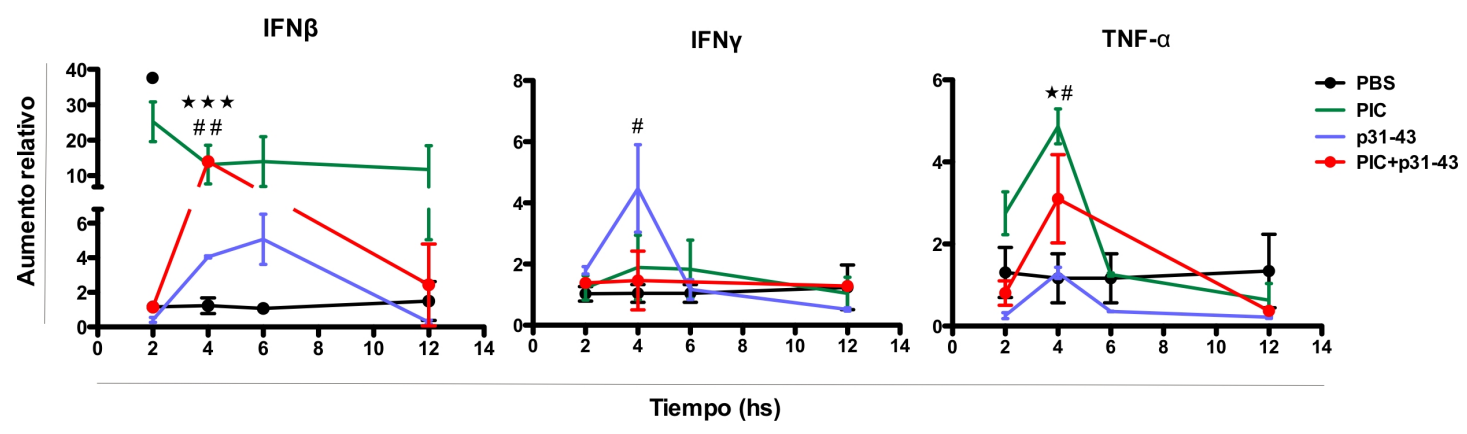

Figura 2.16. Comportamiento diferencial de los estímulos poly (I:C), p31-43 y poly (I:C)+p31-43.

Análisis con PCR en tiempo real de los niveles de ARNm de IFN $\beta$, IFN $\gamma$ y TNF $\alpha$ entre las 2 y $12 \mathrm{hs}$ post-tratamiento con PIC+p31-43 (Rojo), PIC (Verde), p31-43 (Celeste) y PBS (Negro). Para cada tiempo, todos los valores fueron normalizados con el gen constitutivo HPRT. Todos los resultados fueron expresados como aumento relativo a la media de los valores de los ratones tratados con PBS en cada punto de tiempo $\left(2^{-\Delta \Delta t}\right)$. $N=4$ ratones por grupo, Test $t$ No pareado: $\star p<0,05$ y $\star \star \star \mathrm{p}<0,001$ PIC+p31-43 vs PBS; $\bullet P<0.05$ PIC+p31-43 vs PIC; \# $\mathrm{p}<0.05$ y $\# \# \mathrm{p}<0.01$ PIC+p31-43 vs p31-43, en cada punto de tiempo. 
observado con p31-43 (Figura 2.16). No se observó un incremento de IFN $\gamma$ presentado a las 4hs cuando el estímulo fue p31-43, pero sí un moderado incremento de la expresión de $\mathrm{TNF} \alpha$ a las 4hs, significativamente más alto que cuando se inyectó sólo p31-43 (Figura 2.16). En resumen, el estímulo doble indujo la expresión de ARNm de IFN $\beta$ y TNF $\alpha$ a las 4 hs post-tratamiento en forma similar a poly (I:C) y no indujo IFN $\gamma$ a diferencia del estímulo con p31-43.

Situaciones muy contrastantes se observaron cuando se evaluó la expresión de IL-6 e IL-18, las cuales presentaron incrementos significativos respecto a PBS, siendo en ambos casos significativamente mayores a lo observado con p31-43 (Figura 2.17). En el caso de IL-6 se observó una clara inducción a las 4hs, mientras que IL-18 presentó su pico máximo tempranamente a las 2 hs, siendo en este punto significativamente mayor tanto a poly (I:C) como a p31-43 solos (Figura 2.17). Los niveles de expresión de IL-1 $\beta$ no presentaron inducción ni diferencias en ninguno de los casos (Figura 2.17). Por lo tanto, podemos decir que poly (I:C)+p31-43 inducen la expresión a nivel de ARNm de IL-6 e IL-18 de modo diferente a los estímulos separados.

Cuando evaluamos la expresión de las quimoquinas CXCL2 y MCP1 se observaron resultados muy diversos. CXCL2 se vió rápidamente aumentada a las 2hs con el estímulo doble, a diferencia de lo observado con los estímulos individuales y es significativamente diferente a estos (Figura 2.18). MCP1 por su parte, también se vió aumentada a las 4 hs y también dicho aumento fue significativamente diferente a lo observado con los estímulos individuales (Figura 2.18).
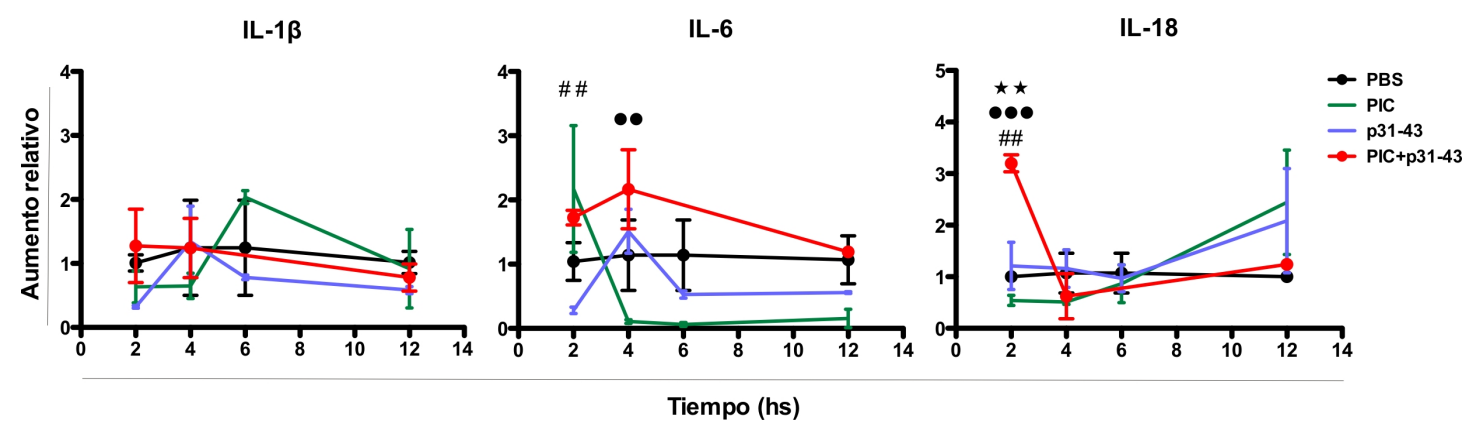

Figura 2.17. El estímulo doble induce la expresión de ARNm de IL-6 e IL-18.

Análisis con PCR en tiempo real de los niveles de ARNm de IL-1 $\beta$, IL-6 y IL-18 entre las 2 y $12 \mathrm{hs}$ post-tratamiento con PIC+p31-43 (Rojo), PIC (Verde), p31-43 (Celeste) y PBS (Negro). Para cada tiempo, todos los valores fueron normalizados con el gen constitutivo HPRT. Todos los resultados fueron expresados como aumento relativo a la media de los valores de los ratones tratados con PBS en cada punto de tiempo $\left(2^{-\Delta \Delta c t}\right)$. $N=4$ ratones por grupo, Test t No pareado: $\star \star \mathrm{p}<0,01 \mathrm{PIC}+\mathrm{p} 31-43$ vs $\mathrm{PBS} ; \bullet \bullet P<0,01$ y $\bullet \bullet \bullet \mathrm{p}<0,001$ PIC+p31-43 vs PIC; \#\# $\mathrm{p}<0.01$ PIC+p31-43 vs $\mathrm{p} 31-43$, en cada punto de tiempo. 


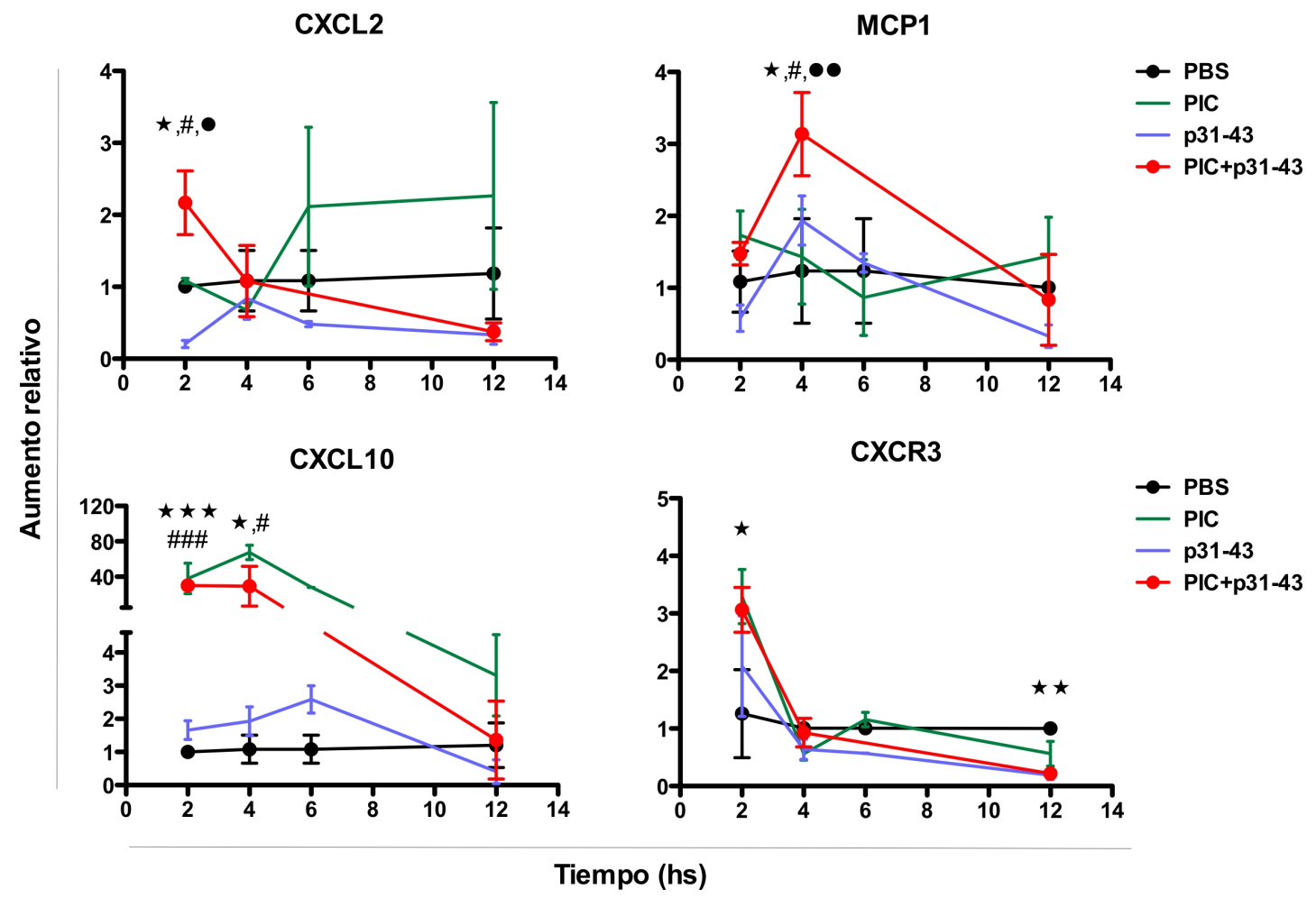

Figura 2.18. El estímulo doble induce la expresión de ARNm de CXCL2, MCP-1, CXCL10 y CXCR3.

Análisis con PCR en tiempo real de los niveles de ARNm de CXCL2, MCP-1, CXCL10 y CXCR3 entre las 2 y 12hs post-tratamiento con PIC+p31-43 (Rojo), PIC (Verde), p31-43 (Celeste) y PBS (Negro). Para cada tiempo, todos los valores fueron normalizados con el gen constitutivo HPRT. Todos los resultados fueron expresados como aumento relativo a la media de los valores de los ratones tratados con PBS en cada punto de tiempo $\left(2^{-\Delta \Delta t}\right)$. $\mathrm{N}=4$ ratones por grupo, Test $t$ No pareado: $\star$ $\mathrm{p}<0,05, \star \star \mathrm{p}<0,01 \mathrm{y} \star \star \star \mathrm{p}<0,001$ PIC $+\mathrm{p} 31-43$ vs PBS; $\bullet P<0,05$ y $\bullet \bullet p<0,01$ PIC+p31-43 vs PIC; \# $\mathrm{p}<0.05$ y \#\#\# $\mathrm{p}<0,001$ PIC+p31-43 vs p31-43, en cada punto de tiempo.

En la evaluación del eje CXCL10/CXCR3 también se observaron resultados diferentes de acuerdo al estímulo utilizado. La cinética de expresión de CXCL10 se mantuvo similar a la observada para poly (I:C) solo, con una fuerte inducción a las 2 y 4hs. Dichos incrementos fueron significativamente distintos a lo observado en el tratamiento con p31-43. Por su parte, la expresión de ARNm de CXCR3 presentó un rápido incremento a las 2hs post-tratamiento con el estímulo doble, similar a lo observado con poly (I:C). En cambio, a las 12 hs el estímulo doble generó una disminución que no fue observada en ningún otro caso.

Por último, en la evaluación de la expresión de dos moléculas relevantes en la patogenia de EC, IL-15 y TG2, se obtuvieron resultados muy similares a los ya observados con los estímulos individuales, donde TG2 no se vio inducida mientras que la expresión de ARNm de IL-15 se vio disminuido (Figura 2.19). 


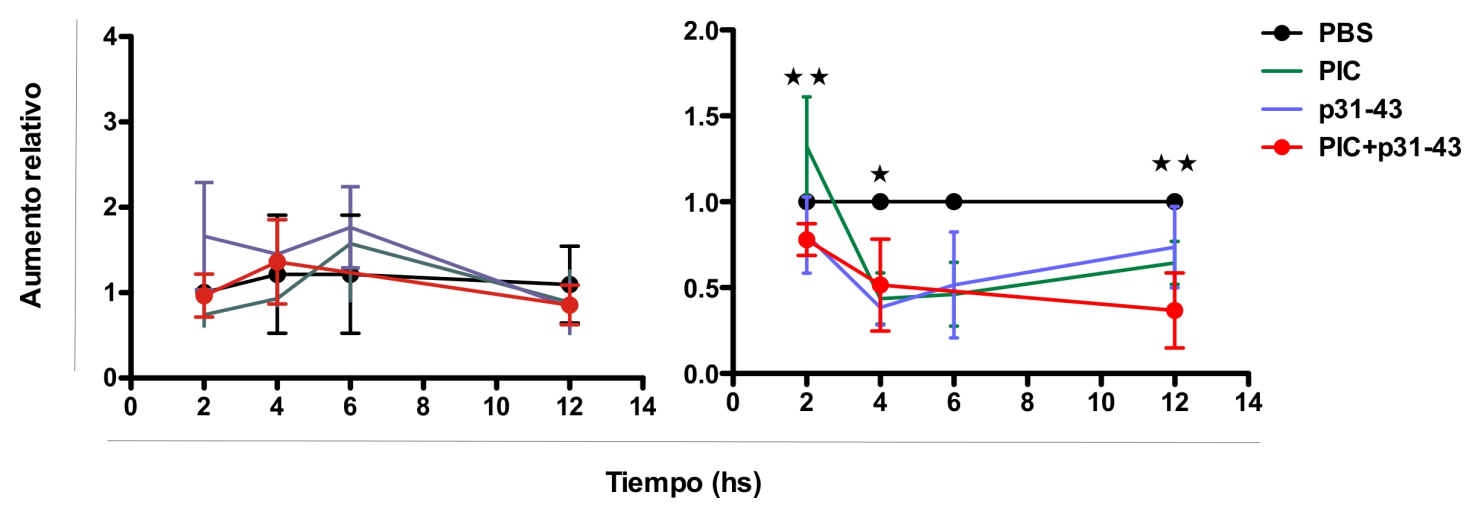

Figura 2.19. El estímulo doble no induce la expresión de ARNm de TG2 o IL-15.

Análisis con PCR en tiempo real de los niveles de ARNm de TG2 e IL-15 entre las 2 y $12 \mathrm{hs}$ posttratamiento con PIC+p31-43 (Rojo), PIC (Verde), p31-43 (Celeste) y PBS (Negro). Para cada tiempo, todos los valores fueron normalizados con el gen constitutivo HPRT. Todos los resultados fueron expresados como aumento relativo a la media de los valores de los ratones tratados con PBS en cada punto de tiempo $\left(2^{-\Delta \Delta \mathrm{ct}}\right)$. $\mathrm{N}=4$ ratones por grupo, Test t No pareado: $\star \mathrm{p}<0,05 \mathrm{PIC}+\mathrm{p} 31-43 \mathrm{vs}$ PBS, en cada punto de tiempo.

En conjunto, estos resultados muestran que las vías inducidas por poly (I:C) y el p31-43 son diferentes y que el estímulo conjunto de ambos, no resulta en un efecto aditivo simple de lo observado con cada estímulo individualmente, sino que las vías desencadenadas son diferentes, al menos parcialmente.

\section{Inducción de muerte celular por el estímulo con poly (I:C)+p31-43}

Finalmente, como hemos mostrado aquí y en el capítulo anterior, una de las mayores diferencias observadas entre los estímulos de poly (I:C) y p31-43 se encuentra en el mecanismo de inducción de daño. Por ese motivo decidimos evaluar el mecanismo de muerte que podría estar implicado cuando se inyecta intraluminalmente el estímulo doble de poly (I:C)+p31-43.

Tomamos secciones de ratones estimulados con el tratamiento doble y analizamos muerte celular mediante la técnica de TUNEL. Las imágenes de microscopía confocal obtenidas muestran una clara diferencia en el número de células TUNEL $^{+}$en lamina propria en el animal tratado con el estímulo doble versus el animal control (Figura 2.20). Los recuentos automatizados de dichas imágenes indicaron que existe significativamente mayor número de células TUNEL $^{+}$en los ratones tratados con poly (I:C)+p31-43 intraluminal que en aquellos que recibieron PBS. Por lo tanto, esto marca una diferencia con lo observado en los ratones tratados sólo con poly (I:C) intraluminal (Figura 1.19B), donde no se observó diferencia significativa en los animales tratados con PBS. 
A

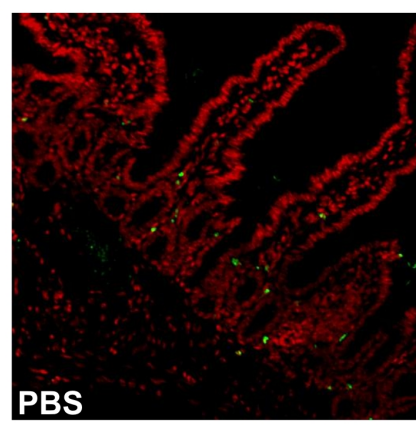

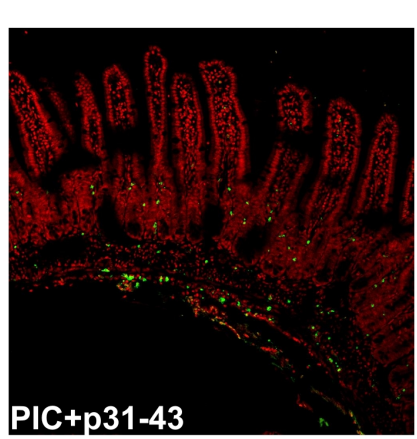

B

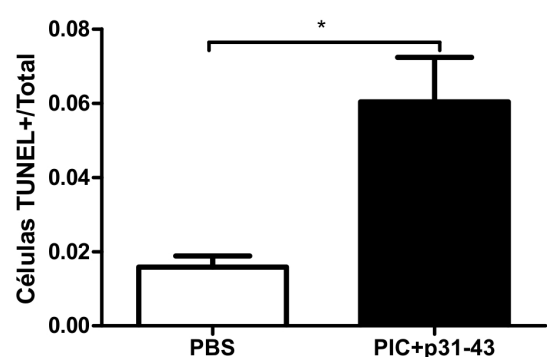

Figura 2.20. El estímulo doble induce muerte celular en lamina propria de ratones C57BL/6.

Análisis de muerte celular mediante la técnica de TUNEL en secciones de intestino delgado de ratones C57BL/6 12hs post-estimulación con PIC+p31-43 o PBS. Los núcleos fueron contrateñidos con Ioduro de propidio (rojo) y las células $\mathrm{TUNEL}^{+}$se observan teñidas con fluoresceína (verde). Las imágenes fueron tomadas en un microscopio confocal Leica (A). De las imágenes tomadas se realizó una cuantificación automatizada del número de células TUNEL ${ }^{+}$y de células totales mediante el programa Image J. Se grafica la relación del número de células TUNEL ${ }^{+}$referido al número de células totales (B). Test t no pareado, ${ }^{*} \mathrm{p}<0,05$.

Cuando evaluamos en un estudio cinético el nivel de expresión de Bax y Bcl2 en los ratones tratados con el estímulo doble, se observó un comportamiento muy particular. A las 2hs post-tratamiento con poly (I:C)+p31-43 se observó un claro cociente anti-apoptótico de $\mathrm{Bax}$ y $\mathrm{Bcl} 2$ respecto al control, similar a lo que se observaba en el tratamiento con poly (I:C). Esta situación reviertió a las 4hs a un cociente normal comparable al control y presentó una tendencia a las 12 hs a un proceso pro-apoptótico, similar a lo que se observaba en el estímulo de p31-43 (Figura 2.21).

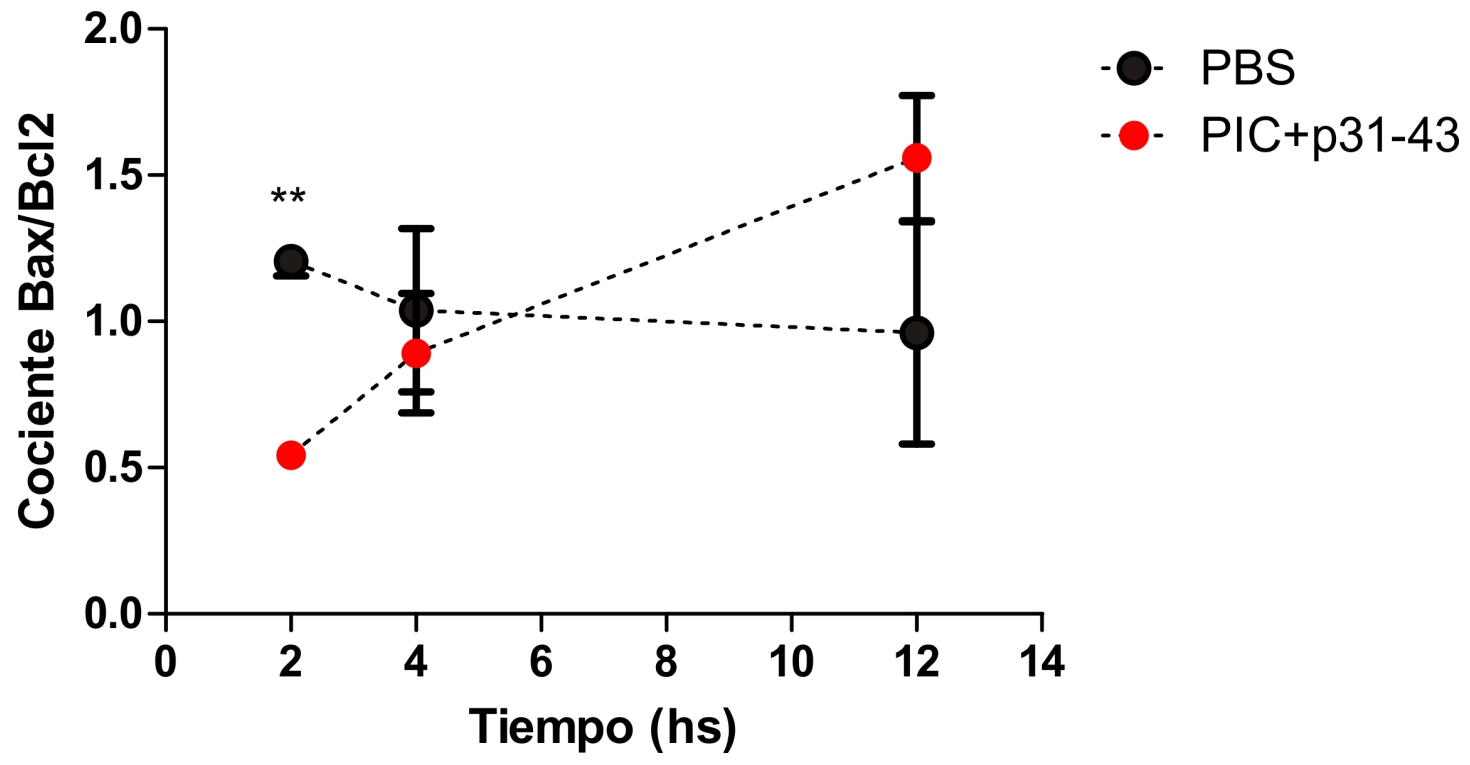

Figura 2.21. Estudio cinético del cociente $\mathrm{Bax} / \mathrm{Bcl} 2$ luego del tratamiento con poly (I:C)+p31-43.

La expresión de ARNm de Bcl2 y Bax fue determinada mediante PCR en Tiempo Real en muestras de intestino delgado de ratones C57BL/6 luego de 2, 4 y $12 \mathrm{hs}$ post-estimulación con poly (I:C)+p31-43 (PIC+p31-43) o PBS. Se calculó el cociente Bax/Bcl2 en cada punto de tiempo. N=4,Test t no pareado, ** $\mathrm{p}<0,01$ del tratamiento con PIC+p31-43 versus el control de PBS. 

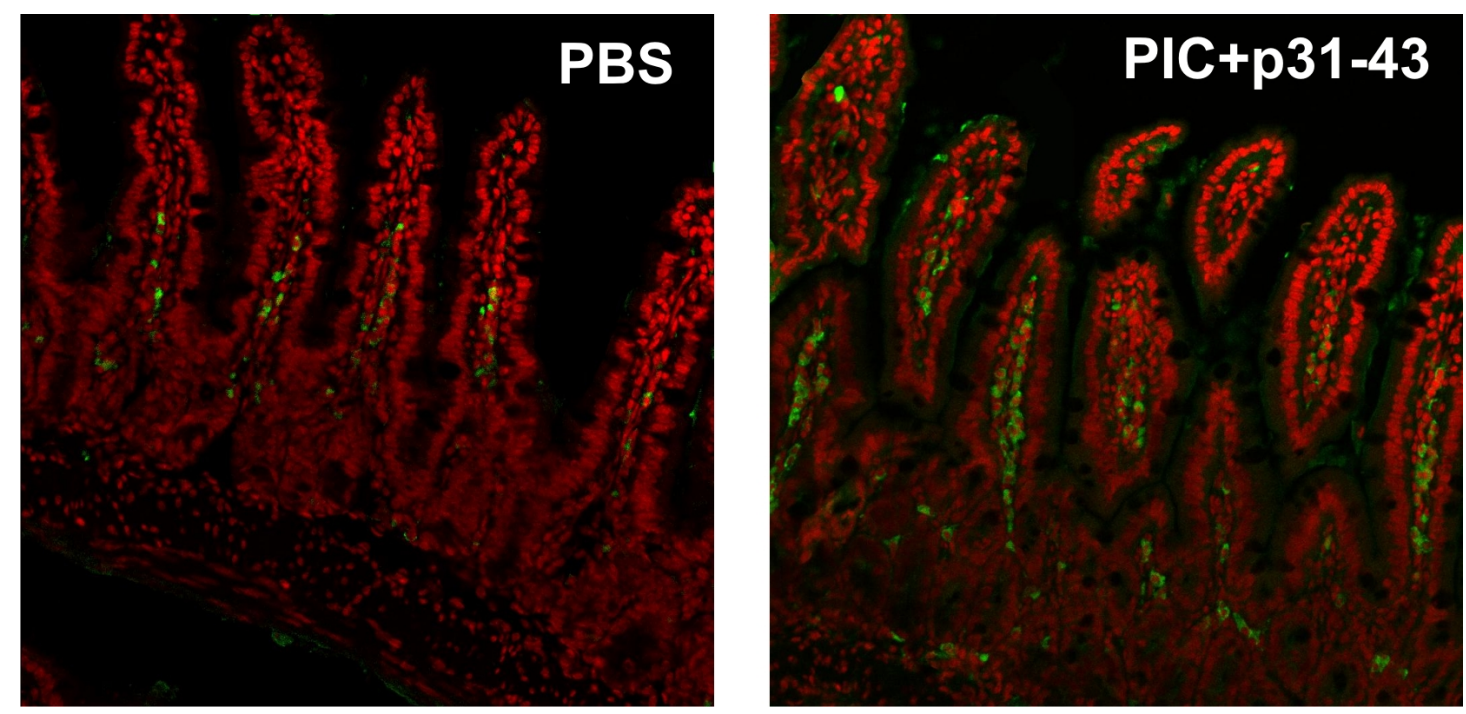

Figura 2.22. El estímulo doble induce la expresión de Caspasa 3 clivada en lamina propria.

Imágenes representativas de la expresión de Caspasa 3 clivada en secciones de intestino delgado mediante la marca fluorescente con un anticuerpo anti-Caspasa 3 conjugado con Alexa488. Muestras tomadas a las $12 \mathrm{hs}$ post-estimulación con PBS o PIC+p31-43. Las imágenes fueron tomadas con un microscopio confocal Leica y procesadas con el programa ImageJ.

Por último, decidimos medir la expresión de Caspasa 3 clivada en secciones de intestino delgado luego de $12 \mathrm{hs}$ de estímulo mediante inmunofluorescencia (Figura 2.22).

Así, observamos que el estímulo doble generó un enorme incremento en la expresión de Caspasa 3 clivada en lamina propria como claramente se puede ver en las microfotografías obtenidas en un microscopio confocal (Figura 2.22). Esto es claramente distinto a lo observado para los estímulos individuales en el mismo tiempo considerado e indica que la Caspasa 3, Caspasa efectora tanto de la vía intrínseca como extrínseca de apoptosis, es fuertemente inducida por el estímulo combinado de poly (I:C) y el p31-43. 


\section{DISCUSIÓN}

En este capítulo desarrollamos un modelo de enteropatía mediante la inyección de p31-43 intraluminal en ratones C57BL/6. El daño generado se caracteriza por un descenso del cociente $\mathrm{V} / \mathrm{C}$, un incremento del número de LIEs y un incremento del score histológico. Esta es la primera vez que se evalúan los efectos in vivo sobre la mucosa intestinal de este péptido derivado de $\alpha$-gliadinas.

En primer lugar encontramos que el daño generado por p31-43 es específico de la composición aminoacídica del mismo y no debido a un efecto osmótico por la simple presencia de un péptido en altas concentraciones en la luz del intestino. Particularmente demostramos que es la composición de aminoácidos la responsable del daño, dado que utilizando un péptido de la misma composición pero distinta secuencia (PDS) aún se genera daño en la mucosa intestinal de ratones C57BL/6. Esto está de acuerdo con el concepto general preestablecido de la mayoría de los estudios que indica que la toxicidad de estos péptidos y del gluten radica en la particular composición de aminoácidos de las prolaminas (Iacomino et al. 2013; Ménard et al. 2012; Lebreton et al. 2012; Meresse, Malamut, and Cerf-Bensussan 2012).

Por otra parte, determinamos que este péptido tiene un fuerte efecto proliferativo en las criptas de intestino delgado, evidenciado como un aumento del número de células $\mathrm{Ki}^{+} 7^{+}$en las criptas de los ratones estimulados con p31-43 respecto a los animales del grupo control. Si bien con el método dinámico de determinación del estado proliferativo, CCPR, no encontramos resultados diferentes para p31-43 y PBS a las 72hs, a las $12 \mathrm{hs}$ encontramos un mayor perfil proliferativo mediante el método estático con el anticuerpo anti-Ki67. Un efecto proliferativo marcado ha sido descripto previamente por la estimulación con p3143 in vitro sobre células Caco-2 y enterocitos de biopsias de pacientes celíacos y en ambos esquemas experimentales se determinó que esa proliferación era dependiente del Factor de Crecimiento Epidermal (EGF) y de IL-15 (M Vittoria Barone et al. 2011). En nuestro caso, no encontramos una expresión elevada de IL15, pero sería de utilidad determinar la presencia de la proteína en lugar de su ARNm, dado los complejos patrones de expresión que esta citoquina presenta (Abadie and Jabri 2014).

Por otra parte, el p31-43 induce la expresión a nivel de ARNm de las quimoquinas CXCL9 y CXCL10 en intestino delgado, mientras que disminuye CXCL11 y el receptor de estas quimoquinas, CXCR3. Este resultado sugiere que 
existe posiblemente un mecanismo de reclutamiento de células CXCR3+ dado el incremento de dos de sus ligandos, CXCL9 y CXCL10. Sería de importancia la evaluación a nivel proteína de CXCR3, para dilucidar si este eje quimotáctico se encuentra implicado en el daño producido por p31-43. Como ha sido descripto en algunos trabajos, este eje parece jugar un rol de vital importancia en la patogenia de EC (Karen M Lammers et al. 2011; Bondar et al. 2014). Proponemos que la inducción de este eje es responsable del daño observado en nuestro modelo y que remarca el posible efecto del p31-43 en la patogenia de EC, por ejemplo en el reclutamiento de células de un perfil Th1, y también en otras patologías autoinmunes como Diabetes Mellitus tipo I o Lupus (Eizirik, Colli, and Ortis 2009; Steinmetz et al. 2009).

Por otra parte, nuestro modelo de enteropatía mostró una rápida respuesta inflamatoria con incremento de la expresión de IFN $\beta$ e IFN $\gamma$. Estos resultados son coherentes con lo que se observa in vitro. Se ha encontrado que p31-43 es un potente inductor de un perfil proinflamatorio en macrófagos aislados de ratones C57BL/6, con un incremento en la expresión de las citoquinas IFN $\beta$, TNF $\alpha$, IL-12 e IL-6 y de las quimoquinas CXCL10 y MCP5 (Thomas et al. 2006). En nuestro modelo encontramos que el p31-43 es capaz de inducir de un modo rápido la expresión de IFN $\gamma$, el cual podemos suponer es parte del establecimiento del perfil inflamatorio en estos animales, junto con la inducción de IFNs tipo I. Ambas citoquinas han sido fuertemente relacionadas con la inducción y el establecimiento de la patología en EC (Fernández-Salazar et al. 2011; Garrote et al. 2008; Ludvig M Sollid and Jabri 2013). Además, la inducción de IFN $\gamma$ e IFN $\beta$ correlaciona con el aumento de expresión de las quimoquinas CXCL9 y CXCL10, las cuales presentan un mecanismo similar y son importantes en la patogenia de tiroiditis autoinmunes (Antonelli et al. 2010).

Otro de los efectos in vivo observados en nuestro modelo es la inducción de muerte celular en intestino de ratones estimulados con p31-43. En nuestro modelo evidenciamos un aumento de la muerte celular tanto en lamina propria como en enterocitos. Este incremento en la muerte celular por p31-43 también correlaciona con estudios anteriores in vitro. En el modelo descripto por D'Arienzo, et al. (D'Arienzo et al. 2009) ratones HLA-DQ8 tratados con indometacina y toxina colérica presentan un incremento de células apoptóticas cuando son sometidos a una sensibilización con gliadinas. Si bien nuestro modelo no está planteado en el mismo contexto genético que el de ese trabajo, pudimos encontrar un efecto específico del p31-43 que ha sido descripto para gliadinas y 
concluimos que dicho efecto no es dependiente del entorno genético. En este estudio, si bien no caracterizamos los mecanismos de muerte, sí observamos una modificación del cociente de expresión de las moléculas pro y anti-apoptóticas, Bax y Bcl2, respectivamente, hacia un valor pro-apoptótico. Por lo tanto, podemos suponer que esta vía estaría implicada en la muerte celular inducida por p31-43. Sin embargo, es necesario un estudio más profundo para saber si la vía que implica las Caspasas tiene alguna importancia en este modelo como así también sería necesaria la evaluación de la relevancia otros tipos de muerte celular en el daño inducido por el péptido tales como piroptosis y necroptosis.

En nuestro estudio descartamos que los efectos observados puedan ser atribuidos a la presencia de una contaminación con LPS, mediante el uso de animales C3H-HeJ. A su vez, encontramos que el adaptador MyD88 tiene un rol fundamental en la señalización inducida por el p31-43 en intestino delgado. Así, el uso de animales KO para MyD88 demostró que este factor es absolutamente necesario para la inducción de daño y para la inducción de muerte celular. De manera similar, Thomas, et al. (2006) describieron que PT-gliadina es capaz de inducir alteraciones de la permeabilidad y citoquinas y quimoquinas proinflamatorias de un modo dependiente de MyD88, utilizando ensayos in vitro, en líneas celulares epiteliales y macrófagos aislados de ratones C57BL/6 (Thomas et al. 2006). Nada se sabía hasta el momento sobre MyD88 en ensayos in vivo y su relación con la toxicidad del p31-43. Por lo tanto, este trabajo de tesis muestra por primera vez que la inducción de daño y muerte celular in vivo de p31-43 es completamente dependiente de MyD88 en un modelo murino en animales normales.

En un trabajo de Lammers, et al. ya se había descripto en experimentos in vitro una relación entre gliadinas, CXCR3 y MyD88 en el contexto de la EC. Este trabajo describe que PT-gliadina es capaz de unirse al receptor CXCR3 y que mediante la señalización por medio de MyD88 es responsable de una alteración de la permeabilidad epitelial, con la consecuente liberación de zonulina (K M Lammers et al. 2008). Sin embargo, este trabajo solamente observó colocalización de gliadinas y CXCR3 en células transfectadas con el receptor, mediante el uso de microscopía de fluorescencia de campo ampliado. Además de trabajar con la fracción PT-gliadinas, los autores encontraron que dos péptidos derivados de gliadinas se unían a CXCR3. Sin embargo, estas secuencias no corresponden a ninguno de los péptidos conocidos por ser inductores de EC, y se encuentran muy poco representados en la composición de las gliadinas. Por lo tanto, la relevancia 
biológica de este resultado es cuestionable. Por otro lado, dadas las características fisicoquímicas de las gliadinas estudios más detallados, como FRET por ejemplo, son necesarios para establecer unívocamente dicha interacción

Nuestro estudio no evaluó la interacción de p31-43 con CXCR3, y no existe otra evidencia que indique cual puede ser el receptor de p31-43.

De manera clara, hemos mostrado que los mecanismos inducidos de enteropatía y muerte celular son dependientes de la señalización por MyD88 aunque las vías implicadas aún son desconocidas.

Dado que MyD88 es el adaptador de gran parte de los receptores de patrones de reconocimiento (PRR), entre ellos varios TLRs sería de interés determinar si la señalización del p31-43 mediante la vía de MyD88 es dependiente de algún PRR. En nuestro trabajo pudimos evidenciar que TLR4 no está implicado en la generación de daño por p31-43, dado que los ratones $\mathrm{C} 3 \mathrm{H}$ HeJ presentaron enteropatía de modo similiar a lo observado en los C57BL/6. Algunos trabajos han profundizado en la relación entre la toxicidad de p31-43 y la vía del EGF (M Vittoria Barone et al. 2011; Nanayakkara, Lania, et al. 2013; Luciani et al. 2010). Se sabe que la estructura de los TLRs funcionalmente presentan muchas semejanzas con el receptor del EGF (Gay et al. 2014). Sería de interés analizar en futuros estudios si el efecto de p31-43 está mediado por este EGF o implica la acción de nuevas vías de señalización.

En conclusión, si bien se requieren muchos más estudios para disecar completamente las vías implicadas en el daño por p31-43, esta es la primera vez que se describe el efecto in vivo del p31-43 en la mucosa intestinal de ratones C57BL/6 normales y se describen algunos puntos clave en su modo de acción.

Por otra parte, en este capítulo se desarrolló un modelo complementario de daño mediante la inyección intraluminal de dos inductores innatos previamente estudiados en el Capítulo 1 y en este Capítulo: poly (I:C) y p31-43.

Se estima que en la patogenia de EC varios factores ambientales podrían tener su efecto en forma concomitante. Dentro de esos factores ambientales se incluyen las infecciones intestinales y los antígenos dietarios. Por ello, este modelo buscó evaluar en etapas tempranas cómo estos dos factores de distinto origen podían afectar a la inducción de enteropatía que cada uno genera por separado.

Por ello, inyectamos simultáneamente poly (I:C) y p31-43 en ratones C57BL/6 y evaluamos algunos de los parámetros considerados en los modelos anteriores. Encontramos que el estímulo doble genera a las $12 \mathrm{hs}$ de tratamiento 
un cociente V/C comparable con el observado en el p31-43, sin embargo la severidad se mantiene por más tiempo, observándose que a las $72 \mathrm{hs}$ el cociente V/C aún se encuentra menor al control de PBS y a los animales tratados con p3143. Por lo tanto, vemos que el estímulo doble produce un daño que puede diferenciarse del producido por poly (I:C) y p31-43 administrados individualmente.

Respecto a la inducción de mediadores inflamatorios, observamos un perfil de citoquinas distinto en los ratones tratados con el estímulo doble. En este caso, se induce a nivel de ARNm la expresión de IFN $\beta$ a valores intermedios entre lo observado con poly (I:C) y lo observado con p31-43. Por otra parte se produjo la inducción de TNF $\alpha$ que no fue observada con el p31-43, y por el contrario no se observó inducción de IFN $\gamma$. Las citoquinas IL-6 e IL-18 fueron inducidas en el estímulo doble tempranamente, a diferencia de lo observado con poly (I:C) o p3143.

La evaluación de las moléculas relevantes en la EC presentó algunas diferencias también. Si bien la expresión de TG2 no ha sido inducida en ningún caso, IL-15 se ve disminuido en el estímulo doble en todos los puntos de tiempo. Al igual que lo observado con anterioridad, sería de interés evaluar la expresión a nivel proteína de IL-15, debido a los complejos mecanismos de regulación de la transcripción, traducción y secreción de esta proteína (Abadie and Jabri 2014).

Un panorama similar se observó en el estudio de quimoquinas. Se observó una clara inducción de CXCL2, MCP-1, CXCL10 y CXCR3 en el intestino de ratones tratados con el estímulo doble. Estos resultados indican que mediante el estímulo doble, se podría producir un mayor reclutamiento de mediadores inflamatorios, que explicarían las diferencias observadas en la expresión de citoquinas.

Las diferencias de mecanismos para el estímulo doble son evidentes cuando evaluamos la muerte celular. Además de una mayor inducción de muerte celular con el estímulo doble, se puede observar un fuerte incremento de Caspasa-3 clivada. A su vez, observamos una tendencia a un cociente pro-apoptótico de $\mathrm{Bax} / \mathrm{Bcl} 2$, lo que sugiere la participación de la vía intrínseca en la muerte celular observada a las 12hs. Estos resultados en conjunto son fundamentales para entender que esta combinación de estímulos puede generar un mecanismo de muerte diferente molecular y cinéticamente a lo observado con los estímulos individuales, dado que, por ejemplo, ni poly (I:C) ni p31-43 indujeron el clivaje de Caspasa 3 a las $12 \mathrm{hs}$ como observamos en el estímulo doble. Estas observaciones señalan a la vía de las Caspasas y a la vía intrínseca como posibles inductores de 
muerte. Sería de interés evaluar qué otros mecanismos están puestos en juego en este proceso y cómo este sistema se diferencia de los anteriores. 


\section{CONCLUSIONES}

Desarrollamos un modelo de enteropatía a partir de la inyección del p31-43 con características muy particulares y distintivas a nuestro modelo de enteropatía con poly (I:C). Este estudio es el primero en mostrar los efectos in vivo del p31-43, poniendo énfasis en las vías inflamatorias y de señalización reclutadas por este péptido en el intestino delgado como así también los mecanismos de muerte inducidos por el mismo. De este modo, este estudio sienta las bases para profundizar las vías de señalización y los posibles receptores que este péptido puede tener en la mucosa intestinal, de modo de comprender su participación tanto en la inducción como en el mantenimiento de EC. El empleo de la combinación de un factor dietario (p31-43) y un factor viral (poly (I:C)) establece un modelo óptimo para el estudio de la interacción de diferentes inductores en un sistema complejo in vivo, para entender de qué modo los aportes individuales de cada uno de los estímulos pueden sumarse e incluso actuar cooperativamente para inducir vías de señalización comunes a ambos, pero también establecer nuevas vías de patogenia en intestino delgado que deberán ser estudiadas 


\section{CAPÍTULO 3: Poly (I:C) y p31-43 producen}

enteropatía que predispone a una respuesta exacerbada a la ingesta de gliadinas. Desarrollo de un modelo crónico de enteropatía de intestino delgado 



\section{CAPÍTULO 3. Poly (I:C) y p31-43 producen enteropatía que}

predispone a una respuesta exacerbada a la ingesta de gliadinas. Desarrollo de un modelo crónico de enteropatía de intestino delgado

Gran parte de las actividades experimentales descriptas en este capítulo se desarrollaron en el laboratorio de la Dra. Elena Verdu (Farcombe Institute, McMaster University, Hamilton, Canadá), donde se dispone de la cepa NOD-DQ8 y condiciones de trabajo experimental con animales adecuadas para los protocolos realizados. Parte de los resultados de este capítulo fueron publicados en el artículo "Intraluminal Administration of Poly I:C Causes an Enteropathy That Is Exacerbated by Administration of Oral Dietary Antigen". Araya, Romina E., Jury, Jennifer, Bondar, Constanza, Verdu, Elena F., Chirdo, Fernando G. PLoS ONE, 2014

\section{INTRODUCCIÓN}

\section{Permeabilidad intestinal: tipos de uniones intercelulares}

El epitelio intestinal es una monocapa de células que constituye la barrera más grande e importante de interacción con el ambiente externo. Actúa como una barrera selectivamente permeable permitiendo la absorción de nutrientes, electrolitos y agua, mientras mantiene una defensa efectiva contra toxinas, antígenos y microorganismos presentes en el lumen intestinal. El epitelio mantiene su función de barrera selectiva a través de la formación de redes proteína-proteína complejas que mecánicamente unen células adyacentes y sellan el espacio intercelular. Las redes de proteínas que conectan las células epiteliales forman tres complejos adhesivos: desmosomas, uniones adherentes y uniones estrechas (Figura 3.1). Estos complejos macromoleculares consisten en proteínas transmembranas que interactúan extracelularmente con células adyacentes e intracelularmente con proteínas adaptadoras que las unen al citoesqueleto.

El epitelio intestinal media la permeabilidad selectiva por dos rutas principales de pasaje: paracelular y transepitelial/transcelular. La permeabilidad transcelular está generalmente asociada con el transporte de solutos a través de las células epiteliales y predominantemente se encuentra regulado por los transportadores selectivos de aminoácidos, electrolitos, ácidos grasos de cadena 


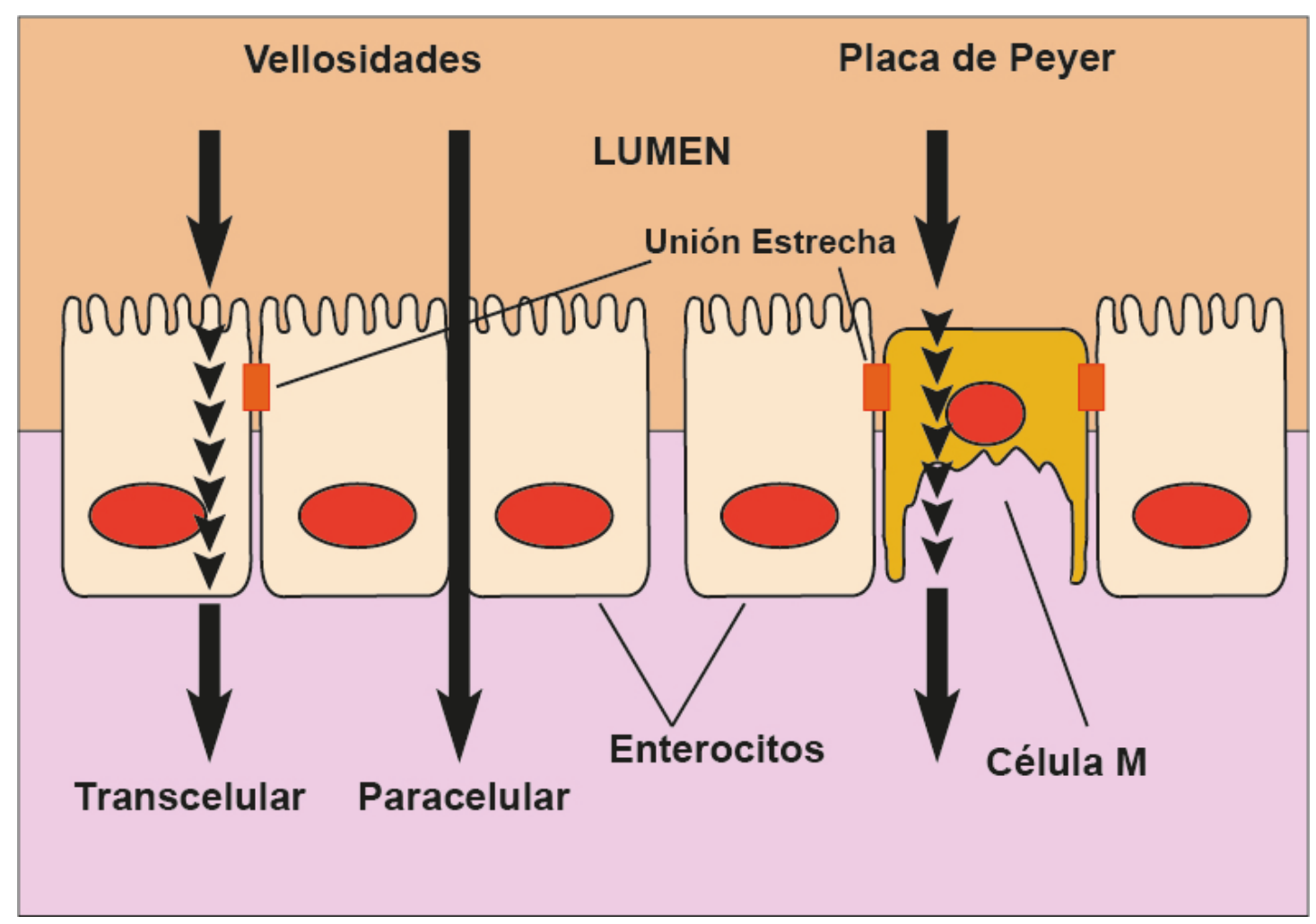

Figura 3.1. Rutas de pasaje de solutos y estructura del epitelio.

En la imagen se encuentran descriptos el pasaje transcelular y paracelular. Se esquematizan los enterocitos (vellosidades), las células M (Placas de Peyer) y las uniones estrechas.

corta y azúcares. La permeabilidad paracelular está asociada con el pasaje por el espacio entre las células epiteliales y es regulado por complejos intercelulares localizados en la unión de las membranas apical-laterales y a lo largo de la membrana lateral (Groschwitz and Hogan 2009) (Figura 3.1).

En lo que se refiere al transporte transcelular, es de destacar a las células M. Estas células, que constituyen alrededor del 20\% del epitelio que cubre a las placas de Peyer, tienen amplias diferencias con los enterocitos. No poseen ribete en cepillo, por lo tanto no tienen anclaje de mucus y presentan una superficie expuesta directamente al contenido del lumen intestinal. Realizan una activa endocitosis hacia vesículas no degradativas y poseen un activo sistema de transporte de vesículas, por medio del cual finalmente se vuelca el contenido de las vesículas en una cavidad interna de la células $\mathrm{M}$ en íntimo contacto con la placa de Peyer. En conjunto, estas propiedades determinan una muy eficiente forma de translocación de macromoléculas desde el lumen hacia el interior de la placa de Peyer. El pasaje de macromoléculas intactas o con escasa degradación tiene consecuencias muy relevantes en el armado de la respuesta adaptativa en las placas de Peyer y en la mucosa intestinal. 
En un estado fisiológico normal, las moléculas, aún aquellas de pequeño tamaño pero inmunológicamente activas, pueden cruzar la barrera epitelial. Existen enzimas digestivas provenientes del páncreas y presentes en el ribete en cepillo de la mucosa que son capaces de degradar la mayor parte de las proteínas que ingresan al lumen. Son reducidas a fragmentos o péptidos cortos y aminoácidos (hasta el 90\%) y son absorbidas a través de la vía transcelular seguido por la degradación lisosomal que las convierte en péptidos pequeños no inmunogénicos o aminoácidos. La porción remanente de proteínas es transportada como proteína intacta, pudiendo generar luego una respuesta inmune antígeno específica. En este grupo particular de proteínas se incluye a las proteínas derivadas de gluten, como se describió en detalle en el Capítulo 2. Por su secuencia, estas proteínas son poco degradadas persistiendo fragmentos de gran tamaño en el lumen. Además del pasaje paracelular, como veremos luego, estos fragmentos pueden ser translocados específicamente por el receptor CD71. Cuando la integridad de la barrera intestinal se compromete (pérdida estructural de las uniones estrechas), se puede desencadenar una respuesta inflamatoria exacerbada y una respuesta inmune a macromoléculas que normalmente se encuentran en el lumen pero ahora cruzan el epitelio intestinal. Esta respuesta

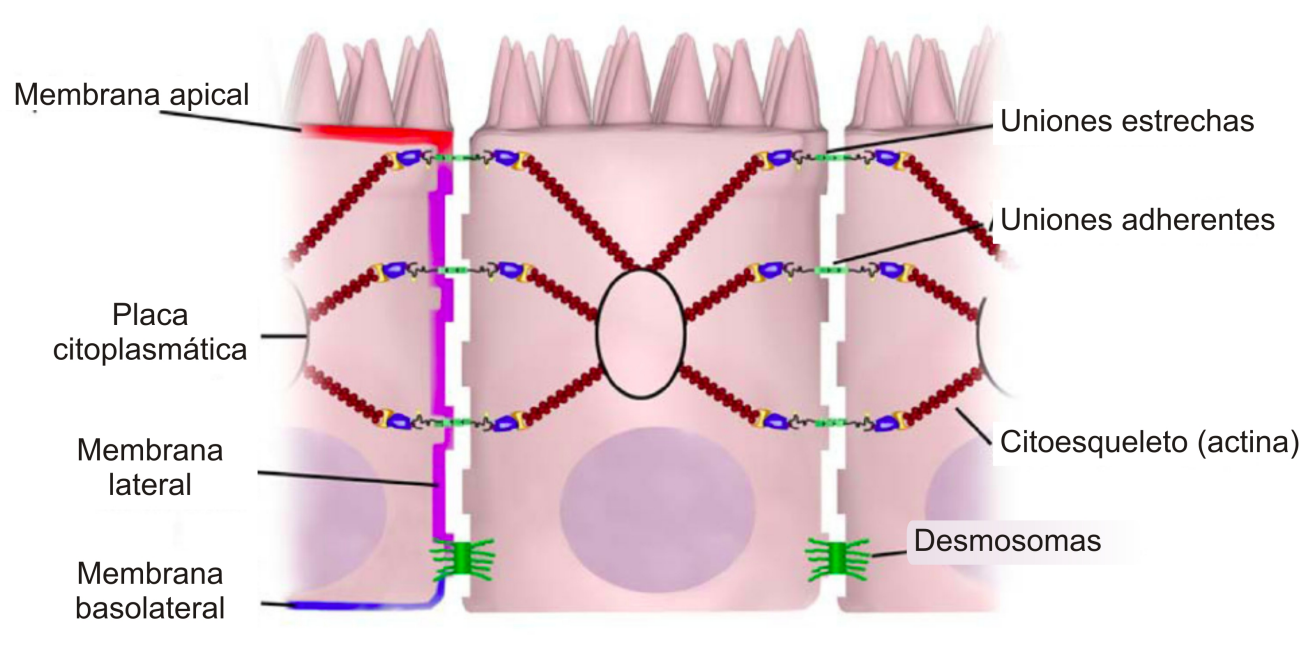

Figura 3.2. Esquema de los complejos macromoleculares de unión entre células del epitelio intestinal.

El epitelio intestinal consiste en una monocapa de células epiteliales polarizadas. Las células adyacentes están conectadas por 3 complejos principales: desmosomas, uniones adherentes y uniones estrechas. Los desmosomas están localizados en placas densas que están conectadas a filamentos de queratina. Las uniones adherentes y estrechas consisten de proteínas conectadas intracelularmente con proteínas adaptadoras al citoesqueleto de actina. El conjunto de proteínas de los complejos de unión forman las "Placas citoplasmáticas" (Figura adaptada de Groschwitz \& Hogan 2009). 
inflamatoria en su fase temprana puede desencadenar patologías crónicas como enfermedad inflamatoria intestinal, alergia alimentaria, enfermedad celíaca e incluso otras enfermedades autoinmunes (A. Fasano 2001; A M Mowat 2003; Mittal and Coopersmith 2014; Peterson and Artis 2014).

Los complejos de uniones adherentes (UA) consisten en proteínas transmembrana que unen células adyacentes asociadas a un citoesqueleto de actina por medio de proteínas estructurales citoplasmáticas. Las UA y los desmosomas se cree que son más importantes en la unión mecánica de células adyacentes. Las uniones estrechas (UE), por su parte, son complejos de unión principalmente apicales y responsables del sellado del espacio intercelular y la regulación del transporte paracelular de solutos iónicos. Las uniones adherentes y las uniones estrechas son también importantes en la regulación de la proliferación celular, la polarización y la diferenciación (Groschwitz and Hogan 2009).

Las UA, también conocidas como zonula adherens, son complejos de proteínas en la membrana lateral que se localizan en puntos de contacto célulacélula (Figura 3.2). Están formadas por interacciones entre proteínas transmembrana, proteínas adaptadoras intracelulares y el citoesqueleto. Las UA principales están formadas por interacciones de cadherina-catenina. Las Cadherinas Epiteliales (E-Cadherina) son glicoproteínas transmembrana que poseen un dominio C-terminal intracelular y un dominio N-terminal extracelular. El dominio extracelular forma interacciones homotípicas con cadherinas de células vecinas y promueve de este modo la adhesión célula-célula. El dominio intracelular contiene un dominio de unión a cateninas que interactúa con miembros de la superfamilia de cateninas. Los complejos cadherina-catenina son importantes no solo para la unión a células adyacentes, sino también para el mantenimiento de la polaridad celular, la regulación de la migración, la proliferación epitelial y la formación de otros complejos adherentes tales como desmosomas.

Las uniones estrechas (UE) son los complejos de unión adhesiva más apical en las células epiteliales de mamíferos que forman un anillo tipo cinturón continuo alrededor de las células epiteliales en el borde entre las regiones de la membrana lateral y apical (Figura 3.2). Las UE son complejos dinámicos multiproteicos que funcionan como una barrera paracelular selectiva o semipermeable, la cual facilita el pasaje de iones y solutos a través del espacio 
intercelular, mientras previene la translocación de antígenos luminales, microorganismos enteros, sus componentes y toxinas.

Los dominios extracelulares de las proteínas transmembrana de las UE en las células adyacentes se anastomosan para sellar la UE. Similar a las UA, los dominios intracelulares interactúan con varias proteínas estructurales, proteínas adaptadoras y complejos de señalización para regular la unión al citoesqueleto, la polaridad celular, la señalización celular y el tráfico de vesículas. Las regiones intracelulares de las UE poseen dominios que reclutan e interactúan con un anillo compuesto por actina y miosina de modo directo o indirecto. Los complejos de redes de interacciones de proteínas intracelulares son también conocidas como “placa citoplasmática” (Figura 3.2).

\section{Proteínas de la Unión Estrecha.}

Las UE consisten de cuatro familias únicas de proteínas transmembranas: ocludinas, tricelulina, claudinas y moléculas de adhesión (JAMs) (Figura 3.3).

La ocludina es expresada predominantemente en las UEs de células epiteliales y endoteliales, pero también en astrocitos, neuronas y células dendríticas. La ocludina es una proteína integral de membrana con dos loops extracelulares. Estos loops extracelulares y los dominios transmembrana regulan la permeabilidad paracelular selectiva. Intracelularmente, el extremo C-terminal interactúa con la proteína ZO, la cual es requerida para unir ocludina al citoesqueleto de actina (Figura 3.3).

La tricelulina es una proteína integral de membrana que se encuentra concentrada en las UE orientadas verticalmente y es responsable del contacto tricelular (entre tres o más células a la vez) (Figura 3.3).

Las claudinas son proteínas integrales de membrana de 20-27kDa con cuatro dominios transmembrana hidrofóbicos, dos loops extracelulares y dominios $\mathrm{N}$ - y C-terminales citoplasmáticos. Los loops extracelulares son críticos para las interacciones proteína-proteína homofílicas y/o heterofílicas de las UE y para la formación de canales iónicos selectivos. El dominio C-terminal intracelular está involucrado en el anclaje de Claudina al citoesqueleto por medio de interacciones con ZO-1, -2 y -3 (Figura 3.3). Las claudinas son importantes para la regulación de la función de barrera, principalmente afectando la permeabilidad paracelular. Además, son importantes para determinar la selectividad en el transporte iónico de la UE. Las claudinas también juegan un rol en la motilidad de las células epiteliales. 


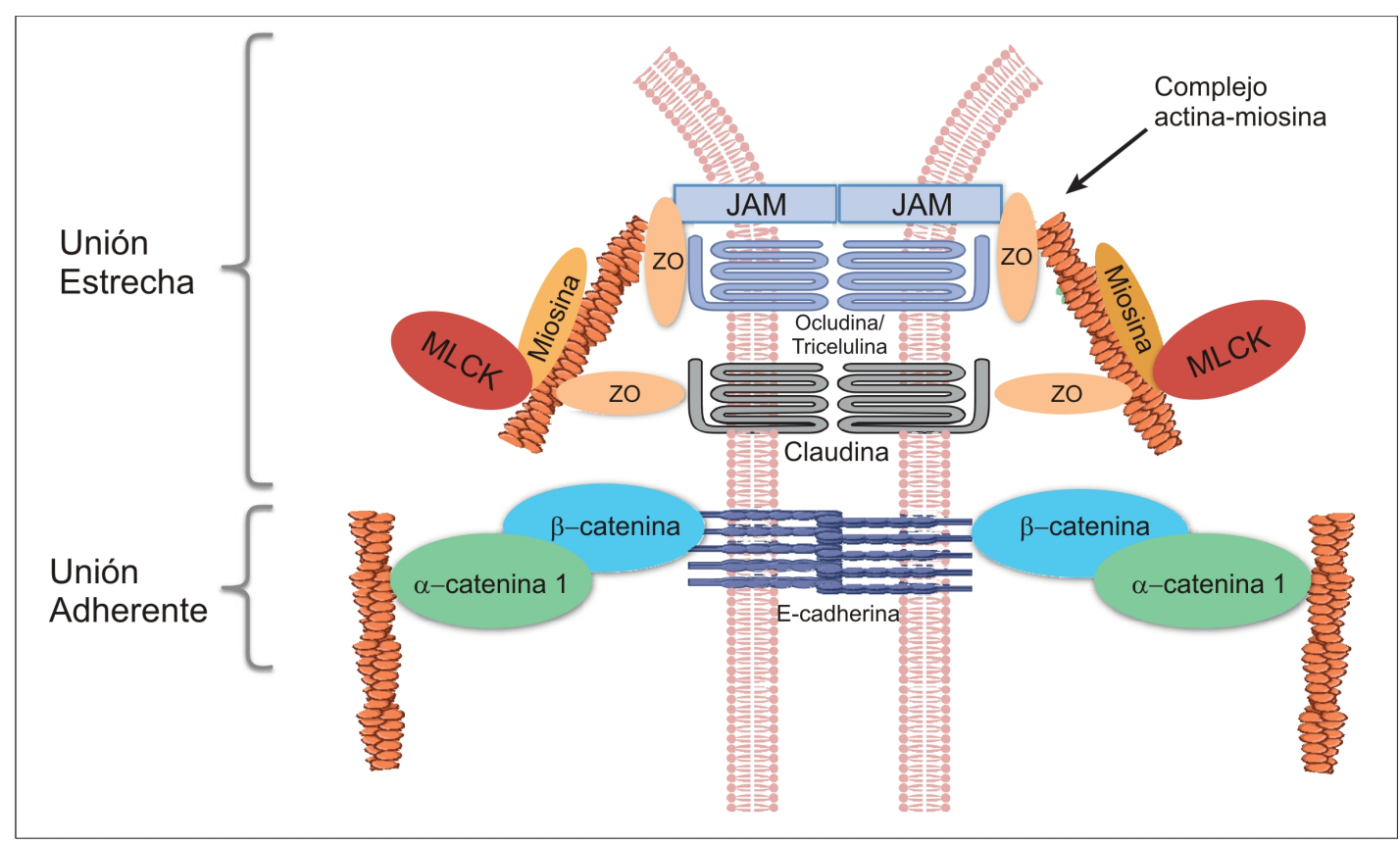

Figura 3.3. Composición de las uniones intercelulares en el epitelio.

Proteínas extracelulares, JAM, ocludinas o ticelulinas y claudinas interactúan con proteínas zonula occludens o ZO intracelulares y el anillo de actina-miosina para regular la permeabilidad. MLCK modula la contracción del anillo de actina-miosina. Se observan las cadherinas extracelulares interactuando con cateninas intracelulares que a su vez interactúan con los anillos de actinamiosina para formar las uniones adherentes. (Figura adaptada de Mittal \& Coopersmith 2014)

Las JAMs son proteínas integrales de membrana que pertenecen a la superfamilia de las inmunoglobulinas $y$ tienen dos unidades tipo inmunoglobulina en el dominio extracelular (Figura 3.3). Las JAMs son expresadas en múltiples tipos celulares, incluyendo las células epiteliales, endoteliales e inmunes. La región extracelular de las JAMs unen múltiples ligandos a través de interacciones homo y heterofílicas, las cuales se cree que regulan las funciones celulares y la permeabilidad paracelular de las JAMs. Las JAMs son importantes en la formación y el ensamblaje de las UE en las células del epitelio intestinal.

\section{Regulación de la integridad de las uniones estrechas.}

La expresión de proteínas de unión en el epitelio intestinal está altamente regulada y depende del segmento intestinal (intestino delgado o grueso), la localización vellosidad/cripta y la región de la membrana celular (apical, lateral o basolateral). El complejo patrón de expresión de las UE en el intestino está relacionado a las funciones específicas y a la localización de una región intestinal particular. La expresión de las proteínas de UA y UE está también regulada por fosforilación. Una de las quinasas más estudiadas en la regulación de la UE y en el inicio de patologías intestinales ha sido la MLCK (miosin light chain kinase). La 
MLCK es la quinasa responsable de fosforilar la cadena liviana de miosina (MLC) y generar así la desestructuración de las uniones estrechas por condensación de los anillos de actina y miosina (Groschwitz and Hogan 2009; Cunningham and Turner 2012; Turner 2009). Muchos estudios fueron orientados a evaluar su mecanismo de acción. Se encontró que MLCK por sí sola es suficiente para generar disfunción en la barrera intestinal y pérdida de estructura de la unión estrecha (Shen et al. 2006). Por otra parte, la fosforilación de MLC por MLCK es en parte responsable de la disfunción de las UE inducida por TNF $\alpha$. Incluso bajas dosis de IFN $\gamma$ y TNF $\alpha$ tienen un efecto sinérgico en la activación de MLCK y la disminución de la función de barrera. El mecanismo de acción de la MLCK sucedería vía un proceso dependiente de ZO-1. Si bien no existen hasta el momento resultados que soporten una acción de MLCK sobre claudinas y ocludinas, no se descarta a estas moléculas como posibles mediadores del aumento de la permeabilidad (Groschwitz and Hogan 2009; Cunningham and Turner 2012).

Otro de los reguladores específicos de las uniones estrechas que ha tomado gran importancia en la patogénesis de EC es la zonulina, identificada en el humano como un precursor de la Haptoglobina 2 (pre-haptoglobina 2), la cual presenta analogía con la toxina de Vibrio cholerae, ZOT (Zonula Occludens Toxin). ZOT interactúa con un receptor de superficie del enterocito específico, produciendo la polimerización dependiente de PKC de los microfilamentos de actina y propiciando así la regulación de la vía paracelular. Se supone que ZOT está imitando en su acción a un modulador endógeno de las uniones estrechas y se sugiere que ese modulador es la pre-haptoglobina 2 (Tripathi et al. 2009; a Fasano et al. 2000).

\section{Permeabilidad intestinal y enfermedad celíaca}

Estudios clínicos y experimentales sugieren que la EC presenta una función de barrera intestinal alterada y esto puede jugar un rol en el desarrollo de la enfermedad permitiendo que péptidos derivados de gluten crucen la barrera intestinal y activen el sistema inmune. Los pacientes con EC tienen una permeabilidad intestinal incrementada y una morfología de las uniones estrechas alterada. En parte estas alteraciones pueden persistir aún en pacientes asintomáticos que se encuentran en dieta libre de gluten (Bjarnason and Peters 1984; Schulzke et al. 1998; Smecuol et al. 1997). Algunos estudios sugieren que la permeabilidad intestinal incrementada existe previo a la aparición de la enfermedad y consideran que la permeabilidad podría tener un rol importante en 
el desarrollo de la enfermedad (van Elburg et al. 1993). El gluten y sus componentes tóxicos gliadinas y gluteninas han sido muy bien estudiados. Se ha observado que algunos péptidos derivados de gluten estimulan directamente la producción de zonulina e inducen un incremento de la permeabilidad intestinal (Bjarnason and Peters 1984; Schulzke et al. 1998; Smecuol et al. 1997; K M Lammers et al. 2008; Drago et al. 2006; Karen M Lammers et al. 2011). Estudios de asociación genómica (GWAS) en poblaciones celíacas han encontrado polimorfismos (SNPs) en genes de componentes de las uniones estrechas asociados con EC (Hunt et al. 2008; Heyman et al. 2012; Wapenaar et al. 2008).

Bajo condiciones fisiológicas el epitelio intestinal establece restricciones al pasaje de componentes presentes en el lumen, en particular de nuestro interés, los péptidos derivados de gluten. Como hemos mencionado, los pacientes con EC activa tienen un compromiso de la integridad de las UE y una permeabilidad paracelular incrementada, lo cual podría permitir que péptidos derivados de gluten crucen la barrera intestinal y activen el sistema inmune. Se ha descripto que las gliadinas afectan directamente la función de barrera intestinal en parte por la inducción de la expresión de zonulina. Zonulina se une a su receptor expresado en el enterocito y media una serie de efectos, entre los que podemos mencionar cambios en el citoesqueleto mediados por la activación de PKC, reducción de la expresión de ZO-1 y ocludina, que en conjunto conducen a la disrupción de la integridad del complejo de la UE incrementando la permeabilidad intestinal (Drago et al. 2006; Clemente et al. 2003; a Fasano et al. 2000). La incubación de monocapas de epitelio intestinal humano o biopsias de pacientes celíacos con gliadinas, estimula la secreción de zonulina e incrementa la permeabilidad intestinal (Drago et al. 2006). La liberación de zonulina inducida por gliadinas está mediada por una vía de señalización dependiente de MyD88 (K M Lammers et al. 2008). Estudios clínicos han demostrado también una correlación positiva entre la permeabilidad intestinal aumentada y los niveles de zonulina intestinal en pacientes con EC activa ( A. Fasano et al. 2000).

En este sentido, se ha propuesto como estrategia terapéutica el uso de una molécula inhibitoria con similitudes a la toxina de zonula occludens (ZOT) (Paterson et al. 2007). Sin embargo, es aún poco claro de qué modo la permeabilidad intestinal es una causa primaria o una consecuencia de la inflamación intestinal.

Recientemente, se describió un nuevo mecanismo de pasaje específico de gliadinas en la mucosa intestinal. Este es un mecanismo alternativo de transporte 
transcelular de gliadina que involucra un retro-transporte del complejo IgAGliadinas mediante el receptor CD71 (Matysiak-Budnik et al. 2008; Heyman and Menard 2009). CD71 es un receptor de transferrina localizado en la región apical de la membrana de los enterocitos diferenciados. Este mecanismo de transporte permitiría explicar la llegada de péptidos de gran tamaño a la lamina propria aún en condiciones donde el epitelio no presenta alteraciones en su permeabilidad. CD71 se encuentra inducido y expresado apicalmente en EC activa conduciendo a una translocación selectiva y protegida hacia la lamina propria.

\section{Modelos animales con ratones NOD-DQ8}

Los modelos animales raramente reproducen el espectro completo de las enfermedades humanas complejas. A su vez, las enfermedades en humanos a menudo expresan diferentes fenotipos clínicos. Por lo tanto, la utilidad de los modelos animales reside en reproducir ciertos aspectos de la patogénesis de las enfermedades en orden de obtener conocimiento de los mecanismos, aunque sea sólo sobre algunas etapas y proponer estrategias terapéuticas a ser testeadas en ensayos clínicos.

Existen, como ya describimos antes, una amplia variedad de modelos animales orientados al estudio de la intolerancia al antígeno dietario, gliadinas.

Particularmente, es el interés de esta sección prestar especial atención a aquellos modelos orientados a determinar la participación de HLA-DQ8 y la respuesta específica en el desarrollo de EC. Uno de estos modelos utilizó un ratón transgénico que expresaba el gen de la molécula DQ8 (Black, Murray, and David 2002). En este modelo, no se observó desarrollo espontáneo de signos asociados a enteropatía. Sin embargo, una vez sensibilizados con gluten por inyección intraperitoneal, los ratones desarrollaron una fuerte respuesta proliferativa de células T como así también una producción de anticuerpos anti-gliadinas elevada (Black, Murray, and David 2002). Otro estudio realizado con estos mismos ratones demostró que si a la inyección intraperitoneal de gliadinas se le suma la administración oral durante 3 semanas, se producía un incremento en el número de LIEs $\mathrm{CD}^{+}$, pero aún así, no se observaba cambios histológicos (atrofia vellositaria). En forma llamativa, los animales tratados presentaban una disfunción neuromuscular dependiente de gliadinas (E F Verdu et al. 2008).

Los resultados obtenidos en estos modelos muestran que el entorno generado por la molécula de HLA-DQ8 puede ser apropiado para la inducción de 
cierto tipo de respuesta pero es insuficiente per se para el desarrollo completo de las alteraciones observadas en EC.

Considerando que otros genes de predisposición deben estar involucrados, se emplearon animales de la cepa NOD con el fin de evaluar la contribución de un contexto de autoinmunidad al desarrollo de un modelo de EC. Estos animales han contribuido sustancialmente al conocimiento de los mecanismos de Diabetes Mellitus Tipo I (DMI), enfermedad asociada a EC (Rashtak, Marietta, and Murray 2009; Barera et al. 2002; Ludvigsson et al. 2006). Los ratones NOD presentaron altura de vellosidad reducida y un incremento en el número de LIEs mientras ingirieron gluten en su dieta (Maurano et al. 2005). Estos resultados revelaron que los animales NOD podían ser un modelo experimental útil para evaluar mecanismos de la patogénesis de EC.

Es sabido que DMI y EC comparten los alelos de susceptibilidad DQ2-DR3 y DQ8-DR4. Aunque son elementos críticos, la sola presencia de estas moléculas no es suficiente para el desarrollo de estas patologías.

Por todo lo mencionado, con el fin de evaluar la contribución tanto del entorno de autoinmunidad conferido por los ratones NOD como la participación de moléculas de los alelos de susceptibilidad, ratones NOD fueron cruzados con ratones transgénicos DQ8, obteniendo los ratones denominados NOD Abo DQ8 (NOD-DQ8). Estos animales son capaces de generar tolerancia al gluten sin desarrollar espontáneamente signos asociados a Sensibilidad al gluten (Marietta et al. 2004). Estos resultados sugieren que aún en presencia de un entorno de autoinmunidad, la expresión de DQ8 no es suficiente para generar alteraciones en la mucosa intestinal que reproduzcan lo observado en EC. Por lo tanto, estos modelos indican que los factores genéticos de susceptibilidad deben acompañarse de otros factores.

Un estudio reciente con ratones NOD-DQ8, realizado en colaboración con el grupo de la Dra Verdú (Hamilton, Canadá) encontró que la depleción parcial de linfocitos $\mathrm{T}$ regulatorios inyectando un anticuerpo anti-CD25, conduce a un incremento en el número de LIEs $\mathrm{CD}^{+} \mathrm{y}$ una disminución del cociente $\mathrm{V} / \mathrm{C}$. Ambos cambios sólo fueron significativos cuando se realizó una sensibilización con gliadinas después de la depleción de los linfocitos T regulatorios. En forma llamativa, se observó una fuerte respuesta inflamatoria en páncreas, con insulitis severa; sin embargo, estos ratones no generaron hiperglucemia (Galipeau et al. 2011). Estos resultados sugieren que mediante una disrupción temporal pero severa de los linfocitos $\mathrm{T}$ regulatorios en los ratones NOD-DQ8 se pueden 
reproducir algunas de las características de la enteropatía dependiente de gluten si se los estimula con gliadinas. Además, también fue demostrado que la respuesta generada en intestino delgado puede tener consecuencias extraintestinales.

Como ya ha sido mencionado, los modelos experimentales desarrollados han permitido evaluar algunos aspectos relacionados con la respuesta específica frente a gliadinas. Sin embargo, hay dos aspectos relevantes que no han sido abordados aún. El primero, se refiere a los eventos iniciales que promueven una respuesta inflamatoria local (estudios desarrollados en los capítulos anteriores). El segundo, y de suma relevancia en el contexto de la patología, es conocer si la alteración provocada durante la respuesta inicial tiene consecuencias a largo plazo en la respuesta frente a gliadinas y en el establecimiento de la lesión crónica. 
CAPÍTULO 3

\section{OBJETIVOS}

El objetivo de esta sección es investigar si la respuesta inflamatoria local inicial inducida por poly (I:C) o por el péptido p31-43, conduce a una enteropatía crónica dependiente de gliadinas en un modelo de ratones NOD-DQ8, genéticamente susceptibles a autoinmunidad y en presencia de una molécula capaz de presentar péptidos derivados de gluten. 


\section{RESULTADOS}

\section{Enteropatía inducida por poly (I:C) en el intestino delgado de ratones NOD-DQ8.}

En los capítulos anteriores hemos evaluado el efecto de la administración intraluminal de poly (I:C) y de péptido p31-43 en ratones C57BL/6. En estos modelos experimentales hemos caracterizado las etapas tempranas durante la generación de la enteropatía. Nuestro interés es evaluar si la alteración histológica producida puede condicionar el tipo de respuesta desencadenada frente a un desafío en una etapa posterior. Con este fin, el modelo de enteropatía fue desarrollado esta vez en animales de la cepa NOD-DQ8. Estos animales fueron elegidos en virtud de las propiedades conferidas por el entorno NOD, de mayor susceptibilidad al desarrollo de respuestas autorreactivas, y por expresar la molécula HLA-DQ8, que tiene alta afinidad por algunos péptidos derivados de prolaminas. Estos animales ya han sido usados en modelos experimentales para

A

PBS

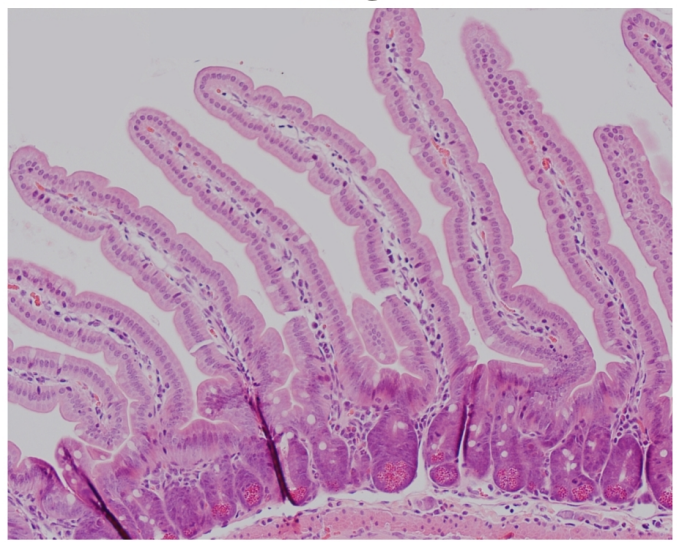

PIC

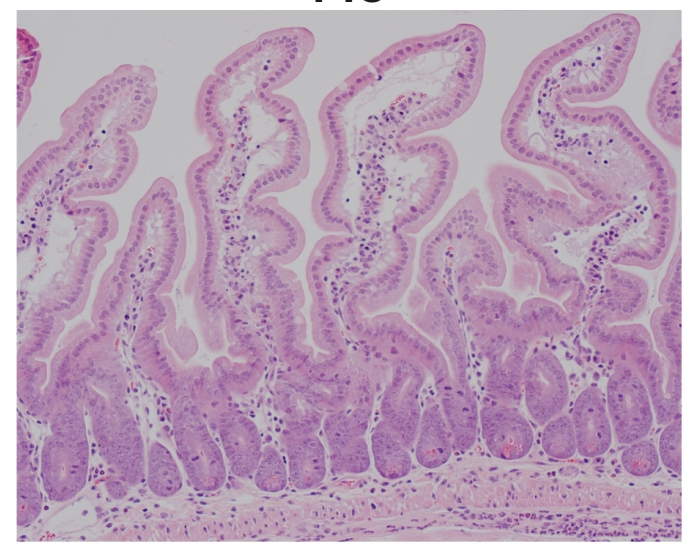

B
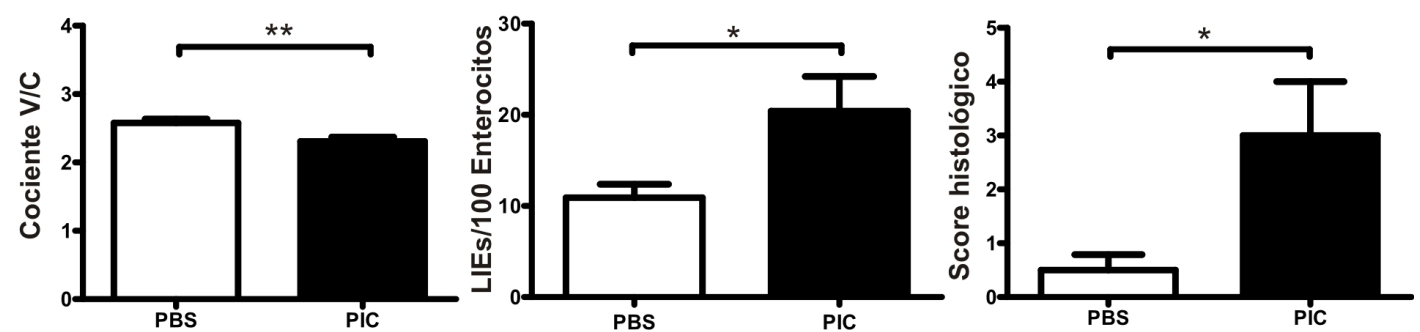

Figura 3.4. La administración de poly (I:C) induce daño en el intestino delgado de ratones NOD-DQ8 luego de $12 \mathrm{hs}$.

Secciones teñidas con H\&E representativas de intestino delgado proximal de ratones NOD-DQ8 después de $12 \mathrm{hs}$ de administración de poly (I:C) (PIC) o PBS (A). Análisis morfológicos de intestino delgado de ratones NOD-DQ8: Cociente Vellosidad/Cripta (V/C), score histológico y número de LIEs después de $12 \mathrm{hs}(\mathbf{B})$. $\mathrm{N}=4$ ratones por grupo, test $\mathrm{t}$ no pareado, ${ }^{*} \mathrm{P}<0,05,{ }^{*} * \mathrm{P}<0,01$. 
estudiar la respuesta frente a péptidos de gluten (Galipeau et al. 2011; Suwanai et al. 2010).

Por ello, dado que nos proponemos trabajar sobre un entorno genético diferente al de los animales C57BL/6 usados previamente, evaluamos si en ratones NOD-DQ8 se reproduce la respuesta temprana y el modelo de enteropatía inducido por la administración intraluminal de poly (I:C) o p31-43.

La evaluación morfológica de la mucosa intestinal en animales NOD-DQ8 tratados con poly (I:C) mostró signos claros de enteropatía, caracterizados por infiltrado celular en lamina propria, edema y acortamiento de las vellosidades a las 12hs post-tratamiento (Figura 3.4A). Los parámetros morfométricos revelaron una marcada reducción en el cociente V/C en los ratones NOD-DQ8 tratados con poly (I:C). También, el número de LIEs y el score histológico fueron más altos en los ratones tratados con poly (I:C) respecto a lo que se observa con PBS (Figura 3.4B).

Respuesta inflamatoria inducida por poly (I:C) en el intestino delgado de ratones NOD-DQ8.

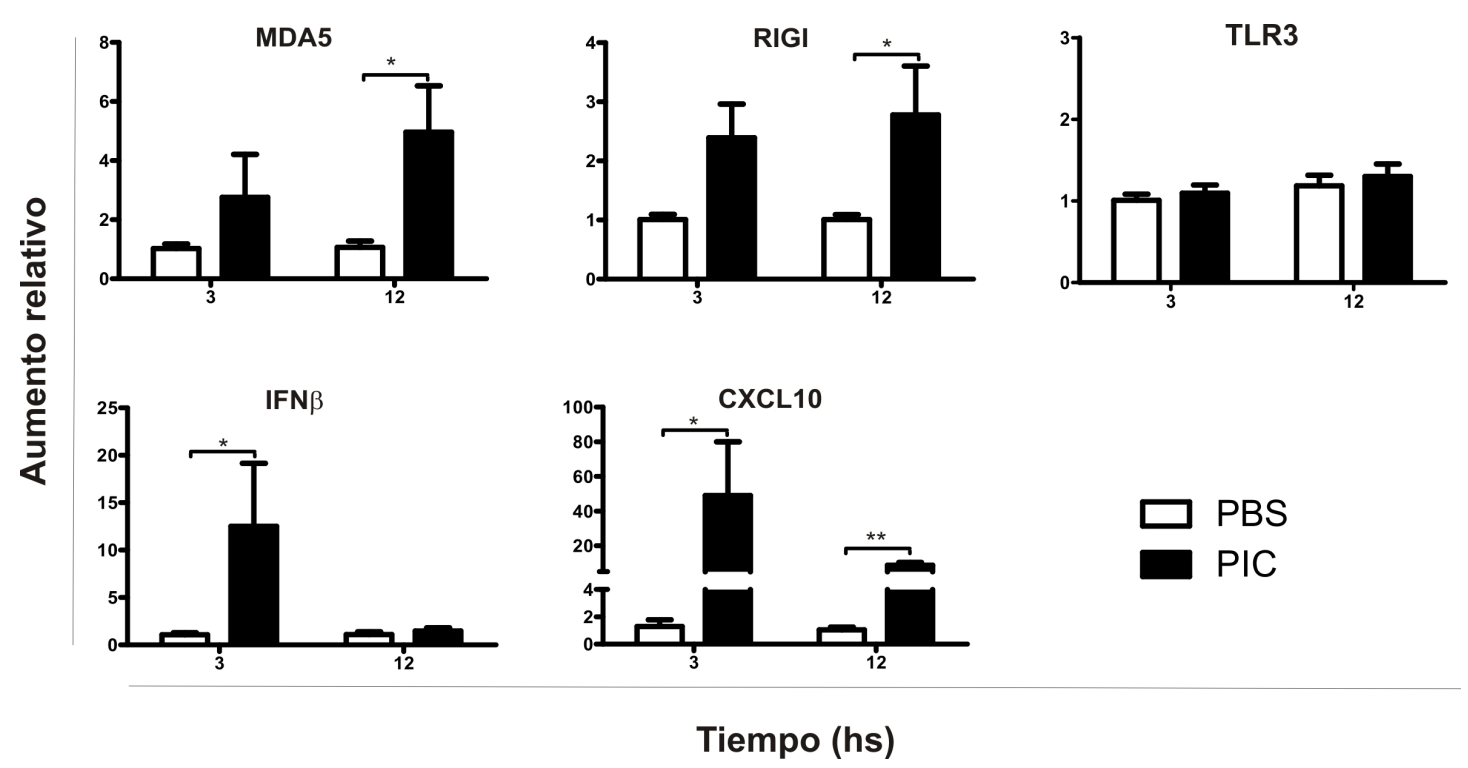

Figura 3.5. Poly (I:C) genera una respuesta proinflamatoria e induce la expresión de ARNm de MDA5 y RIG-I en el intestino delgado de ratones NOD-DQ8.

Análisis por Real Time PCR de la expresión de ARNm de IFN $\beta$, CXCL10, TLR3, MDA5 y RIG-I posttratamiento con poly (I:C) (PIC) o PBS. Todos los valores fueron normalizados según la expresión de un gen constitutivo (HPRT). Todos los resultados fueron expresados como aumento relativo del tratamiento con PBS o poly (I:C) versus la media del tratamiento con PBS en cada punto de tiempo $\left(2^{-\Delta \Delta C t}\right)$. $\mathrm{N}=4$ ratones por grupo, test $\mathrm{t}$ no pareado, ${ }^{*} \mathrm{P}<0.05$, ${ }^{* *} \mathrm{P}<0.01$, tratados con poly (I:C) versuscontroles de PBS en el mismo punto de tiempo. 
Los ensayos anteriores mostraron que los ratones NOD-DQ8 reproducen la histología del modelo de enteropatía caracterizado en animales C57BL/6. Con el fin de determinar si el contexto inflamatorio generado en el intestino delgado de esta cepa es comparable al obtenido en C57BL/6 se analizaron diferentes mediadores inflamatorios en fragmentos de intestino delgado por PCR cuantitativa 3 ó 12 hs post-estimulación.

El análisis de la expresión de los receptores de poly (I:C), mostró que MDA5 y RIG-I, fueron inducidos en la mucosa del intestino delgado. La expresión de ambos receptores se incrementó a las 3hs, pero fue más alta a las 12 hs después del tratamiento. La sobreexpresión de estos receptores se observó más tarde que en los ratones C57BL/6 (Figura 1.16). A las 3 y 12 hs de la inyección de poly (I:C) no se observaron diferencias en la expresión de TLR3 comparados con los animales del grupo control. Esta es una diferencia con lo observado en animales C57BL/6, donde se encontró aumento en la expresión del ARNm de TLR3 (Figura 1.16).

Se observó un fuerte y rápido incremento en los niveles de ARNm de IFN $\beta$ en la mucosa del intestino delgado de los ratones NOD-DQ8 tratados con poly (I:C). Este aumento fue transiente retornando a niveles basales a las $12 \mathrm{hs}$ post-estímulo (Figura 3.5). Se observó un incremento de 40 veces en los niveles de ARNm de CXCL10 a las 3hs en los ratones tratados con poly (I:C). A las $12 \mathrm{hs}$, a diferencia de lo observado en ratones C57BL/6 donde los niveles de CXCL10 retornaron a
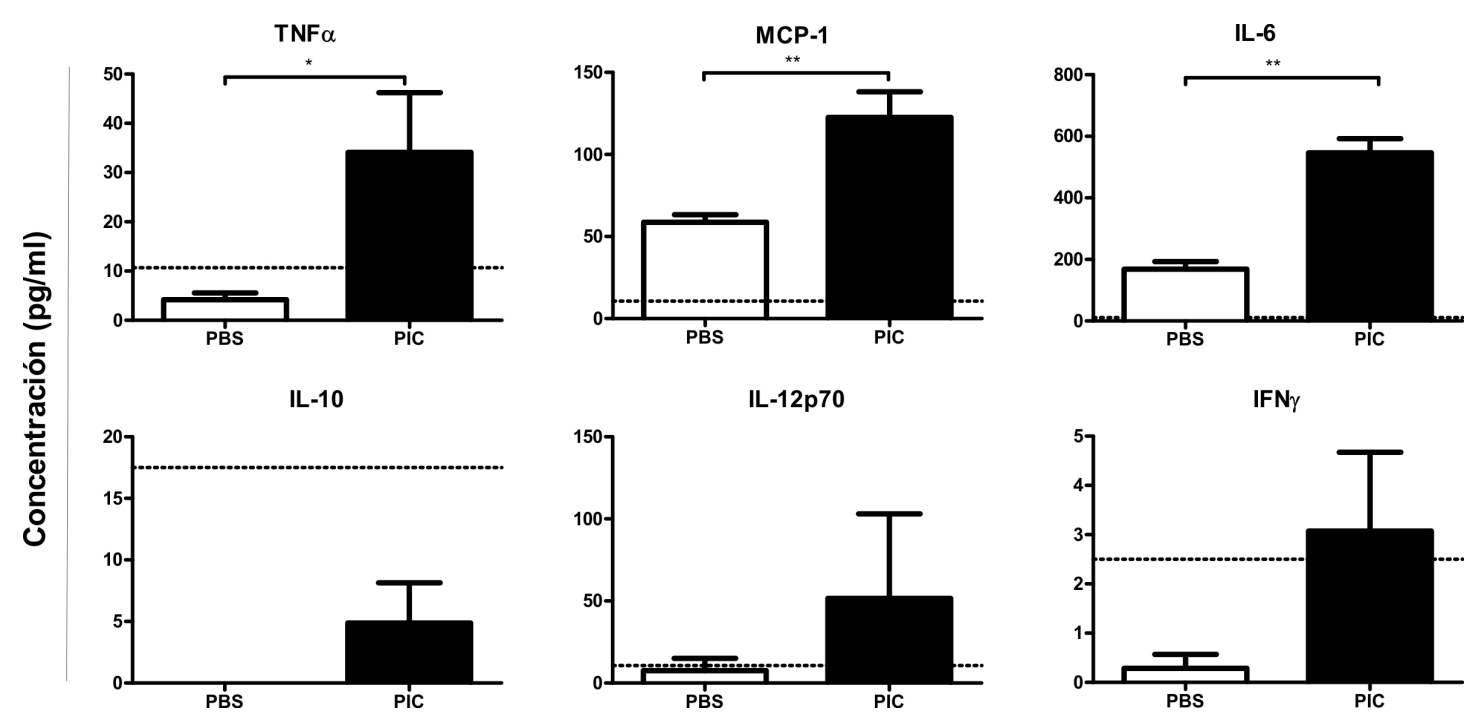

Figura 3.6. Niveles incrementados de TNFa, MCP-1 e IL-6 en suero después de la administración intraluminal de poly (I:C).

Se determinó la concentración de TNFa, MCP-1 e IL-6 en suero de ratones NOD-DQ8 luego de 3hs post-tratamiento con poly (I:C) o con PBS, mediante la utilización de un kit de inflamación CBA (Cytometric Bead Array, BD). La línea punteada representa el límite de detección. N= 4 ratones por grupo, test t no pareado, ${ }^{*} \mathrm{P}<0.05,{ }^{* *} \mathrm{P}<0.01$. 
los valores basales (Figura 1.18), en los animales NOD-DQ8 la expresión de CXCL10 se mantuvo más elevada que en los animales del grupo control (Figura 3.5).

A pesar de las diferencias encontradas en la cinética de expresión de los mediadores inflamatorios y de los receptores de poly (I:C), en términos generales el modelo de enteropatía en ratones NOD-DQ8 reproduce lo observado en animales C57BL/6.

Debido a que nuestro objetivo es establecer un modelo que permita evaluar la respuesta a largo plazo, nos interesó analizar los niveles sistémicos de los mediadores inflamatorios en los animales tratados intraluminalmente con poly (I:C). Observamos que, en sangre periférica la concentración de TNF $\alpha$, IL-6 y MCP1 fue significativamente más alta luego de 3hs de la administración intraluminal de poly (I:C) comparado con los animales del grupo control (Figura 3.6). En cambio, los niveles séricos de IL-10, IL-12p70 e IFN $\gamma$ no mostraron cambios significativos.

Estos resultados sugieren que la administración intraluminal de poly (I:C) no sólo produce una respuesta inflamatoria local, sino que también tiene efectos a nivel sistémico.

La administración intraluminal de poly (I:C) y un antígeno dietario por vía oral inducen enteropatía en ratones NOD-DQ8

Habiendo observado que los ratones NOD-DQ8 reproducen el modelo de enteropatía aguda y caracterizado la respuesta inflamatoria local y sistémica, nos propusimos desarrollar un modelo experimental que permita analizar si la alteración provocada en la enteropatía aguda tenía un efecto a largo plazo.

Dado que el objetivo fue evaluar si existe una respuesta exacerbada frente a péptidos derivados de gliadinas, los animales fueron mantenidos en una dieta completa, libre de gluten, hasta el momento de la cirugía. A partir de las 24 hs de la administración intraluminal de poly (I:C), un grupo de animales fue desafiado con gliadinas por vía oral durante dos semanas. Luego del sacrificio se procedió a la recolección de muestras para los estudios histológicos, de expresión y funcionales. El esquema de la Figura 3.7 muestra el procedimiento completo y los diferentes grupos de animales.

Ninguno de los grupos presentó un cambio de peso significativo a lo largo de las 2 semanas de tratamiento (No mostrado). 


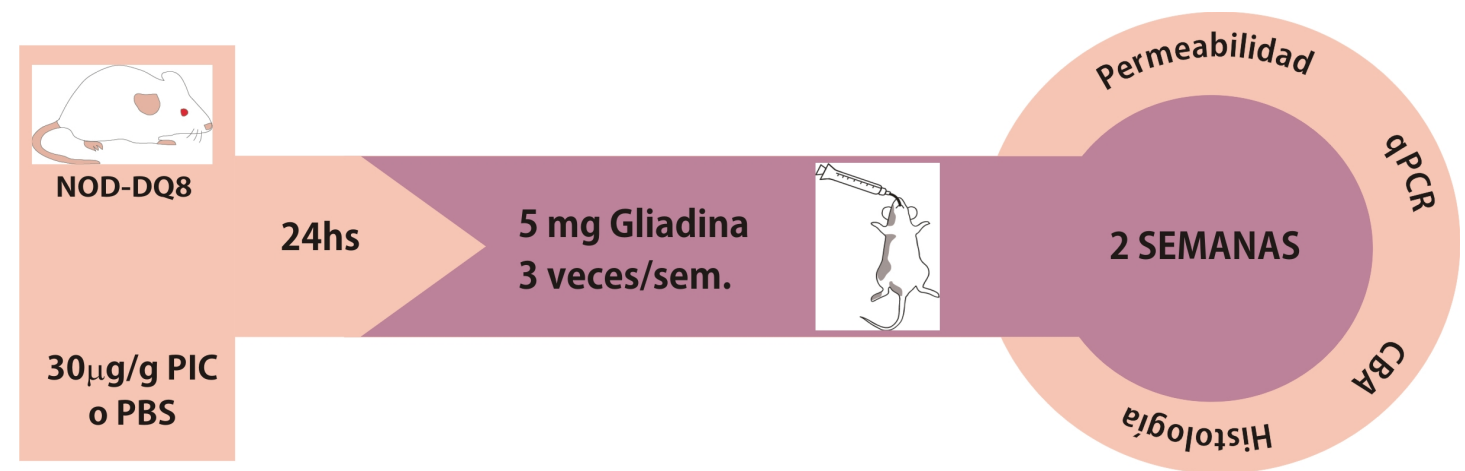

$$
\begin{aligned}
& \text { Grupo 1: PBS + Gliadina } \\
& \text { Grupo 2: PBS + DLG } \\
& \text { Grupo 3: PIC + Gliadina } \\
& \text { Grupo 4: PIC + DLG }
\end{aligned}
$$

Figura 3.7. Esquema que representa el desarrollo experimental realizado con los ratones NOD-DQ8 en el modelo crónico.

Los ratones NOD-DQ8 fueron estimulados con poly (I:C) (PIC) o PBS intraluminal y luego de 24hs se comenzó con la administración intragástrica de $5 \mathrm{mg}$ de Gliadina o la solución vehículo como control (DLG), 3 veces por semana durante 2 semanas. Previo al ensayo los animales consumían alimento libre de gluten. Concluido ese tiempo se sacrificaron los 4 grupos de animales y se obtuvieron muestras de intestino y sangre. Durante las 2 semanas se registró el peso de los animales.

En primer lugar, observamos que los animales del grupo control que recibieron PBS intraluminal y fueron mantenidos en dieta libre de gluten no presentaron ninguna alteración histológica luego de dos semanas de protocolo.

En los animales que fueron tratados con poly (I:C) intraluminal, independientemente de si estuvieron en dieta de exclusión o no, se observó edema subepitelial y moderada separación del epitelio de las vellosidades (Figura 3.8A). El análisis histológico mostró que ambos grupos tuvieron un cociente $\mathrm{V} / \mathrm{C}$ alterado, y similares recuentos de LIEs luego de 2 semanas de la administración de poly (I:C) con o sin administración de gliadinas (Figura 3.8B). En cambio, la evaluación del score histológico mostró claramente que la administración de gliadinas posterior a la inducción de enteropatía genera cambios severos en la mucosa de intestino delgado de los animales tratados con poly (I:C) y con la administración de gliadinas (Figura 3.8B). De esta manera, si bien los animales tratados con poly (I:C) pero en dieta libre de gluten mostraron alteración en el cociente $\mathrm{V} / \mathrm{C}$, los cambios morfológicos severos fueron sólo observados en el grupo de ratones NOD-DQ8 tratados con poly (I:C) que recibieron gliadinas por vía oral. Esto es claramente consecuencia de ambos factores: la alteración provocada por poly (I:C) intraluminal y la respuesta exacerbada de daño frente a la administración de gliadinas por vía oral durante dos semanas. 


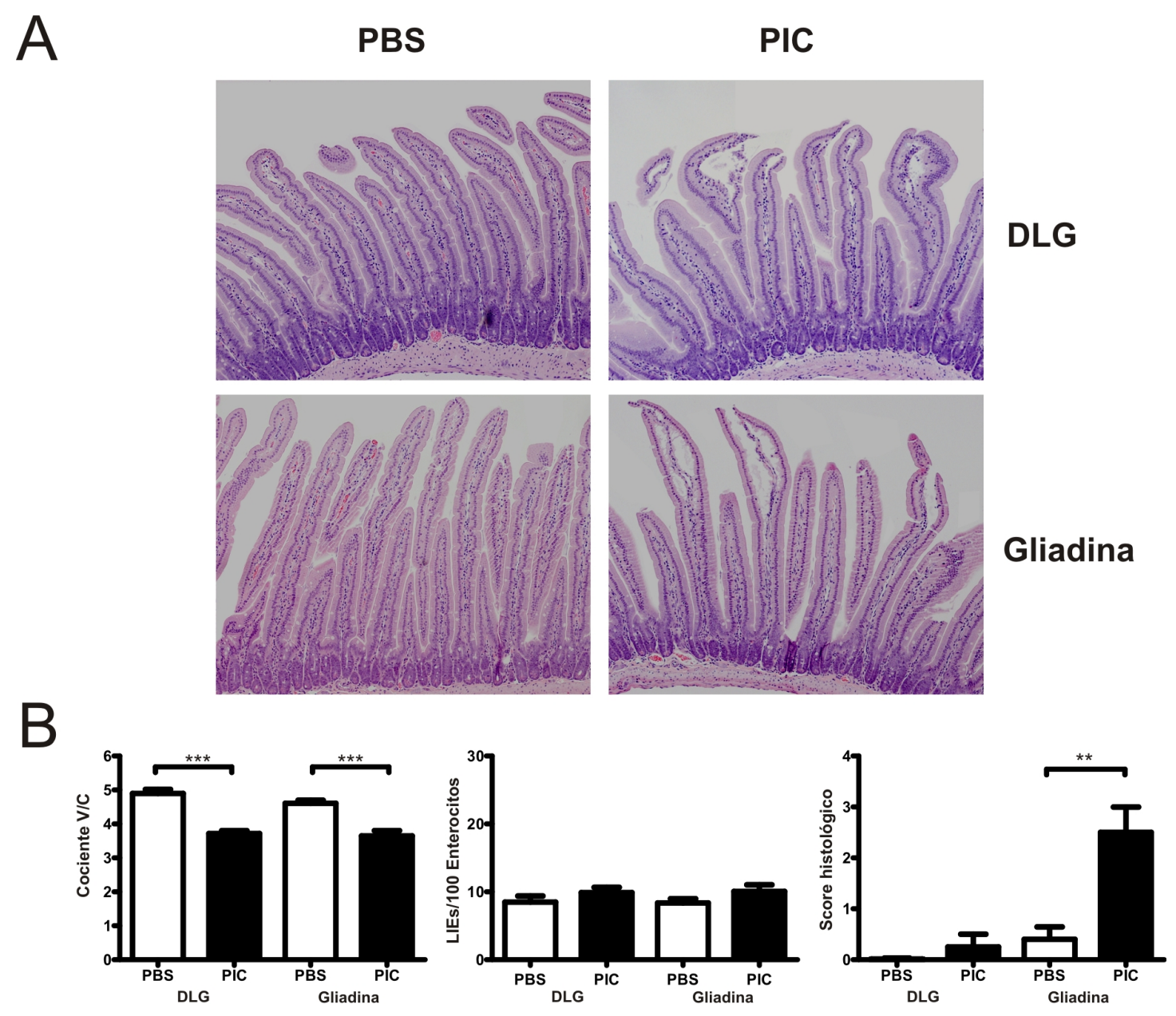

Figura 3.8. La administración oral de gliadinas induce daño histológico en los ratones NOD-DQ8 tratados intraluminalmente con poly (I:C).

Secciones teñidas con H\&E representativas del intestino delgado proximal obtenidas de ratones tratados con PBS o poly (I:C) (PIC) y mantenidos en dieta libre de gluten (DLG) o alimentados oralmente con gliadina durante 2 semanas (A). Análisis morfológico de intestino delgado de ratones NOD-DQ8 tratados con poly (I:C) o PBS bajo dieta libre de gluten (DLG) o alimentados por vía oral con gliadina durante 2 semanas: cociente V/C, recuento de LIEs y Score Histológico. N= 4-5 ratones por grupo, Test t no pareado, ${ }^{* *} \mathrm{P}<0.01$, ${ }^{* * *} \mathrm{P}<0.001$ (B).

Dada la permanencia del daño histológico en los animales que recibieron gliadinas por vía oral decidimos evaluar si existían alteraciones en la funcionalidad de la mucosa intestinal. Para ello utilizamos la técnica Ussing chamber, desarrollada por Ussing y Zehran en 1951, la cual es un método de gran utilidad para el estudio de la integridad de la barrera epitelial. Este método permite evaluar tanto la permeabilidad epitelial como el transporte transepitelial de electrolitos en una misma pieza de intestino (Clarke 2009).

El equipo para Ussing chamber consta de dos piezas separadas que permiten colocar, entre ambas, un epitelio aislado (en nuestro caso un segmento de intestino delgado de ratón) y crear dos compartimientos, uno correspondiente a la mucosa y otro a la serosa como se observa en la Figura 3.9. 


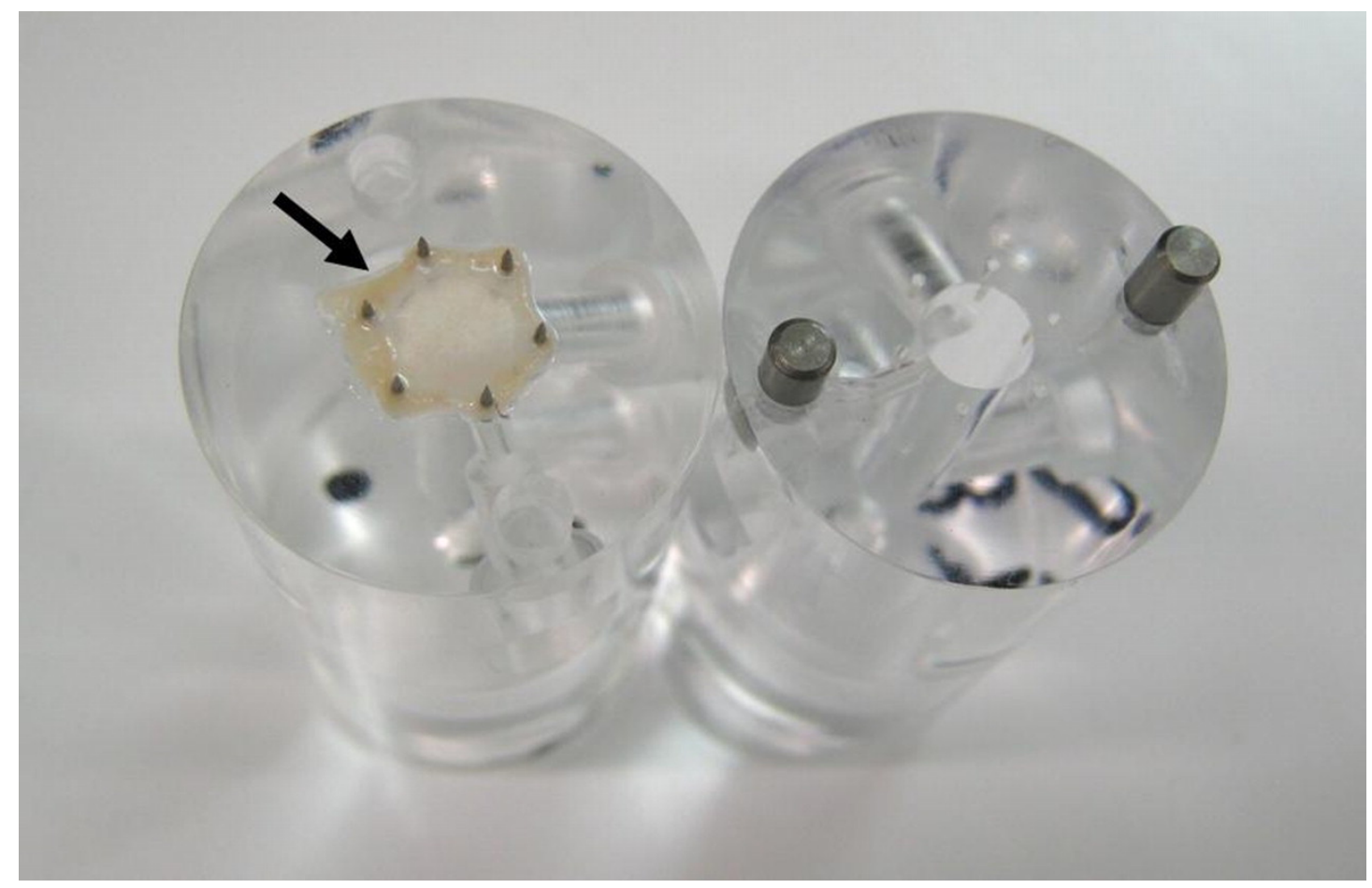

Figura 3.9. Método Ussing chamber.

En esta fotografía se observa un preparado representativo de intestino delgado de ratón (flecha negra) montado sobre los pines correspondientes al compartimiento seroso de la cámara. Luego se ensambla con el compartimiento mucoso mediante la inserción de los pines en sus correspondientes orificios y los tornillos guía (fotografía tomada de Clarke 2009).

La cámara está conectada a un reservorio en el que se introduce una solución nutritiva, permitiendo la continua perfusión del tejido. Dos pares de electrodos permiten medir la diferencia de potencial entre ambos compartimientos (Vt) e inducir la intensidad de corriente necesaria para conseguir que la diferencia de potencial sea cero (corriente de cortocircuito, Isc).

De ese modo, en condiciones estándar, se anulan los gradientes eléctricos, químicos, hidrostáticos y osmóticos entre ambos lados del tejido. En la práctica, esto equivale a eliminar el flujo pasivo de iones, con lo cual la Isc es equivalente al transporte activo iónico electrogénico (Clarke 2009).

Por otro lado, las Ussing chamber permiten llevar a cabo estudios de permeabilidad. Dichos estudios se basan en la medida del flujo de iones y moléculas marcadas. El paso neto de iones está definido por la resistencia transepitelial (TER) o, su inversa, la conductancia (Gt=1/TER). Ésta se calcula mediante la ley de Ohm tras medir el incremento en Isc inducido al aplicar un voltaje conocido $(\mathrm{Gt}=\Delta \mathrm{Isc} / \Delta \mathrm{V})$ y correlaciona positivamente con la permeabilidad iónica. En el caso del intestino, la Gt está determinada casi en su totalidad por la ruta paracelular $\mathrm{y}$, por lo tanto, es indicativa del estado de las uniones intercelulares (Clarke 2009). En nuestro caso, la molécula marcada que se utilizó 

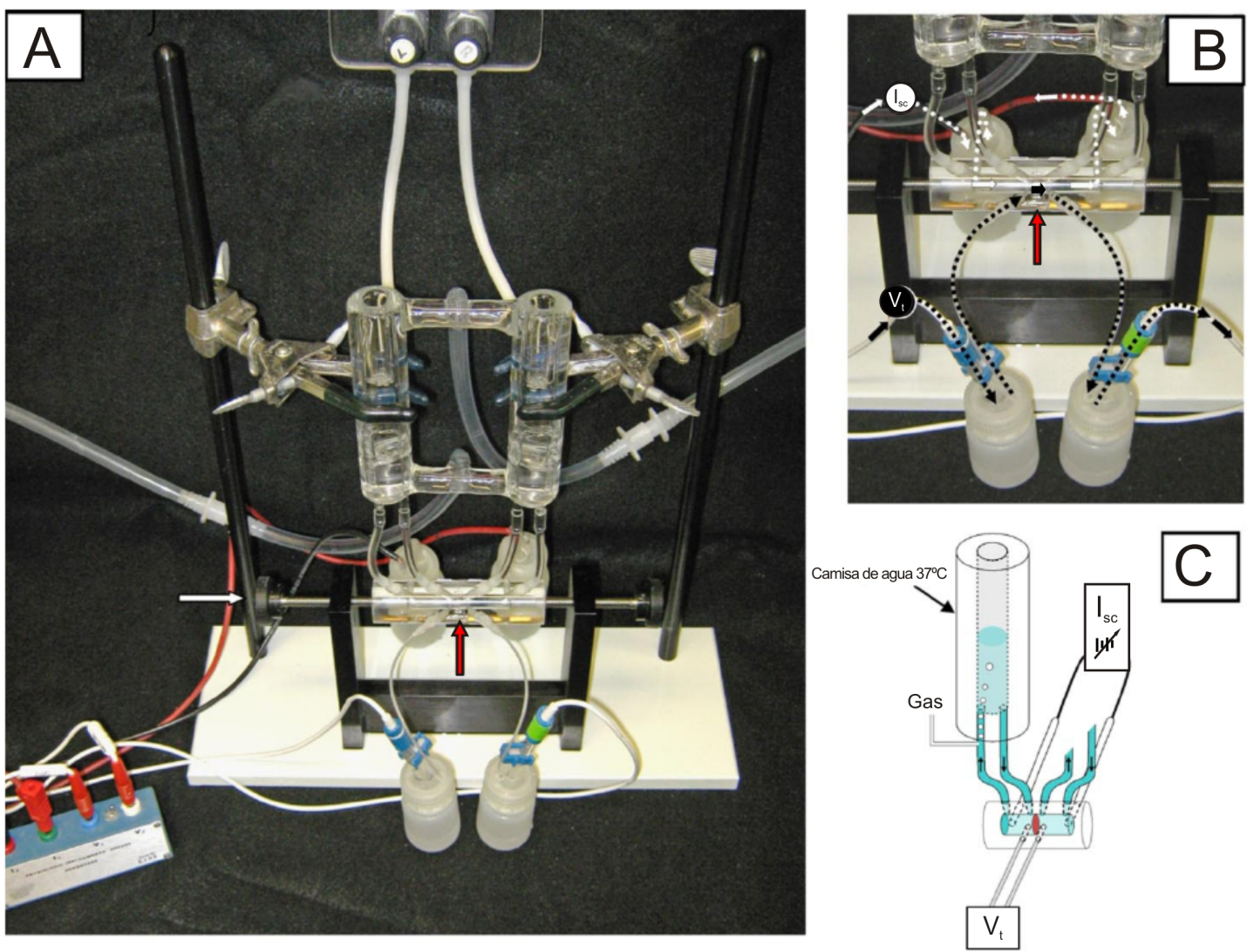

Figura 3.10. Diseño clásico de una Ussing Chamber.

Ensamblaje del equipo con los reservorios para la camisa de agua, la Ussing Chamber (el preparado de intestino se encuentra montado verticalmente; flecha roja) asegurado con tornillos a enroscar desde el lateral (flecha blanca) y electrodos internos para el mantenimiento del voltaje constante (A). Vista más cercana de la medida de voltaje (Vt) y la corriente de cortocircuito (short-circuit current, Isc). El hemi-electrodo de calomel usado para la medida de Vt está conectado a cada preparado intestinal (flecha roja). Los electrodos de $\mathrm{Ag}-\mathrm{AgCl}$ usados para la inducción de Isc que pasa a través del preparado están conectados a la cámara (B). Diagrama esquemático de los circuitos para la medida de Vt y Isc de la Ussing Chamber. La reperfusión circulante de buffer se realiza por desplazamiento de gas (95\% O2-5\%CO2). El preparado intestinal (disco rojo) es la separación entre las cámaras de los compartimientos de la mucosa y la serosa (C). Figura adaptada de (Clarke 2009).

para medir el transporte de solutos a través de la membrana fue el ${ }^{51} \mathrm{Cr}$-EDTA, sin embargo la técnica admite el uso de otras moléculas para tal fin. El ${ }^{51} \mathrm{Cr}$-EDTA correlaciona con el pasaje de oligopéptidos y macromoléculas según se ha demostrado en modelos de inflamación intestinal (DeMeo et al. 2002).

En la Figura 3.10A se muestra el equipo montado completo utilizado para esta determinación. En la Figura 3.10B se muestran las inserciones de los electrodos en las cámaras mientras que la Figura 3.10C esquematiza de qué modo y en qué lugar se miden los distintos parámetros.

En el estudio de la alteración de la función de la barrera epitelial en el modelo de sensibilización con poly (I:C) y administración oral de gliadinas se observó un incremento en la conductancia transepitelial en los ratones NOD-DQ8 tratados con poly (I:C) cuando recibieron gliadinas por dos semanas. Este cambio 
Conductancia transepitelial

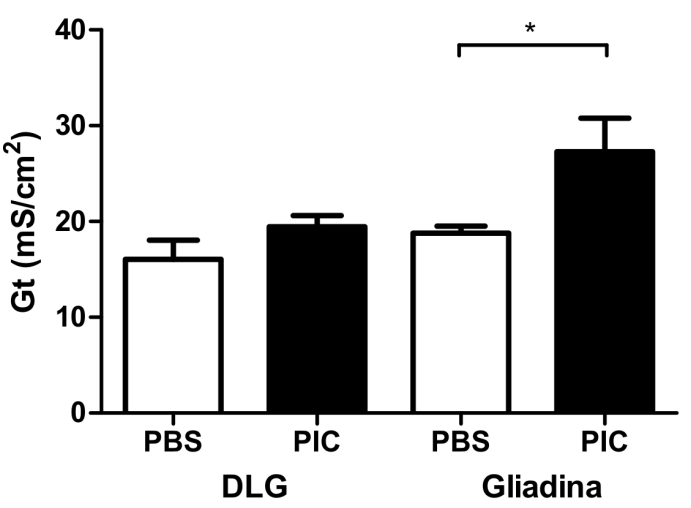

${ }^{51} \mathrm{Cr}$-EDTA

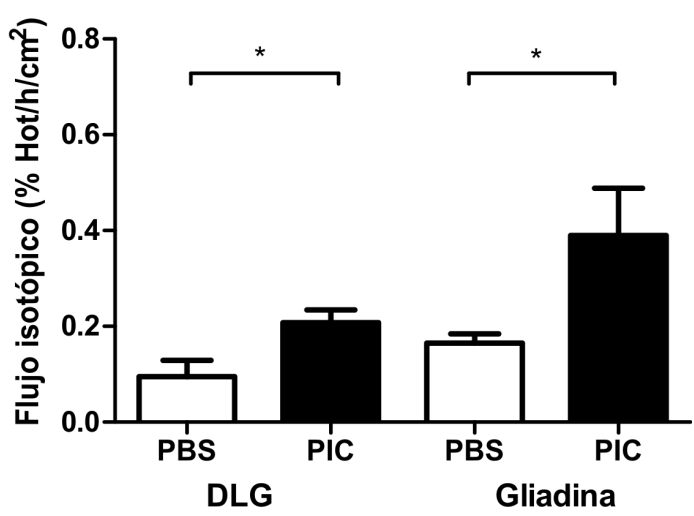

Figura 3.11. La administración oral de gliadinas induce disfunción de la barrera epitelial en ratones NOD-DQ8 tratados con poly (I:C).

Después de 2 semanas de tratamiento con gliadinas por vía oral, secciones de intestino delgado fueron montadas en Ussing chambers y se midió la Conductancia Transepitelial $(\mathrm{mS} / \mathrm{cm} 2)$ y el Flujo isotópico $\left(\% \mathrm{Hot} / \mathrm{h} / \mathrm{cm}^{2}\right)$. Cada barra representa la media de 4 ratones y cada medida pertenece a dos tejidos por cada ratón. N= 3-4 ratones por grupo, ANOVA de dos vías y test posterior de Bonferroni, * $\mathrm{P}<0.05$.

no fue observado en ratones tratados con poly (I:C) mantenidos en una dieta libre de gluten o en ratones del grupo control (Figura 3.11). La evaluación del flujo isotópico de ${ }^{51} \mathrm{Cr}$-EDTA mostró un incremento en la permeabilidad paracelular luego de dos semanas del tratamiento con poly (I:C) independientemente de la administración de gliadinas. Sin embargo, el porcentaje de incremento tiende a ser más alto en los ratones que recibieron gliadinas por vía oral que en aquellos en DLG (Media por cada tratamiento: PBS-DLG: 0.095\%, poly I:C-DLG: 0.22\%, PBSgliadina: 0,17\%, poly (I:C)-gliadina: 0,56\% Hot $/ \mathrm{h} / \mathrm{cm}^{2}$ ).

Estos resultados muestran que la administración de gliadinas por vía oral durante dos semanas exacerba el daño en la mucosa intestinal causado por poly (I:C) con consecuencia negativa en la funcionalidad del tejido. El aumento del pasaje a través del epitelio genera procesos inflamatorios persistentes que podrían amplificar los mecanismos de daño y conducir a la cronicidad del proceso.

Con el objeto de evaluar si los cambios en la mucosa de intestino delgado se veían reflejados a nivel sistémico, se determinaron los niveles séricos de citoquinas y quimoquinas proinflamatorias, luego de dos semanas de protocolo.

Se encontró que los niveles de IL-12p70 y TNFa estaban incrementados en sangre periférica en los ratones que recibieron gliadinas comparados con aquellos en DLG, aún en ausencia del tratamiento con poly (I:C) (Figura 3.12A). Sin embargo, no se observaron diferencias en la producción de las citoquinas MCP-1, IL-6 e IFN $\gamma$ en cualquiera de los grupos (Figura 3.12A). 

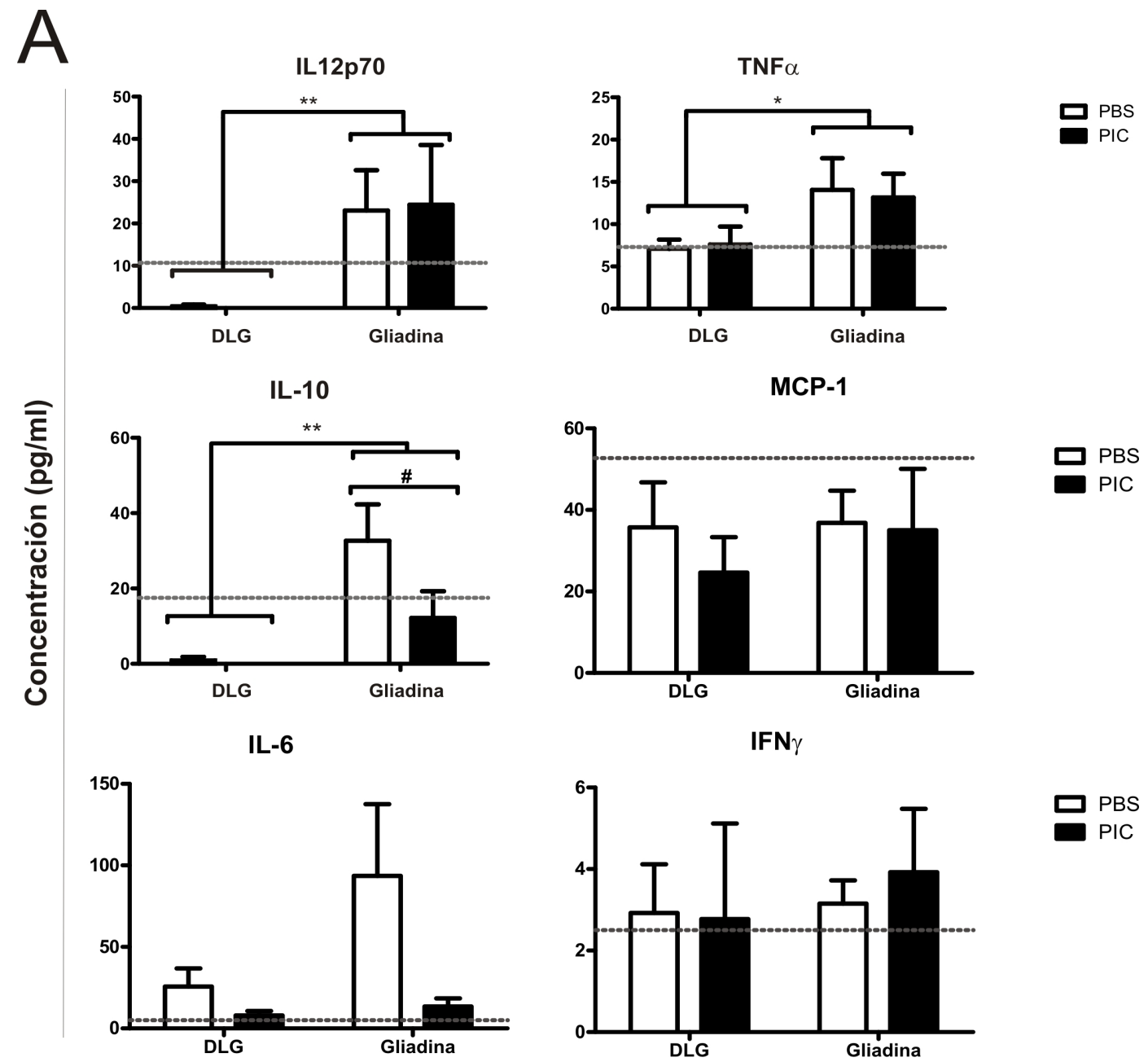

IFN $\gamma$

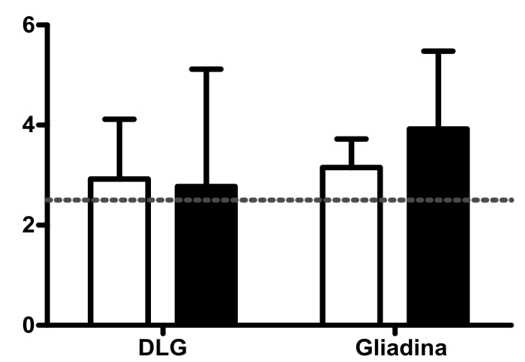

$\square$ PBS

PIC

IL-12p70/IL-10

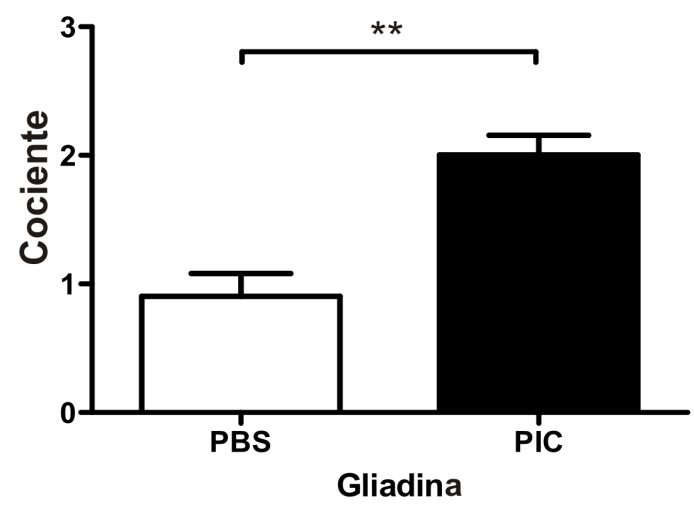

Figura 3.12. La administración oral de gliadinas incrementa los niveles séricos de citoquinas proinflamatorias en ratones NOD-DQ8 tratados con poly (I:C).

Análisis de IL-12p70, TNF $\alpha$, IL-10, MCP1, IL-6 e IFN $\gamma$ en muestras de suero de ratones tratados con poly (I:C) (PIC) o PBS bajo dieta libre de gluten (DLG) o alimentados con gliadina por 2 semanas. La concentración sérica de citoquinas fue determinada con un kit de inflamación CBA (Cytometric Bead Array). La línea punteada representa el límite de detección. $\mathrm{N}=4-5$ ratones por grupo, ANOVA de dos vías y test posterior de Bonferroni, ${ }^{*} \mathrm{P}<0.05$, ${ }^{* *} \mathrm{P}<0.01$ Gliadina versus DLG; \#P $<0.05$ poly I:C versus PBS en ratones alimentados con gliadina (A). Relación de las concentraciones de IL-12p70/ IL-10 a partir de los datos anteriores. $\mathrm{N}=4$, test $t$ no pareado (B) 
La administración de gliadinas por vía oral también indujo un incremento en la citoquina anti-inflamatoria IL-10 (Figura 3.12A). Llamativamente, el tratamiento con poly (I:C) eliminó la producción de IL-10 inducida por gliadinas (Figura 3.12A).

Los niveles de IL-12p70 e IL-10 estuvieron debajo del límite de detección en ratones con DLG (Figura 3.12A). De manera relevante, la administración oral de gliadinas en los ratones tratados con poly (I:C) produjo un desbalance sustancial en la relación IL-12p70/IL-10, sugiriendo un mecanismo proinflamatorio de larga duración (Figura 3.12B).

Estos resultados sugieren que el proceso inflamatorio local inducido por poly (I:C) intraluminal en el intestino delgado predispone a una alteración funcional severa y a una respuesta inflamatoria frente a gliadinas administradas oralmente.

\section{Enteropatía inducida por p31-43 en el intestino delgado de ratones NOD-DQ8.}

En esta sección nos propusimos evaluar si los animales NOD-DQ8 reproducen el modelo de enteropatía desarrollado usando el péptido p31-43 en
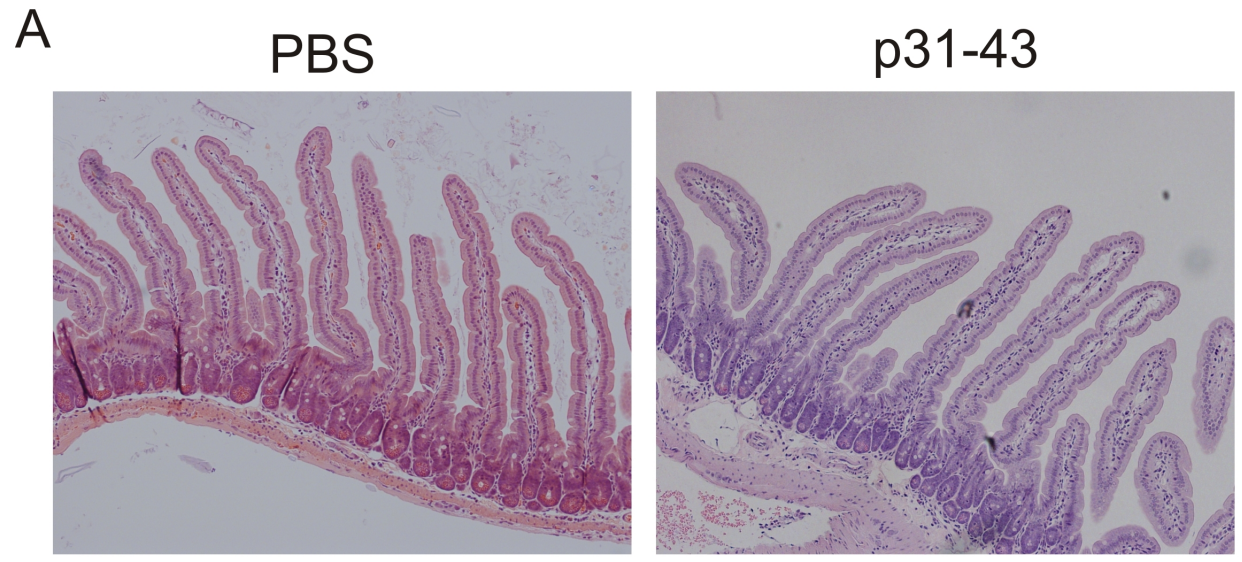

B
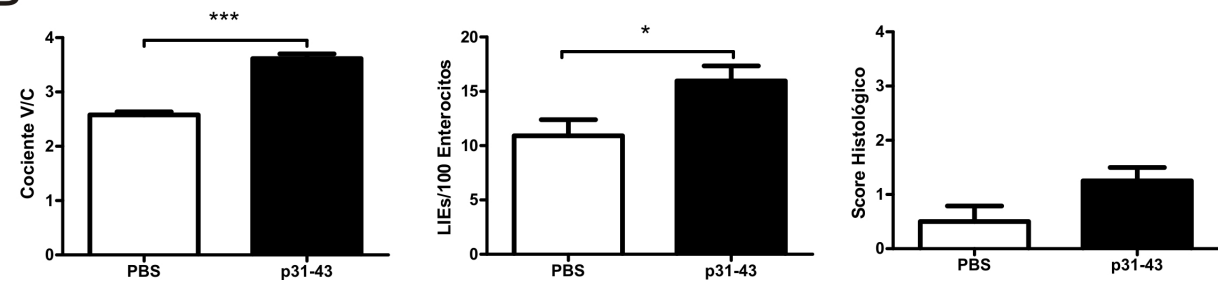

Figura 3.13. p31-43 incrementa el infiltrado intraepitelial en el intestino delgado de ratones NOD-DQ8 luego de $12 \mathrm{hs}$.

Secciones teñidas con H\&E representativas de intestino delgado proximal de ratones NOD-DQ8 después de 12hs de administración de p31-43 o PBS (A). Análisis morfológicos de intestino delgado de ratones NOD-DQ8: Cociente Vellosidad/Cripta (V/C), score histológico y número de LIEs después de $12 \mathrm{hs}$ de tratamiento $(\mathbf{B})$. $\mathrm{N}=4$ ratones por grupo, test $\mathrm{t}$ no pareado, ${ }^{*} \mathrm{P}<0,05,{ }^{*} * * \mathrm{P}<0,001$. 
ratones $\mathrm{C} 57 \mathrm{BL} / 6$. Con este fin, se administró p31-43 intraluminal en el intestino delgado de ratones NOD-DQ8 y luego de 12hs se analizó la histología de la mucosa intestinal.

Sorprendentemente, a diferencia de lo observado en ratones C57BL/6, la evaluación de secciones de intestino delgado evidenció escasos signos de daño en ratones tratados con p31-43. Las imágenes muestran sólo un leve edema en algunas vellosidades de los ratones tratados con p31-43, con infiltrado en el compartimiento intraepitelial (Figura 3.13A).

El análisis morfométrico mostró que el cociente V/C en los ratones NODDQ8 estimulados con p31-43 es más alto que en los controles, hallazgo opuesto a lo esperado según los resultados obtenidos en ratones C57BL/6 (Figura 3.13B).

Sin embargo, la respuesta inflamatoria se ve reflejada por un incremento en el número de los LIEs en los ratones tratados con p31-43. El score histológico fue comparable al observado en el control, aunque levemente más elevado (Figura 3.13B).

Cuando evaluamos por separado la longitud de las vellosidades y la profundidad de las criptas en los dos grupos de ratones, encontramos que el incremento en el cociente $\mathrm{V} / \mathrm{C}$ se produce a expensas del incremento en la longitud de las vellosidades sin modificación de la profundidad de las criptas (Figura 3.14). Por lo tanto, además del estado proinflamatorio observado en los animales NOD-DQ8 tratados con p31-43, si bien no se observa una hipertrofia de criptas, existe una respuesta hiperproliferativa provocada por el p31-43 en las primeras 12 hs. Este estado hiperproliferativo podría determinar un cociente V/C aumentado en este corto período de tiempo.

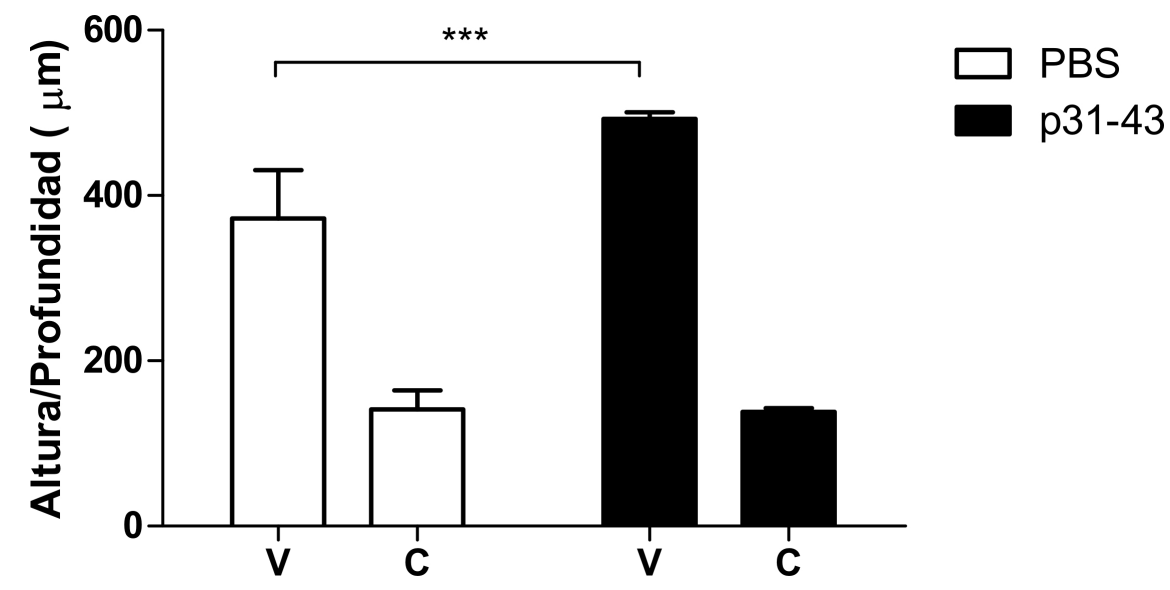

Figura 3.14. El incremento en el cociente V/C por el p31-43 sucede a expensas del aumento de la longitud de las vellosidades.

Determinación morfométrica de la longitud de las vellosidades y de la profundidad de las criptas en ratones NOD-DQ8 tratados con p31-43 o PBS intraluminal después de $12 \mathrm{hs}$. N=4 ratones por tratamiento. Test t no pareado. ${ }^{* * *} \mathrm{p}<0,001$ 


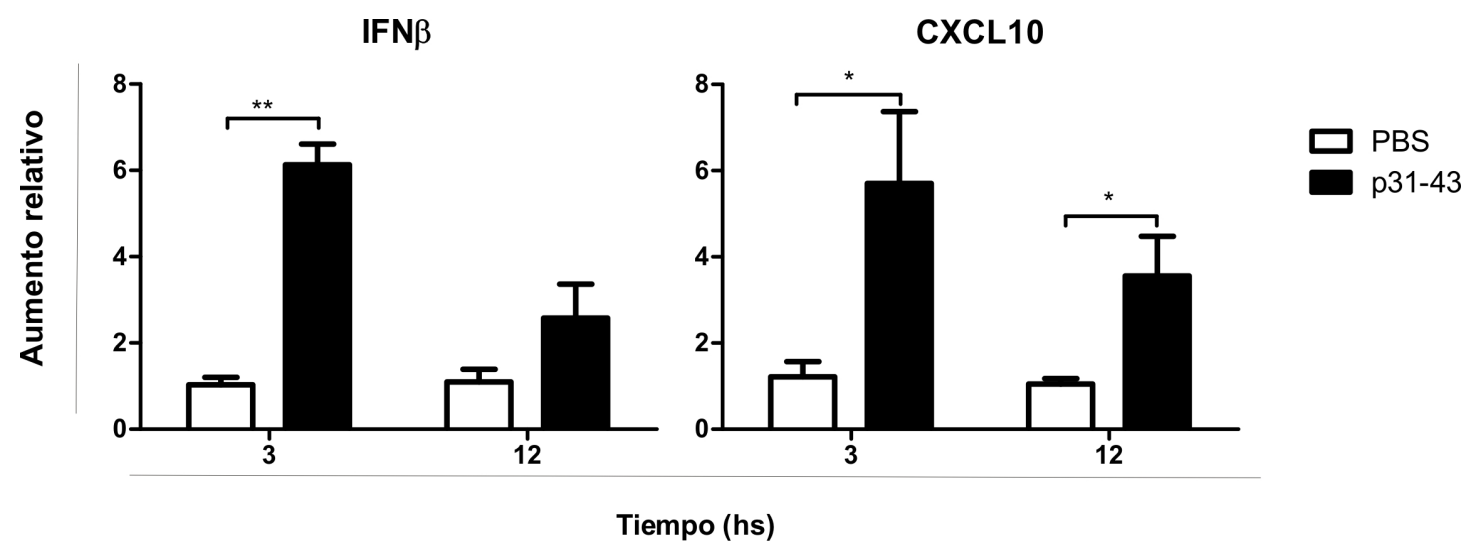

Figura 3.15. Inducción de la expresión de ARNm de IFN $\beta$ y CXCL10 en el intestino delgado de ratones NOD-DQ8 tratados con p31-43.

Análisis de Real Time PCR de la expresión de ARNm de IFN $\beta$ y CXCL10 post-tratamiento con p31-43 o PBS. Todos los valores fueron normalizados según la expresión de un gen constitutivo (HPRT). Todos los resultados fueron expresados como aumento relativo del tratamiento con PBS o p31-43 versus la media del tratamiento con PBS en cada punto de tiempo $\left(2^{-\Delta \Delta \mathrm{Ct}}\right) . \mathrm{N}=4$ ratones por grupo, test t no pareado, ${ }^{*} \mathrm{P}<0.05,{ }^{* *} \mathrm{P}<0.01$, tratados con $\mathrm{p} 31-43$ versus controles de $\mathrm{PBS}$ en el mismo punto de tiempo.

Con el fin de evaluar la respuesta inflamatoria en los ratones NOD-DQ8 medimos la expresión de mediadores inflamatorios por PCR cuantitativa en piezas de intestino delgado luego de 3 y 12 hs del procedimiento quirúrgico. En los ratones NOD-DQ8 tratados con p31-43 se observó un incremento significativo en los niveles de ARNm de IFN $\beta$ y CXCL10 a las 3hs post-tratamiento. El aumento de CXCL10 fue significativo aún a las 12hs post-tratamiento con p31-43 respecto a los animales control (Figura 3.15).

Si bien hemos observado la expresión de mediadores inflamatorios y un aumento en el número de LIEs, la histología mostró vellosidades de mayor longitud y, por lo tanto, una relación V/C alterada en ratones NOD-DQ8 tratados con p31-43. Este efecto, como mencionamos con anterioridad, puede ser consecuencia de un descontrol en la actividad proliferativa de las criptas. Debido a esto, quisimos determinar si dicho incremento podía estar asociado a un aumento en la proliferación celular en las criptas evaluando la expresión del marcador Ki67.

Se observó un incremento en el número de células $\mathrm{Ki} 67^{+}$en criptas de intestino delgado de ratones NOD-DQ8 luego de 12hs post-estimulación con p3143 comparado con los ratones del grupo control (Figura 3.16). Por lo tanto, hemos evidenciado un rol particular del p31-43 en los ratones NOD-DQ8, que de una manera aún no conocida, induce un aumento en la actividad proliferativa en las criptas y provocando finalmente un aumento del cociente $\mathrm{V} / \mathrm{C}$ en un contexto inflamatorio. 


\section{PBS}

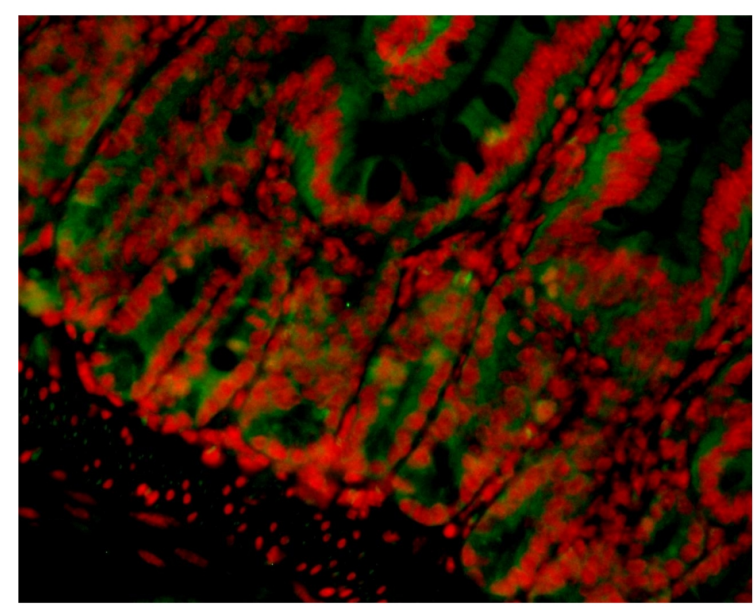

p31-43
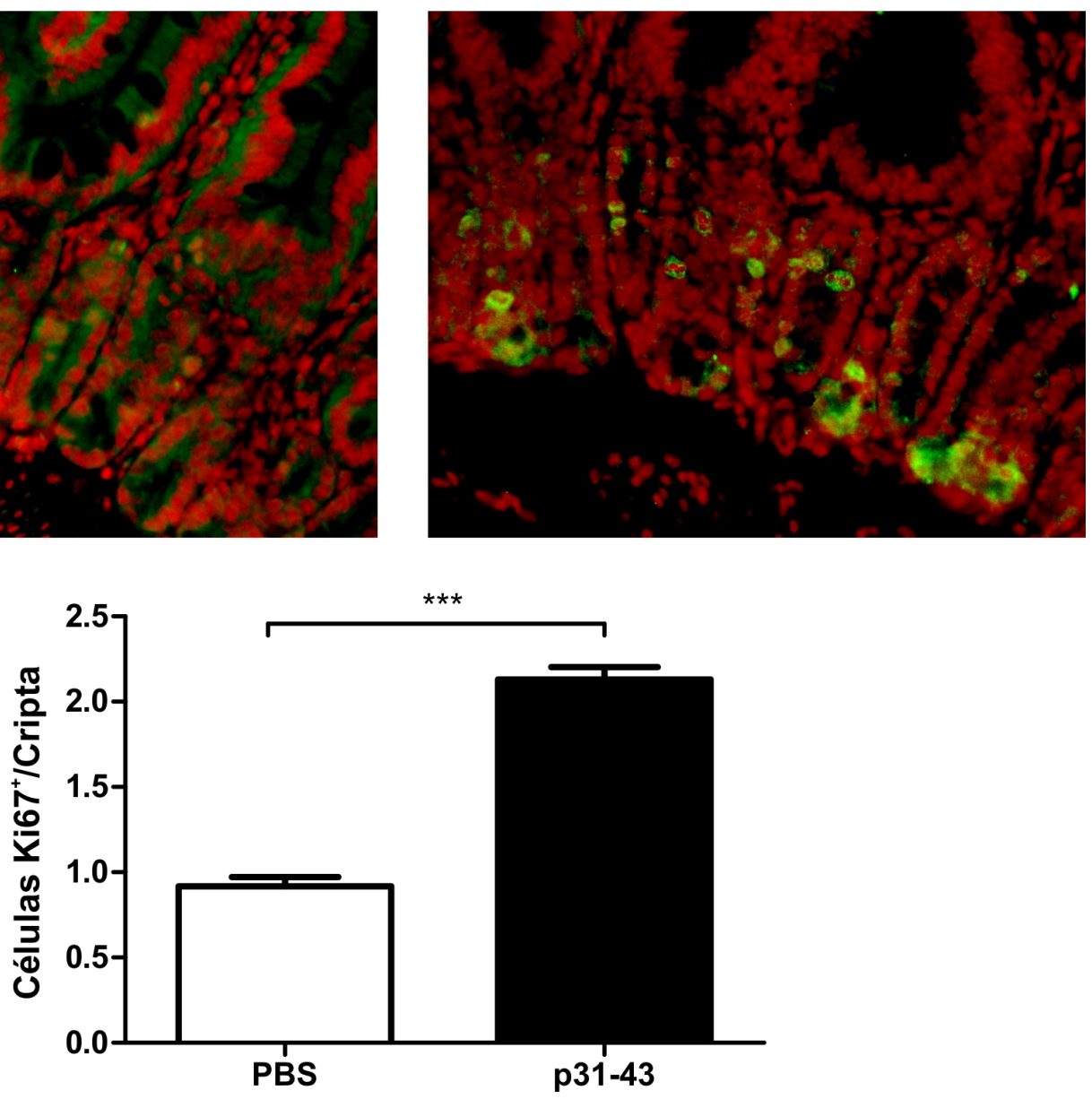

Figura 3.16. p31-43 induce un perfil proliferativo en las criptas de intestino delgado de ratones NOD-DQ8.

Imágenes representativas de la marca fluorescente del anticuerpo anti-Ki67 en células de la cripta de ratones NOD-DQ8 tratados con p31-43 o el control con PBS por 12hs tomadas en un microscopio de fluorescencia Nikon (A). Análisis de proliferación celular por medio del recuento de células Ki67 ${ }^{+}$ en secciones de intestino delgado. Muestras tomadas a las 12hs post-estimulación con PBS o p31-43. $\mathrm{N}=4$ ratones por grupo, test t no pareado, ${ }^{* * * *} \mathrm{P}<0,001$ (B).

\section{La administración intraluminal de p31-43 exacerba la respuesta a gliadinas por vía} oral y causa enteropatía severa en ratones NOD-DQ8.

Ya que observamos un incremento del infiltrado linfocitario en el compartimiento epitelial y un efecto proliferativo del p31-43 sobre el epitelio de ratones NOD-DQ8 en el modelo agudo, nos propusimos evaluar el establecimiento de un modelo crónico de enteropatía basado en la alteración primaria de la mucosa intestinal debida a la administración intraluminal de p31-43 seguida de la estimulación por vía oral con gliadinas durante dos semanas, en un protocolo equivalente al desarrollado anteriormente con poly (I:C). 


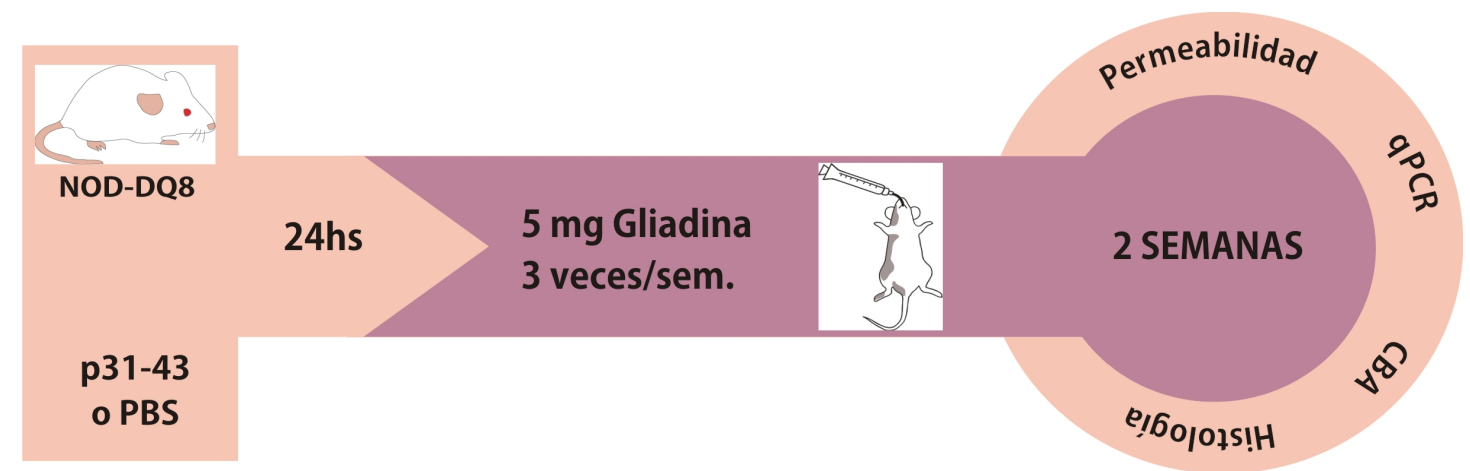

Grupo 1: PBS + Gliadina
Grupo 2: PBS + DLG
Grupo 3: p31-43 + Gliadina
Grupo 4: p31-43 + DLG

Figura 3.17. Esquema que representa el desarrollo experimental realizado con los ratones NOD-DQ8 en el modelo crónico.

Los ratones NOD-DQ8 fueron estimulados con p31-43 o PBS intraluminal y luego de $24 \mathrm{hs}$ se comenzó con la administración intragástrica de gliadina o la solución vehículo como control (DLG), 3 veces por semana durante 2 semanas. Hasta el momento de la cirugía los animales consumían alimento libre de gluten. Concluido ese tiempo se sacrificaron los 4 grupos de animales y se obtuvieron muestras de intestino y sangre. Durante las 2 semanas se registró el peso de los animales.

Con este fin, mediante el procedimiento de microcirugía ya descripto, se administró por vía intraluminal PBS o p31-43 en intestino delgado proximal de ratones NOD-DQ8 mantenidos en dieta libre de gluten. Luego de 24hs del procedimiento quirúrgico los animales fueron alimentados con dieta libre de gluten o con gliadinas, tres veces por semana durante 2 semanas. Una vez concluidas las dos semanas, los animales fueron sacrificados y se recolectaron muestras de sangre y de intestino delgado para su análisis (Figura 3.17). Ninguno de los grupos presentaron diferencias en el cambio de peso a lo largo de las dos semanas de experimento (No se muestra).

La dieta libre de gluten no afectó la estructura histológica del intestino delgado de ratones NOD-DQ8 del grupo control tratado con PBS. Por otro lado, la evaluación histológica mostró un edema subepitelial extendido y una separación moderada del epitelio de las vellosidades en ratones tratados con p31-43 y luego alimentados con gliadinas (Figura 3.18A). Los parámetros histológicos medidos revelaron que ambos grupos tratados con p31-43 tuvieron cocientes V/C, recuentos de LIEs y scores histológicos alterados (Figura 3.18B). Sin embargo, los cambios morfológicos más persistentes y severos en la mucosa del intestino delgado fueron observados solamente en los ratones NOD-DQ8 tratados con p3143 que fueron alimentados con gliadinas. De esta manera, si bien dos semanas luego de la administración intraluminal de p31-43 persisten signos de alteración 
A

DLG

Gliadina
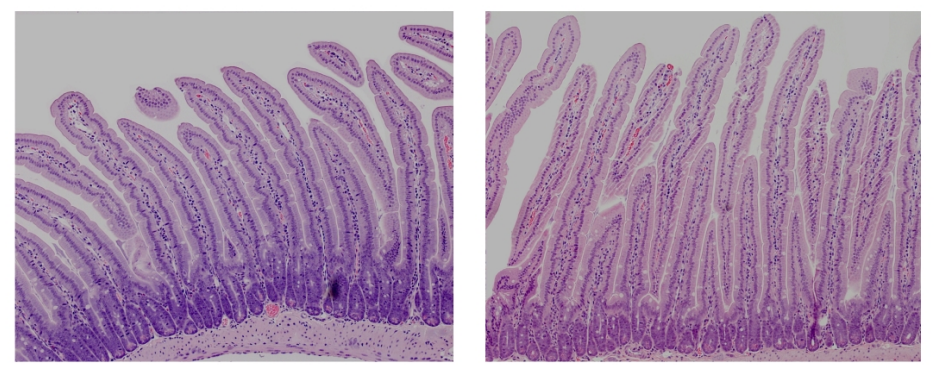

\section{PBS}
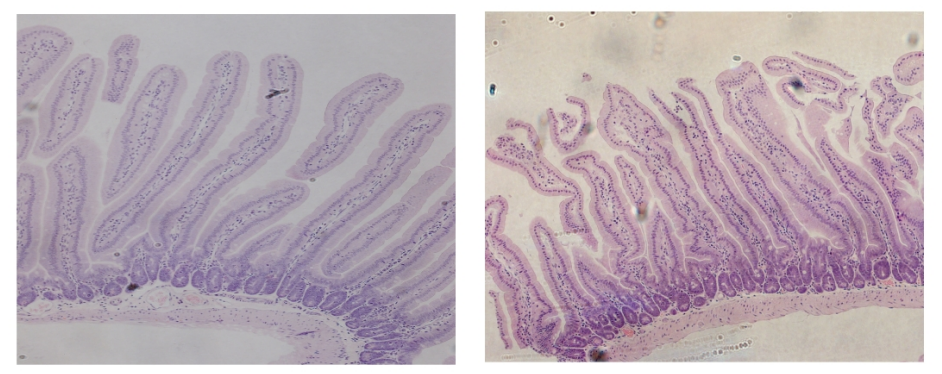

p31-43

B
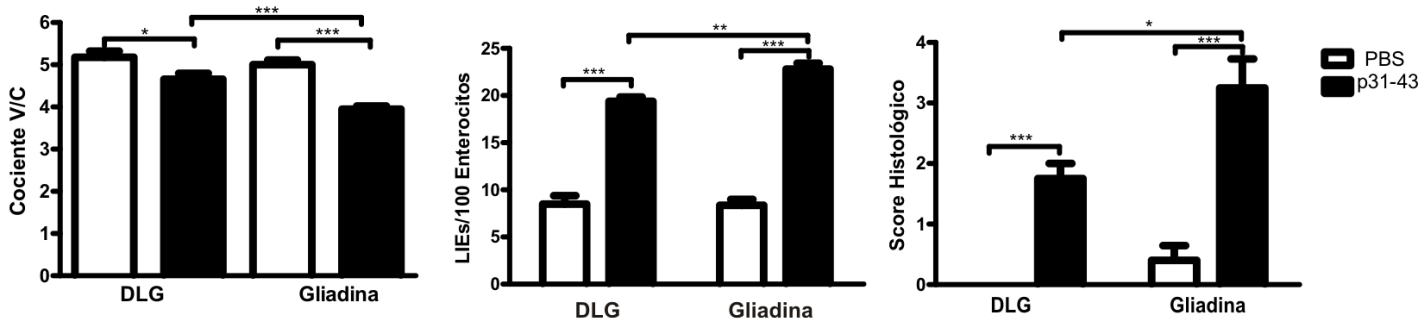

Figura 3.18. La administración oral de gliadinas induce daño histológico en ratones NOD-DQ8 tratados con p31-43.

Secciones teñidas con H\&E representativas de intestino delgado proximal de ratones NOD-DQ8 tratados con PBS o p31-43 y mantenidos en dieta libre de gluten (DLG) o alimentados con gliadina durante 2 semanas. (A). Análisis morfológico del intestino delgado de ratones NOD-DQ8 tratados con PBS o p31-43 y posteriormente en DLG o alimentados con Gliadinas durante 2 semanas: Cociente $\mathrm{V} / \mathrm{C}$, recuento de LIEs y score histológico. $\mathrm{N}=4-5$ ratones por grupo, Test t no pareado, $* \mathrm{P}<0.05,{ }^{* *} \mathrm{P}<0.01, * * * \mathrm{P}<0.001$ (B).

en la mucosa aún en animales en DLG, la severidad del daño está asociado principalmente a la administración de gliadinas por vía oral (Figura 3.18B).

De esta manera, si bien dos semanas luego de la administración intraluminal de p31-43 persisten signos de alteración en la mucosa aún en animales en DLG, la severidad del daño está asociado principalmente a la administración de gliadinas por vía oral (Figura 3.18B).

La enteropatía inducida por p31-43 predispone a una respuesta exacerbada a gliadinas.

Hemos mostrado que la administración oral de gliadinas en animales pretratados con p31-43 exacerba el daño en la mucosa intestinal comparado con animales en dieta libre de gluten. Nos propusimos evaluar si los cambios histológicos estaban asociados a la alteración funcional de la mucosa intestinal. 
Conductancia Transepitelial

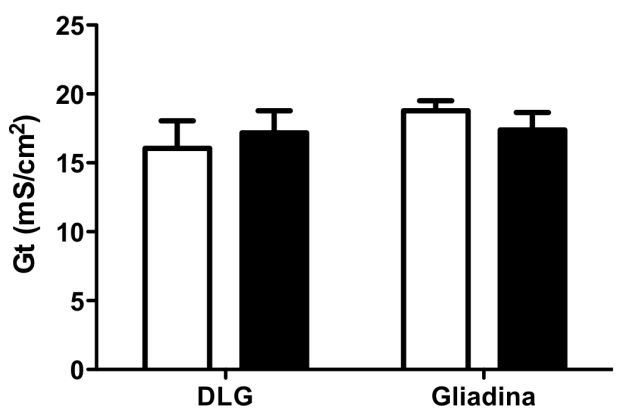

${ }^{51}$ Cr-EDTA

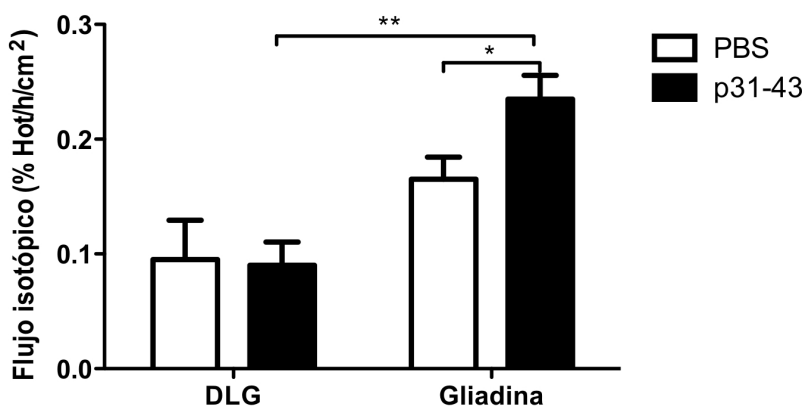

Figura 3.19. Gliadina induce disfunción de la barrera en ratones NOD-DQ8 tratados con p31-43.

Después de 2 semanas de tratamiento, secciones de intestino delgado fueron montadas en Ussing chambers y se midió la Conductancia Transepitelial $(\mathrm{mS} / \mathrm{cm} 2)$ y el Flujo isotópico $\left(\% \mathrm{Hot} / \mathrm{h} / \mathrm{cm}^{2}\right)$. Cada barra representa la media de 4 ratones y cada medida pertenece a dos tejidos por cada ratón. $\mathrm{N}=3-4$ ratones por grupo, ANOVA de dos vías y test posterior de Bonferroni, ${ }^{*} \mathrm{P}<0.05$.

Para esto, en forma similar a la mostrada anteriormente, estudiamos parámetros fisiológicos mediante el uso de la técnica Ussing chamber. Se observó un incremento en el permeabilidad paracelular evidenciado como aumento del flujo de ${ }^{51} \mathrm{Cr}$-EDTA en los ratones NOD-DQ8 tratados con p31-43 cuando recibieron gliadinas por dos semanas, pero no en ratones tratados con p31-43 mantenidos en DLG o en los ratones controles tratados con PBS. Los valores obtenidos para cada grupo fueron: PBS-DLG: 0,095\%, p31-43-DLG: 0,090\%, PBS-gliadina: 0,165\%, p31-43-gliadina: 0,235\% Hot/h/ $\mathrm{cm}^{2}$ (Figura 3.19). La evaluación de la conductancia transepitelial por su parte y a diferencia del modelo crónico con poly (I:C) no mostró diferencias entre los grupos dos semanas después del tratamiento (Figura 3.19).

En conjunto, hemos demostrado que la administración intraluminal de p3143 causa alteración de la mucosa intestinal que induce una respuesta exacerbada frente a gliadinas administradas por vía oral. Esto no sólo fue determinado por cambios histológicos severos sino también por la alteración funcional de la mucosa. A su vez, el aumento de permeabilidad puede actuar como un mecanismo de amplificación de los fenómenos inflamatorios y de los mecanismos de daño.

Las alteraciones observadas por p31-43 y gliadinas son, sin embargo, distintas de las observadas en los ratones tratados con poly (I:C) y gliadina, indicando que como fue descripto en el capítulo 2 probablemente estos dos estímulos generen mecanismos diferentes de daño. 


\section{DISCUSIÓN}

En capítulos previos describimos la inducción de enteropatía mediante la administración local de poly I:C (como modelo de la respuesta innata desencadenada por una infección viral) y del péptido de gliadinas, p31-43, (descripto como inductor de diferentes procesos inflamatorios in vitro). En ambos casos, la administración intraluminal de los inductores limitó, principalmente, los fenómenos desencadenados a aquellos producidos directamente en el intestino delgado proximal.

Desde el punto de vista histológico, la enteropatía inducida tanto por poly I:C como por p31-43, parece revertir al transcurrir el tiempo. Esto sugiere la participación de mecanismos de remodelamiento y reparación del tejido que se activan concomitantemente a la respuesta inflamatoria generada. En este contexto, nos preguntamos si la alteración histológica temprana puede tener consecuencias funcionales a largo plazo aún cuando tiende a resolverse.

Con este fin, decidimos emplear ratones NOD-DQ8, los cuales carecen de las moléculas de CMH clase II endógenas y expresan el gen para HLA-DQ8 humano (alelo de susceptibilidad de EC) (Marietta et al. 2004; Rajagopalan et al. 2003). Estudios previos que utilizaron este modelo de ratón han demostrado que la sensibilización con gliadinas resulta en una disfunción de la barrera intestinal y en enteropatía leve (Galipeau et al. 2011). Para proceder a evaluar el uso de estos animales en un protocolo a largo plazo, en primer lugar evaluamos la respuesta temprana generada por administración de poly I:C o p31-43.

El uso de los ratones NOD-DQ8 para analizar la respuesta a poly (I:C) a largo plazo fue utilizado bajo la hipótesis de que factores de origen viral podrían ser disparadores de una mayor susceptibilidad a gliadinas en un contexto genético predisponente. En la etapa aguda del modelo, los ratones NOD-DQ8 tratados con poly (I:C) desarrollaron daño en la mucosa caracterizado por un score histológico más alto que en los ratones controles, infiltrado celular en LP, reducción del cociente $\mathrm{V} / \mathrm{C}$, incremento del recuento de LIEs y sobreexpresión de ARNm de IFN $\beta$ y CXCL10 en la mucosa intestinal. Esto fue también acompañado por niveles más altos de TNFa, IL-6 y MCP1 en sangre periférica. Un día después de la administración de poly (I:C), un grupo de ratones NOD-DQ8 fue sometido a un desafío oral con gliadinas mientras otro fue mantenido en DLG. Los estudios de permeabilidad indicaron un incremento de la permeabilidad paracelular en los ratones tratados con poly (I:C) después de 2 semanas independientemente de la 
dieta a la que fueron sometidos. Poly (I:C) además indujo alteraciones en el cociente $\mathrm{V} / \mathrm{C}$ comparado con los ratones control tanto en el grupo desafiado con gliadina como en los ratones en DLG. Sin embargo, sólo los ratones tratados con poly (I:C) que recibieron gliadinas presentaron un valor de score histológico global más alto, demostrando cambios severos en la mucosa. Más aún, los ratones NOD-DQ8 tratados con poly (I:C) que fueron desafiados con gliadinas fueron los únicos que presentaron un incremento significativo de la conductancia transepitelial. Es de remarcar que después de dos semanas de ingestión de gliadinas, los ratones NOD-DQ8 mostraron niveles incrementados de las citoquinas proinflamatorias IL-12p70 y TNF $\alpha$ en sangre periférica, comparada con aquellos en DLG, mostrando una relación causal con los desafíos con gliadinas y no con el tratamiento con poly (I:C). Además, la inducción de IL-10 por gliadinas, una característica observada antes en los modelos murinos de DQ8 de sensibilidad al gluten (Galipeau et al. 2011; Natividad et al. 2009; Black, Murray, and David 2002), fue inhibida en los ratones tratados previamente con poly (I:C). A su vez, se observó un desbalance en la relación IL-12p70/IL-10 en ratones NODDQ8 tratados con poly (I:C) y desafiados con gliadinas. Es de destacar la relevancia de este hallazgo dado que ambas citoquinas tienen un efecto directo sobre la función de barrera y el daño intestinal. El correcto ensamblaje de los componentes de las uniones estrechas es crítico para preservar la integridad de la barrera y TNF $\alpha$ es reconocido como uno de los principales mediadores asociados con el daño en la mucosa intestinal en la enfermedad de Crohn y en EC (Kleinschek et al. 2009; Kolodziej et al. 2011; Zimmermann et al. 2014). La señalización de TNF $\alpha$ activa la quinasa de cadena liviana de miosina (MLCK, myosin light chain kinase) y la remodelación de las uniones estrechas conduciendo a una pérdida de la función de barrera (Turner 2009; Kolodziej et al. 2011).

En conclusión, poly (I:C) intraluminal induce un daño severo en la mucosa del intestino delgado en ratones NOD-DQ8. La adición de gliadinas en la dieta produce un efecto sinérgico proinflamatorio y a una alteración de la función de barrera del intestino. Nuestros resultados sostienen la hipótesis sobre un rol crítico de los IFNs tipo I en la pérdida de tolerancia al gluten después de una infección viral como un evento disparador de EC. Esto es particularmente importante en huéspedes genéticamente susceptibles, promoviendo inflamación así como también potenciando el establecimiento de la respuesta de tipo Th1 específica de gliadinas. Nuestros resultados hasta este punto proveen una 
explicación mecanística de la asociación entre las infecciones entéricas y los desórdenes post-inflamatorios y funcionales (Stene et al. 2006; Troncone and Auricchio 2007; Marshall et al. 2006; Marshall et al. 2010; Garg et al. 2006).

Nuestra segunda hipótesis de trabajo fue que el origen del disparo inflamatorio en la mucosa es generada por el p31-43, y que esto predispone a una respuesta exacerbada posterior frente a gliadinas administradas por vía oral. En primer lugar analizamos si los efectos agudos de la administración de p31-43 observado en el capítulo 2 en ratones normales podían replicarse en ratones NOD-DQ8.

Encontramos que el modelo agudo con p31-43 difiere en algunos aspectos del obtenido con poly (I:C), demostrando una vez más que los efectos de estos dos inductores estarían mediados por vías de señalización diferentes. Observamos que los ratones NOD-DQ8 estimulados con p31-43 intraluminalmente presentan una histología aparentemente normal. Sorprendentemente, los valores del cociente V/C son mayores para los ratones inducidos con p31-43 que para los tratados con PBS. Observamos un aumento en la capacidad proliferativa de las criptas, medida como incremento en el número de células $\mathrm{Ki} 7^{+}$en las mismas. En este punto, nuestra hipótesis es que esta hiperproliferación podría tener su correlato con una mayor actividad proliferativa del epitelio diferenciado llevando al aumento observado de la longitud de las vellosidades. A pesar de la aparente ausencia de daño, es de destacar que el recuento de LIEs es más alto en ratones NOD-DQ8 tratados con p31-43 que en aquellos tratados con PBS. Por lo tanto, si bien la arquitectura histológica está conservada, existe un proceso inflamatorio en progreso en este tejido. Cuando evaluamos los mediadores inflamatorios en estos animales, encontramos que existe inducción de la expresión de IFN $\beta$ y CXCL10 a las 3 y 12 hs post-inyección de p31-43. Estos resultados demuestran que el efecto del p31-43 sobre la mucosa intestinal es particularmente diferente al inducido por poly (I:C), y esto se evidencia cuando dichos estímulos son utilizados en un entorno genético condicionando.

El incremento de la expresión de IFNs tipo I y CXCL10 inducido por p31-43 en un modelo in vivo es de alta relevancia. Los IFNs tipo I han sido indicados como los principales responsables tanto de la inducción de la respuesta inflamatoria temprana como del sostenimiento y expansión de la respuesta Th1 crónica (Devasenan Devendra et al. 2005; Abadie et al. 2011; Fernández-Salazar et al. 2011). A su vez, trabajos de nuestro grupo sobre piezas de biopsias de 
duodeno de pacientes celíacos han establecido que CXCL10 tiene un rol fundamental para el reclutamiento de células $\mathrm{CXCR}^{+}$en la mucosa intestinal: linfocitos T, LIEs y células plasmáticas (Bondar et al., 2014). Esta es la primer demostración de que el p31-43 puede mediar este efecto in vivo.

Entonces decidimos comprobar si este proceso inflamatorio inducido por p31-43 predispone al desarrollo de una respuesta exacerbada al gluten. Para ello tratamos ratones NOD-DQ8 con p31-43 o PBS y luego de 24hs de estímulo procedimos a alimentarlos con dieta libre de gluten o con gliadinas por vía oral durante 2 semanas. Luego de esas 2 semanas de desafío, encontramos que sólo los animales tratados con p31-43 presentaron parámetros morfométricos más fuertemente alterados cuando se comparan con los ratones en DLG y con los ratones controles.

Por otro lado, el análisis de la funcionalidad del intestino delgado de estos ratones demuestra que hay una alteración del transporte paracelular de ${ }^{51} \mathrm{Cr}$ EDTA en los ratones tratados con p31-43 y alimentados con gliadinas respecto a los que permanecieron en DLG y a los controles de PBS. El efecto de gliadinas sobre la permeabilidad intestinal en relación a EC ha sido ampliamente estudiado (Drago et al. 2006; K M Lammers et al. 2008; Heyman et al. 2012). Sin embargo, ningún estudio demostró el efecto sobre la permeabilidad de gliadinas y sus péptidos derivados in vivo. Por lo tanto, este es el primer estudio que logra evidenciar los efectos de gliadinas y del p31-43 a largo plazo sobre la permeabilidad intestinal en un contexto genético apropiado. Este incremento en la permeabilidad intestinal podría ser representativo de los mecanismos iniciales de patogenia observados en EC. Un estudio más completo de nuestro modelo animal deberá ser llevado a cabo para entender las vías que se activan por la presencia del p31-43 en la luz del intestino, que junto con una alimentación rica en gliadinas predispone a una alteración de la permeabilidad y el desarrollo de enteropatía.

Por lo tanto, concluimos que sumada a la clara afección histológica e inflamatoria observada por los análisis morfométricos, el pretratamiento con p31-43 genera una alteración de la funcionalidad de la barrera intestinal en ratones desafiados con gliadinas.

Se sabe que los péptidos de gliadinas pueden incrementar la permeabilidad intestinal por mecanismos innatos amplificando el circuito del daño de la mucosa propio de EC (Clemente et al. 2003; DePaolo et al. 2011; Heyman et al. 2012; Nanayakkara, Lania, et al. 2013). IL-15 ha sido descripta como una citoquina 
relevante en las etapas iniciales de daño en EC, y en especial algunos estudios muestran que puede ser inducida por p31-43. En este sentido, no observamos cambios en la expresión de IL-15 asociados con este modelo. Sin embargo, debido a que la expresión de IL-15 tiene un control post-transcripcional complejo, las determinaciones de IL-15 a nivel de ARNm no dan cuenta de su actividad biológica. Por otro lado, la evaluación a nivel de proteína resulta técnicamente difícil, y no se obtienen resultados claros. Estudios del grupo de la Dra. Verdú han permitido caracterizar en detalle el modelo de ratones NOD-DQ8 (Galipeau et al. 2011). En particular, se sabe que IL-15 no está involucrada en los mecanismos de daño en estos ratones. Estos resultados ponen en duda la relevancia de IL-15 en la enteropatía experimental y aún se discute de qué modo esta citoquina es parte de la patogenia de EC (N Korneychuk, Meresse, and Cerf-Bensussan 2014). Ante esta situación, se han intentado generar modelos murinos que permitan determinar el rol de IL-15 como inductor de enteropatía. Un ejemplo de esta búsqueda es el modelo de ratones Dd-IL-15Tg, los cuales expresan IL-15 bajo el promotor de $\mathrm{CMH}$ clase I, lo que resulta en la sobreexpresión de IL-15, en particular por su relación con la respuesta inmune en la mucosa, en células de NLM y en LP. Estos ratones tienen una expansión a temprana edad de células NK y linfocitos $\mathrm{T} \mathrm{CD8}{ }^{+}$. El resultado final es la muerte temprana de los animales por leucemia linfocítica con un fenotipo NK (Fehniger et al. 2001). Este estudio da luz acerca de la complejidad en la regulación de la expresión de IL-15 y que la sola sobreexpresión de esta citoquina no es suficiente para generar inflamación en intestino. Otro modelo que ha servido para describir el efecto de IL-15 en el epitelio intestinal es el de los ratones hIL-15Tge, los cuales expresan la forma secretada de IL-15 humana bajo el control del promotor T3b, el cual es específico de las células del epitelio intestinal. Estos animales tienen una sobreexpresión de IL-15 en el epitelio intestinal, aunque la citoquina también aparece en LP y circulación. En los ratones hIL-15Tge se produce una aumento de linfocitos $\mathrm{T}$ $\mathrm{CD}^{+}$intestinales y luego de varios meses, desarrollan una enteropatía severa similar a la observada en EC (Ohta et al. 2002). Sin embargo, aunque esta enteropatía no es específica de ningún antígeno dietario, los animales producen anticuerpos IgA anti-TG2 (Yokoyama et al. 2009). Estos resultados destacan la capacidad de las células $\mathrm{T}$ CD8 ${ }^{+}$citotóxicas del intestino a inducir daño mediado por IL-15. Por el contrario, no explican el rol de los linfocitos T CD4+ específicos para gluten en el desencadenamiento de EC. 
Para ello, las siguientes estrategias intentaron evaluar la sobreexpresión de IL-15 en un contexto de HLA-DQ8. Los animales que surgen de la cruza de los ratones HLA-DQ8 con H2-D -IL-15Tg, cuando son alimentados con gliadina durante 10 días no desarrollan daño en intestino pero sí presentan un incremento en la producción de anticuerpos anti-gliadina y anti-TG2, junto con un incremento del número de LIEs y células T productoras de IFN $\gamma$. Sin embargo, estos animales no producen grandes cantidades de IL-15 en intestino y se ha sugerido que este el motivo por el cual no desarrollan enteropatía. En un modelo de cooperación de IL-15 con linfocitos $\mathrm{T} \mathrm{CD}^{+}$específicos de gluten con la inhibición de los mecanismos inmunorregulatorios, IL-15 generó la activación de linfocitos $\mathrm{T}$ citotóxicos, medido como incremento de su proliferación y de producción de granzima B (Natalia Korneychuk et al. 2014), con el consecuente daño en la mucosa luego de 3 meses.

De todos estos modelos podemos concluir que la sola presencia de IL-15 no es suficiente para determinar la pérdida de tolerancia frente a péptidos derivados de gluten, con lo cual si bien se reconoce un rol relevante de IL-15 en la patología, es claro que no es responsable del inicio o desencadenamiento de la enfermedad. 


\section{CONCLUSIÓN}

En este trabajo demostramos que tanto poly (I:C) como el p31-43 inducen una alteración en la mucosa intestinal que determina una subsiguiente respuesta anómala al desafío con gluten. Ambos estímulos presentan diferencias en sus mecanismos de acción y plantean dos posibilidades distintas para el disparo de una enteropatía aguda que mediante la inducción de sensibilidad al gluten podría dar origen a un proceso crónico, como sucedería en EC. De manera relevante esto puede tener implicancias en el conocimiento sobre el mecanismo de patogenia de esta enfermedad como así también de otros síndromes de Sensibilidad al gluten no celíaco. 


\section{CONCLUSIONES FINALES Y PERSPECTIVAS}

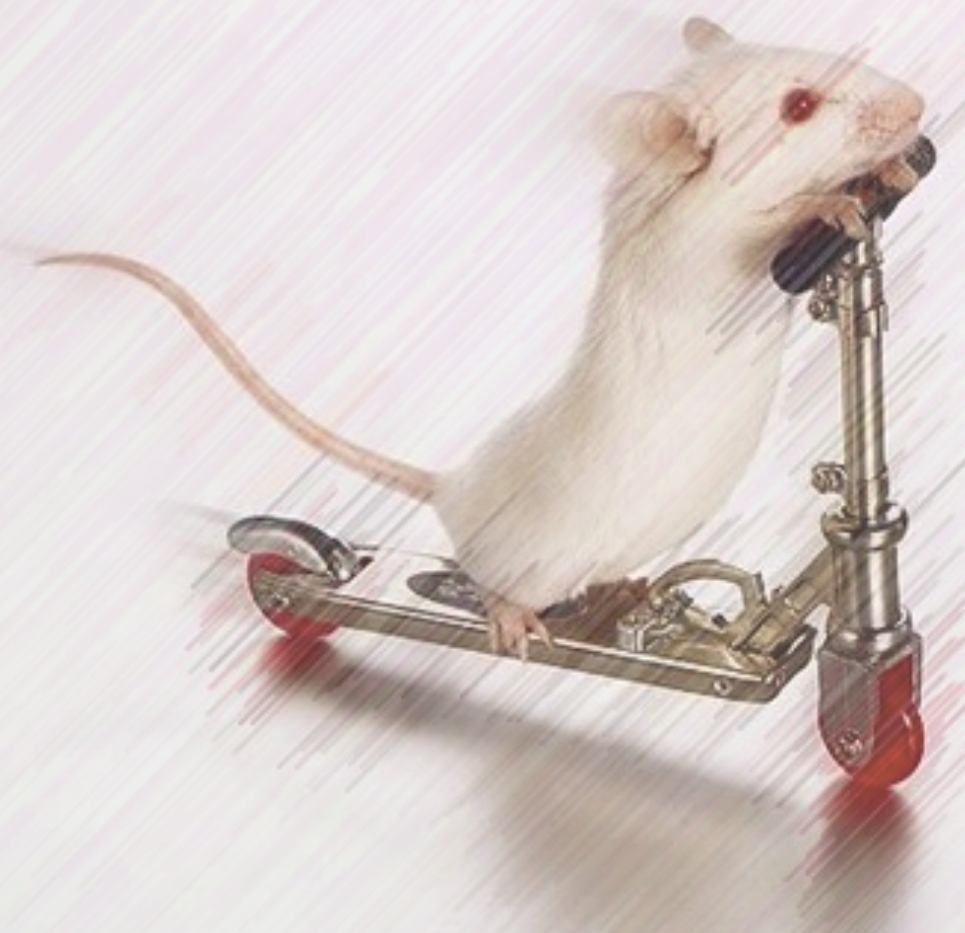





\section{Conclusiones finales y Perspectivas}

A lo largo de este trabajo de tesis abordamos distintas estrategias experimentales con el fin de generar modelos murinos que nos permitan entender los eventos tempranos inflamatorios durante una injuria a nivel del intestino delgado y cómo estos eventos podrían conducir a una enteropatía crónica, como la que se observa en EC.

Para comenzar, realizamos un trabajo de puesta a punto del método de inyección de los inductores en la luz del intestino delgado, generando un protocolo que nos permitió la administración directa de los inductores intraluminalmente sin la degradación enzimática propia de la vía oral y minimizando los efectos de un procedimiento microquirúrgico.

Nuestro primer modelo de inducción de enteropatía fue llevado a cabo por la inyección intraluminal de poly (I:C). Contrastamos este modelo con otros preexistentes que utilizaban una vía sistémica de inducción y caracterizamos a nivel de mediadores inflamatorios y celulares el daño generado en la mucosa de estos animales. Encontramos que el eje CXCL10/CXCR3 participa en la inducción de enteropatía, junto con los IFNs tipo I y TNF $\alpha$, y que las poblaciones celulares de monocito/macrófagos y células dendríticas tienen un rol importante en la generación y severidad del daño.

Planteamos además el estudio de los mecanismos de muerte celular en el intestino delgado encontrando que, probablemente otras vías de muerte distintas a la apoptosis, estén participando en el daño intestinal.

El segundo modelo desarrollado consistió en la inyección intraluminal del péptido derivado de $\alpha$-gliadina, p31-43. Si bien este péptido ha sido estudiado en diferentes ensayos in vitro, no se había evaluado en un modelo in vivo. Encontramos que el p31-43 genera enteropatía en ratones C57BL/6 y que el daño es específico de la composición particular de aminoácidos, mas no de su secuencia. Observamos que este péptido induce un estado hiperproliferativo en las criptas y muerte celular en lamina propria y epitelio por apoptosis. El daño histológico y la muerte celular fueron dependientes de MyD88. Demostramos que el eje CXCL10/CXCR3 estuvo implicado y se indujo la expresión de citoquinas proinflamatorias como IFN $\gamma$ e IFN $\beta$. Este modelo se diferenció del anterior en el tipo de daño y en los mecanismos que se activaron como consecuencia. 
Nuestro tercer modelo consistió en la combinación de un estímulo de origen dietario (p31-43) con un estímulo de origen viral (poly (I:C)), inyectados intraluminalmente en intestino delgado de ratones C57BL/6. Encontramos que el estímulo combinado también es capaz de producir enteropatía, con similitudes y diferencias respecto a lo que se observó en los estímulos individuales. Esta combinación genera un perfil inflamatorio particular, con incrementos en citoquinas proinflamatorias tales como IFN $\beta$ y TNF $\alpha$, como así también con la inducción del eje CXCR3/CXCL10. A diferencia de los estímulos individuales, el estímulo doble generó un incremento en IL-6 e IL-18, como así también las quimoquinas CXCL2 y MCP1. Por lo tanto, en cuanto al perfil inflamatorio se puede concluir que el estimulo doble generó una respuesta más intensa que los estímulos individuales.

Por otra parte, la combinación de poly (I:C)+p31-43 generó un marcado incremento en la muerte celular, caracterizada por la activación de Caspasa 3 en una gran proporción de células de la lamina propria de los animales tratados, situación que no se había observado antes en los estímulos individuales. Por lo tanto, concluimos que la combinación de poly (I:C)+p31-43 conduce a un daño más severo caracterizado por la participación de vías distintas a las observadas con poly (I:C) o p31-43.

Por otra parte, generamos un cuarto modelo de enteropatía que consistió en un estímulo temprano con poly (I:C) intraluminal, seguido de un desafío oral con gliadinas durante 2 semanas en ratones NOD-DQ8. Estos animales desarrollaron enteropatía aguda con inducción de citoquinas proinflamatorias e inducción de los receptores de poly (I:C). También presentaron una enteropatía a largo plazo que fue más severa cuando la dieta contenía gliadinas. A las 2 semanas, los animales presentaron un perfil proinflamatorio evidenciado a nivel sistémico, como así también una alteración de la función de barrera intestinal con un claro aumento de la permeabilidad.

Nuestro quinto modelo de enteropatía se elaboró en el contexto de ratones NOD-DQ8, pero esta vez se realizó un estímulo intraluminal con p31-43 seguido de una alimentación con gliadinas durante 2 semanas. Estos animales presentaron tempranamente hiperproliferación en criptas e incremento en el número de LIEs, junto con la inducción de citoquinas proinflamatorias, pero sin aparente producción de daño en el tejido. Sin embargo, a las 2 semanas estos animales presentaron enteropatía, la cual fue claramente más severa cuando los animales habían consumido gliadinas. La enteropatía estuvo asociada con una 
alteración de la función de barrera, particularmente por un trastorno en el transporte paracelular.

Estos dos últimos modelos tienen la utilidad de permitir la evaluación de diferentes inductores innatos o péptidos derivados de gliadina en la patología asociada a gluten, en un contexto genético asociado a EC. Sería de utilidad evaluar la respuesta específica a gliadinas luego de la inducción con estas moléculas, como así también el desarrollo de la enteropatía a tiempos más largos de desafío.

En conclusión, nuestros resultados dan soporte experimental a la hipótesis que ubica a los IFNs tipo I como inductores importantes para la pérdida de tolerancia a antígenos dietarios tales como gluten después de una infección viral, como pudo ser demostrado con poly (I:C) en el modelo de NOD-DQ8. Por otra parte, nuestros resultados con p31-43 dan a este péptido un rol protagónico en el disparo de una respuesta inflamatoria intestinal dependiente de MyD88 y en la inducción de sensibilidad al gluten a largo plazo, con lo cual proponemos un estudio exhaustivo de este péptido en estos modelos in vivo, de modo de caracterizarlo como posible factor de inducción temprano del desencadenamiento, como así también del mantenimiento de la enteropatía observada en paciente celíacos con la enfermedad activa.

Destacamos entonces que, por primera vez, se demuestra la inducción de enteropatía por la presencia de poly I:C o p31-43 en el lumen de intestino delgado en un modelo experimental. De especial relevancia en el conocimiento de los mecanismos tempranos de la patogenia de EC, mostramos que la inducción de enteropatía por poly I:C o p31-43 predispone a una respuesta exacerbada frente a gliadinas de la dieta.

Este modelo experimental reproduce probablemente la situación in vivo en el curso del desarrollo de la enteropatía en EC, donde factores adicionales a la genética y la ingesta de gluten son necesarios para el desencadenamiento de la patología.

El modelo desarrollado permitirá realizar estudios sobre los mecanismos y mediadores (hoy desconocidos) involucrados en las etapas tempranas de EC y permitirá evaluar si los cambios tempranos en la mucosa intestinal condicionan el desarrollo de otras condiciones patológicas en sitios extraintestinales. A su vez, constituye un excelente modelo para generar conocimiento sobre los mecanismos que determinan la Sensibilidad al gluten no celíaca. 


\section{REFERENCIAS BIBLIOGRÁFICAS}





\section{Referencias Bibliográficas}

Abadie, Valérie, and Bana Jabri. 2014. "IL-15: A Central Regulator of Celiac Disease Immunopathology." Immunological Reviews 260: 221-34. doi:10.1111/imr.12191.

Abadie, Valérie, Ludvig M Sollid, Luis B Barreiro, and Bana Jabri. 2011. "Integration of Genetic and Immunological Insights into a Model of Celiac Disease Pathogenesis." Annual Review of Immunology 29 (1). Annual Reviews: 493-525. doi:10.1146/annurevimmunol-040210-092915.

Abreu, Maria T. 2010. “Toll-like Receptor Signalling in the Intestinal Epithelium: How Bacterial Recognition Shapes Intestinal Function." Nature Reviews Immunology 10 (2). Nature Publishing Group: 131-44. doi:10.1038/nri2707.

Antonelli, Alessandro, Silvia Martina Ferrari, Poupak Fallahi, Emiliano Ghiri, Clara Crescioli, Paola Romagnani, Paolo Vitti, Mario Serio, and Ele Ferrannini. 2010. "InterferonAlpha, -Beta and -Gamma Induce CXCL9 and CXCL10 Secretion by Human Thyrocytes: Modulation by Peroxisome Proliferator-Activated Receptor-Gamma Agonists." Cytokine 50 (3). Elsevier Ltd: 260-67. doi:10.1016/j.cyto.2010.01.009.

Barera, Graziano, Riccardo Bonfanti, Matteo Viscardi, Elena Bazzigaluppi, Giliola Calori, Franco Meschi, Cesare Bianchi, and Giuseppe Chiumello. 2002. "Occurrence of Celiac Disease after Onset of Type 1 Diabetes: A 6-Year Prospective Longitudinal Study." Pediatrics 109 (5): 833-38. doi:10.1542/peds.109.5.833.

Barone, M Vittoria, Delia Zanzi, Mariantonia Maglio, Merlin Nanayakkara, Sara Santagata, Giuliana Lania, Erasmo Miele, et al. 2011. "Gliadin-Mediated Proliferation and Innate Immune Activation in Celiac Disease Are due to Alterations in Vesicular Trafficking." PloS One 6 (2). Public Library of Science: e17039. doi:10.1371/journal.pone.0017039.

Barone, Maria Vittoria, Merlin Nanayakkara, Giovanni Paolella, Mariantonia Maglio, Virginia Vitale, Raffaele Troiano, Maria Teresa Silvia Ribecco, et al. 2010. "Gliadin Peptide P31-43 Localises to Endocytic Vesicles and Interferes with Their Maturation.” PLoS ONE 5 (8). Public Library of Science: e12246. doi:10.1371/journal.pone.0012246.

Barone, Maria V, Anna Gimigliano, Gabriella Castoria, Giovanni Paolella, Francesco Maurano, Franco Paparo, Maria Maglio, et al. 2007. "Growth Factor-like Activity of Gliadin, an Alimentary Protein: Implications for Coeliac Disease." Gut 56 (4): 480-88. doi:10.1136/gut.2005.086637.

Biagi, F, O Luinetti, J Campanella, C Klersy, C Zambelli, V Villanacci, A Lanzini, and G $\mathrm{R}$ Corazza. 2004. "Intraepithelial Lymphocytes in the Villous Tip: Do They Indicate 
Potential Coeliac Disease?" Journal of Clinical Pathology 57 (8): 835-39. doi:10.1136/jcp.2003.013607.

Bjarnason, I, and T J Peters. 1984. "In Vitro Determination of Small Intestinal Permeability: Demonstration of a Persistent Defect in Patients with Coeliac Disease." Gut 25: 145-50. doi:10.1136/gut.25.2.145.

Black, Kay E, Joseph A Murray, and Chella S David. 2002. "HLA-DQ Determines the Response to Exogenous Wheat Proteins: A Model of Gluten Sensitivity in Transgenic Knockout Mice.” The Journal of Immunology 169: 5595-5600.

Bondar, Constanza, Romina E Araya, Luciana Guzman, Eduardo Cueto Rua, Nestor Chopita, and Fernando G Chirdo. 2014. "Role of CXCR3/CXCL10 Axis in Immune Cell Recruitment into the Small Intestine in Celiac Disease." PLoS ONE 9 (2). Public Library of Science: e89068. doi:10.1371/journal.pone.0089068.

Broquet, Alexis H, Yoshihiro Hirata, Christopher S McAllister, and Martin F Kagnoff. 2011. "RIG-I/MDA5/MAVS Are Required to Signal a Protective IFN Response in RotavirusInfected Intestinal Epithelium." The Journal of Immunology 186: 1618-26. doi:10.4049/jimmunol.1002862.

Bustin, Stephen a, Vladimir Benes, Jeremy a Garson, Jan Hellemans, Jim Huggett, Mikael Kubista, Reinhold Mueller, et al. 2009. "The MIQE Guidelines: Minimum Information for Publication of Quantitative Real-Time PCR Experiments." Clinical Chemistry 55 (4): 611-22. doi:10.1373/clinchem.2008.112797.

Capozzi, Antonella, Olimpia Vincentini, Pietro Gizzi, Alessandra Porzia, Agostina Longo, Cristina Felli, Vincenzo Mattei, et al. 2013. "Modulatory Effect of Gliadin Peptide 10-Mer on Epithelial Intestinal CACO-2 Cell Inflammatory Response." PloS One 8 (6): e66561. doi:10.1371/journal.pone.0066561.

Caputo, Ivana, Maria Vittoria Barone, Marilena Lepretti, Stefania Martucciello, Ivan Nista, Riccardo Troncone, Salvatore Auricchio, Daniele Sblattero, and Carla Esposito. 2010. "Celiac Anti-Tissue Transglutaminase Antibodies Interfere with the Uptake of Alpha Gliadin Peptide 31-43 but Not of Peptide 57-68 by Epithelial Cells." Biochimica et Biophysica Acta (BBA) - Molecular Basis of Disease 1802 (9): 717-27. doi:http://dx.doi.org/10.1016/j.bbadis.2010.05.010.

Carrero, Javier A, Boris Calderon, and Emil R Unanue. 2004. "Type I Interferon Sensitizes Lymphocytes to Apoptosis and Reduces Resistance to Listeria Infection." The Journal of Experimental Medicine 200 (4): 535-40. doi:10.1084/jem.20040769.

Clarke, Lane L. 2009. “A Guide to Ussing Chamber Studies of Mouse Intestine.” American Journal of Physiology. Gastrointestinal and Liver Physiology 296 (6): G1151-66. doi:10.1152/ajpgi.90649.2008. 
Clemente, M G, S De Virgiliis, J S Kang, R Macatagney, M P Musu, M R Di Pierro, S Drago, M Congia, and A Fasano. 2003. "Early Effects of Gliadin on Enterocyte Intracellular Signalling Involved in Intestinal Barrier Function." Gut 52 (2): 218-23. doi:10.1136/gut.52.2.218.

Cunningham, Kevin E., and Jerrold R. Turner. 2012. "Myosin Light Chain Kinase: Pulling the Strings of Epithelial Tight Junction Function.” Ann N Y Acad Sci 1258 (1): 3442. doi:10.1111/j.1749-6632.2012.06526.x.Myosin.

Chirdo, F G, O R Millington, H Beacock-Sharp, and A M Mowat. 2005. "Immunomodulatory Dendritic Cells in Intestinal Lamina Propria." European Journal of Immunology 35 (6): 1831-40. doi:10.1002/eji.200425882.

D’Arienzo, Rossana, Rosita Stefanile, Francesco Maurano, Diomira Luongo, Paolo Bergamo, Giuseppe Mazzarella, Riccardo Troncone, Salvatore Auricchio, Chella David, and Mauro Rossi. 2009. “A Deregulated Immune Response to Gliadin Causes a Decreased Villus Height in DQ8 Transgenic Mice.” European Journal of Immunology 39 (12): 3552-61. doi:10.1002/eji.200839161.

De Kauwe, A, Z Chen, R P Anderson, C L Keech, J D Price, O Wijburg, D C Jackson, J Ladhams, J Allison, and J McCluskey. 2009. "Resistance to Coeliac Disease in Humanized HLADR3 DQ2 Transgenic Mice Expressing Specific Anti-Gliadin CD4+ T Cells.” The Journal of Immunology 182: 7440-50.

De Koning, Barbara A E, Jolanda M van Dieren, Dicky J Lindenbergh-Kortleve, Maria van der Sluis, Tetsuya Matsumoto, Keizo Yamaguchi, Alexandra W Einerhand, Janneke N Samsom, Rob Pieters, and Edward E S Nieuwenhuis. 2006. "Contributions of Mucosal Immune Cells to Methotrexate-Induced Mucositis." International Immunology 18 (6): 94149. doi:10.1093/intimm/dxl030.

DeMeo, Mark T, Ece a Mutlu, Ali Keshavarzian, and Mary C Tobin. 2002. "Intestinal Permeation and Gastrointestinal Disease.” Journal of Clinical Gastroenterology 34 (4): 385-96. doi:10.1097/00004836-200204000-00003.

DePaolo, R W, V Abadie, F Tang, H Fehlner-Peach, J A Hall, W Wang, E V Marietta, et al. 2011. "Co-Adjuvant Effects of Retinoic Acid and IL-15 Induce Inflammatory Immunity to Dietary Antigens." Nature 471 (7337). Nature Publishing Group, a division of Macmillan Publishers Limited. All Rights Reserved.: 220-24. doi:http://www.nature.com/nature/journal/v471/n7337/abs/10.1038-nature09849unlocked.html\#supplementary-information.

Devendra, D., and G. S. Eisenbarth. 2004. "Interferon Alpha - A Potential Link in the Pathogenesis of Viral-Induced Type 1 Diabetes and Autoimmunity." Clinical Immunology 111: 225-33. doi:10.1016/j.clim.2004.01.008. 
Devendra, Devasenan, Jean Jasinski, Evie Melanitou, Maki Nakayama, Marcella Li, Brooke Hensley, Johanna Paronen, et al. 2005. "Interferon-Alpha as a Mediator of Polyinosinic:Polycytidylic Acid - Induced Type 1 Diabetes.” Diabetes 54 (SEPTEMBER): 2549-56.

Di Cagno, Raffaella, Maria De Angelis, Ilaria De Pasquale, Maurice Ndagijimana, Pamela Vernocchi, Patrizia Ricciuti, Francesca Gagliardi, et al. 2011. "Duodenal and Faecal Microbiota of Celiac Children: Molecular, Phenotype and Metabolome Characterization." BMC Microbiology 11 (1): 219. doi:10.1186/1471-2180-11-219.

Di Niro, Roberto, Daniele Sblattero, Fiorella Florian, Marco Stebel, Lorena Zentilin, Mauro Giacca, Vincenzo Villanacci, et al. 2008. "Anti-Idiotypic Response in Mice Expressing Human Autoantibodies.” Molecular Immunology 45 (6): 1782-91. doi:10.1016/j.molimm.2007.09.025.

Di Niro, Roberto, Federica Ziller, Fiorella Florian, Sergio Crovella, Marco Stebel, Marco Bestagno, Oscar Burrone, et al. 2007. "Construction of Miniantibodies for the in Vivo Study of Human Autoimmune Diseases in Animal Models." BMC Biotechnology 7 (1): 46. doi:10.1186/1472-6750-7-46.

Di Sabatino, A, K M Pickard, J N Gordon, V Salvati, G Mazzarella, R M Beattie, A Vossenkaemper, et al. 2007. "Evidence for the Role of Interferon-Alfa Production by Dendritic Cells in the Th1 Response in Celiac Disease." Gastroenterology 133 (4): 1175-87. doi:10.1053/j.gastro.2007.08.018.

Dixit, Evelyn, Steeve Boulant, Yijing Zhang, Amy S Y Lee, Charlotte Odendall, Bennett Shum, Nir Hacohen, et al. 2010. "Peroxisomes Are Signaling Platforms for Antiviral Innate Immunity.” Cell 141 (4). Elsevier Ltd: 668-81. doi:10.1016/j.cell.2010.04.018.

Drago, Sandro, Ramzi El Asmar, Mariarosaria Di Pierro, Maria Grazia Clemente, Amit Tripathi, Anna Sapone, Manjusha Thakar, et al. 2006. "Gliadin, Zonulin and Gut Permeability: Effects on Celiac and Non-Celiac Intestinal Mucosa and Intestinal Cell Lines." Scandinavian Journal of Gastroenterology 41 (March 2005): 408-19. doi:10.1080/00365520500235334.

Eizirik, Décio L, Maikel L Colli, and Fernanda Ortis. 2009. “The Role of Inflammation in Insulitis and Beta-Cell Loss in Type 1 Diabetes.” Nature Reviews. Endocrinology 5 (4): 219-26. doi:10.1038/nrendo.2009.21.

Fasano, A. 2001. "Intestinal Zonulin: Open Sesame!" Gut 49: 159-62. doi:10.1136/gut.49.2.159.

Fasano, a, T Not, W Wang, S Uzzau, I Berti, a Tommasini, and S E Goldblum. 2000. "Zonulin, a Newly Discovered Modulator of Intestinal Permeability, and Its Expression in Coeliac Disease." Lancet 355: 1518-19. doi:10.1016/S0140-6736(00)02169-3. 
Fehniger, T a, K Suzuki, a Ponnappan, J B VanDeusen, M a Cooper, S M Florea, a G Freud, M L Robinson, J Durbin, and M a Caligiuri. 2001. "Fatal Leukemia in Interleukin 15 Transgenic Mice Follows Early Expansions in Natural Killer and Memory Phenotype CD8+ T Cells." The Journal of Experimental Medicine $193 \quad$ (2): 219-31. doi:10.1084/jem.193.2.219.

Fernández-Salazar, Luis, María Álvarez-Quiñones, José Manuel González Hernández, Adela Fraile, Eduardo Mayor, Eduardo Arranz, and José Antonio Garrote. 2011. "IFN Beta 1b Induced Celiac Disease.” Scandinavian Journal of Gastroenterology 46 (July): 1525-26. doi:10.3109/00365521.2011.613950.

Forsberg, Göte, Anna Fahlgren, Per Hörstedt, Sten Hammarström, Olle Hernell, and Marie-Louise Hammarström. 2004. "Presence of Bacteria and Innate Immunity of Intestinal Epithelium in Childhood Celiac Disease." The American Journal of Gastroenterology 99 (5): 894-904. doi:10.1111/j.1572-0241.2004.04157.x.

Fox, James G., Stephen W. Barthold, Muriel T. Davisson, Christian E. Newcomer, Fred W. Quimby, and Abigail L. Smith. 2007. The Mouse in Biomedical Research. Normative Biology, Husbandry, and Models. American College of Laboratory Animal Medicine Series. Vol. 3. doi:10.1016/B978-012369454-6/50054-6.

Freitag, T L, S Rietdijk, Y Junker, Y Popov, a K Bhan, C P Kelly, C Terhorst, and D Schuppan. 2009. "Gliadin-Primed CD4+CD45RBlowCD25- T Cells Drive Gluten-Dependent Small Intestinal Damage after Adoptive Transfer into Lymphopenic Mice.” Gut 58 (12): 1597-1605. doi:10.1136/gut.2009.186361.

Gaggero, a, B Azzarone, C Andrei, Z Mishal, R Meazza, E Zappia, a Rubartelli, and S Ferrini. 1999. "Differential Intracellular Trafficking, Secretion and Endosomal Localization of Two IL-15 Isoforms." European Journal of Immunology 29: 1265-74. doi:10.1002/(SICI)1521-4141(199904)29:04\&\#60;1265::AID-IMMU1265\&\#62;3.0.CO;2-V.

Galipeau, Heather J, Nestor E Rulli, Jennifer Jury, Xianxi Huang, Romina Araya, Joseph a Murray, Chella S David, Fernando G Chirdo, Kathy D McCoy, and Elena F Verdu. 2011. "Sensitization to Gliadin Induces Moderate Enteropathy and Insulitis in Nonobese Diabetic-DQ8 Mice.” Journal of Immunology (Baltimore, Md.: 1950) 187 (8): 4338-46. http://www.pubmedcentral.nih.gov/articlerender.fcgi?artid=3493154\&tool=pmcentrez\&re ndertype $=$ abstract.

García, Mónica, Zeynep Dogusan, Fabrice Moore, Shintaro Sato, Gunther Hartmann, Decio L Eizirik, and Joanne Rasschaert. 2009. "Regulation and Function of the Cytosolic Viral RNA Sensor RIG-I in Pancreatic Beta Cells.” Biochimica et Biophysica Acta 1793 (11). Elsevier B.V.: 1768-75. doi:10.1016/j.bbamcr.2009.09.005.

Garg, Amit X, John Marshall, Marina Salvadori, Heather R Thiessen-Philbrook, Jennifer Macnab, Rita S Suri, R Brian Haynes, Janet Pope, and William Clark. 2006. “A 


\section{Referencias Bibliográficas}

Gradient of Acute Gastroenteritis Was Characterized, to Assess Risk of Long-Term Health Sequelae after Drinking Bacterial-Contaminated Water." Journal of Clinical Epidemiology 59 (4): 421-28. doi:http://dx.doi.org/10.1016/j.jclinepi.2005.08.014.

Garrote, J A, E Gómez-González, David Bernardo, Eduardo Arranz, Fernando Chirdo, Antonio Garrote, Emma Gomez-Gonzalez, David Bernardo, Eduardo Arranz, and Fernando Chirdo. 2008. "Celiac Disease Pathogenesis: The Proinflammatory Cytokine Network." Journal of Pediatric Gastroenterology and Nutrition 47 (suppl 1): 27-32.

Garside, P, M V Felstein, E A Green, and A M Mowat. 1991. "The Role of Interferon Alpha/beta in the Induction of Intestinal Pathology in Mice." Immunology 74 (2): 279-83.

Gay, Nicholas J., Martyn F. Symmons, Monique Gangloff, and Clare E. Bryant. 2014. “Assembly and Localization of Toll-like Receptor Signalling Complexes." Nature Reviews Immunology 14 (8). Nature Publishing Group: 546-58. doi:10.1038/nri3713.

Goodlad, R a, W Lenton, M a Ghatei, T E Adrian, S R Bloom, and N a Wright. 1987. "Effects of an Elemental Diet, Inert Bulk and Different Types of Dietary Fibre on the Response of the Intestinal Epithelium to Refeeding in the Rat and Relationship to Plasma Gastrin, Enteroglucagon, and PYY Concentrations." Gut 28: 171-80. doi:10.1136/gut.28.2.171.

Groom, Joanna R, and Andrew D Luster. 2011. "CXCR3 in T Cell Function." Experimental Cell Research 317 (5): 620-31. doi:10.1016/j.yexcr.2010.12.017.

Groschwitz, Katherine R., and Simon P. Hogan. 2009. "Intestinal Barrier Function: Molecular Regulation and Disease Pathogenesis.” J Allergy Clin Immunol. 124 (1): 3-22. doi:10.1016/j.biotechadv.2011.08.021.Secreted.

Günther, Claudia, Barbara Buchen, G.-W. Gui-Wei He, Mathias Hornef, Natalia Torow, Helmut Neumann, Nadine Wittkopf, et al. 2014. "Caspase-8 Controls the Gut Response to Microbial Challenges by Tnf-a-Dependent and Independent Pathways." Gut, 1-10. doi:10.1136/gutjnl-2014-307226.

Hall, C, D Youngs, and M R Keighley. 1992. "Crypt Cell Production Rates at Various Sites around the Colon in Wistar Rats and Humans." Gut 33: 1528-31. doi:10.1136/gut.33.11.1528.

Heyman, Martine, Juliette Abed, Corinne Lebreton, and Nadine Cerf-Bensussan. 2012. "Intestinal Permeability in Coeliac Disease: Insight into Mechanisms and Relevance to Pathogenesis." Gut 61 (9): 1355-64.

Heyman, Martine, and Sandrine Menard. 2009. "Pathways of Gliadin Transport in Celiac Disease." Annals of the New York Academy of Sciences 1165 (1). Blackwell Publishing Inc: 274-78. doi:10.1111/j.1749-6632.2009.04032.x. 
Hirata, Yoshihiro, Alexis H Broquet, Luis Menchén, and Martin F Kagnoff. 2007. "Activation of Innate Immune Defense Mechanisms by Signaling through RIG-I/IPS-1 in Intestinal Epithelial Cells." Journal of Immunology (Baltimore, Md. : 1950) 179: 5425-32. doi:179/8/5425 [pii].

Honda, K, and K Takeda. 2009. "Regulatory Mechanisms of Immune Responses to Intestinal Bacteria." Mucosal Immunology 2 (3): 187-96. doi:10.1038/mi.2009.8.

Hooper, L V, and A J Macpherson. 2010. "Immune Adaptations That Maintain Homeostasis with the Intestinal Microbiota.” Nature Reviews Immunology 10 (3): 159-69. doi:10.1038/nri2710.

Hue, S, J J Mention, R C Monteiro, S Zhang, C Cellier, J Schmitz, V Verkarre, et al. 2004. “A Direct Role for NKG2D/MICA Interaction in Villous Atrophy during Celiac Disease." Immunity 21 (3): 367-77.

Hunt, Ka, Alexandra Zhernakova, Graham Turner, and Gar Heap. 2008. "Novel Celiac Disease Genetic Determinants Related to the Immune Response." Nature 40 (4): 395-402. doi:10.1038/ng.102.Novel.

Iacomino, Giuseppe, Olga Fierro, Sabato D’Auria, Gianluca Picariello, Pasquale Ferranti, Claudia Liguori, Francesco Addeo, and Gianfranco Mamone. 2013. "Structural Analysis and Caco-2 Cell Permeability of the Celiac-Toxic A-Gliadin Peptide 31-55." Journal of Agricultural and Food Chemistry 61: 1088-96. doi:10.1021/jf3045523.

Ishii, K J, S Koyama, A Nakagawa, C Coban, and S Akira. 2008. "Host Innate Immune Response and beyond: Making Sense of Microbial Infections." Cell Host Microbe 3: 352-63.

Ishii, Ken J, Shohei Koyama, Atsushi Nakagawa, Cevayir Coban, and Shizuo Akira. 2008. "Host Innate Immune Receptors and beyond: Making Sense of Microbial Infections." Cell Host \& Microbe 3 (6): 352-63. doi:10.1016/j.chom.2008.05.003.

Izcue, A, J L Coombes, and F Powrie. 2009. "Regulatory Lymphocytes and Intestinal Inflammation." Ann Rev Immunol 27: 313-38.

Jabri, B, and L M Sollid. 2009. "Tissue-Mediated Control of Immunopathology in Coeliac Disease.” Nature Reviews Immunology 9: 858-70.

Kasarda, D D, T W Okita, J E Bernardin, P A Baecker, C C Nimmo, E J Lew, M D Dietler, and F C Greene. 1984. "Nucleic Acid (cDNA) and Amino Acid Sequences of AlphaType Gliadins from Wheat (Triticum Aestivum)." Proceedings of the National Academy of Sciences of the United States of America 81 (15): 4712-16. http://www.pubmedcentral.nih.gov/articlerender.fcgi?artid=391560\&tool=pmcentrez\&ren dertype $=$ abstract.

Kato, H, O Takeuchi, E Mikamo-Satoh, R Hirai, T Kawai, K Matsushita, A Hiiragi, T S Dermody, T Fujita, and S Akira. 2008. "Length-Dependent Recognition of Doublestranded 
Ribonucleic Acids by Retinoic Acid-inducible Gene-I and Melanoma Differentiationassociated Gene 5.” The Journal of Experimental Medicine 205 (7): 1601-10.

Kawai, Taro, and Shizuo Akira. 2008. "Toll-like Receptor and RIG-1-like Receptor Signaling." Annals of the New York Academy of Sciences 1143: 1-20. doi:10.1196/annals.1443.020.

Kleinschek, Melanie a, Katia Boniface, Svetlana Sadekova, Jeff Grein, Erin E Murphy, Scott P Turner, Lisa Raskin, et al. 2009. "Circulating and Gut-Resident Human Th17 Cells Express CD161 and Promote Intestinal Inflammation." The Journal of Experimental Medicine 206 (3): 525-34. doi:10.1084/jem.20081712.

Kolodziej, Lauren E, James P Lodolce, Jonathan E Chang, Jeffrey R Schneider, Wesley A Grimm, Sarah J Bartulis, Xiaorong Zhu, et al. 2011. "TNFAIP3 Maintains Intestinal Barrier Function and Supports Epithelial Cell Tight Junctions.” PLoS ONE 6 (10). Public Library of Science: e26352. doi:10.1371/journal.pone.0026352.

Korneychuk, N, B Meresse, and N Cerf-Bensussan. 2014. "Lessons from Rodent Models in Celiac Disease.” Mucosal Immunology 8 (1). Nature Publishing Group: 18-28. doi:10.1038/mi.2014.102.

Korneychuk, Natalia, Emma Ramiro-Puig, Julien Ettersperger, Julie Schulthess, Nicolas Montcuquet, Hiroshi Kiyono, Bertrand Meresse, and Nadine Cerf-Bensussan. 2014. "Interleukin 15 and CD4+ T Cells Cooperate to Promote Small Intestinal Enteropathy in Response to Dietary Antigen." Gastroenterology 146 (4). Elsevier, Inc: 1017-27. doi:10.1053/j.gastro.2013.12.023.

Lammers, K M, R Lu, J Brownley, B Lu, C Gerard, K Thomas, P Rallabhandi, et al. 2008. "Gliadin Induces an Increase in Intestinal Permeability and Zonulin Release by Binding to the Chemokine Receptor CXCR3." Gastroenterology 135 (1): 194-204.

Lammers, Karen M, Sunaina Khandelwal, Fatima Chaudhry, Debby Kryszak, Elaine L Puppa, Vincenzo Casolaro, and Alessio Fasano. 2011. "Identification of a Novel Immunomodulatory Gliadin Peptide That Causes Interleukin-8 Release in a Chemokine Receptor CXCR3-Dependent Manner Only in Patients with Coeliac Disease.” Immunology 132 (3). Blackwell Publishing Ltd: 432-40. doi:10.1111/j.1365-2567.2010.03378.x.

Lebreton, Corinne, Sandrine Ménard, Juliette Abed, Ivan Cruz Moura, Rosanna Coppo, Christophe Dugave, Renato C. Monteiro, et al. 2012. "Interactions Among Secretory Immunoglobulin A, CD71, and Transglutaminase-2 Affect Permeability of Intestinal Epithelial Cells to Gliadin Peptides.” Gastroenterology 143 (3): 698-707.e4. doi:10.1053/j.gastro.2012.05.051.

Luciani, Alessandro, Valeria Rachela Villella, Angela Vasaturo, Ida Giardino, Massimo Pettoello-Mantovani, Stefano Guido, Olivier N Cexus, et al. 2010. "Lysosomal 
Accumulation of Gliadin p31-43 Peptide Induces Oxidative Stress and Tissue Transglutaminase-Mediated PPAR $\gamma$ Downregulation in Intestinal Epithelial Cells and Coeliac Mucosa." Gut 59 (3): 311-19. doi:10.1136/gut.2009.183608.

Ludvigsson, Jonas F., Johnny Ludvigsson, Anders Ekbom, and Scott M. Montgomery. 2006. "Celiac Disease and Risk of Subsequent Type 1 Diabetes: A General Population Cohort Study of Children and Adolescents." Diabetes Care 29 (11): 2483-88. doi:10.2337/dc06-0794.

Lundin, K. E. 1993. "Gliadin-Specific, HLA-DQ(alpha 1*0501,beta 1*0201) Restricted T Cells Isolated from the Small Intestinal Mucosa of Celiac Disease Patients.” Journal of Experimental Medicine 178 (1): 187-96. doi:10.1084/jem.178.1.187.

Maiuri, L, R Troncone, M Mayer, S Coletta, a Picarelli, M De Vincenzi, V Pavone, and S Auricchio. 1996. "In Vitro Activities of A-Gliadin-Related Synthetic Peptides: Damaging Effect on the Atrophic Coeliac Mucosa and Activation of Mucosal Immune Response in the Treated Coeliac Mucosa." Scandinavian Journal of Gastroenterology 31 (9): 247-53. doi:10.3109/00365529609004874.

Maiuri, Luigi, Carolina Ciacci, Ida Ricciardelli, Loredana Vacca, Valeria Raia, Salvatore Auricchio, Jean Picard, Mohamed Osman, Sonia Quaratino, and Marco Londei. 2003. "Association between Innate Response to Gliadin and Activation of Pathogenic $T$ Cells in Coeliac Disease.” Lancet 362 (9377): 30-37. doi:10.1016/S0140-6736(03)13803-2.

Mamone, Gianfranco, Pasquale Ferranti, Mauro Rossi, Peter Roepstorff, Olga Fierro, Antonio Malorni, and Francesco Addeo. 2007. "Identification of a Peptide from A-Gliadin Resistant to Digestive Enzymes: Implications for Celiac Disease." Journal of Chromatography B: Analytical Technologies in the Biomedical and Life Sciences 855: 23641. doi:10.1016/j.jchromb.2007.05.009.

Manca, C, L Tsenova, A Bergtold, S Freeman, M Tovey, J M Musser, C E Barry, V H Freedman, and G Kaplan. 2001. "Virulence of a Mycobacterium Tuberculosis Clinical Isolate in Mice Is Determined by Failure to Induce Th1 Type Immunity and Is Associated with Induction of IFN-Alpha /beta." Proceedings of the National Academy of Sciences of the United States of America 98 (10): 5752-57. doi:10.1073/pnas.091096998.

Marietta, Eric, Kay Black, Michael Camilleri, Patricia Krause, Roy S Rogers III, Chella David, Mark R Pittelkow, and Joseph A Murray. 2004. "A New Model for Dermatitis Herpetiformis That Uses HLA-DQ8 Transgenic NOD Mice." The Journal of Clinical Investigation 114 (8). The American Society for Clinical Investigation: 1090-97. doi:10.1172/jci21055.

Marietta, Eric V, and Joseph a Murray. 2012. “Animal Models to Study Gluten Sensitivity.” Seminars in Immunopathology 34 (4): 497-511. doi:10.1007/s00281-0120315-y. 
Marshall, John K, Marroon Thabane, Mark R Borgaonkar, and Cindy James. 2007. "Postinfectious Irritable Bowel Syndrome After a Food-Borne Outbreak of Acute Gastroenteritis Attributed to a Viral Pathogen." Clinical Gastroenterology and Hepatology 5 (4): 457-60. doi:http://dx.doi.org/10.1016/j.cgh.2006.11.025.

Marshall, John K, Marroon Thabane, Amit X Garg, William F Clark, Paul Moayyedi, Stephen M Collins, and Walkerton Health Study Investigators. 2010. "Eight Year Prognosis of Postinfectious Irritable Bowel Syndrome Following Waterborne Bacterial Dysentery." Gut 59 (5): 605-11. doi:10.1136/gut.2009.202234.

Marshall, John K, Marroon Thabane, Amit X Garg, William F Clark, Marina Salvadori, and Stephen M Collins. 2006. "Incidence and Epidemiology of Irritable Bowel Syndrome After a Large Waterborne Outbreak of Bacterial Dysentery." Gastroenterology 131 (2): 44550. doi:http://dx.doi.org/10.1053/j.gastro.2006.05.053.

Matsumoto, Misako, and Tsukasa Seya. 2008. “TLR3: Interferon Induction by Double-Stranded RNA Including poly(I:C).” Advanced Drug Delivery Reviews 60 (7): 80512. doi:10.1016/j.addr.2007.11.005.

Matysiak-Budnik, Tamara, Ivan Cruz Moura, Michelle Arcos-Fajardo, Corinne Lebreton, Sandrine Ménard, Céline Candalh, Karima Ben-Khalifa, et al. 2008. "Secretory IgA Mediates Retrotranscytosis of Intact Gliadin Peptides via the Transferrin Receptor in Celiac Disease." The Journal of Experimental Medicine 205 (1): 143-54. doi:10.1084/jem.20071204.

Maurano, F., G. Mazzarella, D. Luongo, R. Stefanile, R. D\&apos;Arienzo, M. Rossi, S. Auricchio, and R. Troncone. 2005. "Small Intestinal Enteropathy in Non-Obese Diabetic Mice Fed a Diet Containing Wheat.” Diabetologia 48: 931-37. doi:10.1007/s00125-005$1718-2$.

Mazzarella, G. 2003. “An Immunodominant DQ8 Restricted Gliadin Peptide Activates Small Intestinal Immune Response in in Vitro Cultured Mucosa from HLA-DQ8 Positive but Not HLA-DQ8 Negative Coeliac Patients." Gut 52 (1): 57-62. doi:10.1136/gut.52.1.57.

McAllister, Christopher S, Omar Lakhdari, Guillaume Pineton de Chambrun, Mélanie G Gareau, Alexis Broquet, Gin Hyug Lee, Steven Shenouda, Lars Eckmann, and Martin F Kagnoff. 2013. "TLR3, TRIF, and Caspase 8 Determine Double-Stranded RNA-Induced Epithelial Cell Death and Survival In Vivo.” The Journal of Immunology 190 (1): 418-27. doi:10.4049/jimmunol.1202756.

McCartney, S, W Vermi, S Gilfillan, M Cella, T L Murphy, R D Schreiber, K M Murphy, and M Colonna. 2009. "Distinct and Complementary Functions of MDA5 and TLR3 in poly(I:C)-Mediated Activation of Mouse NK Cells.” J Exp Med 21;206 (13): 2967-76. 
Ménard, Sandrine, Corinne Lebreton, Michael Schumann, Tamara Matysiak-Budnik, Christophe Dugave, Yoram Bouhnik, Georgia Malamut, et al. 2012. "Paracellular versus Transcellular Intestinal Permeability to Gliadin Peptides in Active Celiac Disease." American Journal of Pathology 180 (2). Elsevier Inc.: 608-15. doi:10.1016/j.ajpath.2011.10.019.

Meresse, Bertrand, Georgia Malamut, and Nadine Cerf-Bensussan. 2012. "Celiac Disease: An Immunological Jigsaw.” Immunity 36 (6). Elsevier Inc.: 907-19. doi:10.1016/j.immuni.2012.06.006.

Mirolo, Massimiliano, Marco Fabbri, Marina Sironi, Annunciata Vecchi, Angelo Guglielmotti, Giorgina Mangano, Giuseppe Biondi, Massimo Locati, and Alberto Mantovani. 2008. "Impact of the Anti-Inflammatory Agent Bindarit on the Chemokinome: Selective Inhibition of the Monocyte Chemotactic Proteins." European Cytokine Network 19 (September): 119-22. doi:10.1684/ecn.2008.0133.

Mittal, Rohit, and Craig M. Coopersmith. 2014. "Redefining the Gut as the Motor of Critical Illness." Trends in Molecular Medicine 20 (4). Elsevier Ltd: 214-23. doi:10.1016/j.molmed.2013.08.004.

Molberg, O, S N Mcadam, R Körner, H Quarsten, C Kristiansen, L Madsen, L Fugger, et al. 1998. "Tissue Transglutaminase Selectively Modifies Gliadin Peptides That Are Recognized by Gut-Derived T Cells in Celiac Disease.” Nature Medicine 4 (6): 713-17. http://www.ncbi.nlm.nih.gov/pubmed/9623982.

Mowat, A M. 2003. "Anatomical Basis of Tolerance and Immunity to Intestinal Antigens.” Natue Reviews Immunology 3 (4): 331-41.

Mowat, Allan M., and William W. Agace. 2014. "Regional Specialization within the Intestinal Immune System." Nature Reviews Immunology, no. September. doi:10.1038/nri3738.

Nanayakkara, Merlin, Roberta Kosova, Giuliana Lania, Marco Sarno, Alessandra Gaito, Martina Galatola, Luigi Greco, et al. 2013. “A Celiac Cellular Phenotype, with Altered LPP Sub-Cellular Distribution, Is Inducible in Controls by the Toxic Gliadin Peptide P3143.” PloS One 8 (11): e79763. doi:10.1371/journal.pone.0079763.

Nanayakkara, Merlin, Giuliana Lania, Mariantonia Maglio, Valentina Discepolo, Marco Sarno, Alessandra Gaito, Riccardo Troncone, Salvatore Auricchio, Renata Auricchio, and Maria Vittoria Barone. 2013. "An Undigested Gliadin Peptide Activates Innate Immunity and Proliferative Signaling in Enterocytes: The Role in Celiac Disease." The American Journal of Clinical Nutrition 98 (4): 1123-35. doi:10.3945/ajcn.112.054544.

Natividad, Jane M, Xianxi Huang, Emma Slack, Jennifer Jury, Yolanda Sanz, Chella David, Emmanuel Denou, et al. 2009. "Host Responses to Intestinal Microbial Antigens in 
Gluten-Sensitive Mice." PLoS ONE 4 (7). Public Library of Science: e6472. doi:10.1371/journal.pone.0006472.

Ohta, N., T. Hiroi, M.-N. Kweon, N. Kinoshita, M. H. Jang, T. Mashimo, J.-I. Miyazaki, and H. Kiyono. 2002. "IL-15-Dependent Activation-Induced Cell Death-Resistant Th1 Type CD8 +NK1.1+ T Cells for the Development of Small Intestinal Inflammation." The Journal of Immunology 169 (1). American Association of Immunologists: 460-68. doi:10.4049/jimmunol.169.1.460.

Omagari, D., Y. Mikami, H. Suguro, K. Sunagawa, M. Asano, E. Sanuki, I. Moro, and K. Komiyama. 2009. "Poly I:C-Induced Expression of Intercellular Adhesion Molecule-1 in Intestinal Epithelial Cells." Clinical and Experimental Immunology 156: 294-302. doi:10.1111/j.1365-2249.2009.03892.x.

Omagari, D., N. Takenouchi-Ohkubo, S. Endo, T. Ishigami, a. Sawada, I. Moro, M. Asano, and K. Komiyama. 2011. "Nuclear Factor Kappa B Plays a Pivotal Role in Polyinosinic-Polycytidylic Acid-Induced Expression of Human??-Defensin 2 in Intestinal Epithelial Cells." Clinical and Experimental Immunology 165: 85-93. doi:10.1111/j.13652249.2011.04404.x.

Østvik, Ann E, Atle vb Granlund, Marit Bugge, Nadra J Nilsen, Sverre H Torp, Helge L Waldum, Jan K Damås, Terje Espevik, and Arne K Sandvik. 2013. "Enhanced Expression of CXCL10 in Inflammatory Bowel Disease: Potential Role of Mucosal Toll-like Receptor 3 Stimulation." Inflammatory Bowel Diseases 19 (2): 265-74 10.1002/ibd.23034. http://journals.lww.com/ibdjournal/Fulltext/2013/02000/Enhanced_Expression_of_CXCL 10_in_Inflammatory.7.aspx.

Paterson, B M, K M Lammers, M C Arrieta, a Fasano, and J B Meddings. 2007. “The Safety, Tolerance, Pharmacokinetic and Pharmacodynamic Effects of Single Doses of AT1001 in Coeliac Disease Subjects: A Proof of Concept Study." Alimentary Pharmacology \& Therapeutics 26 (June): 757-66. doi:10.1111/j.1365-2036.2007.03413.x.

Perico, Norberto, Ariela Benigni, and Giuseppe Remuzzi. 2008. "Present and Future Drug Treatments for Chronic Kidney Diseases: Evolving Targets in Renoprotection.” Nature Reviews. Drug Discovery 7 (nOvEMbER): 936-53. doi:10.1038/nrd2685.

Perrot, Ivan, Florence Deauvieau, Catherine Massacrier, Nicola Hughes, Pierre Garrone, Isabelle Durand, Olivier Demaria, et al. 2010. “TLR3 and Rig-like Receptor on Myeloid Dendritic Cells and Rig-like Receptor on Human NK Cells Are Both Mandatory for Production of IFN-Gamma in Response to Double-Stranded RNA.” Journal of Immunology 185 (4): 2080-88. doi:10.4049/jimmunol.1000532.

Peterson, Lance W, and David Artis. 2014. "Intestinal Epithelial Cells: Regulators of Barrier Function and Immune Homeostasis.” Nature Reviews. Immunology 14 (3). Nature Publishing Group: 141-53. doi:10.1038/nri3608. 
Plot, Leeor, and Howard Amital. 2009. "Infectious Associations of Celiac Disease." Autoimmunity Reviews 8 (4). Elsevier B.V.: 316-19. doi:10.1016/j.autrev.2008.10.001.

Pott, Johanna, Silvia Stockinger, Natalia Torow, Anna Smoczek, Cornelia Lindner, Gerald McInerney, Fredrik Bäckhed, et al. 2012. "Age-Dependent TLR3 Expression of the Intestinal Epithelium Contributes to Rotavirus Susceptibility." PLoS Pathogens 8 (5). doi:10.1371/journal.ppat.1002670.

Quaedackers, J S, R J Beuk, L Bennet, A Charlton, M G oude Egbrink, A J Gunn, and E Heineman. 2000. “An Evaluation of Methods for Grading Histologic Injury Following Ischemia/reperfusion of the Small Bowel.” Transplant Proceedings 32 (6): 1307-10.

Rajagopalan, Govindarajan, Yogish C Kudva, Richard A Flavell, and Chella S David. 2003. "Accelerated Diabetes in Rat Insulin Promoter-Tumor Necrosis Factor-A Transgenic Nonobese Diabetic Mice Lacking Major Histocompatibility Class II Molecules.” Diabetes 52 (2): 342-47. doi:10.2337/diabetes.52.2.342.

Rashtak, Shadi, Eric V Marietta, and Joseph A Murray. 2009. “Celiac Sprue: A Unique Autoimmune Disorder." Expert Reviews of Clinical Immunology 5 (5): 593-604. doi:10.1586/eci.09.30.Celiac.

Reikine, Stephanie, Jennifer B. Nguyen, and Yorgo Modis. 2014. "Pattern Recognition and Signaling Mechanisms of RIG-I and MDA5." Frontiers in Immunology 5 (July): 1-7. doi:10.3389/fimmu.2014.00342.

Rizza, Paola, Franca Moretti, and Filippo Belardelli. 2010. "Recent Advances on the Immunomodulatory Effects of IFN-Alpha: Implications for Cancer Immunotherapy and Autoimmunity." Autoimmunity 43 (3). InformaLondon, UK: 204-9. doi:10.3109/08916930903510880.

Rulli, Nestor E, Angelo Guglielmotti, Giorgina Mangano, Michael S Rolph, Claudia Apicella, Ali Zaid, Andreas Suhrbier, and Suresh Mahalingam. 2009. "Amelioration of Alphavirus-Induced Arthritis and Myositis in a Mouse Model by Treatment with Bindarit, an Inhibitor of Monocyte Chemotactic Proteins." Arthritis \& Rheumatism 60 (8). Wiley Subscription Services, Inc., A Wiley Company: 2513-23. doi:10.1002/art.24682.

Sarno, Marco, Giuliana Lania, Marialaura Cuomo, Federica Nigro, Francesca Passannanti, Andrea Budelli, Francesca Fasano, et al. 2014. "Lactobacillus Paracasei CBA L74 Interferes with Gliadin Peptides Entrance in Caco-2 Cells.” International Journal of Food Sciences and Nutrition, July. Informa UK Ltd. London, 1-7. doi:10.3109/09637486.2014.940283.

Schiff, L J, A M Shefner, P W Barbera, and S M Poiley. 1974. "The Use of BSVR-SrCr Mice for Detection of Murine Strains of Toxigenic Escherichia Coli." Laboratory Animal Science 24 (5): 752-56. http://www.ncbi.nlm.nih.gov/pubmed/4371746. 
Schulzke, Jorg-Dieter, Carl J Bentzel, Ines Schulzke, Ernst-Otto Riecken, and Michael Fromm. 1998. "Epithelial Tight Junction Structure in the Jejunum of Children with Acute and Treated Celiac Sprue." Pediatr Res 43 (4). International Pediatrics Research Foundation, Inc.: 435-41. http://dx.doi.org/10.1203/00006450-199804000-00001.

Shan, Lu, Shuo-Wang Qiao, Helene Arentz-Hansen, Øyvind Molberg, Gary M. Gray, Ludvig M. Sollid, and Chaitan Khosla. 2005. "Identification and Analysis of Multivalent Proteolytically Resistant Peptides from Gluten: Implications for Celiac Sprue." Journal of Proteome Research 4 (5). American Chemical Society: 1732-41. doi:10.1021/pr050173t.

Shen, Le, Eric D Black, Edwina D Witkowski, Wayne I Lencer, Vince Guerriero, Eveline E Schneeberger, and Jerrold R Turner. 2006. "Myosin Light Chain Phosphorylation Regulates Barrier Function by Remodeling Tight Junction Structure." Journal of Cell Science 119: 2095-2106. doi:10.1242/jcs.02915.

Siegel, Matthew, Pavel Strnad, R Edward Watts, Kihang Choi, Bana Jabri, M Bishr Omary, and Chaitan Khosla. 2008. "Extracellular Transglutaminase 2 Is Catalytically Inactive, but Is Transiently Activated upon Tissue Injury.” PLOS ONE 3 (3). Public Library of Science: e1861. doi:10.1371/journal.pone.0001861.

Sironi, M, A Guglielmotti, N Polentarutti, F Fioretti, C Milanese, M Romano, C Vigini, et al. 1999. "A Small Synthetic Molecule Capable of Preferentially Inhibiting the Production of the CC Chemokine Monocyte Chemotactic Protein-1." European Cytokine Network 10 (3): 437-42. http://www.ncbi.nlm.nih.gov/pubmed/10477401.

Smecuol, E., J. C. Bai, H. Vazquez, Z. Kogan, a. Cabanne, S. Niveloni, S. Pedreira, L. Boerr, E. Maurino, and J. B. Meddings. 1997. "Gastrointestinal Permeability in Celiac Disease.” Gastroenterology 112: 1129-36. doi:10.1016/S0016-5085(97)70123-9.

Snégaroff, Jacques, Gérard Branlard, Isabelle Bouchez-Mahiout, Béatrice Laudet, Martina Tylichova, Thierry Chardot, Catherine Pecquet, et al. 2007. "Recombinant Proteins and Peptides as Tools for Studying IgE Reactivity with Low-Molecular-Weight Glutenin Subunits in Some Wheat Allergies." Journal of Agricultural and Food Chemistry 55 (24): 9837-45. doi:10.1021/jf071432x.

Sollid, L M, and E Thorsby. 1994. "HLA Susceptibility Genes in Celiac Disease: Genetic Mapping and Role in Pathogenesis.” Gastroenterology 106 (4): 1133.

Sollid, L. M. 1989. "Evidence for a Primary Association of Celiac Disease to a Particular HLA-DQ Alpha/beta Heterodimer." Journal of Experimental Medicine 169 (1): 345-50. doi:10.1084/jem.169.1.345.

Sollid, Ludvig M, and Bana Jabri. 2013. "Triggers and Drivers of Autoimmunity: Lessons from Coeliac Disease.” Nature Reviews Immunology 13 (4). Nature Publishing 
Group, a division of Macmillan Publishers Limited. All Rights Reserved.: 294-302. http://dx.doi.org/10.1038/nri3407.

Sollid, Ludvig M, B Lie, and A. Lie Benedicte. 2005. "Celiac Disease Genetics : Current Concepts and Practical Applications." Clinical Gastroenterology and Hepatology 3 (9): 84351. doi:10.1016/S1542-3565(05)00532-X.

Steinmetz, Oliver M, Jan-Eric Turner, Hans-Joachim Paust, Matthias Lindner, Anett Peters, Kirstin Heiss, Joachim Velden, et al. 2009. "CXCR3 Mediates Renal Th1 and Th17 Immune Response in Murine Lupus Nephritis.” Journal of Immunology (Baltimore, Md. : 1950) 183 (7): 4693-4704. doi:10.4049/jimmunol.0802626.

Stene, Lars C, Margo C Honeyman, Edward J Hoffenberg, Joel E Haas, Ronald J Sokol, Lisa Emery, Iman Taki, et al. 2006. "Rotavirus Infection Frequency and Risk of Celiac Disease Autoimmunity in Early Childhood: A Longitudinal Study." American Journal of Gastroenterology 101 (10). The American College of Gastroenterology: 2333-40. http://dx.doi.org/10.1111/j.1572-0241.2006.00741.x.

Suwanai, Hirotsugu, Martha Angela Wilcox, Diane Mathis, and Christophe Benoist. 2010. "A Defective Il15 Allele Underlies the Deficiency in Natural Killer Cell Activity in Nonobese Diabetic Mice." Proceedings of the National Academy of Sciences of the United States of America 107 (20): 9305-10. doi:10.1073/pnas.1004492107.

Terrazzano, G., M. Sica, C. Gianfrani, G. Mazzarella, F. Maurano, B. De Giulio, S. de Saint-Mezard, et al. 2007. "Gliadin Regulates the NK-Dendritic Cell Cross-Talk by HLA-E Surface Stabilization." The Journal of Immunology 179: 372-81. doi:10.4049/jimmunol.179.1.372.

Thomas, K E, A Sapone, A Fasano, and S N Vogel. 2006. "Gliadin Stimulation of Murine Macrophage Inflammatory Gene Expression and Intestinal Permeability Are MyD88-Dependent: Role of the Innate Immune Response in Celiac Disease." The Journal of Immunology 176 (4): 2512-21.

Tjellström, B, L Stenhammar, L Högberg, K Fälth-Magnusson, K-E Magnusson, T Midtvedt, T Sundqvist, and E Norin. 2005. "Gut Microflora Associated Characteristics in Children with Celiac Disease." The American Journal of Gastroenterology 100 (12): 278488. doi:10.1111/j.1572-0241.2005.00313.x.

Tripathi, Amit, Karen M Lammers, Simeon Goldblum, Terez Shea-Donohue, Sarah Netzel-Arnett, Marguerite S Buzza, Toni M Antalis, et al. 2009. "Identification of Human Zonulin, a Physiological Modulator of Tight Junctions, as Prehaptoglobin-2." Proceedings of the National Academy of Sciences of the United States of America 106 (39): 16799-804. doi:10.1073/pnas.0906773106. 
Troncone, R, C Gianfrani, G Mazzarella, L Greco, J Guardiola, S Auricchio, and P De Berardinis. 1998. "Majority of Gliadin-Specific T-Cell Clones from Celiac Small Intestinal Mucosa Produce Interferon-Gamma and Interleukin-4." Digestive Diseases and Sciences 43 (1): 156-61. http://www.ncbi.nlm.nih.gov/pubmed/9508518.

Troncone, R., and S. Auricchio. 2007. "Rotavirus and Celiac Disease: Clues to the Pathogenesis and Perspectives on Prevention." Journal of Pediatric Gastroenterology and Nutrition $\quad 44 \quad$ (5): $\quad 527-28 \quad 10.1097 /$ MPG.0b013e31804ca0ec. http://journals.lww.com/jpgn/Fulltext/2007/05000/Rotavirus_and_Celiac_Disease__Clues _to_the.1.aspx.

Turner, Jerrold R. 2009. "Intestinal Mucosal Barrier Function in Health and Disease." Nature Reviews Immunology 9 (11). Nature Publishing Group: 799-809. http://dx.doi.org/10.1038/nri2653.

Van Elburg, R M, J J Uil, C J Mulder, and H S Heymans. 1993. "Intestinal Permeability in Patients with Coeliac Disease and Relatives of Patients with Coeliac Disease." Gut 34: 354-57. doi:10.1136/gut.34.3.354.

Verdu, E F, X Huang, J Natividad, J Lu, P A Blennerhassett, C S David, D M McKay, and J A Murray. 2008. "Gliadin-Dependent Neuromuscular and Epithelial Secretory Responses in Gluten-Sensitive HLA-DQ8 Transgenic Mice." American Journal of Physiology - Gastrointestinal and Liver Physiology 294 (1): G217-25. doi:10.1152/ajpgi.00225.2007.

Verdu, E F, M Mauro, J Bourgeois, and D Armstrong. 2007. "Clinical Onset of Celiac Disease after an Episode of Campylobacter Jejuni Enteritis." Canada Journal of Gastroenterology 21 (7): 453-55.

Verdu, Elena F. 2012. "Editorial: Differences in Intestinal Microbial Composition in Children With IBS-What Does It All Mean?” American Journal of Gastroenterology 107 (11). American College of Gastroenterology: 1752-54. http://dx.doi.org/10.1038/ajg.2012.291.

Visser, J, J Rozing, A Sapone, K Lammers, and A Fasano. 2009. “Tight Junctions, Intestinal Permeability, and Autoimmunity: Celiac Disease and Type 1 Diabetes Paradigms. Ann N Y Acad Sci.” Annals of New York Academy of Science 1165: 195-205.

Wapenaar, Martin C, Alienke J Monsuur, Ad A van Bodegraven, Rinse K Weersma, Marianna R Bevova, Ronald K Linskens, Peter Howdle, et al. 2008. “Associations with Tight Junction Genes PARD3 and MAGI2 in Dutch Patients Point to a Common Barrier Defect for Celial Disease and Ulcerative Colitis.” Methods 57 (4): 463-67.

Weber, F, V Wagner, S B Rasmussen, R Hartmann, and S R Paludan. 2006. “DoubleStranded RNA Is Produced by Positive-Strand RNA Viruses and DNA Viruses but Not in Detectable Amounts by Negative-Strand RNA Viruses.” Journal of Virology 80 (10): 505964 . 
Wieser, Herbert. 2007. “Chemistry of Gluten Proteins.” Food Microbiology 24: 11519. doi:10.1016/j.fm.2006.07.004.

Yokoyama, Seiji, Kazuko Takada, Masatomo Hirasawa, Liyanage P. Perera, and Takachika Hiroi. 2011. "Transgenic Mice That Overexpress Human IL-15 in Enterocytes Recapitulate Both B and T Cell-Mediated Pathologic Manifestations of Celiac Disease." Journal of Clinical Immunology 31: 1038-44. doi:10.1007/s10875-011-9586-7.

Yokoyama, Seiji, Nobumasa Watanabe, Noriko Sato, Pin-Yu Perera, Lyvouch Filkoski, Toshiyuki Tanaka, Masayuki Miyasaka, Thomas A Waldmann, Takachika Hiroi, and Liyanage P Perera. 2009. “Antibody-Mediated Blockade of IL-15 Reverses the Autoimmune Intestinal Damage in Transgenic Mice That Overexpress IL-15 in Enterocytes.” Proceedings of the National Academy of Sciences of the United States of America 106 (37): 15849-54. doi:10.1073/pnas.0908834106.

Yoneyama, Mitsutoshi, and Takashi Fujita. 2007. "Function of RIG-I-like Receptors in Antiviral Innate Immunity." Journal of Biological Chemistry 282 (21): 15315-18. doi:10.1074/jbc.R700007200.

Yoneyama, Mitsutoshi, Koji Onomoto, Michihiko Jogi, Teppei Akaboshi, and Takashi Fujita. 2015. "Viral RNA Detection by RIG-I-like Receptors." Current Opinion in Immunology 32. Elsevier Ltd: 48-53. doi:10.1016/j.coi.2014.12.012.

Yu, Man, and Stewart J. Levine. 2011. “Toll-like Receptor 3, RIG-I-like Receptors and the NLRP3 Inflammasome: Key Modulators of Innate Immune Responses to DoubleStranded RNA Viruses.” Cytokine and Growth Factor Reviews 22 (2). Elsevier Ltd: 63-72. doi:10.1016/j.cytogfr.2011.02.001.

Zanoni, Giovanna, Riccardo Navone, Claudio Lunardi, Giuseppe Tridente, Caterina Bason, Simona Sivori, Ruggero Beri, et al. 2006. "In Celiac Disease, a Subset of Autoantibodies against Transglutaminase Binds Toll-like Receptor 4 and Induces Activation of Monocytes." PLoS Medicine $3 \quad$ (9): 1637-53. doi:10.1371/journal.pmed.0030358.

Zhou, Rongbin, Haiming Wei, Rui Sun, and Zhigang Tian. 2007. "Recognition of Double-Stranded RNA by TLR3 Induces Severe Small Intestinal Injury in Mice." The Journal of Immunology 178: 4548-56.

Zhou, Rongbin, Haiming Wei, Rui Sun, Jian Zhang, and Zhigang Tian. 2007. "NKG2D Recognition Mediates Toll-like Receptor 3 Signaling-Induced Breakdown of Epithelial Homeostasis in the Small Intestines of Mice." Proceedings of the National Academy of Sciences of the United States of America 104 (18): 7512-15. doi:10.1073/pnas.0700822104. 
Zhou, Y., M. Guo, X. Wang, J. Li, Y. Wang, L. Ye, M. Dai, L. Zhou, Y. Persidsky, and W. Ho. 2012. "TLR3 Activation Efficiency by High or Low Molecular Mass Poly I:C." Innate Immunity 0 (0): 1-9. doi:10.1177/1753425912459975.

Zimmermann, Christian, Silvia Rudloff, Günter Lochnit, Sevgi Arampatzi, Wolfgang Maison, and Klaus-Peter Zimmer. 2014. "Epithelial Transport of Immunogenic and Toxic Gliadin Peptides In Vitro.” PLoS ONE 9: e113932. doi:10.1371/journal.pone.0113932.

Zone, John J, C Anthony Egan, Ted B Taylor, and Laurence J Meyer. 2004. "IgA Autoimmune Disorders: Development of a Passive Transfer Mouse Model." The Journal of Investigative Dermatology. Symposium Proceedings / the Society for Investigative Dermatology, Inc. [and] European Society for Dermatological Research 9 (1): 47-51. doi:10.1111/j.1087-0024.2004.00840.x.

Zone, John J, Linda A Schmidt, Ted B Taylor, Christopher M Hull, Michael C Sotiriou, Troy D Jaskowski, Harry R Hill, and Laurence J Meyer. 2011. "Dermatitis Herpetiformis Sera or Goat Anti-Transglutaminase-3 Transferred to Human Skin-Grafted Mice Mimics Dermatitis Herpetiformis Immunopathology." Journal of Immunology (Baltimore, Md.: 1950) 186 (7). American Association of Immunologists: 4474-80. doi:10.4049/jimmunol.1003273.

Zurita, E, G Moreno, A Errea, M Ormazabal, M Rumbo, and D Hozbor. 2013. "The Stimulated Innate Resistance Event in Bordetella Pertussis Infection Is Dependent on Reactive Oxygen Species Production." Infection and Immunity 81 (7): 2371-78. doi:10.1128/IAI.00336-13. 